\title{
History and Political Economy
}

Essays in Honour of P.D. Groenewegen

\author{
Edited by \\ Tony Aspromourgos \\ and John Ludewijks
}

Routledge Studies in the History of Economics

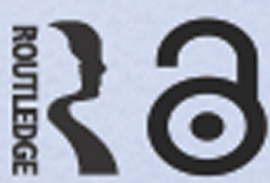




\section{History and Political Economy}

Peter Groenewegen's status as one of the foremost historians of economic thought in the world is unquestionable. His work within economics is a legacy which shall benefit scores of future economists and historians.

This collection of essays offers substantial and diverse contributions to the history of economic thought in honour of Professor Groenewegen. Figures whose work is analysed in terms of its impact on contemporary economic issues and policies include:

- Alfred Marshall

- John Maynard Keynes

- William Stanley Jevons

The contributors to this impressive volume include G.C.Harcourt, A.W. Coats and Milton Friedman. With the added value of a comprehensive bibliography of Groenewegen's work, this book is sure to find (and deserve) its place on the bookshelves of many economists and historians.

Tony Aspromourgos is Associate Professor of Economics at the University of Sydney, Australia. One of his previous books, On the Origins of Classical Economics is also available from Routledge.

John Lodewijks is Associate Professor at the University of New South Wales, Australia. 


\title{
Routledge Studies in the History of Economics
}

\author{
1 Economics as Literature \\ Willie Henderson
}

2 Socialism and Marginalism in Economics 1870-1930

Edited by Ian Steedman

3 Hayek's Political Economy

The socio-economics of order

Steve Fleetwood

4 On the Origins of Classical Economics

Distribution and value from William Petty to Adam Smith

Tony Aspromourgos

5 The Economics of Joan Robinson

Edited by Maria Cristina Marcuzzo, Luigi Pasinetti and Alesandro Roncaglia

6 The Evolutionist Economics of Léon Walras

Albert Jolink

7 Keynes and the 'Classics'

A study in language, epistemology and mistaken identities

Michel Verdon

8 The History of Game Theory, Vol 1

From the beginnings to 1945

Robert W.Dimand and Mary Ann Dimand

9 The Economics of W.S.Jevons

Sandra Peart

10 Gandhi's Economic Thought

Ajit K.Dasgupta

11 Equilibrium and Economic Theory

Edited by Giovanni Caravale

12 Austrian Economics in Debate

Edited by Willem Keizer, Bert Tieben and Rudy van Zijp 


\section{Ancient Economic Thought}

Edited by B.B.Price

\section{The Political Economy of Social Credit and Guild Socialism}

Frances Hutchinson and Brian Burkitt

\section{Economic Careers}

Economics and economists in Britain 1930-1970

Keith Tribe

\section{Understanding 'Classical' Economics}

Studies in the long-period theory

Heinz Kurz and Neri Salvadori

17 History of Environmental Economic Thought

E.Kula

18 Economic Thought in Communist and Post-Communist Europe Edited by Hans-Jürgen Wagener

19 Studies in the History of French Political Economy

From Bodin to Walras

Edited by Gilbert Faccarello

20 The Economics of John Rae

Edited by O.F.Hamouda, C.Lee and D.Mair

21 Keynes and the Neoclassical Synthesis

Einsteinian versus Newtonian macroeconomics

Teodoro Dario Togati

22 Historical Perspectives on Macroeconomics

Sixty years after the 'General Theory'

Edited by Philippe Fontaine and Albert Jolink

23 The Founding of Institutional Economics

The leisure class and sovereignty

Edited by Warren J.Samuels

24 Evolution of Austrian Economics

From Menger to Lachmann

Sandye Gloria

25 Marx's Concept of Money: the God of Commodities Anitra Nelson 
26 The Economics of James Steuart

Edited by Ramón Tortajada

27 The Development of Economics in Europe since 1945 Edited by A.W.Bob Coats

28 The Canon in the History of Economics

Critical essays

Edited by Michalis Psalidopoulos

29 Money and Growth

Selected papers of Allyn Abbott Young

Edited by Perry G.Mehrling and Roger J.Sandilands

30 The Social Economics of JeanBaptiste Say

Markets \& virtue

Evelyn L.Forget

31 The Foundations of Laissez-Faire

The economics of Pierre de Boisguilbert Gilbert Faccarello

32 John Ruskin's Political Economy

Willie Henderson

33 Contributions to the History of Economic Thought

Essays in honour of R.D.C.Black

Edited by Antoin E.Murphy and Renee Prendergast

34 Towards an Unknown Marx

A commentary on the manuscripts of 1861-63

Enrique Dussel

35 Economics and Interdisciplinary Exchange

Edited by Guido Erreygers

36 Economics as the Art of Thought

Essays in memory of G.L.S. Shackle

Edited by Stephen F.Frowen and Peter Earl

37 The Decline of Ricardian Economics

Politics and economics in PostRicardian theory

Susan Pashkoff

38 Piero Sraffa

His Life, thought and cultural heritage 
39 Equilibrium and Disequilibrium in Economic Theory The Marshall-Walras divide Michel de Vroey

40 The German Historical School

The historical and ethical approach to economics Edited by Yuichi Shionoya

41 Reflections on the Classical Canon in Economics

Essays in honor of Samuel Hollander

Edited by Sandra Peart and Evelyn Forget

42 Piero Sraffa's Political Economy

A centenary estimate

Edited by Terenzio Cozzi and Roberto Marchionatti

43 The Contribution of Joseph Schumpeter to Economics

Economic development and institutional change

Richard Arena and Cecile Dangel

44 On the Development of Long-run Neo-Classical Theory

Tom Kompas

45 F.A.Hayek as a Political Economist

Economic analysis and values

Edited by Jack Birner, Pierre Garrouste and Thierry Aimar

46 Pareto, Economics and Society

The mechanical analogy

Michael McLure

47 The Cambridge Controversies in Capital Theory

A study in the logic of theory development Jack Birner.

48 Economics Broadly Considered

Essays in honor of Warren J. Samuels

Edited by Steven G.Medema, Jeff Biddle and John B.Davis

49 Physicians and Political Economy

Six studies of the work of doctoreconomists

Edited by Peter Groenewegen

50 The Spread of Political Economy and the Professionalisation of Economists 
Economic societies in Europe, America and Japan in the Nineteenth Century

Massimo Augello and Marco Guidi

\section{Historians of Economics \& Economic Thought}

The construction of disciplinary memory

Steven G.Medema and Warren J. Samuels

52 Competing Economic Theories

Sergio Nisticò and Domenico Tosato

53 Economic Thought and Policy in Less Developed Europe

The 19th Century

Edited by Michalis Psalidopoulos and Maria-Eugenia Almedia Mata

54 Family Fictions and Family Facts

Harriet Martineau, Adolphe Quetelet and the population question in England 1798-1859

Brian Cooper

\section{Eighteeth-Century Economics}

Peter Groenewegen

56 The Rise of Political Economy in the Scottish Enlightenment

Edited by Tatsuya Sakamoto and Hideo Tanaka

57 Classics and Moderns in Economics Volume I

Essays on Nineteenth and Twentieth Century Economic Thought

Peter Groenewegen

58 Classics and Moderns in Economics Volume II

Essays on Nineteenth and Twentieth Century Economic Thought

Peter Groenewegen

59 Marshall's Evolutionary Economics

Tiziano Raffaelli

60 Money, Time and Rationality in Max Weber

Austrian Connections

Stephen D.Parsons

61 Classical Macroeconomics

Some modern variations and distortions

James C.W.Ahiakpor

62 The Historical School of Economics in England and Japan

Tamotsu Nishizawa 
63 Classical Economics and Modern Theory

Studies in Long-Period Analysis

Heinz D.Kurz and Neri Salvadori

64 A Bibliography of Female Economic Thought to 1940

Kirsten K.Madden, Janet A.Sietz and Michele Pujol

65 Economics, Economists and Expectations

From Microfoundations to Macroeconomics

Warren Young, Robert Leeson and William Darity Jr.

66 The Political Economy of Public Finance in Britain, 1767-1873

Takuo Dome

\section{Essays in the History of Economics}

Warren J.Samuels, Willie Henderson, Kirk D.Johnson and Marianne Johnson

68 History and Political Economy

Essays in Honour of P.D. Groenewegen

Edited by Tony Aspromourgos and John Lodewijks

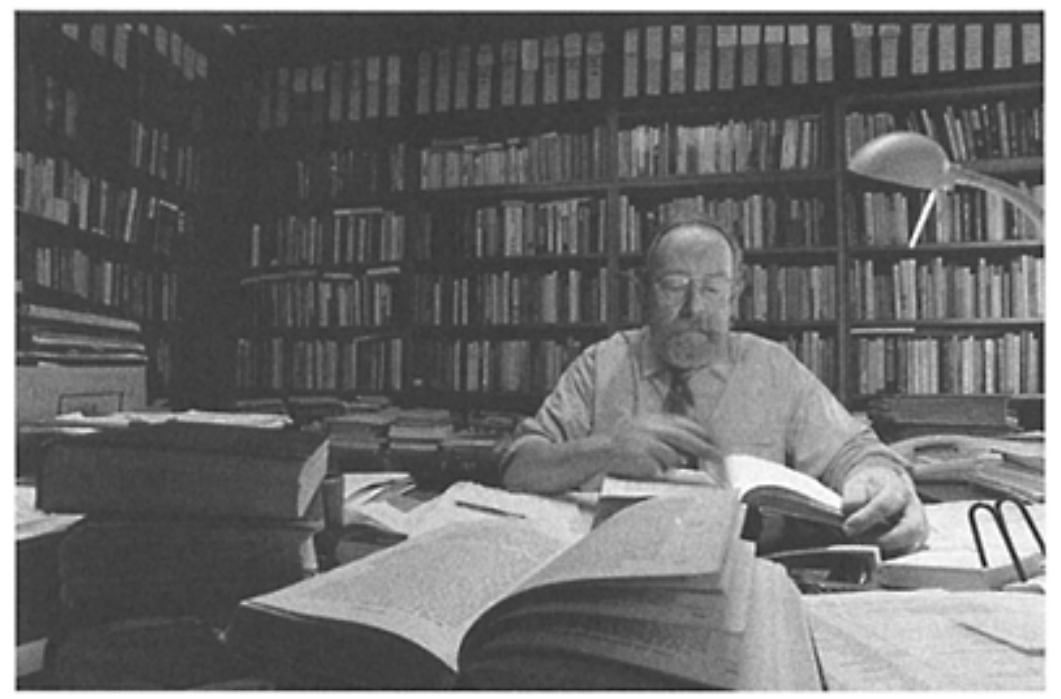




\section{History and Political Economy}

Essays in Honour of

P. D. Groenewegen

Edited by Tony Aspromourgos and John Lodewijks 
First published 2004 by Routledge

Published 2017 by Routledge

2 Park Square, Milton Park, Abingdon, Oxon OX14 4RN

711 Third Avenue, New York, NY 10017, USA

Routledge is an imprint of the Taylor \& Francis Group, an informa business

Copyright (C) 2004 Tony Aspromourgos and John Lodewijks for selection and editorial matters; individual chapters, the contributors

The Open Access version of this book, available at www.tandfebooks.com, has been made available under a Creative Commons Attribution-Non Commercial-No Derivatives 4.0 license.

British Library Cataloguing in Publication Data

A catalogue record for this book is available from the British Library

Library of Congress Cataloging in Publication Data

A catalog record for this title has been requested

ISBN 978-0-415-32762-6 (hbk) 


\section{Contents}

Notes on contributors $\quad$ xii

Foreword by xvi

A.W.(Bob) Coats

Preface xviii

Introduction: The Historian of Economics as Archaeologist 1

TONY ASPROMOURGOS AND JOHN LODEWIJKS

1 Economic Value and Moral Value in Aristotle 14

COSIMO PERROTTA

2 Adam Smith's Socio-Economic Man-and the Macro-foundations of 26

Microeconomics

GIANNI VAGGI

3 On Say's Law

ARNOLD HEERTJE

4 Thomas Tooke's Legacy to Monetary Economics 51

MATTHEW SMITH

5 William Thomas Thornton and John Stuart Mill: A Victorian 68

Friendship

MARK DONOGHUE

6 A Grin Without a Cat: W.S.Jevons' Elusive Equilibrium 88 MICHAEL V.WHITE

7 Henry George on Property Rights in Land and Land Value: Equal and 107 Private, or Common and Public? JOHN PULLEN

8 Groenewegen's Marshall: A Review 126 MILTON FRIEDMAN

9 New Orientations in Marshallian Studies 129 GIACOMO BECATTINI

10 Marshall on India 142

TIZIANO RAFFAELLI

11 Alfred Marshall and Grand Social Reform 152

JOHN K.WHITAKER

12 History and Theory in Marshall 163

NEIL HART

13 Keynes as a Writer: Three Case Studies

ROD O'DONNELL 
14 'The Functionless Investor': Keynes's Euthanasia of the Rentier Revisited TONY ASPROMOURGOS

15 Some Reflections on Keynes, Policy and the Second World War 216 SEAN TURNELL AND G.C.HARCOURT

16 HOPE in the Antipodes

JOHN LODEWIJKS

Bibliography of Peter Diderik Groenewegen $\quad 234$

$\begin{array}{ll}\text { References } & 244\end{array}$

$\begin{array}{ll}\text { Index } & 265\end{array}$ 
Gianni Vaggi has published extensively on the history of economics and development economics. He is the author, with Peter Groenewegen, of A Concise History of Economic Thought (Palgrave, 2002). Prof Vaggi is also a member of the Advisory Board of the European Journal of the History of Economic Thought. He is Professor of Development Economics at the Università di Pavia.

John K.Whitaker is Professor of Economics at the University of Virginia. The author of many articles on economic theory and the history of economic thought, he has edited the early manuscripts, and subsequently the correspondence, of Alfred Marshall and has written extensively on Marshall's life and thought. He served as President of the History of Economics Society in 1984.

Michael V.White has published extensively in the history of economics, his work appearing in History of Political Economy, The Manchester School, the Journal of the History of Economic Thought, History of Economics Review, the Cambridge Journal of Economics, Economic Inquiry and the Economic Record. His research is principally concerned with the work of W.S.Jevons. Dr White is Senior Lecturer in economics at Monash University, Melbourne. 


\section{Contributors}

Tony Aspromourgos has published extensively on the history of economics-including in Australian Economic Papers, History of Economic Ideas and the Journal of the History of Economic Thought. He is the author of On the Origins of Classical Economics (Routledge, 1996). Dr Aspromourgos is also a member of the Editorial Board of the European Journal of the History of Economic Thought. He is Associate Professor of Economics at the University of Sydney.

Giacomo Becattini is an expert on British economic thought of the nineteenth century and especially the work of Marshall. He is Professor in the Dipartimento di Scienze Economiche, Università di Firenze and his articles have appeared in numerous journals including the Marshall Studies Bulletin and Rivista Italiana degli Economisti. He is the author of Alfred Marshall: Industry and Character in Victorian Economics (Elgar, 2004).

A.W.(Bob) Coats is Professor Emeritus of Economic and Social History at the University of Nottingham and was previously Research Professor of Economics at Duke University. His many publications include Economists in Government (Duke University Press, 1981), Economists in International Agencies (Praeger, 1986), The Sociology and Professionalization of Economics (Routledge, 1993) and The Development of Economics in Western Europe since 1945 (Routledge, 1999).

Mark Donoghue is Assistant Professor at the National University of Singapore, having previously held appointments at the University of Sydney and the Australian National University. His work in the history of economics has appeared in the Scottish Journal of Political Economy, The Manchester School and the European Journal of the History of Economic Thought.

Milton Friedman is Senior Research Fellow at the Hoover Institution, Stanford University, and was previously Professor of Economics at the University of Chicago. He has made influential contributions to economic theory, methodology and political economy. Prof Friedman was awarded the Nobel Prize in Economics in 1976. He is the author of numerous academic papers, as well as Capitalism and Freedom (University of Chicago Press, 1962) and Free to Choose (with R.Friedman, Harcourt Brace Jovanovich, 1979).

G.C.Harcourt is Emeritus Reader in the History of Economic Theory, University of Cambridge (1998), Emeritus Fellow, Jesus College, Cambridge (1998) and Professor Emeritus, University of Adelaide (1988). He is author and/or editor of many books and numerous articles in journals and chapters in books, including Some Cambridge Controversies in the Theory of Capital (CUP, 1972), and seven volumes of selected essays. He also co-edited with Peter Riach A 'Second Edition' of The General Theory, 2 vols (Routledge, 1997).

Neil Hart has published extensively on Marshall, including in Australian Economic Papers, the Cambridge Journal of Economics and History of Economics Review. His research interests include macroeconomic policy, Post-Keynesian economics and 
history of economic thought. He is Lecturer in economics at the University of Western Sydney.

Arnold Heertje is Professor in the History of Economic Thought at the University of Amsterdam. He is a prolific editor and writer and former President of the International Joseph A.Schumpeter Society. Prof Heertje is the builder of one of the great libraries of first edition works. He recently edited the multi-volume series, The Makers of Modern Economics (Elgar, 1995-1997).

John Lodewijks has published in History of Political Economy, History of Economic Ideas, Journal of the History of Economic Thought, Research in the History of Economic Thought and Methodology and the Journal of Economic Methodology. He was editor of the History of Economics Review for almost a decade and is currently Associate Professor of Economics at the University of New South Wales, Sydney.

Rod O'Donnell, a leading authority on Keynes, is interested in the foundations, arguments and boundaries of economics. He gained his $\mathrm{PhD}$ from Cambridge University for a thesis eventually published as Keynes: Philosophy, Economics and Politics (Macmillan, 1989). Currently he is working on an edition of Keynes's remaining unpublished papers. He is Professor of Economics at Macquarie University, Sydney.

Cosimo Perrotta has published in History of Political Economy and the European Journal of the History of Economic Thought, and contributed to the Elgar Companion to Classical Economics (Elgar, 1998). He is the author of Produzione e Lavoro Produttivo nel Mercantilismo e nell'Illuminismo (Congedo, 1988). Prof Perrotta is on the Scientific Board of History of Economic Ideas and is Professor of the History of Economic Thought at the Università di Lecce.

John Pullen has spent much of his professional life poring over the editions of Malthus' Principles and is a renowned authority in this area; yet a little over half of his fifty publications are on other subjects-Senior, Hearn, Major Douglas, Henry George and Richard Jones. Pullen is a regular contributor to History of Political Economy and is Associate Professor of Economics at the University of New England, Australia.

Tiziano Raffaelli is Associate Professor of the History of Economic Thought in the Dipartimento di Filosofia, Università di Pisa and Managing Editor of the Marshall Studies Bulletin. He has jointly edited a volume on Alfred Marshall's Lectures to Women (Elgar, 1995) and is the author of Marshall's Evolutionary Economics (Routledge, 2003). Prof Raffaelli is on the editorial board of History of Economic Ideas.

Matthew Smith has published in Contributions to Political Economy, the European Journal of the History of Economic Thought and the Journal of the History of Economic Thought. He is also a member of the Editorial Board of the History of Economics Review. Dr Smith is currently a Lecturer in economics at the University of Sydney.

Sean Turnell has published in the Economic Record, Journal of Economic History and History of Economics Review. His research interests include the history of global monetary institutions, the economics of Keynes and the history of Australian economics. He is a member of the Editorial Board of the History of Economics Review and Lecturer in economics at Macquarie University, Sydney. 



\section{Foreword}

The invitation to contribute a foreword to this collection of essays came as a pleasant surprise, and a welcome opportunity I could not refuse, given my knowledge and admiration for Peter Groenewegen's immense contribution over the past four decades to the historical study of economic ideas as well as to public finance and policy in Australia.

As is obvious from the Introduction by Tony Aspromourgos and John Lodewijks, and the bibliography of Peter's very extensive writings included in this volume, much of Peter's non-historical work is concerned with Australian topics and problems, and may be comparatively little known outside his homeland. By contrast, his work in the history of economics has a strong international focus and readership. Indeed, Peter's familiarity with European subjects and his proficiency in European languages is still most unusual among English-speaking historians of economic thought.

Though we have usually been separated by great distances, Peter and I have met periodically in various countries, corresponded frequently, and collaborated in a variety of ways on a number of scholarly projects. We have also participated in various conferences and workshops in Australia, Britain, and the United States. Thus my familiarity with his scholarship may be narrow in compass, but it is not lacking in depth. I must however admit that I have not been involved in any of the famous Critical Drinking sessions (vide Aspromourgos 2003:4-5)!

In considering what to say here I consulted a number of Australian colleagues and friends in an attempt to place Peter in context, especially with respect to academic and scholarly matters. More recently I have noted with interest that in his paper on teaching the history of economic thought at the University of Sydney (Groenewegen 2003d) he made no reference to the bitter and protracted conflict between the mainstream (orthodox) economists and the oppositional advocates of political economy, although in conversation he could not conceal his sadness in discussing that painful experience. Yet he expressed no bitterness. Neither then, nor on any subsequent occasion, has he compromised or betrayed his own high scholarly standards. And a perusal of his bibliography reveals that he has written journal articles and book chapters on a variety of species of economic heterodoxy, including Post-Keynesian, Marxist, Radical and Sraffian economics. His approach has invariably been scholarly, balanced and fair-minded.

Given the need for brevity, I shall conclude simply by referring to two major interlinked running themes in Peter Groenewegen's 1995 magnum opus - the exemplary, magisterial biography of Alfred Marshall, A Soaring Eagle. (The eagle, being a symbol of St John the Evangelist, forms part of the coat of arms for St John's, Marshall's Cambridge college.) The first is the long and unusual relationship between Marshall and his wife, Mary Paley; one that Peter has termed 'a weird and wonderful partnership' (Groenewegen 1993a - an early version of chapters 8 and 14 of $A$ Soaring Eagle). The second is what Peter calls 'the Enigma of Marshall's Character', the subtitle of the biography's concluding chapter. In presenting these themes Peter conclusively demonstrates the relevance of biography to the history of economics, an issue that has 
been debated contentiously by George Stigler, William Jaffé, and Donald Walker. Groenewegen's tenacity in tracing relevant evidence has been remarkable and where the evidence is limited or conflicting, his judgment has been remarkably sound. Remarkable too is the range of material incorporated, such as that concerning the more intimate aspects of Marshall's marriage; his treatment of his able wife as collaborator and/or assistant; his over-sensitivity to criticism of his work and to controversy. Parts of the biography are indispensable to an understanding of the nature and influence of his economics, and his stature in the economists' pantheon. No doubt some present day readers will be deterred by the sheer magnitude of Groenewegen's undertaking. Yet for those who have the energy and determination to stay the course, the rewards will indeed be great.

The history of economics discipline has this as well as many other reasons to be proud of - and grateful for-Peter Groenewegen's contribution.

A.W.(Bob) Coats 


\section{Preface}

When Peter Groenewegen indicated his intention to enter into formal retirement from his university in 2002, some of us who had been close to him naturally turned our thoughts to how we might honour his career. This volume, appearing at about his sixty-fifth birthday, is the major result.

We thank all the contributors who enthusiastically responded to our call for papers. We thank also the following for providing valuable advice as referees of various chapters: G.Becattini, W.Coleman, J.Creedy, M.Donoghue, T.Endres, N.Hart, J.King, B.Littleboy, D.Moggridge, R.O’Donnell, C.Panico, C. Perrotta, J.Pullen, T.Raffaelli, M.Schneider, M.Smith, I.Steedman, G. Vivenza and M.V.White. We are also grateful to Michael White and Peter Groenewegen for wider advice. Peter Kriesler was instrumental at the early stages of the project and we thank him for his encouragement and support. We are also indebted to staff at Routledge, especially Robert Langham, Terry Clague, Faye Kaliszczak and Simon Bailey. Alan Walker very professionally undertook the bulk of the work towards preparation of the index.

We thank the American Economic Association and Milton Friedman for permission to reprint his review of A Soaring Eagle-and acknowledge with thanks the permission of the Faculty of Economics and Business, University of Sydney, to reproduce the photograph at page vi. The School of Economics and Political Science within the University also kindly provided funding support. J.M.Keynes (1979-89), The Collected Writings of John Maynard Keynes, 30 vols., Macmillan, are quoted with the permission of Palgrave Macmillan. A.Smith (1976), The Theory of Moral Sentiments, ed. D.D.Raphael and A.L.Macfie, Clarendon, is quoted with the kind permission of Oxford University Press.

It is our hope that these essays will be a tribute to the impact of Peter Groenewegen's scholarship and intellectual friendship on all the contributors, as well as many others. We hope also that the collection is testimony to the contribution historical studies can make to contemporary analysis and policy.

Tony Aspromourgos John Lodewijks

Sydney

February 2004 



\section{Introduction}

\section{The Historian of Economics as Archaeologist \\ Tony Aspromourgos and John Lodewijks ${ }^{*}$}

It is a pleasure and a privilege for us to introduce the following set of essays, in honour of Peter Groenewegen's corpus of contributions to scholarship over the last three and a half decades or so. This introductory essay outlines the contours and character of Groenewegen's life of scholarship.

\section{A Career In Brief}

Peter Groenewegen was born in February 1939 in the Dutch mining town of Kerkrade and his family migrated to Australia in early 1952. Groenewegen (1997) provides a detailed autobiographical account of his career and we will not duplicate that material here. He officially retired from the University of Sydney in 2002 - the university he has been a vital contributor to, as student, teacher and scholar, more or less continuously since the late 1950s, save for a doctoral sojourn at The London School of Economics and Political Science in the early 1960s.

We may first raise this question: what is the appropriate 'record' of an intellectual life? Groenewegen himself no doubt has a considered answer to this question, since one of his major achievements has been to himself provide a 'record' - a 900-page biography - of the father of English 'neo-classical' economics, Alfred Marshall (Groenewegen 1995). To briefly record here the main lines of Groenewegen's life of intellectual achievement, we may summarize the key elements of his $C V$.

He has published more than fifty journal articles since 1967, and more than sixty chapters in books from 1977. With regard to books, there are his edited translations of A.R.J.Turgot in 1977; an Australian public finance textbook in three editions from 1979 (Groenewegen 1979a); his history of Australian economics with Bruce McFarlane (Groenewegen and McFarlane 1990) — and of course, the biography of Marshall. As well, Groenewegen contributed four tax monographs from 1976 to 1985 , and edited (or, in three of these cases, co-edited) a further ten books between 1983 and 2001. ${ }^{1}$ From 1982 to 2000 he also edited (some of these cases involving also translation) nine numbers in his Reprints of Economic Classics series of important and neglected writings from the history of economics, all with scholarly introductions and extensive editorial notes. Finally, there are a number of contributions by Groenewegen to reference works, of which the most significant are his twenty-six entries in The New Palgrave (Eatwell et al. 1987). Recently, he has edited his own collected essays in the history of economics for Routledge, in three volumes (Groenewegen 2002a; 2003a).

In addition to all these tangible published results of his research activity, Groenewegen has made extensive contributions to institutional organizations of scholarly communities. 
He served as editor of Economic Papers, a journal of the Economic Society of Australia, from 1973 to 1981, and on the editorial boards of eight international journals between 1986 and the present, and has regularly refereed for more than a dozen different journals. He was an Australian Research Council Senior Research Fellow, 1991-95. He served as President of the New South Wales Branch of the Economic Society of Australia in 197879 and was President of the History of Economic Thought Society of Australia from 1981 to 1989. He was a member of the Humanities and Social Sciences Panel of the Australian Research Council from 1989 to 1992. Groenewegen was elected a Fellow of the Academy of Social Sciences in Australia in 1983. Typically, he has played an active role in that institution - as Chair of Panel B (Economics), 1986-90; member of the Executive, 1986-89; NSW Branch Convener since 1991; member of the Membership Committee, 1994-97, and of its International Committee since 1997. No doubt related to the last, Groenewegen has been honoured as a foreign or corresponding member of Dutch, Italian and French academic societies since 1993, 1994 and 1997 respectively (Koninglijke Nederlandse Akademie der Wetenschappen, Società Italiana degli Economisti, Association Charles Gide pour l'Etude de la Pensée Economique).

For the sake of completing the record, he holds the degrees of Bachelor of Economics with First Class Honours (Sydney, 1961), Master of Economics (Sydney, 1963) and PhD in Economics (L.S.E., 1965), and - putting aside visiting appointments - his academic positions during his career, all at the University of Sydney, were: Teaching Fellow in Economics 1961-63, Lecturer in Economics 1965-67, Senior Lecturer in Economics 1968-74, Associate Professor of Economics 1974-80, Professor of Economics 19812002, and since then, honoured as Emeritus Professor of the University. Groenewegen served as Head of the Department of Economics in the University in 1979-80, 1983 and 1987-90. He turned sixty-three on 13 February 2002 and retired the following day. ${ }^{2}$ Now, in his sixty-fifth year, some of his colleagues honour him with this volume of essays.

\section{Groenewegen's Life of Scholarship}

Let us return briefly to Groenewegen's corpus of published research, to attempt to convey a sense of its contours and character. Most of it falls within two broad areas, history of economic thought and public finance (with particular reference to taxation reform), as is already evident in our listing of his various mono-graphs. Because of its largely applied Australian content, Groenewegen's public finance research is not well known internationally. ${ }^{3}$ While the essays that follow are devoted to the history of economics, the field in which Groenewegen built an international reputation, it may be worth briefly highlighting some of his contributions to Australian public finance.

Groenewegen wrote his first paper on public finance in 1971 advocating a simplified tax system consisting of a reformed income tax, a value added tax and a net wealth tax. This paper, and those that were to follow, led to him acquiring a highly visible public profile as a tax reformer and expert on fiscal federalism. For a couple of decades he was regarded as one of the three leading Australian public finance experts. His strong and persistent advocacy for a value-added tax gives him some claim to being 'called the "grandfather" of the GST' - the Australian Goods and Services Tax (Dollery 2002:147). His views on public finance were aired at places such as the OECD and in the United 
States Commission on Intergovernmental Relations. In the context of this volume we should stress two points. First, he had tried to associate history with economics in all his applied and practical work in public finance and taxation. Secondly, he filled a very valuable gap in Australian public finance. There was no Australian public finance textbook and students used foreign texts despite the obvious institutional and historical differences relating to fiscal federalism and taxation. Groenewegen admirably filled this gap with a completely Australian text, not a foreign adaptation. Yet such an undertaking had its costs. Indeed from the second half of the 1970s he was busily engaged in writing his public finance text, as well as conducting his own research in taxation, and these endeavours, however valuable to the Australian community and economics profession, distracted him from much publishing in the history of economics until the end of the 1980s (2002a:xix). Given this public finance preoccupation for over a decade (19771989), his research output in the history of economics is even more remarkable.

The main focus of his earlier historical scholarship was classical economics, in both its British and Continental European dimensions - most particularly, Turgot In fact, not a small part of the significance of his work on the eighteenth century (and to some extent earlier) was to make evident the multinational sweep of the formative development of political economy, to raise the profile of Continental economic literature, for a discipline somewhat prone to Anglocentricity. Most of this research is now assembled in Groenewegen (2002a), though the twenty-six New Palgrave entries in large measure are a summary embodiment of that scholarship. ${ }^{4}$ Later of course, Marshall inevitably dominates, as Groenewegen entered into the long period of research work that produced the biography of Marshall and many other related papers. ${ }^{5}$ Twenty-one of the thirty-two papers reprinted in Groenewegen (2003a) were originally published after the 1980s, and a majority of these concern Marshall. The whole period of his scholarship, but especially the 1970s and 1980s, has involved considerable rethinking of the meaning of classical economics, with attendant controversies. There are some who have thought that these disputes were symptomatic of a struggle for ownership of the past, the history of the discipline, by contending contemporary schools. Others of us have thought that it has been more about overcoming a certain kind of 'Whig history', in the creation of which Groenewegen's subject, Alfred Marshall, played no small role. Groenewegen has diagnosed a crucial part of Marshall's role in this process, in an article we regard as one of his best (Groenewegen 1993b; cf. Groenewegen 1991 and 2003c:3-4). Indeed an examination of his three volumes of selected articles in the history of economics leads to the conclusion that the last volume, covering articles written over the last decade or so, surpasses even the earlier excellent contributions. No doubt the financial support of the Australian Research Council played a role here. Freed from administrative burdens and excessive teaching obligations, and supported by several capable research assistants, the scholarly output flowed.

\section{Two Appreciations}

To gain greater insight into Groenewegen's approach to the history of economics we interviewed one of his former research assistants, Mark Donoghue, who has gone on to establish a considerable research reputation in his own right, and a long time Australian 
colleague in the history of economics, and the compiler of the variorum edition of Malthus' Principles, John Pullen. These two commentators raise issues that may be explored in further detail.

Pullen emphasized Peter's compendious knowledge of the history of thought and his amazing memory of dates, events and ideas. Unlike those that seek a grand synthesis (at the cost of perhaps some inconsistencies with the historical record), Peter gets his hands dirty spending countless hours digging into the past-even, if need be, translating texts. Whereas some historians of thought in the quest for the big picture interpretation of the history of economics may leave it to others to fill in all the details, it is precisely these details that worry Groenewegen. Inconsistencies with historical fact offend his sense of scholarship. It is said he never finished reading Heilbroner's Worldly Philosophers because he became so irritated with the historical inaccuracies. To Pullen, Groenewegen is a model of academic responsibility engaged in dispassionate objective research. A true archaeologist engaged in ferreting out the past.

A further contribution that Pullen hastens to note is Groenewegen's help at a personal level. His advice and comments on draft papers are sought by a significant section of the Australian and international history of thought community. In many ways he is the father figure of history of economics in Australia. He was very enthusiastic in support of the formation of the History of Economic Thought Society of Australia and was the automatic and unanimous choice for President, a position he himself relinquished in time as he felt there was no need for such an authority figure in a community of scholars. He enjoys immensely face-to-face contact at international conferences and is a vigorous proponent of ideas as witnessed in various sharp exchanges with all and sundry. Groenewegen believes that criticism is not a form of abuse. From criticism comes the growth of knowledge and without critical responses knowledge rapidly stultifies (Dollery 2002:138).

Over the years Groenewegen has written extensive critiques of research in the history of economics. He demands high standards of scholarship. On Pickering's collected works of Malthus he says that the 'introduction is a veritable desert of misinformation' and 'the usefulness and consistency of the editorial notes are on par with the quality of the Introduction' (2003a: vol. I, 63). Some say he has mellowed with age. A recent issue of the History of Political Economy (2003, no. 2) would disabuse anyone of that notion. On pages $345-6$ he notes of the book he is reviewing:

The simplistic nature of such broad generalizations for those familiar with this literature indicates the sublime shallowness of this work. Seemingly erudite, it is replete with weak argument and undocumented assertion, among which, very occasionally, an unexplored insight can be found.

Not only historical work experiences his wrath. He comments that Michael Pusey's attacks on economic rationalism 'illustrate the poverty of Australian sociology when it masquerades as economic critic' and displays 'Pusey's rather profound ignorance of economics past and present' (2003a: vol II, 267, 275 n. 5).

It is his jousts with major figures in our craft-Terence Hutchison, Samuel Hollander and Don Patinkin - that are particularly insightful. In his paper 'New light on the origins of modern economics' he provides a very detailed examination of Hutchison 
(Groenewegen 2002a: Ch. 3). While he endorses the significance that Hutchison places on the internationalization of economic discourse from the 1740s to the 1770s he finds fault with the downplaying of the physiocrats and the over emphasis on subjective approaches to value. Indeed in Hutchison's treatment there is a systematic omission of production and distribution theory in the final decade before the Wealth of Nations. Groenewegen emphasizes that Classical Political Economy was a study of the production, distribution and circulation of wealth. Hutchison's interpretation instead emphasizes the development of a notion of interdependence between economic harmony, equilibrating tendencies and freedom of trade (ibid.: 86-91).

Groenewegen has also presented a detailed critique of Don Patinkin's interpretation of aspects of Keynes (Groenewegen 2003a: vol. II, Ch. 24); but it is his antipathy towards Samuel Hollander's massive reinterpretation of the classics that merits attention here. Groenewegen has often mentioned the Sraffian influence on his work in the history of economics and the usefulness of the surplus approach and natural prices as features that clearly distinguished classical from later marginalist economics. This surplus approach to value and distribution is contrasted with the Hollander approach that analyzes postSmithian developments as a continuous completion and improvement of a supply and demand inspired Marshallian approach to value and distribution. Groenewegen emphasizes the historical difficulty of interpreting the past with modern meanings and the continual search for precursors. Samuel Hollander wants to fit Smith into a neo-classical general equilibrium context, and not into the classical context of accumulation and growth (2002a:401). Groenewegen's De Quincey paper (2003a: vol. I, Ch. 7) was motivated by Hollander's faulty interpretation of the classics. In turn, Hollander has labeled Groenewegen a 'Sraffian' (Groenewegen 1997:15).

To Mark Donoghue, Groenewegen is the foremost scholarly professor of economics in Australia and a world-class scholar. The image he projects is that of an independent researcher beavering away in the archives. He is someone renowned for reading everything. He is a careful, meticulous scholar with an encyclopedic knowledge of the literature, a master craftsman with meticulous files, nothing ever being regarded as so unimportant as to be dispensed with. Groenewegen, he says, takes a relativist approach to the subject, emphasizing the importance of context. Each individual must be set in the social, historical and political context of his or her time. This stress on the importance of contextual reading for understanding a classical text demands a higher standard of scholarship and greater historical knowledge yet yields a far richer appreciation of the work studied (2003a: vol II, 43).

The history of economics has gone through a number of methodological fashions over the last twenty-five years, including flirtations with the philosophy and history of science. To some observers, Groenewegen's great-man approach, where history is shaped because we are 'standing on the shoulders of giants' is 'old-fashioned'. His focus on the historical details attracts critics who complain of the excessive footnotes or trivial minutiae (Brewer 1997). Groenewegen does not accept the criticisms of excessive detail in his work. The facts included are all pertinent to an understanding of Marshall: 'A context, essential for understanding Marshall's work, cannot easily be over-drawn with too much detail, since it invariably illuminates aspects of his behaviour, trivial though this may seem when some of the details are looked at individually' (Groenewegen 1997:20). In terms of research approach, perhaps E.R. Weintraub has been the most scathing about the quality 
of published history of economic thought and has long advocated the need for historians of economics to attain the standards of the true historian. He has used A Soaring Eagle as an exemplar of the standards the profession should try to meet (Weintraub 1996).

Groenewegen's work habits are worth mentioning if only to give a guide to his voluminous output which ranks him among the top half dozen publishers in the Australian economics community. He is a voracious reader who devours more than 200 books a year in addition to economics reading (Dollery 2002:132). Groenewegen notes that he read 2 volumes (900 pages) over 4 afternoons of solid reading, for a book review (2003a: vol. II, 278). Mere mortals, like the present editors, can achieve but a fraction of this. When George Stigler in 1962 remarked that 'no man could live long enough or read fast enough to read everything written on Marshall' he had clearly not counted on one Peter Groenewegen (O'Brien 1997:1859). He typically rises early and spends the mornings doing the basic research and leaves the afternoons for the writing up (typically ten pages or so of a chapter). His correspondence is immense and all dealt with immediately. He feels a strong obligation to students and always makes prompt comments on draft chapters. He is very supportive of students and makes them feel that their research is of importance and is genuinely pleased with their success. Feedback on his own work from peers is also crucial. While working on his Soaring Eagle he arranged for no less than five Marshall specialists to comment on each chapter (Bob Coats, John Whitaker, Giacomo Becattini, Ronald Coase and Rita McWilliams-Tullberg) in addition to two local readers (Michael White and Peter Kriesler).

While Groenewegen is well-known as a scholar of eighteenth-century political economy the irony is that he will be best known as the biographer of the neo-classical Alfred Marshall. In his inaugural lecture at the University of Sydney he listed his main interests as classical political economy and Post-Keynesian economics and mentions 'my work on the reconstruction of political economy on what are called Post-Keynesian lines' (2003a: vol I, 17-19). Yet after his appointment as Professor of Economics his research interest is predominantly Marshall and the 'moderns' - the latter designating adherents to the use of marginalist method in economics. How do we account for this change in research orientation?

In some ways it is a puzzle. For one enamoured by classical concerns of surplus and labour measures of value, the supply and demand scissors of Marshall may seem beyond the pale. Moreover, in 1881 Marshall advanced a marginal productivity theory of distribution (ibid.: vol I, 27, 146). Denis O'Brien (1997:1864) notes that there is a large literature, almost all of it connected with Cambridge, denigrating Marshall, and the critics included Joan Robinson and Sraffa. How do we explain why Groenewegen invested so much of his intellectual energies into this pioneer of marginalism who was the key figure in the professionalization of neo-classical economics? The most straightforward explanation is that there was a niche to be filled. No comprehensive Marshall biography was available. Others well positioned to provide one had indicated that this was not on their research horizon. Groenewegen stepped in to fill the gap, as he had with his Australian public finance text.

Perhaps there are other factors at work too. Marshall was a fascinating and complex figure. Marshall's classical attributes and apparent regard for Ricardo needed explaining. Marshall attempted to reconcile the old economics of Ricardo with the new economics of marginalism as a way of completing the classical economists' theories and his view that 
Ricardo's theory of value needed completion rather than reconstruction attracted Groenewegen's attention (ibid.: vol. II, 35). After the biography, Groenewegen (ibid.: vol. II, 196-7) noted that:

The biographer of Marshall can dispel many myths. ...Marshall the neoclassical is another myth...it is dangerous to draw lines of continuity from the system that Marshall constructed...to the practices of the present or, for that matter, some of the practices in economic theorizing constructed in his name in the Cambridge of the 1920s and 1930s. Marshall, the founder of the basic tools of modern micro-economics, is also a convenient myth. It obfuscates the fact that the invention of microeconomics as a subset of work in the discipline occurred well after his death, thereby effectively hiding the fact that his economics blends what are now called micro- and macro-considerations. Moreover, it neglects the stress that Marshall placed on the interdependence of all parts of his subject and its links with many of the social sciences.

Evidently Groenewegen acquired a much greater admiration for Marshall's subtle economics. It was clear that Marshall moved out of the straight-jacket of marginalism in his later years when he realized its shortcomings (ibid.: vol. II, 94). Marshall's supply and demand analysis was not narrowly conceived. It had to be handled with great care with respect to time, interdependence, space and institutions. There was a 'need to set Marshall apart in some way from marginalist economics' (ibid.: vol. I, 147). 'Marshall remains an enigma' (ibid.) in that while he supported many of the marginalist fundamental principles he was painfully aware of many of the complications and difficulties in its application.

The Soaring Eagle project started in 1984 and took two and a half years to write up in first substantive draft. Groenewegen (2003a: vol II, 196) asks: 'Was it worth it?' The favourable reviews clearly answer in the affirmative. Gavin Reid's (1996:1073-4) review in the Economic Journal states that Groenewegen's Soaring Eagle 'is an outstanding, indeed definitive, contribution to Marshallian studies...it is with this work of Groenewegen's that Marshallian studies have been established once and for all on a rocklike foundation'. He goes on to add that the 'twenty-one chapters in this book are carefully crafted, meticulously annotated, and based on the widest and deepest access to source material that has ever been attempted'. Denis O'Brien (1997:1884), in his review essay of Groenewegen (and John Whitaker) on Marshall concludes by saying that 'we shall not see the like of this work again'. Milton Friedman acclaims 'Groenewegen's magnificent biography of Alfred Marshall' in his glowing review that we reprint in this volume.

\section{Intergenerational Relationships}

When taken together with the accompanying chronological bibliography, the above records, clearly enough, the main elements of tangible achievement in Peter Groenewegen's research life to date. Without doubt, much of this corpus will still be read 
for a very long time. It is an enduring contribution to the fundamental purpose of a university, and of an academic life: the preservation and advancement of knowledge. But we would venture to add that there is more to an academic life than this; much more, of great significance, that is intangible and somewhat hidden from the public record. The real substance of learning, and the heart and substance of a university of any significance, is constituted by the life of its intellectually active staff and students, of quality. Groenewegen is an exemplar of that species. He would perhaps agree with Socrates, that the things that matter can be learnt, but not taught. In this respect, it is the example of an intellectual life like Groenewegen's, which is the most powerful catalyst for learning, at least by those with the quality to grasp it.

More generally, we would like to draw attention here to the importance of intergenerational relationships and bonds in the making and sustaining of intellectual life. It is the informal social structures of this intergenerational transfer of tempers, intellectual cultures, ideas, and so on, which is the largely hidden terrain upon which occurs the reproduction of the scientific sensibility, from generation to generation. In this way, Groenewegen is beholden to those who supported his cultural and intellectual development, and others of us are beholden to him, for our development. In the hard black and white of an academic $C V$, few traces of this vitally important element of an academic life are to be seen. But just as in our physical lives, so in our intellectual livesallowing some good fortune-we get to experience the Three Ages of Man.

Groenewegen's tutelage came from a number of sources. In reminiscences of his academic life he particularly mentions Bernard Corry (his London PhD supervisor), Ronald Meek (external examiner of his Ph.D), Maurice Dobb and Jacob Viner (Dollery 2002:131-3). We know that Corry strongly influenced the approach he took to his teaching of the classics at the University of Sydney. His $\mathrm{PhD}$ thesis concerned the growth of value, production and distribution theory from 1650 to 1776 and owed its inspiration to earlier work by Maurice Dobb (Groenewegen 1997:8). Groenewegen was a great admirer of Dobb's 1973 book, Theories of Value and Distribution since Adam Smith. Groenewegen was also strongly influenced by the scholarship of and personal interaction with Jacob Viner. Indeed it could be said that he has tried to emulate Viner's approach to scholarship. He counts Viner as 'another of my economic heroes': 'It is difficult to say whether he was the greatest historian of economic thought...reflections on the subject...suggest few other candidates for the position' (Groenewegen 2003a: vol II, 246). The comments Groenewegen makes about Viner on the high standards required when writing intellectual history and the need to ascertain the meaning of authors in their own terms are equally pertinent to his own work: it require[s] contextual reading, placing authors in their wider social and economic conditions, combined with their literary heritage for which a biographical dimension was invariably a useful input' (ibid.: vol. II, 254). ${ }^{6}$

The give and take of intellectual exchanges can be illustrated by Groenewegen's 'change of mind' on Turgot. We are indebted to Michael White for pointing this out to us. This reversal can be clearly seen in his Turgot papers reprinted in Groenewegen (2002a: Chs. 16-19). In a 1970 paper he notes that Turgot's problem of value measurement is essentially the problem of exchange value and his analysis resembles contributions to the neo-classical school (ibid.: 293). In his 1971 paper it is stated that the essence of Turgot's theory is the supply and demand determination of the rate of interest 
where the 'rate of interest reflects the relative scarcity of capital'. Groenewegen acknowledges that Turgot's theory of capital is 'an important improvement on that of Quesnay' and his theory of capital and interest is 'superior to that of all other economists of the eighteenth century' (ibid.: 307-9). A decade later there is a significant 'change of mind' on Turgot. In a 1982 paper he says that Turgot was not a precursor of neo-classical approaches, that while there are some superficial similarities, these are not essential components of his system of thought. His surplus approach, focusing on production and distribution of disposable wealth, "clearly establish the overall classical nature of Turgot's value theory'. Turgot 'is clearly in the classical mould... if his economic system is compared with the core of the post-1870 neo-classical analysis, little resemblance can be found between them'. 'Similarly in the case of capital theory, Turgot's "modernity" can be exaggerated and its proximity to neo-classical thought over-emphasised': 'It must be concluded that the resemblance between Turgot's economics and that of post-1870 writers is superficial, and that the similarities which exist should not be taken as a sign that Turgot was in any real sense a precursor of this type of economics' (ibid.: 324-6).

What caused the 'change of mind'? Groenewegen in 1983 notes that he has been influenced by Meek's critique of the neo-classical interpretation of Turgot. He notes that in earlier papers he had argued that some of Turgot's contributions to economic analysis resemble the work of the marginalist school to a far greater extent than those of his contemporaries and most immediate successors. This was especially the case with his theory of value and exchange, and of capital and interest (ibid.: 344). He now sees that the neo-classical interpretation is out of context and relates only to primitive societies. A fuller explanation is found in footnote 97 (ibid.: 358) where he says that his earlier (1970) views on this subject have been altered as a result of reading a penetrating critique of his neo-classical interpretation by Roberto Finzi and after further thought on the matter.

More generally, Groenewegen's intellectual inspirations and influences have had a distinctly 'Cambridge' flavour-from the period when that university's economics played a fundamental, dynamic and original role in the directions of twentieth-century economics. Groenewegen had portraits of many of the economists he admires on the walls of his Professorial university office; but Joan Robinson had a special place in that pantheon - as did Jacob Viner (whose portrait also appeared there), as a scholar (see also Groenewegen 1994; 2003c: 8). Joan Robinson guided his teaching of Post-Keynesian economics. Perhaps the particular esteem for Robinson is because she combined a variety of traits which attracted him: a typically Cambridge pragmatic approach to theorizing, with problems of social progress and policy never far 'out of the frame'; a political Leftism morally informing her intellectual activity (though surely a different kind of Leftism to Groenewegen's political temper); and finally, a certain feistiness, which he also has been known to exhibit. The printed version of his 1981 inaugural lecture as Professor of Economics is prefaced with the following dedication (cf. Dollery 2002:141; Groenewegen 2003b:2, 3; 2003c:7-8, 9; 1983):

This Lecture is dedicated to Professor Joan Robinson whose writings constituted the major influence of a living economist on my economic education. My intellectual debt to her work in preparing this lecture is self-evident and, I hope, sufficiently acknowledged. To her influence on my teaching of economics, only my students can testify. 
(as repr., slightly revised, Groenewegen 2003a: vol. I, 30)

Groenewegen is happy to call himself a 'dissenting economist' (Dollery 2002:152) and harbours a strong belief in the crucial role of the state in a civilized society. He acknowledges the strong connection between Post-Keynesian economics and history of economic thought in Australia and it was, particularly in the early years, often more PostKeynesian than history of economics. In this context it is perhaps useful to say a little about an episode involving interactions with colleagues and students that were less fruitful and personally painful. This involved a long running political economy dispute at the University of Sydney (Jones and Stilwell 1986). Groenewegen's views on this episode are available in Groenewegen (1979b:206) where he speaks of intellectual apartheid and expresses his opposition to a separate department and courses in political economy. Also apparent is his adverse reaction to the anti-theoretical stance of members of the political economy group who engage in descriptive 'current affairs economics' (ibid: 188). In his 1986 Newcastle Lecture he concluded by stating that Post-Keynesian economics is the only serious alternative to mainstream economics (Groenewegen 1986:32). He summed up the dispute as a 'long, and in the end, rather unproductive conflict' that produced unwelcome turmoil in the economics department of the University with which he was for so long associated (Groenewegen 1997:14).

\section{Post-Retirement}

Now, in his 'senior' years, Peter Groenewegen will find other roles to fill. Perhaps only historians can fully appreciate the contingencies in human affairs, which can be the difference between great success and heart-breaking failure. The notion that human quality always gets its reward in the end is a fable suitable only for the comforting of children. Happily, in Peter Groenewegen's case, a grand life of contribution (not yet over!) has received substantial recognition. We have drawn attention above to the somewhat hidden, informal social fabric which plays such a crucial role in the preservation of our intellectual culture, around key figures like Peter Groenewegen. In what follows, colleagues who have shared that culture with him add their token of recognition and acknowledgment to him. If there is one single theme which captures the spirit and intention of his life of scholarship it is perhaps the vital importance of historical studies for political economy, and vice versa: the relation between 'history and political economy'-as exemplified by Smith, Marx and Marshall—was, not accidentally, the theme of his inaugural lecture as Professor. Groenewegen motivates his lecture in the following terms:

...it was history which led me to the study of economics when as a high school student in the 1950s I realised that an understanding of modern world history could not be achieved without considerable knowledge of economics. My subsequent study of economics has taught me that the inverse of this proposition is also true, an understanding of modern economics and its practical application cannot be achieved without a solid knowledge of history in its manifold aspects. ... Smith, Marx and Marshall 
...were directly involved in history and political economy, since their major works involved the application of a historical method for the elucidation of the basic laws of the science of political economy. All three were therefore more than mere economists - they were superb economic historians, philosophers and social scientists, who saw their subject matter as the study of 'man in society' and who viewed that subject matter as a source for action and not just contemplation...[who] tried to resolve the theoretical problem of blending analytical considerations with the force of history.

(Groenewegen 1982a:19-20)

And consider his following retrospective thoughts:

In general, I would say that a lot of history runs through all my material. Even my material on public finance, including my text, has a reasonable amount of the history of public finance tossed into it. ... I think it has given my writings on economics per se always a sense of touch with reality, with actuality. History and institutionalism, which to a very large extent go very closely together, inform nearly all of my economics. I recall attending a seminar in Canberra of the international public finance group, and sitting next to a German colleague. He said, 'Oh I had a look at your textbook. You are a very strong institutionalist'. I must say that I had never seen my text in that way, but when I looked at it from that perspective I found it very difficult to argue with that judgement.

(Dollery 2002:138-9; cf. 157)

But institutionalist in what sense? Surely not old institutionalism in terms of Veblen or Mitchell or Commons - and Groenewegen would be even more uncomfortable in the company of the neo-classical new institutionalists. All he means is that he thinks institutions and history are vitally important in understanding the past and present. Moreover, the background of a particular economist is then highly important in understanding that economist's work (Dollery 2002:140; Groenewegen 2003a: vol. I, 12). The interest in biography and the institutional features that shaped Australian economics are important parts of Groenewegen's research agenda.

In one of his recent volumes of selected essays, Groenewegen (ibid.: vol. I, 11) surveys four decades of his work in the history of economics and comments that "what surprised me was on how little of the specific historiographical contents of this work I had changed my mind'. The volumes reflect Groenewegen's broad interest in the history of economics. He is a generalist in a craft that is becoming more specialized. His early work was on Turgot and history of mainly British value, production and distribution theory written from 1650 to 1776 . He substantially broadened that canvas to incorporate continental influences, the moderns and Australian economics. Groenewegen (1997:25) believes that 'the discipline needs the presence of the historian of economics as gadfly, critic and collective memory of non-defunct alternatives in puzzle-solving from earlier times'. The study of the history of economics 'reminds practicing economists of the traditional links in their subject with practical policy concerns, ethical and moral values, 
and the systematic explanation of economic phenomena. It likewise reminds one of the historical relativity in economic thinking which makes the now far too prevalent view of universal applicability of the economic theory an inherently nonsensical viewpoint' (2002a:91). We hope the essays that follow are some testament to these beliefs.

\section{Overview of the Essays}

The essays which follow cover a diverse set of issues. First, Cosimo Perrotta goes back to Aristotle, who is the origin of much of western science, to inquire into the relation between economic value and moral value. Gianni Vaggi takes up the notion of 'economic man' in Adam Smith and explores the idea that there is no singular or unitary human type inhabiting the Smithian social economy, rather, a multiplicity of social types. The notion of a single principle governing human conduct belongs not to Smith's political economy but to modern, formalist neo-classical economics. Arnold Heertje provides a very detailed examination of Say's Law and suggests that it had normative significance for Say-an interpretation that will be a challenge for those who have seen it merely as a positive law. Matthew Smith evaluates the legacy of Thomas Tooke, showing that his banking school ideas exerted considerable influence on Mill and Marx - and that Tooke's critique of the classical quantity theory of money had an important influence on Wicksell and, to a lesser extent, Marshall. Mark Donoghue explores the close and lasting relationship between William Thornton and John Stuart Mill. In particular, their intellectual collaboration reveals that while Mill's influence on the younger man's career was pervasive, there was a two-way exchange of ideas. Michael V.White shows that the persistent problem in neo-classical economics, of explaining how a market equilibrium is attained, appeared in the first published marginalist text, Jevons' Theory of Political Economy. Jevons' peculiar response to the problem is carefully explained. John Pullen examines Henry George's philosophy of natural rights and the implications this has for the practical implementation and political acceptability of his policy of land-value taxation.

The following five chapters - by Milton Friedman, Giacomo Becattini, Tiziano Raffaelli, John K.Whitaker and Neil Hart_engage with the figure at the centre of Peter Groenewegen's work in the history of economic thought from the late 1980s onward, Alfred Marshall. We reprint Friedman's review of $A$ Soaring Eagle, which illustrates that leading lights of the economics profession, not only historians of thought, find immense value in the history of economics. Becattini's chapter is a passionate plea for extending the revival of interest in Marshall to general issues concerning the interconnection between economic and social phenomena. Raffaelli argues that Marshall had a keen interest in India. Moreover, his general ideas on the relationship between custom and competition, and the possibilities for social and economic progress, were shaped and tested in the Indian context. John Whitaker considers Marshall the social reformer, his search for a 'middle way' between the excesses of capitalism and socialism. Neil Hart examines Marshall's notions of historical (or evolutionary) and equilibrium methods in economics and comes to the conclusion that his legacy in fact favoured his less preferred methodology - ahistorical equilibrium economic analysis - to the detriment of the discipline. 
Three papers on Keynes follow. Rod O'Donnell raises a conundrum: given that Keynes is widely regarded as an outstanding prose stylist and essayist, why has achieving agreement as to his meaning been so difficult? He concludes that Keynes's writing tends to sacrifice clarity for fluency. Aspromourgos takes up one of Keynes's neglected policy inferences from the final chapter of the General Theory, 'euthanasia' of the rentierreconstructing the logic of Keynes's notion and his attempted application of the idea in the 1940s, as well as sketching in a formal framework the conditions under which the notion might still be applicable today. Sean Turnell and Geoffrey Harcourt examine Robert Skidelsky's portrayal of Keynes's role as policy maker and adviser in the final decade of his life. A number of issues related to Keynes's policy work are especially relevant to current policy debates. Finally, John Lodewijks examines a productive group of historians of economics located in Australia and New Zealand. Of course, the major figure in this community is the man in whose honour this festschrift has been assembled.

\section{Notes}

* The comments of Neil de Marchi, Mark Donoghue, Peter Groenewegen, John Pullen and Michael White are greatly appreciated in preparing this Introduction, some elements of which are drawn from Aspromourgos (2003) - the text of an address given at the 15th History of Economic Thought Society of Australia Conference, July 2002, in a session in honour of Groenewegen.

1 A comprehensive bibliography of Groenewegen's published writings, but not including book reviews, appears at the end of this volume.

2 About that time, our University of New South Wales colleague Geoff Fishburn commented on the possible significance of retiring on St Valentine's Day - though more with thought of massacres than of loves.

3 For Groenewegen's own views on his work in public finance in general and tax reform in particular, see Dollery (2002:145-50).

4 In preparing his collected papers for publication, Groenewegen (2002b:xvi-xvii) made a policy decision not to include any of the dictionary entries, primarily because of their brevity (and in some cases, duplication) - and with regard to the two volume 2003 collection, a number of Marshall papers were omitted because much of their content found its way into $A$ Soaring Eagle (Groenewegen 2003b:10-11, which also lists other conscious omissions).

5 The first published results of the Marshall research appear in 1988 - though Groenewegen (1982a), a version of his 1981 inaugural lecture as Professor of Economics, also considers Marshall.

6 We may add that he has not always followed Viner's advice-for example, that 'footnotes are not free goods' and their use should be carefully rationed (Groenewegen 2003a: vol. II, 8). His 1983 History of Political Economy twenty-page article on Turgot had 146 footnotes, many of which were long and detailed, amounting to another 12 pages (Groenewegen 2002a: Ch. 19). 


\title{
1 \\ Economic Value and Moral Value in Aristotle
}

\author{
Cosimo Perrotta*
}

\section{Defining Economic Value}

According to the definition most widely used by scholars, value (in the moral and social sense) is a principle indicating that which is preferable, that which most deserves the approval of all (cf. Harsanyi 1987; Abbagnano and Fornero 1998; Sciolla 1998). In economics, value (in the sense of exchange value, the only meaning accepted by all economists) is something completely different. It refers to the quantities (different and clearly defined) in which two goods are exchanged. In this sense the two kinds of value cannot be compared. They have totally different meanings. In fact, moral value is a principle while exchange value is a measure. However both kinds of value give rise to a code of conduct, to a standard of behaviour. These rules are both cogent, though in very different ways. Being a code of conduct, moral value makes itself felt in two ways: either through one's sense of duty - as the philosopher Kant (1787:30) says: 'Act as if the maxim from which you act were to become through your will a universal law', or through a natural tendency towards benevolence, as Adam Smith (1759:171-4) believed. Economic value, as a code of conduct, asserts itself in that it is dictated by the criterion of self-interest - that is, of utility — which is the real economic standard. It asserts itself through its appeal to reason: trade can take place only if the exchange value of the two goods is respected. Only then do the two parties achieve an advantage. The advantage in an exchange must be reciprocal.

Both forms of behaviour therefore have a universal validity: moral conduct because it is dictated by the conscience or derives from an innate tendency; economic conduct because the pursuit of self-interest is dictated by reason. In this sense we can talk about economic value. As both forms of behaviour regulate human actions, they also regulate social relationships. Although economic value is totally different from moral value, it either sustains the latter or clashes with it in determining human conduct and social relations. Therefore, when we talk about economic value here, we are referring to something quite different from exchange value. It is also to be distinguished from any concept of value that measures the cost of production or the utility of economic goods, and that underlies prices.

This chapter deals with the relation that Aristotle established between moral value and the principle of self-interest, or utility, which we here call economic value. The Aristotelian vision of this problem had an enormous influence on later economic thought, and is therefore particularly important. The thesis we will put forward is this: if we examine Aristotle's writings, both those that analyse exchange value and those on 
political economy in general (crematistics), we must draw the conclusion that in the history of thought, economic value was born as a negative moral value, as a socially damaging value opposed to moral value. This contrast was already present, though not in analytic terms, in Socrates and his followers - from Xenophon to Antisthenes to Plato, but not in the Sophists (see Perrotta 2003). But with Aristotle it gained the force that would assert itself in the culture that followed. In the next section we will examine Aristotle's attitude to trade and the acquiring of wealth. Then, we will look at the philosopher's complex analysis of exchange and its meanings. The penultimate section examines his analysis of exchange value and the place of the latter in our argument. Lastly, we will see how the relation between economic value and moral value is defined by Aristotle, and then by other later thinkers, on the basis of their attitudes to nondisinterested human relationships, i.e., to the utilitarian relationship between people, aimed at achieving one's own ends.

\section{Illegitimacy of Gain From Trade}

It was Aristotle who created the concept of economic value, but at the same time drastically limited its legitimacy. He was the first to distinguish in Politics between two possible uses of goods. A shoe, he writes, for example, is not made to be bartered but to be worn. However, alongside this proper use there is also an 'improper or secondary' use, that of exchange. The improper use 'arises at first from what is natural, from the circumstance that some have too little, others too much', of a certain good (Politics, b. I, ch. 9, 1257a, 5-10:451a). Trever, then Schefold, rightly maintained that the Aristotelian distinction - contrary to what many authors wrote - is not the same as the distinction made by modern economics between use value and exchange value. The reason is this: Aristotle's aim was to state that exchange is an unnatural activity; which is opposite to the view of modern economics' (Trever 1916:82; Schefold 1999:123). In fact, the mere use of the term 'improper' casts doubt on the rightness of the exchange of goods. This doubt becomes condemnation when the exchange is not strictly motivated by the need of the person involved. Economic value-i.e., the principle of self-interest-is sanctioned only in so far as it serves to satisfy needs, not for commercial trade (cf. Ashley 1895:338 9; Dühring 1966, VIII:555-6). If exchange takes place independently from the needs that the goods can satisfy for the parties involved-i.e., independently of the specific use value of those goods - then it becomes unnatural: 'Hence we may infer that retail trade is not a natural part of the art of getting wealth' (unlike household management).

In fact, if retail trade were natural, in other words if it were connected only to unsatisfied needs, 'men would have ceased to exchange when they had enough' (Politics, b. I, ch. 9, 1257a, 10-20:451a). Precisely because natural needs are limited, household management is an art of wealth-getting which has limits, and has no interest in the unlimited acquisition of wealth. In contrast, retail trade has no such limits, and is therefore unnatural (1257b:451a-2a). ${ }^{1}$ Aristotle therefore distinguishes between two kinds of exchange. One is exchange aimed exclusively at fulfilling unsatisfied needs. The ideal form of this exchange is barter, because it does not allow deviation towards other, lucrative, purposes. The second type of exchange, commercial trade, has profit as its aim, at least for one of the two parties involved. This type of exchange is unnatural and 
negative. It reminds us, says the philosopher, of the unnatural greed of King Midas. Money, which was originally created to facilitate the first type of exchange, has ended up facilitating commercial trade, the aim of which is not the fulfilment of needs but the acquisition of wealth. ${ }^{2}$ As Soudek put it, exchange of equivalents excluded profit because Aristotle "thought it not proper for the "citizen" to get wealthy in this manner. On the other hand, the trader, too, was to be prevented from becoming rich at the expense of the noncommercial citizen' ${ }^{3}$

So far we are still in a context which precedes, logically-and, it seems, chronologically - the analysis of exchange value. ${ }^{4}$ It would be wise however not to remove Aristotle's exchange value analysis from the context of social analysis of which it is part. This separation has indeed often made both analyses incomprehensible. Regarding the restriction imposed on the possession of external goods, to which the growth of trade is naturally connected, there are many passages in Aristotle. In Politics he often shows a deep hostility towards the increase of goods. ${ }^{5}$ One of the clearest and most evocative passages of this type is based on the hierarchy, taken from Plato, of three types of goods: external (economic) goods (of the lowest rank); goods of the body; and goods of the spirit (the highest). ${ }^{6}$ The use of external goods is limited by the fact that these goods enjoy the lowest level of preference: 'the best state of one thing in relation to another corresponds in degree of excellence to the interval between the natures of which we say that these very states are states: so that...it is for the sake of the soul that goods external and goods of the body are eligible at all' (Politics, VII, 1323b, 15-20:527b). Thus goods should be acquired in proportion to their importance: material goods (the least important) in minimum quantities, spiritual goods (the most important) in maximum quantities.

\section{Exchange as an Act of Justice}

\section{Exchange Between Equal Values}

In Nicomachean Ethics Aristotle goes on to examine the rationale of exchange, and inserts this study into the analysis of justice. First of all, he says that economy is subordinate to politics. In fact, the aim of the economy, namely wealth, is merely an instrument used to political ends. Politics is more general, since it concerns the good of all the people in a state (Nicomachean Ethics, book. I, chapters, 1-2, 1094a-b:339a-b). Besides justice in general is the right mean between the two opposite extremes that characterise injustice: that of too much and that of too little (v. 1-2, 1129a-1130b:376a$8 \mathrm{~b}$ ). On this point many authors have stressed the influence of the Pythagoreans (on justice as the mean and as proportion; quantitative expression of it, etc.) - to whom Aristotle himself refers (V.5, 1132b, 21:380a). Soudek synthesises well the meaning of this influence: for Aristotle, 'to establish social order means to find the right proportions and to apply them to the life of the community' (Soudek 1952:23-4).

Particular justice breaks down into distributive justice and corrective or rectificatory justice. The first concerns the 'distributions of honour or money or the other things that fall to be divided among those who have a share in the constitution'. The second concerns the transactions between men, both voluntary and involuntary. Voluntary transactions 
include exchange (Nicomachean Ethics, V.2, 1130b, 30-5, to 1131a, 1-9:378a-b). These two types of justice are the respective subjects of the third and fourth chapters of book V. In chapter 5 then Aristotle deals with reciprocity, which he states is different from the first two forms of justice. In distributive justice, says Aristotle, the sharing out of the awards is a collective decision. This sharing out must not be done in exactly equal parts, but in proportion to people's merit. This holds whether merit is understood as the status of freeman, as democrats believe; whether it means wealth and noble birth, as the supporters of the oligarchy maintain; or lastly whether it is understood as excellence, as the supporters of aristocratic government believe (V.3, 1131a, 10-29:378b). In any case, the criteria for the sharing out indicated by Aristotle are different from the modern ones, but they are clear. Equally clear is the mathematical translation (geometrical proportion) of this concept of proportionality, which closes the chapter.

An interesting application of distributive justice, of the 'modern' type, concerns the 'distribution from the common funds of a partnership'. Obviously, says the author, each must be remunerated in proportion to how much he has contributed (V.4, 1131b, 25$35: 379 a-b)$. Corrective justice on the other hand concerns transactions between individuals. In it the rule of the mean guarantees that each party gives and receives exactly the same quantities as the other party (arithmetical proportion). Notice that this rule prevents there being a gain for one, with a corresponding loss for the other. So for instance, in buying and selling, fairness 'consists in having an equal amount before and after the transaction'? This just sharing out is warranted by the judge, who-as Ross underlines - is the principal agent of corrective justice (Ross 1923, VII:317). Thus Aristotle starts from the quite obvious statement that exchange must take place between equal values. But from this principle he draws the thesis that in fair exchange, gain cannot exist. In fact, gain would violate the equality of remuneration. Here Aristotle confirms the idea he expressed in Politics, that in economic exchange the gain of one of the parties is the loss of the other party (Politics, I, 1258b, 1-2:452b). This is the attitude typical of a static economy, where wealth does not grow. And it is also the attitude of an economy based essentially on self-consumption; where exchange does not go beyond satisfying the producers' needs, and where commercial exchange is not legitimate.

\section{Proportianate Requital}

On these premises Aristotle builds up his analysis of the exchange of reciprocity (in chapter V.5 of Nicomachean Ethics), which has given his commentators so many headaches. On this short chapter there is a huge quantity of comments. They start as early as in the Middle Ages; either Byzantine or Arab or Latin (see, e.g., Vivenza 1997). Since we do not give new interpretations on this matter, we will not take into account the specialised literature-except for some main works. Rather we will try to connect the problem of economic value - in the sense defined above - with the Aristotelian analysis of exchange value. In actual fact, in those pages there are some underlying obscurities, due to the author's uncertainties and contradictions (cf., e.g., Guthrie 1981, XV:374n.). These obscurities however seem to have been over-emphasised (see, e.g., Hutchinson 1995:223, n. 9). Many commentators have taken mere conceptual confusions for analytical mysteries to unveil. Let us see what the problems that have troubled the exegetes are. 
In this chapter (V.5), written later, Aristotle examines a third form of particular justice: the relation of reciprocity between human beings. This relationship is a form of social exchange, of which economic exchange is part. It is the foundation of social life (1132b-3a:380b). Reciprocal justice, says the author, is different from distributive justice (evidently because it concerns relations between individuals and not collective decisions). But it is also different from corrective justice because what is given back is 'in accordance with a proportion and not on the basis of a precisely equal return' (1132b:380b). On this point Pythagoreans were wrong, says Aristotle. They conceived justice itself as reciprocity. As Finley rightly explains, they expressed the lex talionis: an eye for an eye. For Aristotle instead, 'in exchange relations within the framework of the community', reciprocity can be justice provided it is 'on the basis of proportion, not on the basis of equality' (Finley 1970:7). Since people, for Aristotle, are unequal, ${ }^{8}$ it would not be fair to exchange on the basis of equality. Thus reciprocity is a "proportionate requital', established in part according to the role of the person who acted. For instance, 'if an official has inflicted a wound, he should not be wounded in return, and if some one has wounded an official, he ought not to be wounded only but punished in addition' (Nicomachean Ethics, 1132b, 20-30:380a-b).

Aristotle repeats constantly that the principle of 'proportionate requital' is what 'holds men together'. This is 'in associations for [social] exchange'; that is in the community. It therefore regulates social relations. In fact 'men seek to return either evil for evil...or good for good'. If a person cannot implement the first type of requital, he feels like a slave. If he cannot carry out the second type, good for good, then exchange does not take place. Aristotle describes the exchange of good for good as an exchange of courtesies, protected by the Graces. Well, it is to precisely the latter type of exchange that the economic exchange between goods belongs. In fact, immediately afterwards, Aristotle writes that if a builder makes an exchange with a shoemaker there must be 'proportionate equality of goods.... If not, the bargain is not equal, and does not hold; for there is nothing to prevent the work of the one being better than that of the other; they must therefore be equated'. And he adds: 'For it is not two doctors that associate for exchange, but a doctor and a farmer, or in general people who are different and unequal' (1133a, 15-20:380b).

What does it mean that the work of the one can be better than that of the other? Either that, in the same job, the performance of one labourer can be 'better' (i.e., anyway more productive), or that one job can be 'better' (in some sense) than another job. But Aristotle never speaks about different performances in the same kind of work. He always makes comparison between different jobs or professions. In fact he is analysing exchange; which, as he clarifies, does not happen between 'two doctors'. Thus Aristotle speaks about differences, i.e., inequality, between jobs, or producers.

This is therefore the problem: nowadays we perfectly understand the meaning of the proportion between the different quantities of goods exchanged. It is simply the exchange value of the goods. However, we have no understanding of the corresponding proportion between the producers of those same goods - or rather, the original proportion, which should give rise to the proportion between the goods (cf. Finley 1970:13). This proportion between producers violates the fundamental principle of modern political economy. According to this principle exchange equality is achieved through the equalisation of the values of the goods exchanged. But this equalisation is an autonomous 
process, which takes place independently from the characteristics of the economic agents involved in the exchange. Sewall (1901:3) rightly noted: 'In this illustration Aristotle thinks of the persons themselves where we should think of their services'.

In order to solve the Aristotelian riddle, we need to isolate two elements which in the author's exposition seem to be confused to the point of seeming identical. The first is the correct element in his argument. Aristotle is telling us, albeit in a roundabout way, that exchange must take place, in general, between different quantities of the two goods; so that the values of these quantities are equal. In this case, says Aristotle, exchange does not take place on the basis of a 'precisely equal return'. Instead, given the different nature of the occupations and of their respective products, it takes place on the basis of a 'proportionate return'. It is only in this way that the parties involved receive, compared to what they have given, something 'of the same amount and kind', as is required by the principle of exchange (Nic. Ethics, 1133a, 16:380b). Here Aristotle is simply explaining what the exchange value of goods is. In fact, it is because of this that goods-given their different nature, or use value - are normally exchanged in different quantities; but these quantities are established on the basis of the need to express an equal value. As Schumpeter explains: 'if A barters shoes for B's loaves of bread, Aristotelian justice requires that the shoes equal the loaves when both are multiplied by their normal competitive prices' (Schumpeter 1954:62).

The other, fallacious element in the discourse confuses the difference that exists between use values with the difference between producers. The latter difference is underlined by the author's sentence that one work (in the sense of job) can be 'better' than another; 'they must therefore be equated'. Here Aristotle puts forwards his famous equation, usually called now the diagonal conjunction: 'There will, then, be reciprocity when the terms have been equated so that as farmer is to shoemaker, the amount of the shoemaker's work is to that of the farmer's work for which it exchanges' (Nic. Ethics, 1133a, 34-8: 38 la). What is it that makes producers unequal? On this crucial question, historians have given very different answers. Thanks to the obscurity of the text, all of them are compatible with its literal meaning; or at least appear plausible. However they not only are incompatible with each other, but also do not give a fully satisfactory explanation of the many obscurities of these pages.

Soudek (1952:25-30) and Spengler (1955:71-3) maintain that inequality derives from the different skill and training attached to different jobs. 'Equation of goods', Soudek (1952:26) writes, 'is thus identical with the equation of the skills whose products they are'. He resorts to Smith and his theory of skilled labour, to explain Aristotle's idea. But it is not credible that Aristotle could elaborate a theory of exchange based, not only on a sort of labour value theory, but even on the hierarchy of labours of different skill. Both the economic background of Aristotle's time and his evaluation of labour do not make this explanation probable. Lowry (1969) links the diagonal conjunction with the references that Aristotle makes in the very same page, to demand as the measure of the quantities exchanged; and in addition, elaborates a theory of the formation of price on the basis of a bargaining. But Finley (1970:11-12,14) is right in pointing out that the text never hints at an exchange based on bargaining. At the other extreme there is Meikle's interpretation, which reduces the inequality mentioned in the text to the difference in use values, and for the rest maintains that no inequality between producers is ever mentioned by Aristotle (Meikle 1995:129-46). Indeed the evidence of the text, even in the few 
sentences quoted above, seems to contradict him. A famous article by Finley maintains that chapter V.5 of the Ethics on exchange is just a digression, in the framework of the analysis of justice, and that no theory of price whatever can be found in these pages. However he adds that we cannot even speak of this chapter as economic analysis (Finley 1970:15). But an analysis of exchange between goods, mediated by money and by demand, can hardly be defined not economic at all. However Finley's statement can be explained by the more complex analysis, given by an outstanding - although little usedarticle by Thomas Lewis (1978).

Lewis recalls Aristotle's distinction between natural and unnatural exchange. The first covers 'natural' needs (i.e., not excessive; those usually accepted for one's own status). The second aims at enrichment and is to be condemned (cf. Perrotta 2003:194-200). Among the natural exchanges Aristotle distinguishes two main types. The more important is that between householders. Private property, then the household, is the basis of the ideal society, the polis, in which all citizens know each other and cooperate for a good life, both private and public. Although they aim at self-sufficiency, households need to exchange with each other. In such a way they compensate the deficiencies, in some of the necessary products, with the surplus that happens to be in some other products. The main point is that this type of exchange happens in friendship and solidarity; not according to the logic of the market. No one of the parties aims to gain as much as he can, while not caring about the advantage of the other. The other type of exchange happens between petty producers (craftsmen). It is subject to suspicion, because these producers, being not as fully citizens as the householders, do not aim at the welfare of the polis. In consequence, they do not produce for self-sufficiency, but for selling. In order to avoid the damaging purpose of enrichment, this exchange must be strictly checked by rules and the exchange ratios must be settled previously. Although it does not solve the puzzles of the text, Lewis's article does explain why Aristotle analysed exchange between producers in the middle of his treatment of justice. It also disproves the interpretations of Soudek, Spengler, Lowry and Meikle.

In fact we should not think that there is a contradiction between the economic exchange examined in the context of corrective justice (chapter V.4), which took place between equal values, and the definition of exchange examined in the context of justice of reciprocity (chapter V.5). Aristotle does see economic equality (of value) as a particular case of the equality required by justice. In chapter V.4 the author establishes that for an exchange to be fair, it must remunerate each party equally. In chapter V.5 he specifies that this equality must be understood as a proportion reflecting the different 'value' of the jobs involved in the exchange (the fallacious aspect of his argument) or the different nature of the goods exchanged (the correct aspect). The continuity of the arguments in the two chapters is shown by the conclusion of chapter V.5, where Aristotle returns to the subject of corrective justice, as a subject which is also an integral part of reciprocal justice. After the analysis of economic exchange, he says: 'We have now defined the unjust and the just'. And he goes on to explain that the just man is he who gives 'not so as to give more of what is desirable to himself and less to his neighbour...but so as to give what is equal in accordance with proportion' (1133b, 30 to 1134a, 15:381b). 


\section{Secondary Importance of Exchange Value}

Let us conclude our examination of Aristotle's analysis of economic exchange. His observations seem tortuous and obscure precisely because he refuses to acknowledge the autonomous, universal character of this exchange. Proof of this is found in the second part of chapter 5 of book V of Nicomachean Ethics. After explaining 'proportionate requital', the author continues the analysis of economic exchange and asks himself: what do the two goods in an exchange have in common that allows the equating of the goods themselves? They are heterogeneous. In fact they can be exchanged only because they are heterogeneous. However, to be exchanged they 'must be equated'. But to be equated they 'must be somehow comparable'. Now, wonders the philosopher, what is this shared element that permits the exchange (1133a, 15-25)? This question and the following investigation have convinced many historians that Aristotle was looking, albeit groping his way, either for the concept of exchange value or for the concept of the intrinsic value of the good (like labour-value, or cost-of-production-value, or utility-value) as the source of exchange value. Was this actually Aristotle's aim?

The author firstly tries to find this shared element in money; he describes very clearly the beneficial effects of money as a universal equivalent. Prices, he says, make exchange possible, and therefore also the 'association of man with man. Money, then, acting as a measure, makes goods commensurate and equates them; for neither would there have been association if there were not exchange, nor exchange if there were not equality, nor equality if there were not commensurability' (1133b, 16-19:381a-b; see also 1133a, 17$22: 380 \mathrm{~b}$ ). Because of this statement some commentators maintained that in substance Aristotle attributed to money the power of determining exchange value. ${ }^{9}$ In fact it is not so. In the very same page he realises that the exchange value of money also varies, like that of goods; and that ultimately money, through prices, does not establish proportions, but simply indicates proportions (exchange values) which have already been defined: 'That exchange took place thus before there was money is plain; for it makes no difference whether it is five beds that exchange for a house, or the money value of five beds' (1133b, 26-9:381b). W.D.Ross (1923:316-7) and Eric Roll (1938:24), among others, noticed this.

Aristotle then turns to another shared element: need - the translation of the ancient Greek term chreia, often translated also as 'demand'. How to translate properly this term has been the object of a millenary discussion. Soudek (1952:26), and Meikle (1995, ch. 2) in greater detail, denied that chreia can be translated as 'demand'. Langholm, and then Vivenza, have shown that in the Middle Age scholastics translated it in many ways: as need, necessity, use, utility, demand and even work or toil. Langholm has proved that every author gave chreia the meaning which was suitable to his own idea of exchange value. Vivenza concluded that through this path the modern concepts relative to exchange value were generated, although very slowly. ${ }^{10}$ In Ross's translation, 'need' and 'demand' appear strictly connected. Aristotle's reasoning is expressed this way: 'That demand holds things together as a single unit is shown by the fact that when men do not need one another...they do not exchange'. Thus demand, which expresses need, is the unit of measurement shared by the goods exchanged, while money exactly reflects this measurement. It is therefore demand that equates, for instance, five beds with one house (Nic. Ethics, 1133a, 25-30:381a; 1133b, 19-30:381b). 
Meikle has developed a very long analysis in order to prove that demand as the determinant of exchange value cannot be attributed to Aristotle, because it is incompatible with both his general philosophy and the evidence of the text. He also denies that Aristotle has reached a concept of exchange value, either based on demand or on labour (Meikle 1995:25-7, 41-2, 86, 132-5, 145-6). Labour-value is in fact the other idea, although vague, that some historians attributed to Aristotle. Schumpeter criticised the scholars who thought that Aristotle was in search of the absolute value of goods, but added: 'Aristotle was groping for some labor-cost theory of price which he was unable to state explicitly' (Schumpeter 1954:60-2). He attributes Aristotle's 'failure' to his lack of in-depth inquiry. Trever instead, then Gordon, found in that page both elements which will be at the basis of the value concept in modern economics: demand and labour. The latter should appear in the comparison between two works (shoemaker and builder) and their products. On the other side Finley, like Meikle, denied that Aristotle referred 'to labour costs or costs of production'. ${ }^{11}$ The best explanation for why Aristotle could not conceive a labour value theory came from Marx. Aristotle, wrote Marx, lived in an economy in which work was not autonomous, because it was servile. Thus it implied inequality between men. Without equality, labour could not be identified as the source of value, and therefore of exchange value. For this reason the Greek philosopher could not formulate a concept of exchange value. Cerroni supported Marx's interpretation (Marx 1867 [1952]: 25; Cerroni 1976:204-10).

So far so good. Aristotle could not think in modern terms about exchange value, since-for different reasons - both labour and market demand were outside his analytical interest. But what is then the common element or measure between the goods exchanged he is looking for? If Aristotle was concerned with giving exchange a stable and guaranteed ratio, so that no one could attempt to gain at the expenses of the other, how should we call this? I think it is exchange value anyway, although partially different from what modern analysis means by this term. In fact, need represents Aristotle's exchange value; but not as a market demand expressed by individuals - rather, it is a social need that the governance of the polis must guarantee. In sum Aristotle was not concerned with exchange value as the standard of economic (self-interested) behaviour. He was concerned with finding out what was just and what unjust (cf. Trever 1916:84). Somehow he found the new concept, but could not give it the prominence that we would expect. His approach led him to place more importance on the aspect of justice in exchange, than on that of economic calculation.

\section{Economic Value as a Utilarian Relationship Between Men}

\section{In Aristotle}

In the wider context of the philosopher's social analysis, the analysis of exchange value therefore ceases to be a mere logical puzzle and leads us back to a much more significant problem: what relation did Aristotle see between economic value and moral value? Or, to use his terms, what was for him the relation between economic ends and moral virtue? The philosopher's approach is clear right from the beginning. Let us remember again the opening of the Nicomachean Ethics. It states that some goods, or ends, are subordinate to 
others; and among those that are subordinate there is wealth, the aim of the economy (1094a, I.i:339a). The economy is therefore subordinate to politics, since the latter is the science of the highest good (1094b, I.ii:339b). Wealth is not an end in itself; it is only a means to other ends. It is an instrumental good, which has value only in so far as it helps to obtain other goods (1096a, 5-10:340a). Consequently, actions that procure wealth cannot, in turn, be autonomous. They are subordinate to a higher aim.

What is this higher aim, the highest good? It is self-sufficiency; it lets he who possesses it lack for nothing, and it makes him independent of others (1097a-b, VII:342b-3a). The ideal of self-sufficiency may seem to be in contradiction with Aristotle's famous definition of man as a zoön politikon (a political animal). If relations with others determine the very nature of man, how can the highest good be that of isolating oneself from others? To this question we can give an answer that actually shows the coherence of the philosopher. And this answer is illuminating for our problem. The self-sufficiency that Aristotle talks about does not exclude human relations in general. It excludes relations dictated by need - in the sense of economic dependence-and motivated exclusively by self-interest; i.e., economic relations. These relations exist when man is not self-sufficient and therefore lacks autonomy. In fact only the self-sufficient man is truly autonomous and can establish free social relations. Therefore non-economic social relations are autonomous. In contrast, economic relations, being utilitarian, are not autonomous. They establish relations of reciprocal dependence. Essentially Aristotle rejects the idea that a utilitarian relationship between men, like the economic relation, can be basic to human nature and an end in itself.

\section{A Glance at Later Thought}

What influence did Aristotle's position have on later thought? The rejection of a utilitarian relationship between men, and therefore the supremacy of moral value over economic value, found in modern thought another advocate of the highest level: Karl Marx. In Marx's criticism of mercantile relations, he used a model that was essentially the same as that of Aristotle, stating the lack of moral legitimacy of the utilitarian relations created by economic value. There are, among others, two particularly significant points in which this position is made clear. The first is the theory of the fetishistic nature of commodities, put forward in book I of Capital. There Marx (1867 [1952]: 31-7) describes the economic relations which are based on the exchange of commodities as dehumanising relations, in which commodities appear to be fetishes, animated and endowed with powers to dominate men and relations between men. Utilitarian economic relations therefore prevent a truly human, disinterested relationship. In human relations, regulated by the moral principle, men relate to each other on the basis of their needs; not on the basis of the things they own. In contrast, in exchange relations-which are regulated by the selfish criterion of advantage - men relate to each other in a reciprocally utilitarian way. But this makes men, as a group, slaves to things. Moreover, through the subordination of men to things, the subordination of men to other men is realised. The same concept is expressed just as clearly in the slogan 'To each according to his needs, from each according to his abilities', in Marx's Critique of the Gotha Programme (Marx 1875:32). Once mercantile relations regulated by economic value have been abolished, men will rediscover human relations based on solidarity. 
Meikle makes a good point when he associates Aristotle and Marx on the problem of the commensurability of goods exchanged. Both of them, says Meikle, distinguished the capacity of commodities 'to exchange in non-arbitrary proportions' from the exercise of this capacity. That is, they both conceived the value of commodities as prior to exchange value, and as the cause of it. On the contrary Smith and Ricardo, influenced by the 'utilitarian insensitivity' of Hume, could not see this difference. In fact they abolished value as independent from exchange value. Neo-classical economics also is seen by Meikle (1979:213-15; 1995:115-17, 183-90) as dominated by the Humean scepticism. In principle the idea of value as a substance and the rejection of economic value are not necessarily related; but they both reveal the powerful refusal of the economic rationale expressed by Aristotle and by Marx. In fact the criticism of economic value, which links Marx to Aristotle, is the exact opposite of the regulating principle of modern political economy.

In the modern economy there are objective rules underlying the formation of the exchange value of commodities, that is, underlying the quantity ratio of the two goods to be exchanged. These rules express an inner logic of the exchange, regardless of the status of the parties involved. Thanks to this autonomy, the rationale of economic exchange is universal, and regulates acts of exchange in the same way with any economic agent. All this means that in the modern economy the value expressed in exchange relations, that is, exchange value, is independent of moral value. Consequently economic value is also independent of moral value. But independent does not mean contrary or alien. It simply means that economic value - as the principle of utility, or of self-interest, which rationally regulates economic behaviour-is in itself legitimate. However this is diametrically opposed to what Aristotle believed and wanted to prove.

This new approach asserted itself very slowly within traditional ethics. In the mediaeval period Aristotelian philosophers inadvertently changed the original approach. Their considerations on the 'just price' repeated the idea that economic value is subordinate to moral value. However, they legitimised commercial trade. Moreover, in the examination of the components that make up the just price of a good, they included variables like labour, freight and risk, which tended to lend dignity to precisely the economic activities that Aristotle despised (Wood 2002; Ch. 6). Between the end of the seventeenth, and the beginning of the eighteenth, centuries the free thinkers Bayle (1704:359-61) and Mandeville (1705) took another decisive step forward. They set two codes of conduct contrasting each other. On the one hand there is the virtuous life, guided by moral value, which leads to the renunciation of wealth and of the comforts of life. This creates virtuous but poor societies, which fall into decline. On the other hand there is the selfish life, in pursuit of wealth and success. This neglects moral value and prefers economic value as its guiding principle. These societies, founded on the principle of utility, prosper. In fact, these thinkers say, what is a vice in private life (the rejection of the supremacy of moral value) becomes a virtue due to its social effects.

However, even in this spectacular attack on traditional ethics, there is something that links the free thinkers to Aristotle: both of them accept the idea that economic value and moral value are opposite. The attempt to harmonise the two values, which began with the Schoolmen, was taken up again - and brought, as it were, to maturity-during the Enlightenment. The 'philosophy' peculiar to the modern economy finds its great spokesman in Adam Smith. Smith wrote a famous passage on self-interest, where, in the 
often quoted lines, he says that we do not expect our meal out of the benevolence of the butcher or the brewer, but rather, out of their advantage. But this statement is preceded by some illuminating words, which are however quoted less often. It is animals, he writes, that expect their meal out of the benevolence of their master, not men. With this Smith bases the dignity of human relations on men's reciprocal autonomy. But the latter is in turn based on the principle of self-interest. Thus for the modern economy and for its greatest representative, Adam Smith, utilitarian human relations, regulated by economic value, are autonomous relations which find in themselves their own legitimisation. Not only this - the utilitarian relationship is the cornerstone of the dignity and autonomy of individuals. As such, it allows the building of a more dependable form of solidarity, based not on unmotivated, and therefore changeable, benevolence, but rather on selfinterest. Modern individuals can build a relationship of solidarity on their reciprocal autonomy and equal dignity.

Of course it would be equally damaging to maintain the primacy of economic value over moral value. The autonomy of economic behaviour, and through it, the reciprocal autonomy of individuals and their dignity, are effective only in so far as there is a parallel autonomy of moral value from economic value. We can easily see that in history the predominance of one value (moral or economic) over the other has always been cause of terrible social tragedies. It is the reciprocal autonomy between economic and moral value that enables a balance to be created between selfish motives and altruistic motives in human behaviour. This balance seems to be indispensable for human progress. Aristotle saw no need for it.

\section{Notes}

* Translation by Joan McMullin. I am grateful to Amos Witztum and an anonymous referee for very useful comments.

1 On this, see Lowry (1987, VII:218-26).

2 Polictics, 1257b, 10-20:451b. Ross (1923, VII:317) rightly judges as curious Aristotle's idea that money was created in order to facilitate barter, not in order to substitute it.

3 Soudek (1952:23-4). See also Lewis (1978:73-7) on natural and unnatural acquisition in Aristotle.

4 It seems that the first book of Politics was written before the Nicomachean Ethics (Dühring 1966:63-4).

5 Beside the most notorious pages on this argument (Politics, 1258a-b:452a-b), see also, in Politics, 1323a-b:527a-b.

6 Compare Politics, 1323a, 24-30:527a.

7 V.4, 1132a-b: 379b-380a. The quotation is at 1132b, 19-20.

8 Compare Marx (1867 [1952]:25); Lewis (1978:87).

9 See Tozzi (1961:166-8). Marx too arrived at this conclusion, although he realised that, according to Aristotle, exchange value is established before price (Marx 1859 [1971]:49; Marx 1867 [1952]:25).

10 Langholm (1979:42-50, 68-70, 113, 124-6); Vivenza (1997:14, 20-21, 32).

11 Finley (1970:10); Trever (1916:83-4); Gordon (1964:124-6). 


\title{
2 \\ Adam Smith's Socio-Economic Man-and the Macro-foundations of Microeconomics
}

\author{
Gianni Vaggi*
}

\section{The Robinson Crusoe Metaphor}

Robinson Crusoe is the prototype of homo oeconomicus, the agent whose calculations provide the foundations not only of microeconomics but also of macroeconomics. At least since the so called marginalist revolution of the 1870 s mainstream economists analyse specific areas of research with the tools of mathematical optimisation and utility maximisation. In recent years, the behaviour of economic agents has been described in more refined ways than simple utilitarianism guided by instrumental rationality (see Colander 2000:134-6). The 2002 Nobel Prize was awarded to Daniel Kahneman and Vernon Smith for their leading researches into the fields of psychological and experimental economics aimed at innovating 'on the assumption of a homo oeconomicus motivated by self-interest and capable of rational decision making' (available at http://www.nobel.se/economics/laureates/2002/press.html). However, methodological individualism is still the leading method in economic analysis.

The birth of Robinson Crusoe is in 1719, well into the Mercantilist era, and he has a legitimate father: a merchant, adventurer and spy, Daniel Defoe. However, Smith is often regarded as Crusoe's putative father: the mentor who brought him to fame by advancing him from the pages of a novel to those of science, therefore becoming one of the most well-known metaphors of the new science of economics. ${ }^{1}$ More recently, economists have discovered that this putative role should be rather ascribed to David Hume than to Smith, the latter being at most an uncle, and even so not a particularly benign one. Hume is the 'inventor' of utility as the main drive in human nature and in the Theory of Moral Sentiments (1759) (hereafter, TMS) Smith widely criticises the system, 'which places virtue in utility' (TMS: 306), this passage referring to Hume's system.

Nevertheless, a reductionist but widespread view of what economics should be all about takes the economic agent with instrumental rationality and competitive markets as the pillars of the new science. Competitive markets are far away from the problems that Robinson has to solve on his island, but he seems to be perfect to wear the suit of a rationally calculating economic agent provided with limited resources and several needs. There is not much of a society on that Island. Even the arrival of Friday, after twenty-five years of solitude, does not change Robinson's behaviour; Friday looks much more like one more asset to allocate rather than a human being with whom to organise a social life.

The rise to fame of Robinson Crusoe is due neither to Smith nor to Hume, indeed they both ignore him, and he has to wait for the second half of the nineteenth century to enter economics. $^{2}$ Once the Robinson Crusoe metaphor enters the scene it does not leave it. It 
occupies the stage and coupled with another metaphor (that of 'the invisible hand' which is duly ascribed to Smith), it seems to provide all that is needed for microeconomics and also for the foundations of macroeconomics. Economic agents follow the simple principle of 'non-tuism' (Wilson 1976:81, 92), a parametric behaviour guided by price signals alone.

This chapter shows that Smith's work provides solid arguments in favour of an alternative view which we could call the macro-foundations of microeconomics. There the behaviour of human beings requires first the definition of a society, more or less complex; then the search is open for the economic laws and relationships of cause and effect in a particular social division of labour. Human behaviour is by and large guided and constrained inside such a social specification; rules and norms of human conduct derive from the society: the macro-structure plays a major role in determining microeconomic activity. The next section analyses some of the different descriptions of men's behaviour provided by Smith, particularly in TMS. Following this we examine the process of the 'socialisation' of the individual in Smith's work. The final section delves more into the issue of the socialisation of man by examining some passages in the Wealth of Nations (1776) (hereafter, $W N$ ).

\section{How Many Variants of 'Man' in Smith?}

A number of characters appear in Smith's work-man appears in many different variants: self-loving, altruistic, prudent, virtuous, impartial, benevolent, sympathetic, labouring poor, rich (of course), middling rank, prone to vanity. We have one man for each passion plus infinite combinations. We will introduce only five types of man, possibly those characters who can be of interest to economics.

\section{The Sympathetic Man}

In 1967 Alec Macfie with his The Individual in Society opens the door to the historiographic revision of Smith. The 1976 introduction to TMS by Macfie and Raphael tackles the so called das Adam Smith problem. ${ }^{3}$ This leads to a possible reconciliation of the altruistic man of TMS and the selfish man of the $W N$. Above all the analysis of Smith's ethics, the road to virtue, takes the centre of the stage and leads to a number of studies which taken together show how terribly simplistic is the Crusoe metaphor when compared to Smith's analysis of individual behaviour.

According to Smith the dominant principle in human nature is that of sympathy, not utility (see TMS: 9). Of course we feel sympathy with any passion, a fact which leads the editors of TMS to remark that Smith's sympathy must not be confused with Smith's benevolence; per se sympathy does not particularly imply altruism (TMS: 10-11n.). In human nature we find both sympathy and benevolence, which is also a universal passion; but the crucial aspect of Smith's conception of human nature is not so much benevolence, but rather sympathy. Altruism is an extremely helpful attitude, but the fellow feeling which characterises sympathy is enough to provide the cement of society. Fellow feeling is in-built in human nature; it is a natural disposition to take interest in the fortunes of others, that correspondence of sentiments which leads us to participate, at least partially, 
in the sorrow of others. This quality of human nature keeps societies together, and prevents their collapse. Sympathy also helps to resist excessive self-interest, it is that blend of moderation and propriety which bestows on men the moral qualities of the impartial spectator, whose unrelenting industry on markets and whose pursuit of personal well being will never hurt the others.

\section{The Virtuous Man}

The interplay between benevolence and sympathy leads to the problem of virtue. Let us examine the behaviour of the virtuous man, of the man who follows those inclinations which nature has engraved into all human beings and which guide their actions:

The wise and virtuous man is at all times willing that his own private interest should be sacrificed to the public interest of his own particular order of society. He is at all times willing, too, that the interest of his order of society should be sacrificed to the greater interest of the state or sovereignty, of which it is only a subordinate part.

(TMS: 235)

The passage continues with reference to the interest of the entire universe and to God and it gives more force to the natural order which then has both a positive and a normative dimension. Virtuous men are willing to sacrifice their inferior interests in favour of the well-being of a larger set of individuals. The moral rules which drive human behaviour combined with the fact that natural laws are the products of a benevolent God should prevent any serious contrast between the interests of the individual and those of society, even of that large society which is the entire mankind. True, virtue is only an open possibility and benevolence, Hutcheson's principle of human behaviour, is not such a universal and dominating passion and all but a limited number of human beings can possibly achieve virtue. What happens with those men who are not virtuous, but only imperfect creatures? Wise and virtuous men are limited resources (Rosenberg 1990:1). We need a model of man which is less demanding and possibly easier to adopt, a sort of second best to human conduct and here comes our third character: the prudent man.

\section{The Prudent Man}

In the sixth edition of TMS, Part VI on prudence is new. Here Smith seems to rely less on sympathetic human nature and more on natural order and the invisible hand. As for human nature, sometime we find very harsh passages:

Every individual is naturally more attached to his own particular order or society, than to any other. His own interest, his own vanity, the interest and vanity of many of his friends and companions, are commonly a good deal connected with it. He is ambitious to extend its privileges and immunities. He is zealous to defend them against the encroachments of every other order of society. 
In TMS we find one of Smith's remarks on the invisible hand, perhaps the clearest of the three of them, ${ }^{4}$ where the rich are described with terrible terms. They look only for luxury, they are capricious, full of vain and insatiable desires, even more they seem to be granted with 'natural selfishness and rapacity' (TMS: 184). Here the invisible hand, that is deception, comes into the picture and redresses the excessive passions of the rich man. ${ }^{5}$ Men can be deceived and we have the so called law of unintended consequences which plays such a vital role in the Scottish Enlightenment.

Over the years Smith seems to have become more pessimistic about the possibility of achieving virtue, but he still has all the conditions and the 'tools' convenient to build what he regards as a decent and possibly wealthy society (Evensky 1989:140). Prudence seems to be the virtue which most helps to reach that aim. It is therefore necessary to dedicate more time to the 'prudent man'. In the sixth edition of TMS Smith praises the prudent man, the frugal man of $W N$; thus the prudent man may also be seen as a way to reconcile the view of man in $W N$ with that of TMS. The prudent man is the prototype of that middle class that by coupling virtue and prudence can try to reach fortune.

Some interpreters maintain that the whole analytical structure of both $T M S$ and $W N$ rests on the character of the median man supported by a majority rule and this combination results in a sort of robust utilitarianism (Levy 1995:313-18). Men are poorly informed and their judgements are guided by widespread ignorance (Levy 1995:300, 308). There is no real difference between the economic man and the virtuous man: their information is quite partial and they are constantly under the effect of deception by the working of markets. This agent is a median man who observes a common morality, avoids excesses and builds up a good deal of conformism.

Some support to this reductionist view can be derived by passages from $T M S$ where Smith writes that two apparently different ethical possibilities confront human beings:

To deserve, to acquire and to enjoy the respect and admiration of mankind, are the great objects of ambition and emulation. Two different roads are presented to us, equally leading to the attainment of this much desired object; the one, by the study of wisdom and the practice of virtue; the other, by the acquisition of wealth and greatness. Two different characters are presented to our emulation; the one of proud ambition and ostentatious avidity; the other, of humble modesty and equitable justice. Two different models, two different pictures.

(TMS: 62, emphasis added; also 86) ${ }^{6}$

In order to be praised by his contemporaries man can follow the road to virtue but also that of the search for wealth. Smith sympathises with the practice of virtue but he is aware of the frailty of human beings and of the great mob of mankind:

In the middling and inferior stations of life, the road to virtue and that to fortune, to such fortune, at least, as men in such stations can reasonably expect to acquire, are, happily, in most cases, very nearly the same. In all the middling and inferior professions, real and solid professional abilities, joined to prudent, just, firm, and temperate conduct, can very seldom fail of success. 
We might conclude that the prudent pursuit of wealth, with good conduct, can provide a road to social approbation; therefore the utilitarian interpretation of Smith's man is right after all. Even if there are many variants of 'man' in Smith's work there is at least one which is not completely at variance with the ethical considerations of TMS and is fully compatible with the more limited character of $W N$. The middle-man who practices the virtue of prudence, plus the veil of ignorance are not too far away from the Robinson Crusoe metaphor. The prudent man is the Trojan horse to re-establish utilitarianism in Smith's theory. Moreover the whole approach of the micro-foundations of macroeconomics could be justified on the basis of the rational behaviour of the prudent man who is also the ideal economic agent.

There are several reasons to cast doubts on this view. First of all, neither in TMS nor in $W N$ does Smith describe self-love as the founding principle of human societies. In the very beginning of each of his two published books Smith is very careful in establishing the principle on which the text is based - sympathy in TMS and the division of labour in $W N$. Self-love indicates a sort of minimal requirement for the existence of society, provided there are at least agreed social norms according to which individuals behave and reciprocate. Secondly, in the two passages from $T M S$ quoted above Smith emphasises the difference between justice and beneficence and he does not eliminate all the contradictions between the two standards of behaviour, but at most contains and limits them. The two roads point to different paths. The text continues with a reference to the rules of justice and to the fact that honesty is the best policy: To attain to this envied situation, the candidates for fortune too frequently abandon the paths of virtue; for unhappily, the road which leads to the one, and that which leads to the other, lie sometimes in very opposite directions' (TMS: 64). Therefore pursuing fortune only, and abandoning virtue, is not enough to attain happiness - all the more so for the whole society. It is no accident that Smith often refers to the inferior and superior virtues: the 'supreme virtue of beneficence...the inferior virtues of prudence, vigilance, circumspection, temperance, constancy, firmness' (TMS: 304; also 63).

Does the prudent man, or the economic man, embody all these virtues? Probably not. Does this social and economic agent embody only the inferior virtues? The problem of virtuous behaviour still exists: the virtuous man has a huge role to play in the improvement of the economic wealth of society and above all, in the peaceful, decent and benevolent organisation of society. In the quest for individual and collective happiness the problem of virtue cannot be removed.

The gap between the virtuous man and the prudent one is still quite wide. The selfish man and the sympathetic or even benevolent individual cannot be easily reconciled. ${ }^{7}$ But this paper does not focus on the variety of the possible characters in Smith's work, nor on the wide range of virtues and passions influencing human behaviour. We explore the relationship between the micro and macro aspects of Smith's contribution. From this point of view the existence of many possible types of man's behaviour is a premise to the main argument, which is the fact that man, whatever the passions and virtues governing his conduct, is the result of a process of socialisation. Man's behaviour is the outcome of a certain society and here comes a fourth player: the socialised man. 


\section{The Socialised Man}

The prudent man is a character who exists within commercial society, the fourth of the stages described by Smith in the Lectures on Jurisprudence (Meek, Raphael and Steinhereafter, $L J A$ and $L J B$ ) and in Book III of $W N$. Therefore he is already a specific man who continuously adapts his behaviour to a specific type of society in the history of mankind. Man is not an invariant element of nature, a stylised 'agent' with a predetermined and constant behaviour. Our 'man' is being socialised, but even so we must assume that a commercial society builds moral and physical capital, probity and punctuality thus taming the passions. It has been observed that this could be the case but only in competitive conditions (Rosenberg 1990:15-17). In the Lectures we find a wellknown passage in which Smith says that frequent exchanges help to prevent cheating (LJB: 538-9). We could thus assume that the market creates trust or at least punishes mistrust, but that requires that the exchanging partners should not be too unbalanced in terms of market power (Fiori 1992:51). Zanini (1993:12) too highlights the fact that in Smith, man's behaviour is not based on simple individualism. There is a sort of social middle conformation which gives to man's behaviour the social connotation of propriety. Smith writes:

We expect in each rank and profession, a degree of those manners, which, experience has taught us belong to it. But as in each species of things, we are particularly pleased with the middle social conformation, which in every part and feature, agrees most exactly with the general standard...so in each rank,... we are particularly pleased, if they have neither too much, not too little of the character which usually accompanies their particular condition and situation.

(TMS: 201)

The prudent man is an intermediate social agent and there is a social, 'macro' determination of the moral conduct of this individual; the individual of this moderate and intermediate moral conduct is also 'rank specific' and 'profession specific'. According to Zanini (1993:18) the same ethics are to be found in $T M S$ and $W N$. It is impossible to separate ethics and economics, but social ethics prevail over individualistic morality. No single all encompassing description of human behaviour is possible. Whatever the natural predisposition of the individuals, they become specific social characters. The general rules emerge through social experience; morality is a social phenomenon. ${ }^{8}$

\section{The Making of the Impartial Spectator}

What does Smith say about the process of socialisation of individuals? Here we must introduce a fifth character: the impartial spectator, the most sociable man in Smith's view. From the second to the fifth editions of TMS Smith refers to the impartial spectator in the following way: "this abstract man, this representative of mankind, and substitute of the Deity' (TMS: 130). Perhaps he realised that the comparison to the Deity was too much of a metaphor to leave in the text of the sixth edition, but the impartial spectator is the man within, the attempt to put one's self into the position of others, a continuous 
practice of socialisation. The 'impartial and well-informed spectator' (TMS: 130) is the ultimate judge of human action, the judge of a higher tribunal, because concerned not only with the actual behaviour of men, but also with the motivations which inspire that behaviour. The search for the approbation of other men, the desire to be praiseworthy is a useful additional affection of man in society. But how does this process of socialisation take place?

\section{Experience}

The process of socialisation takes place through mutual experience. Experience plays a fundamental role in shaping human behaviour and man's judgements. But where do these rules of justice and of morality come from? 'The general maxims of morality are formed, like any other general maxims, from experience and induction' (TMS: 319). The sympathetic interaction of individuals produces social norms; the rules and conventions are the results of experience (Samuels 1966:185). The simple passions of prudence and sympathy must exert themselves through historical institutions. Following Brown (1992:20) we can say that 'people through their productive activity create their social reality'.

In Smith's works there is an evolutionary flavour; he believes that laws, rules, social norms and trust are the result of a long-lasting process which stimulates certain passions in human nature and which contributes to the building of a decent society. Experience and ethics continuously interact with each other. The moral rules depend on the size and depth of the division of labour and upon the institutions which derive from it. At the same time a widely shared sense of propriety and agreement on formal and informal norms are necessary elements of the process of economic development (Loasby 1996:306-7). There is an interaction of economic organisation and socially generated individual consciousness, a co-evolution of individuals and society (Samuels 1966:187).

\section{Reason}

However, for Smith experience is not alone in shaping the norms of social behaviour: 'by induction from this experience, we establish those general rules. But induction is always regarded as one of the operations of reason. From reason, therefore, we are very properly said to derive all those general maxims and ideas' (TMS: 319). Thus general rules of morality are derived from both reason and induction. Smith underlines that 'the first perception of right and wrong' are first of all the object 'of immediate sense and feeling' (TMS: 320). But reason comes into the elaboration of those feelings in order to produce widely shared norms. Experience is the source of the general rules of morality, but it is a guided experience.

Men have a natural inclination to be sociable, amiable, to avoid conflicts. TMS gives further support to this view of a sociable man: 'Nature, when she formed man for society, endowed him with an original desire to please, and an original aversion to offend his brethren' (TMS: 116; also 292). Nature has given 'man in society' not only the ability to watch the conduct of other people but above all the capacity to look at his conduct as through the eyes of his brethren. Men and women are social animals and it is through their guided experience in society that they acquire the feature of the impartial spectator. 
In a very important passage Smith refers to man and writes: 'Bring him into society, and he is immediately provided with the mirror he wanted before' (TMS: 110).

Habit and experience have an important role to play, but they are also guided by reason and by the authority of conscience. The 'selfish and original passions of human nature' are tamed by the game of the impartial spectator and this leads the individuals to continuously change and adapt their position:

Habit and experience have taught us to do so easily and so readily, that we are scarce sensible that we do it; and it requires, in this case too, some degree of reflection and even of philosophy, to convince us, how little interest we should take in the greatest concerns of our neighbour,... if the sense of propriety and justice did not correct the otherwise natural inequality of our sentiments.

(TMS: 135-6, emphasis added)

Reason, reflection, even philosophy, come into the picture and provide an orientation to the behaviour of men. ${ }^{9}$ Mutual experience and reason are the sources of the general rules of morality, but it is through guided experience that men acquire the aptitude of the 'impartial spectator', which is the ability to look at opposite interests with the eyes of a third person (TMS: 135; also Macfie 1967:52-3). Reason, individual sensations, the social structures and institutions surrounding the individual, all work together in shaping the society and the behaviour of individuals inside it. The evolution of society is the outcome of all the above factors (Brown 1992:320).

\section{Self-Command}

Smith is well aware that the whole process may require considerable effort. Human beings are not immediately gifted with the ability to play the game of the impartial spectator. Men have a very limited experience of the passions and feelings of other people, and tend to be dominated by their own passions: 'When we are about to act...the violent emotions which at that time agitate us, discolour our views of things... every thing appears magnified and misinterpreted by self-love' (TMS: 157; also 137, 158). Notwithstanding human weakness Smith has another powerful weapon in his analysis of the individual in society, a weapon which helps human beings to become the impartial spectator: self-command.

Chapter IV of Part III of TMS is entitled 'Of the Nature of Self-Deceit, and of the Origin and Use of General Rules'. We see Smith's description of how the partial experience of each man is reconciled by the emergence of general social norms and moral rules, which will include the rules of justice. Men are social animals and nature has provided them with a better and more refined remedy than simply the fear of punishment. Nature has not 'abandoned us entirely to the delusions of self-love. Our continual observation upon the conduct of others, insensibly leads us to form to ourselves certain general rules concerning what is fit and proper either to be done or to be avoided' (TMS: 159).

Thus we slowly abandon the partial and indulgent view of our behaviour in favour of the more proper attitude of the impartial spectator. The impartial spectator, the man 
within, helps the individual in society to form the sense of duty, 'the only principle by which the bulk of mankind are capable of directing their actions' (TMS: 162). Smith mentions some of these duties: 'the duties of politeness... of justice, of truth, of chastity, of fidelity, which it is often so diffi-cult to observe' (TMS: 163). It is worth noting that justice is regarded as a duty; justice is not simply a code, the imposition of a penalty against those who violate its rules, a sort of retaliation by society. Justice is part of the general rules of morality which constitute the sense of duty, and which guide the conduct of man in society.

Self-Command is an important element in the making of the sympathetic man, in the building of that fellow feeling which characterises human societies: 'Our sensibility to the feelings of others, so far from being inconsistent with the manhood of self-command, is the very principle upon which the manhood is founded' (TMS: 152). Therefore man learns through experience, through reason, and also through the practice of self-command of his passions; self-command has the possibility to humble the arrogance of self-love (TMS: 83). Smith praises moderation in several passages of $T M S$ : 'Every affection is useful when it is confined to a certain degree of moderation...virtue consists not in any one affection, but in the proper degree of all the affections' (TMS: 306). As a matter of fact, self-command is regarded as that particular virtue from which 'all the other virtues seem to derive their principal lustre' (TMS: 241; also 237). The virtuous man needs prudence, justice, sympathy and benevolence; but also he must exert these virtues according to self-command. ${ }^{10}$ Self-command is recommended by the sense of propriety. Every man can experience it (TMS: 262). ${ }^{11}$

Smith's description of the socialisation of man also includes education, to which he dedicates many pages in $W N$ (e.g., bk V, ch. i, f). There can be a different education for the different orders of people; the people of same rank and fortune may be instructed in a different way with respect to the common people (WN: 52-4). The rules of justice are for all but there are various degrees of knowledge, from the philosopher who unveils the invisible chain of events, to the men of middling rank who exert prudence, to the labouring poor who must be publicly educated in order to avoid the dark side of the division of labour-stupidity ( $W N$ : 49-50).

\section{The Individual in the Wealth of Nations}

\section{Division of Labour}

There is a widespread view that notwithstanding the analysis of ethics in $T M S$, in $W N$ Smith adopts a very simplified version of human conduct. The economic behaviour of man in commercial society would be based on straightforward self-interest plus instrumental rationality. It may not be obvious but even the opening pages of $W N$ provide elements in favour of the view of the macroeconomic foundations of microeconomics. In the first chapters of $W N$ we find indications of how the macro-structure of society influences the behaviour of men. It is time to examine the process of socialisation of the individual in the context of the social division of labour.

The first three chapters of $W N$ are the realm of the division of labour, that is to say of what Smith considers his own principle, not only the principle of wealth but also the 
principle which prevails in civilised societies. However, it is precisely in the opening paragraph of chapter two that Smith tells us that the division of labour is the 'consequence of a certain propensity in human nature to truck, barter, and exchange one thing for another' ( $W N$ : I.ii.1; also I.ii.4). This well-known line seems to lead to the conclusion that Smith plays the reductionist game on human nature and that this is the basis of his masterpiece and of his theory of wealth. In the following paragraph of $W N$ Smith tells us that this propensity to exchange is no irreducible element of human nature because it depends on the faculties of reason and speech ( $W N$ : I.ii.2, emphasis added). Therefore the propensity to exchange is not a general principle of mankind. However, Smith continues by saying that the faculties of reason and speech are not the object of his enquiry in $W N$, and this could be taken as a reductionist view of human behaviour.

Take another famous passage in chapter two, where Smith says that 'it is not from the benevolence of the butcher, the brewer, or the baker, that we expect our dinner, but from their regard to their own interest'. Bring together reductionism and self-interest and the picture is ready for methodological individualism, with economic agents guided by utility and instrumental rationality. Thus why not resort to the Robinson Crusoe metaphor and use it as the founding principle of the economic behaviour of man in society? As a matter of fact this is the popular view, particularly for hasty readers of $W N$.

However, this conclusion is highly inaccurate because it forgets that in these pages Smith is discussing division of labour and not the foundations of human behaviour in society, a subject he has already examined in TMS. The entire Wealth of Nations, and in particular the first three chapters, must be read having in mind the general principle of the division of labour. For instance in the passage concerning the butcher, brewer and baker, Smith describes the social division of labour and the way in which human relations take place in the commercial stage of mankind. It is hard to derive from these few lines all the theoretical implications of the maximising economic agent that always follows the same simple rules of behaviour and ignores the many aspects of social division of labour. ${ }^{12}$ Let us go back to the faculties of reason and speech. Of course reason reminds us of $T M S$, of self-command and propriety, of the formation of human behaviour through experience. Speech or language is the necessary vehicle of communication among individuals; the two faculties distinguish civilised societies, in particular commercial societies, from the societies of animals.

Chapter two of $W N$ continues with the comparison of the conditions of human beings in civilised societies and that of animals, here portrayed as two greyhounds. Animals do not know any 'species contracts'; sometime they seem to co-operate, but it is only 'the accidental concurrence of their passions'; passions are their only guidance. An animal has 'no other means of persuasion, but to gain the favour of those whose services it requires'. Then animals either behave under the impulse of passions, which are no part of the art of persuasion, or they adopt the humble and servile behaviour of the puppy-fawn. Contracts are an instrument of socialisation in civilised societies. On the other hand the bunch of greyhounds is lead by passions, because animals lack means of persuasion. Persuasion is a principle of human nature and its practice becomes a sort of automatic behaviour for men in society. It is because the principle to persuade is such a prevailing feature in human nature, that men must surely find a method to establish contracts and bargain, which is what distinguishes men from dogs (see also $L J A$ : 352 ). It is important to notice that the art of persuasion is not finalised to establish contracts and exchanges - it is the 
opposite: contracts and exchanges are social tools which are used in the endeavour to persuade. ${ }^{13}$ The social construction determines the behaviour of men and the instruments they can use. ${ }^{14}$

\title{
Markets and Men
}

Of course simplifications are needed in the complex world of the division of labour and no doubt Smith makes use of them, but we cannot reduce all the characters Smith presents to us to the metaphor of Robinson Crusoe. Moreover, the micro-foundation approach overstretches the role of the simplifying assumptions on human behaviour in a commercial society and pretends too much from them. The micro-foundations view assumes a very simplified character and this is the pillar upholding the entire structure. No need to talk of virtue or self-command, no need to identify instruments of communication and socialisation: all that is needed is the same simple economic man. Everything, including the wealth of nations depends on this simplified agent, and this is not to be found in Smith, not even in WN. The requirements for building a theory of wealth on a simple micro-behaviour can hardly be found in Smith's work.

In Smith's work there is an interaction between man and society, between human feelings and passions and historical conditions and existing institutions; but the latter take on a leading role in shaping the character of the individual in society. The individual is not a purely passive actor, but his behaviour slowly evolves from the existing social and institutional framework. Samuels (1966) uses a very efficient phrase to indicate that in Smith's view society is a market-plus-framework and not a market alone. ${ }^{15}$ We can go further on Samuels' interpretation. The market itself is an institution and Smith's message about the relationship between the individual, society and wealth may be captured by the following sequence of causation: framework (institutions), plus market (competitive), plus propensity to truck (moderated by propriety and self-command). ${ }^{16}$ The framework comes first and the last element of this chain can hardly be substituted by the simple economic agent of mainstream economics.

\section{The Surplus Produce}

Chapter two of $W N$ provides one more argument in favour of the primacy of macrostructures over microeconomics. In the third paragraph Smith continues his illustration of the origin of the social division of labour and of the separation of society into different activities or branches - that is to say the origin of the exchange economy:

\begin{abstract}
And thus the certainty of being able to exchange all that surplus part of the produce of his own labour, which is over and above his own consumption, for such parts of the produce of other men's labour as he may have occasion for, encourages every man to apply himself to a particular occupation.
\end{abstract}

$(W N \text { : I.ii.3; emphasis added })^{17}$

Of course the certainty to be able to sell one's own 'surplus produce' first of all requires the existence of surplus. The passage indicates an obvious technical prerequisite for the 
specialisation of men: the conditions of production must be such that most of our individuals have a surplus produce to exchange. On his island Robinson Crusoe confronts himself mainly with given natural resources, the individual in society confronts himself primarily with technology and with the amount of 'surplus produce' that technology leaves for him to exchange. Without the advantages of the 'technical' division of labour there would be no chance of achieving a 'surplus produce' above necessary consumption and no stimulus towards specialisation would arise. The framework of Samuels' chain must include institutions, but also the methods of production and the social structure of society. The analysis of the technical division of labour and of the means to increase labour productivity appears in the first chapter of Book I of $W N$. The existence of a 'surplus produce' as a necessary condition for exchange is clearly indicated. This story takes us to the Lectures on Jurisprudence and to Book III of $W N$, where we find a description of the four stages theory-Smith's view of the evolution of human societies and of the emergence of an exchange economy. ${ }^{18}$ Societies change, but their evolution is certainly not explained only or even primarily by the behaviour of a rational economic agent who is guided by self-interest.

\section{Notes}

* I thank an anonymous referee for very helpful suggestions. Remaining errors and flaws are mine.

1 Picchio (2003) gives a beautiful description of Defoe's Robinson, his way of life, his attitude to nature and the way he organises his life. Defoe's Robinson is rather different from homo oeconomicus.

2 See White (1987), which provides an interesting description of the emergence of this metaphor in economics and of its quick and widespread acceptance.

3 See Raphael and Macfie (1976:20ff) and also Macfie (1967:112-13).

4 On the various invisible hands see Ahmad (1990:138) and Macfie (1967:101).

5 On the question of deception see for instance Davis (1990:345-6), who underlines the difference between Smith and Mirabeau and Quesnay's magic harmony of the Philosophie Rurale. Of course the Physiocrats had in mind the enlightened sovereign much more than the individuals in general. On the role of deception and of economic man see for instance Gerschlager (2003).

6 This part was added in the 6th edition (Raphael and Macfie 1976:43). According to Smith the search for approbation or the quest for status are important motivations in human behaviour (Kern 2001:357-8).

7 The tension between self-love and sympathy could be eased making the rather heroic assumption that each individual has all the relevant information about all his possible choices and all their consequences, in the present, and in the near and far future; everything is included in the individual welfare functions (Hammond 1991:150-1, Vaggi 1996:141).

8 There are of course opposite views, Collison Black (1976:63) remarks that Burke played a major role in conveying the idea of the stability of human nature.

9 Imagination plays an important role in the formation of such a useful social attitude. It is thanks to imagination that men can approximate the impartial spectator (TMS: 9-10). Imagination has a leading role in the formation of science as is clear in the History of Astronomy (Smith 1795:88ff).

10 The theme of self-restraint appears also in the Lectures on Rhetoric (Bryce 1983:55, 145-6).

11 There is a case in which the impartial spectator is submerged by 'hostile passions': war. War corrupts 'the propriety of our moral sentiments', because 'the partial spectator is at hand: the 
impartial one at a great distance. In war and negotiation, therefore, the laws of justice are very seldom observed. Truth and fair dealing are almost totally disregarded'.

In wars partiality prevails, even if it is a collective, or national, phenomenon which typically implies the disregard of the feelings of the people of the other country (TMS: 154).

12 Elsewhere we have shown that the principle of the division of labour ultimately derives from 'that principle to persuade which so much prevails in human nature' ( $L J B: 493$; see Vaggi 1996:117-20). On the division of labour see also the very interesting article by Groenewegen (1977a).

13 In the Lectures there is a beautiful passage which explains the importance of conventions and means of communication. Smith links money, to exchange and persuasion: 'The offering of a shilling, which to us appears to have so plain and simple a meaning, is in reality offering an argument to persuade one to do so and so as it is for his interest. Men always endeavour to persuade others to be of their opinion even when the matter is of no consequence to them' (LJA: 352).

14 In chapter two of Book I we meet two important characters: the street porter and the philosopher and the difference among them 'seems to arise not so much from nature, as from habits, customs and education' (WN: I.ii.4).

15 Davis (1990:352) talks of deception-plus-market-plus-framework.

16 This chain may describe Smith's explanation of the wealth of nations, that is to say of economic growth with a good deal of respect for the laws of justice and for social norms (propriety). If we aim at the picture of Smith's view of a prosperous society and of happiness then we may have to insert in the chain also the impartial spectator, possibly in between 'framework' and 'market'.

17 Almost exactly the same words are used in the opening of chapter three and chapter four of $W N$ (see also LJA: 351-2).

18 Ronald Meek and Andrew Skinner have extensively written on this topic (e.g., Meek 1976, Skinner 1993). 


\section{3 \\ On Say's Law}

Arnold Heertje

\section{Introduction}

This essay in honour of Peter Groenewegen is devoted to the history of Say's law. The differences of opinion on the interpretation of the law are reflected in the contradictory names given to the theorem. During most of the nineteenth century, the description 'théorie des débouchés' ('law of markets') is used (Blanqui, II, 1845:198; Coquelin 1854:653). In 1892, Dubois de l'Estang used the wording 'loi fondamentale' (Dubois de l'Estang 1892:653). Afterwards, the dominant description reads 'Say's law' (Keynes 1936:26; Schumpeter 1954:615; Shackle 1967:136), but also in use are expressions like 'Say's identity' (Becker and Baumol 1952:374; Patinkin 1956:119; Patinkin 1989:193; Blaug 1962:137; Blaug 1996:148; Kuenne 1963:308), 'Say's proposition' (Skinner 1969:182), 'Say’s equality' (Patinkin 1956:119; Patinkin 1989:193; Blaug 1962:131; Blaug 1996:148), and 'Say's theorem' (Skinner 1969:184).

\section{Say's Traité of 1803}

In the first edition of the Traité of 1803, the discussion of the law of markets, in the strict sense, only takes three pages (Say, I, 1803:152-5). Say assumes that each producer of a certain good produces more than is needed for his own consumption. The surplus enables the producer to acquire other goods in exchange. To the extent that more goods are being produced, it becomes easier to find outlets for the surpluses of production that emerge in the individual firm: '...ce n'st point tant l'abondance de l'argent qui rend les débouchés faciles, que l'abondance des autres produits en général. C'est une des vérités les plus importantes de l'Économie politique'. Say derives from this axiom that, if '... une nation a trop de produits dans un genre, le moyens de les écouler est d'en créer d'un autre genre'. Apparently, Say wanted to make clear in 1803 that the possibility to sell a particular good is not so much determined by the money supply, but depends on the production of other goods. In this first microeconomic version of the 'law', there is no talk of total demand and total supply being automatically equal at the level of full use of available productive capacity. I do not consider Say's discussion of the relation between consumption and investment in Book 5 of Volume II of the Traité, as part of Say's law, in the strict sense (Say, II, 1803:361-2). However, in Chapter 5, Book 4 of Volume II, Say writes: 'Pour consommer il faut acheter; or on n'achéte qu'avec ce qu'on a produit. La quantité de produits demandés est-elle donc determinée par la quantité de produits créés. Sans aucun doute...La demande de produits en général est donc toujours égale á la 
somme des produits.' This passage is highly compatible with the chapter on the law of markets in Volume I (Say, II, 1803:175-6).

\section{Mill's Commerce Defended}

The first author who pointed out explicitly that the production of goods generates the demand for goods was James Mill: 'The production of commodities creates, and is the one and universal cause which creates a market for the commodities produced' (Mill 1808:81). Mill argued that the market is concerned with the total purchasing power that is formed in the economy. The purchasing power is determined by annual production. But, Mill proceeds, 'if a nation's power of purchasing is exactly measured by its annual produce, as it undoubtedly is, the more you increase the annual produce, the more by that very act you extend the national market, the power of purchasing and the actual purchases of the nation' (Mill 1808:81).

In the economy, there will never be a surplus of capital or consumption goods, as, at each moment, together with the production of goods there emerges the purchasing power to buy the goods. According to Mill, total demand will exactly match the purchasing power, which in its turn equals the value of production. This macroeconomic argument is complemented with the condition that '.. the goods should be adapted to one another; that is to say, that every man who has goods to dispose of should always find all those different sorts of goods with which he wishes to supply himself in return' (Mill 1808:83).

Mill's sophisticated formulation makes it understandable that his name is associated with the original versions of Say's law (Stigler 1965:312). In the correspondence of the autumn of 1814 between Malthus and Ricardo, they speak again and again about 'Mill's theory', according to which 'supply can never exceed demand' (Sraffa, VI, 1951-73:132, 134, 141, 142, 148-9). However, in the Preface of his Principles, Ricardo observes explicitly that Say discovered the principle that production created the channels for demand in response to production (Ricardo, VI, 1817). The interesting point is that here Ricardo is referring to the second edition of Say's Traité, published in 1814, and in which the chapter on the law of markets is much more developed than in the first edition of 1803. In this connection, it should be noted that the second edition of the Traité appeared in May 1814, while Say and Ricardo first met only near the end of November 1814 (Sraffa, VI, 1951-73:156; Meek 1967:56).

According to Sraffa, no copy of the first edition of Say's book was in Ricardo's library in the 1930s (Sraffa, X, 1951-73:399). But Ricardo knew that a few pages were devoted to the 'débouchés', as can be gathered from his article on the funding system, in which he refers to Say's work of 1803 and Mill's Commerce Defended of 1808 (Sraffa, IV, 195173:178). It is almost certain that James Mill was aware of the draft of Ricardo's Preface, as Mill read the whole manuscript of the Principles (Sraffa, VII, 1951-73:97). His son, John Stuart Mill, argued that the theory of the law of markets was developed by Say on the continent and by his father in England. The fact that James Mill did not protest against Ricardo's exclusive reference to Say may be explained by considering his own book Commerce Defended as '... his first introduction to the friendship of David Ricardo, the most valued and most intimate friendship of his life' (Mill, II, 1848:96), and by the 
fact that he recognised and accepted Say's priority. After all, he reviewed the first edition of Say's book in the Literary Journal and drew attention to the law (Winch 1966:34).

\section{Later Editions of Say's Traité}

In the second edition of the Traité, the treatment of the law of markets receives more attention (Say, I, 1814:143-60). Say emphasises even more the neutral role of money in the process of exchange. The topic is dealt with in a more macroeconomic fashion, more comparable with Mill's analysis in Commerce Defended (Mill 1808:81; Say 1814:144). Just like Mill, Say argues that from the production emerges the purchasing power that is necessary to buy the production: '...un produit créé offre, dés cet instant, un débouché á d'autres produits pour tout le montant de sa valeur' (Say, I, 1814:147).

Then Say follows his own line of approach in asking in what way his version of his law is compatible with '...cette prodigieuse difficulté qu'on éprouve, surtout quand la situation des affaires générales est peu prospère, pour l'écoule-ment des produits de l'industrie' (Say, I, 1814:148). From this passage, it follows that Say not only confronts his theory with reality, but also that, on empirical grounds, he acknowledges the phenomenon of overproduction. This discussion makes it clear that he only considers partial overproduction. Balancing overpro-duction in one sector, there is underproduction in another, so that in general there is no overproduction.

Say distinguishes two cases of partial overproduction. First of all, there is the case in which it is difficult to sell a particular good, while other goods in the economy do rise in price, substantially. This case of disequilibrium will disappear automatically as production will be stimulated by higher prices; reallocation takes place so that the partial overproduction disappears. The second case is much more serious, as stagnation in a certain sector is due to natural disaster, political calamities or bad government policies. In this case too, Say excludes the possibility of general overproduction. After the situation returns to normality, the factors of production again move in the direction of the stagnating sector ' ....et le produit de ceux-ci absorbe le trop-plein des autres; l'équilibre se rétablit' (Say, I, 1814:150).

In summary, Say distinguishes two types of partial disequilibria: 1) those that end through the flexibility of the price mechanism; and 2) those of an exogenous nature that only disappear after the influence of the external cause is gone.

In the third edition of Say's Traité of 1817, no changes are made on the topic of the law of markets. But, in the fourth edition of 1819, there are a few important changes (Say, I, 1817:141-56; Say, I, 1819:148-165). They are concerned with the question of whether empirical phenomena of overproduction are in contradiction with the law. On the one hand, there is no reference to a depressive situation in general; on the other hand, in the case of exogenous disequilibrium, it is no longer excluded that the disequilibrium is general, so that overproduction is also of a general nature. If the exogenous case is no longer there, the factors of production move again '...vers les routes où la production est demeurée en arrière; en avançant dans ces voies-lá, elle favorise l'avancement de la production dans toutes les autres' (Say, I, 1819:155). Say does not discuss whether the equilibrium will be restored. 
In a letter to Malthus of 18 December 1814, Ricardo wrote that Say 'supports the doctrine that demand is regulated by production' (Sraffa, VI, 1951-73:163). But, in his Principles of 1817, Ricardo explicitly sees Say as the originator of the principle, neglecting the role of his friend James Mill (Ricardo 1817:399; Sraffa, I, 1951-73:290). According to Ricardo's version of Say's law, nobody will produce without having in mind consumption or sales, so that he "necessarily becomes either the consumer of his own goods, or the purchaser and consumer of the goods of some other person' (Ricardo, I, 1817:400; Sraffa, I, 1951-73:290). Partial overproduction is possible, because, with respect to a certain product, satiation may emerge, but this is impossible for all goods.

The view that general overproduction is impossible was contradicted by Malthus (Malthus 1820:353; Sraffa, II, 1951-73:303; Gordon 1965:438-66). According to Malthus, 'the great mass of commodities is exchanged directly for labour, either productive or unproductive' (Malthus 1820:354).

However, if, due to capital accumulation, unproductive labourers are converted into productive labourers, 'there would evidently be an unusual quantity of commodities of all kinds in the market; while the number of labourers altogether being the same, and the power and will to purchase for consumption among landlords and capitalists being by supposition diminished, commodities would necessarily fall in value, compared with labour, so as to lower profits almost to nothing, and to check for a time further production. But this is precisely what is meant by the term glut, which, in this case, is evidently general not partial' (Malthus 1820:354; Sraffa, II, 1951-73:308).

In his letter to Malthus, Say points out that he did not argue that goods will be exchanged against goods, but that '...les produits ne s'achètent qu'avec des produits' (Say 1820:26). Furthermore, Say argues that, when one offers goods for labour, in fact, goods are exchanged for goods. In his controversy with Malthus, Say points out that the making of something which is not wanted is not part of production. In using this argument, Say's law runs the risk of becoming merely a semantic statement, without empirical content.

In his Elements of 1821, James Mill is again concerned with Say's law (Mill 1821:184). He writes that the whole annual production will be consumed in that year, or that '... what is produced in one year, is consumed in the next' (Mill 1821:184). It would go too far to read into this quotation a reference to a lagged consumption function, as Mill's reasoning is in terms of identities and not relationships.

Mill goes back to the original argument of Say in the first edition of the Traité in looking at the production of a good as a demand for that good, in so far as not more is needed than one produces, and as a demand for other goods, in so far as more is produced than is needed of the good (Mill 1821:186). Mill observes that a partial disequilibrium is compatible with the impossibility of general overproduction, where demand and supply are conceived as aggregates: 'Whatever, therefore, be the amount of the annual produce, it never can exceed the amount of the annual demand' (Mill 1821:190). Mill concludes that production is the only cause of demand: 'It never furnishes supply, without furnishing demand, both at the same time, and both to an equal extent' (Mill 1821:195). 


\section{Two Interpretations of Say's Law}

Let us assume a closed economy, without the role of the government. The value of the national product is $W$, national income is $Y$, and the sum of consumption and investment is denoted by $B$. In our view, Say's law does not imply that $W$ is always at a level, such that all productive capacity is in use. It appears to be the other way around. The postulate of full use of the factors of production is the foundation of the law. We therefore assume that the classical model implies full employment and full capacity. In that case, if we denote the value of the national product at full employment by $W^{*}$, we have $W=W^{*}$.

Two interpretations of Say's law are developed by interpreting the classical view as simply as possible. In doing so, we also deviate from the often complicated literature on the interpretation of Say's law, such as the contribution by Don Patinkin (1956; 1989). The literature on the classical dichotomy has been of great significance for the development of economics in the last century. At the same time, the mathematical methods used are rather far away from the verbal expositions of classical writers. For this reason, an interpretation more in line with classical thinking is needed.

We distinguish a naïve and an advanced interpretation of Say's law. The naïve interpretation follows from $W=W^{*}$ and the identity $Y=W$, national income always being equal to the value of national product. Combining these two equations leads to the equilibrium value of national income $\bar{Y}$ being determined by the value $W^{*}$ of national product.

Adding the equilibrium condition that expenditure $\bar{B}$ equals national income $\bar{Y}$, one arrives at the naïve version of Say's law $\bar{B}=W^{*}$. According to this reasoning, Say's law implies that, in equilibrium, maximal production just equals expenditure, this being made possible through the formation of income by production. This interpretation of Say's law is called 'naive' because the outcome that, via the production $W^{*}$, an equal demand $\bar{B}$ emerges does not express a behavioural relation but only a consequence of the classical postulate $W=W^{*}$, an identity and an equilibrium condition. Statements by Say ('Sans aucun doute'; Say, II, 1803:175) and Mill ('No proposition however in political economy seems to be more certain'; Mill 1808:81) that the 'loi des débouchés' is so self-evident that no further explanation is needed can be made understandable with the naïve interpretation.

The advanced interpretation of the law also starts from the full use of productive capacity: $W=W^{*}$. According to the advanced interpretation, the law implies that each level of production $W$ generates an equal level of demand $B$, so that $B=W$. This interpretation of Say's law, combined with $W=W^{*}$, leads to the equality of the equilibrium value of total demand $\bar{B}$ and the value of maximal production $W^{*}$. The equality $\bar{B}=W^{*}$ is now not postulated, but deduced from the behavioural equation that total demand always equals the value of production. The advanced interpretation of Say's law is close to Ricardo's wording: 'No man produces, but with a view to consume or sell, and he never sells, but with an intention to purchase some other commodity, which may be immediately useful to him, or which may contribute to future production (Ricardo 1817:400; Sraffa, I, 1951-73:290). 
An important consequence concerns the phenomenon of general overproduction. According to the naïve interpretation of Say's law, such a general disequilibrium is completely excluded, but, according to the advanced interpretation, general overproduction is not excluded. Only in combination with the other classical equations is general overproduction excluded. Partial disequilibria are possible according to both interpretations, because 'overall' equilibrium $\bar{B}=W^{*}$ is compatible with a deviation between the composition of total demand $=\bar{C}+\bar{I}$ and the value of total production $W^{*}=\bar{C}$ $+\bar{I}^{*}$. This partial disequilibrium comes to an end by means of the flexibility of the price mechanism. In our view, it is incorrect to identify Say's law with the flexible price system, through which a partial disturbance brings about a new equilibrium (Blaug 1996:148).

\section{Our Interpretation and the Literature}

Although the wording of Say's law in the first edition of the Traite is rather sketchy, the advanced interpretation does fit best to understand Say's interpretation in 1803 . According to this reading, the sales of produced goods do not depend on the quantity of money, but total demand increases if production $W$ increases. However, the original wording of Mill in Commerce Defended can best be understood with the naïve interpretation of Say's law, being a chain of arguments of the classical postulate $W=W^{*}$, the identity $Y=W$, and the equilibrium condition $\bar{B}=\vec{Y}$.

The distinction between the naïve and the advanced interpretation of Say's law helps us to understand why Ricardo referred in the beginning to Mill, and later to Say, as the originator of the law. The argument in Ricardo's Principles is highly compatible with the advanced interpretation of the law, while in his analysis the relationship between expenditure and production is postulated as a behavioural equation. Apparently, at first, Ricardo followed Mill's tautological reasoning, but changed his mind in favour of Say's original formulation, which we denoted as the 'advanced interpretation'. Although Say's exposition in the second edition of the Traité (referred to by Ricardo) resembles Mill's Commerce Defended, Say is also in line with his own original advanced version. The fact that Ricardo was able to distinguish between the advanced and the naïve interpretation may be illustrated by Mill's advanced interpretation of the law in his Elements.

The two types of partial disequilibrium that we distinguished on the basis of the second and third edition of Say's work are compatible with both interpretations of Say's law. It is interesting to note that, in the fourth edition of the Traité, Say presents the case of exogeneous partial disequilibrium differently, so that he gives the impression of not excluding general disequilibrium. It is important that such a disequilibrium is not in contradiction with the advanced interpretation of Say's law, which is the behavioural equation $B=W$, total demand is always equal to the value of total production. If not all productive capacity is used, this implies $W<W^{*}$, viz. actual production is lower than maximal production. While, in general, this situation is temporarily in the classical canon, as under the influence of changes in prices $W$ will be equalised to $W^{*}$, this equilibrium process may be absent if disequilibrium is rooted in a structural situation, as is assumed by Say in the relevant passage (Say, I, 1819:150-55). 
The attack by Malthus on Say boils down to the insight that total demand $B$ may be lower than the value of total production $W$, so that Malthus's argument is a denial of the advanced interpretation of Say's law. Say's answer is that the part of $W$ not wanted does not belong to production (Say 1820:62). This means that Say, instead of the behavioural equation $B=W$, now introduces the identity $B$ ' $=W$ ', '...une tautologie sans intérêt' (Lambert 1963a:55).

On balance, we can draw the conclusion that the distinction between a naïve and an advanced interpretation of Say's law enables us to express, in a simple and consistent manner, the main classical considerations concerning a theorem that causes so much discussion.

\section{Mill's Theory and Say's Law From 1821 Till 1830}

McCulloch in 1825 observed that Say was the first to show that '...effective demand depends upon production' (McCulloch 1825:192). McCulloch's wording appears like the advanced interpretation of Say's law, but it remains to be seen whether McCulloch could distinguish this interpretation from the more tautological view. McCulloch refers to a comparable formulation in the work of an unknown author, implying that total demand for, and total supply of, goods are equal, by definition (McCulloch 1825:93; 1845:21).

We have already observed that Malthus realised the possibility that total effective demand may lag behind the development of supply, if consumers are not able or willing to buy the consumer goods that come on the market as a consequence of capital accumulation. In the second and third editions of his Elements, James Mill discusses Malthus's attack on Say's law (Mill 1824:236-40; 1826:237-45). The impression we get of these passages, written after Ricardo's death, is that Mill returns to the naïve interpretation of the law, expounded in his Commerce Defended of 1808. Against the opinion of Malthus that the want for goods has to be exactly met with capital accumulation, Mill argues that these wants are part of '...the very existence of the capital' and that each '...creation of capital is the creation of a demand' (Mill 1824:237). According to Mill, expenditure, by definition, equals national income and the value of national product. The confusion of Malthus is due to the fact that, from time to time, a partial disequilibrium may be observed, which is of a temporary nature due to the flexibility of the price mechanism. Say, whose own view is more in line with the advanced interpretation of his law, takes the attack of Malthus more seriously, as is indicated by the added paragraph in the fifth edition of the Traité. It is fully compatible with the idea of looking at the relationship between expenditure and production as a behavioural equation that Say defends the stimulus of '...le développement des goûts et des besoins' (Say, I, 1826:193). Consumption no longer automatically follows production, but needs to be stimulated.

After Say, in his letters to Malthus, expressed in a rather vague way the opinion that goods for which there is no demand do not belong to production, he made this idea more precise in an article in which he argues with Sismondi (Say 1824). Say points out that 'Un produit qui ne rembourse pas ses frais de production-n'est pas un produit.' Later, Say repeated this argument in the Cours (Say, II, 1829:295), but not in the Traité. The chapter in the Cours is devoted to the limits of production and a comparison of the costs 
of production and the subjective utility of goods. Perhaps Say's subjectivistic approach explains why Say, near the end of his life, took a more flexible attitude with regard to the necessary character of the equality between expenditure and production than James Mill. Although the chapter on the law of markets in the Cours in essence repeats earlier views, there are more doubts. Moreover, more attention is given to empirical facts which contradict Say's law. On the other hand, it is clear from the last sentence of the six volumes of the Cours which deals with the theorem that Say attached great significance to his law of markets. He observed that his theory is the foundation for cooperation and peace, as the interests of people and populations are not contradictory. From this, it follows that, as an old man, Say interpreted his theory not only as a simple relationship between a few economic quantities, but also as of normative significance. In this respect, it is curious that, in a letter from Mrs. H.Grote-Lewin dated 16 April 1826 to Say's daughter Octavie (who married Charles Raoul Duval in 1830), we found Say's law described as '...the maxim of the science of Pol. Economy, which tells us that we must be producers $^{1}$ in order to be effectual demanders'. ${ }^{2}$ Mrs. Grote knew Say, Ricardo, James and John Stuart Mill very well, but it remains a mystery who provided her with the intelligent and normative formulation of Say's law (Clarke 1962).

\section{The Interpretation of John Stuart Mill}

At around twenty-four years of age, John Stuart Mill wrote his Essays (Mill 1844a). In the Preface, he informs us that the essays were written in the years 1829 and 1830, but in his Autobiography, he refers to 1830 and 1831 as the years of writing (Mill 1873:180). One of the Essays is devoted to Say's law (Mill 1844a:47-75). In my own view, this contribution is one of the highlights of economic literature. Not without regret, Lionel Robbins observes that 'this remarkable reconstruction of the classical position has seldom received explicit recognition' (Robbins 1970:123). Also Mark Blaug considers Mill's essay on Say's law '...perhaps the best exposition of Say's law in the entire literature of English political economy' (Blaug 1958:100). Mill starts with a discussion of the empirical facts which may have given rise to the view that a high level of expenditure is the cause of social wealth. Mill warns against the fallacy of applying a reasoning which is true for one producer to the whole economy. For the individual producer or trader, a huge demand is an advantage, but when this is accompanied by less demand elsewhere in the economy, social advantages and disadvantages have to be balanced against each other. A statement of a microeconomic nature is a 'misleading analogy' if it is also considered to be true at a macroeconomic level (Mill 1844a:51).

Periods during which effective demand is high are also periods of high production. There is full use of productive capacity in these periods, but this does not mean that it is preferable to realise this state of affairs: '.. it is not desirable that the whole capital of the country should be in full employment' (Mill 1844a:67). In view of mistakes with the compatibility of the composition of production and demand, there are always goods of which too much, and others of which too little, will be produced. When all producers intend to expand their production, this is a sign that '....some general delusion is afloat' (Mill 1844a: 67). A general rise in prices, suggesting that producers are all becoming rich overnight, helps to cause the state of euphoria. In contradiction to modern opinions, for 
Mill, a general rise in prices is not the result of an expansion in business, but the cause of the strong propensity to consume and to invest. This temporary expansion comes to an end if the truth breaks through. Mill's analysis implies that a partial disequilibrium is possible, but a general disequilibrium is not.

Mill discusses this impossibility in the latter part of his essay on Say's law. He observes that the statement that, balancing the supply of goods and total demand is based on the assumption of '...a state of barter' (Mill 1844a:69). As soon as money is introduced in society, the statement is no longer 'exactly true' (Mill 1844a:69). The use of money and its utility split the barter exchange into two parts that may differ in time. Somebody who sells '...does not therefore necessarily add to the immediate demand for one commodity when he adds to the supply of another' (Mill 1844a:70). Mill explicitly writes that the introduction of money separates buying and selling from each other, so that it is possible that a general and immediate tendency to sell is accompanied by a comparable general sentiment to postpone buying for some time. Hence, periods of general overproduction may emerge and, according to Mill, nobody will deny 'the possibility of general excess, in this sense of the word' (Mill 1844a:70). Just like partial overproduction, this case of general overproduction of all goods except money, will also last only temporarily. In order to prove that a general overproduction of all goods is impossible, it is necessary to include money in the set of goods: '...there cannot be an excess of all other commodities, and an excess of money at the same time' (Mill 1844a:71).

Therefore, general overproduction does not mean too many goods with respect to demand, but too many goods with respect to money. When, in extreme cases, money is inactive (hoarding), the prices of goods will decrease. If this happens with one or all goods, it may be called overproduction, but only as a short-run phenomena.

Mill's opinion boils down to the proposition that a general overproduction of goods is impossible, if money is one of the goods. If money is not considered to be a good, then a general and partial overproduction of goods is possible, but only temporarily. Mill's interpretation of Say's law is so broad that empirical disequilibria of a partial or general nature are not in contradiction with the law. The essence of his interpretation is that a permanent disequilibrium is not possible, but that a temporary partial or general disequilibrium may be the consequence of '... want of commercial confidence' (Mill 1844a:74).

In Mill's contribution, it is intriguing that he does not interpret Say's law in such a way that, in each period $t$, expenditure $B_{t}$ is equal to the value of production $W_{t}$. In his view, in the long run, total demand for goods is equal to total supply. Unemployment in the short run is possible and is not in contradiction with the law. We can look at Mill's analysis as a refinement of the advanced interpretation of the law, according to which, in each period, the level of expenditure is determined by the level of production.

Let us summarise Mill's original contribution with the help of modern economic analysis. Walras's law implies that the total supply of goods and money is equal to the total demand for goods and money. 'Say's identity' implies the equality of total supply of, and total demand for, goods. 'Say's equality' concerns the adjustment of the price level that eliminates a disequilibrium between total demand and total supply. Mill's version means that Walras's law always holds; that Say's identity is only true in a barter economy; and that in a money economy a disequilibrium will be of a temporary nature in 
view of Say's equality. In our terminology, Mill is of the opinion that the advanced interpretation of Say's law leads to the long-run equality of expenditure and the value of production. The treatment of Say's law in his Principles of 1848 does not add to our understanding of his analysis (Mill, I, 1848:82-5; II, 1848:89-103).

\section{Discussion of the Literature}

The idea of introducing identities and behavioural equations in order to study Say's law goes back to the 1950s and 1960s. Patinkin described 'Say's identity' by means of the relationship $B=Y$, total effective demand being equal to national income, independent of the level of prices (Patinkin 1949:337; 1956:249-52; 1989:355-9). Becker and Baumol also made use of an analytical approach in order to analyse Say's law of markets (Becker and Baumol 1952). Skinner followed a similar line of approach by making use of identities like $C+I=C+S$ (Skinner 1967:163; 1969:177-95).

In 1971, I published an essay on Say's law, in which I produced two graphs in order to summarise a simple interpretation of the thinking of the classical economists (Heertje 1971). In both graphs, the vertical $W=W^{*}$ ensures that productive capacity will be used in full. In Graph 1, this line was combined with the line $Y=W$ by way of definition. In Graph 2 , the vertical line was combined with $B=W$ by way of a hypothesis on the aggregate behaviour of economic agents in the economy. Formally, in Graph 1, Say's law $\bar{B}=W^{*}$ has the character of an equilibrium condition, but a verbal exposition may easily give the impression that expenditure follows without any doubt from production. In particular, the description by Mill, and some of Say's remarks, can be explained with this scheme. In Graph 2, the general idea of Say's law is represented by the $45^{\circ}$ line $B=W$. This interpretation, which later was also suggested by Patinkin, reflects the intentions of Say and Ricardo (Patinkin 1981:170). John Stuart Mill's subtle analysis is a variant, as he does not assume that, in each period, aggregate supply and demand are equal, but that, in the long run, both aggregates will be equalised. He has a long-term interpretation of the law in mind, just like David Ricardo. In a letter to Malthus, Ricardo writes '...I put these immediate and temporary effects quite aside, and fix my whole attention on the permanent state of things which will result from them' (Sraffa, VII, 1951-73:120).

Our interpretation of Say's law does not require that full employment is always the actual state of affairs, as Keynes supposes (Keynes 1936:26). Only if the law is combined with the postulate that, under the influence of the price mechanism, all available factors of production will be fully used, does the proposition result that, under all circumstances, the only classical equilibrium is the full-employment equilibrium.

I doubt whether Keynes' view that 'the idea that we can safely neglect the aggregate demand function is fundamental to the Ricardian economics', is correct (Keynes 1936:32). Keynes seems to overlook the role of Say's law in classical economics as a behavioural equation that effective demand will be equal to the value of production (Fetter 1965b:138; 1969:68; Meek 1967:66).

Furthermore, the content of the law should not be confused with the role of the classical economists' attachment to the price mechanism as an equilibrating force. This confusion can be found in the work of those authors who use the terminology 'Say's identity' (Becker and Baumol 1952:374; Blaug 1996:148). Blaug also brings changes in 
relative prices under Say's identity. The law expresses only one of the relationships that are characteristic for the classical system and is no substitute for the whole argument that leads to the conclusion that, in the short or in the long run, a general disequilibrium is excluded. In this sense, Patinkin's reproach of the classical economists that they 'failed to specify the market mechanism which makes this law valid' is unfounded (Patinkin 1956:475; 1989:649). Patinkin does not take into account the significance that John Stuart Mill attaches to the price mechanism (Patinkin 1956:476; 1989:650). Like Fellner, who states that '... any reasonable version of Say's law must be interpreted as a "long run" theorem' (Fellner 1960:81), Patinkin looks at Say's law as a long-run relationship. Our argument shows that both James Mill and Say assumed that, in the short and the long run, expenditure will be equal to the value of production. In any case, Ricardo saw in the law a long-run relationship, but also in most cases a short-run proposition. In view of the long-run interpretation of John Stuart Mill and Ricardo, the judgement of Goodwin that Say's law is tenable in view of the lags between expenditure and production, goes a little bit too far (Goodwin 1970:45).

According to Schumpeter, Say '...hardly understood his discovery' (Schumpeter 1954:625). In my view, Say understood the social significance of his theorem, as well as the content of his law. However, it is true that, in an earlier debate, Say departed from the main line and he did neglect the monetary consequences of the introduction of money in a society in which the division of labour plays a major role.

In 1972, T.Sowell published a monograph on Say's law, in which he presented an historical analysis (Sowell 1972). After a lengthy discussion of quite a number of interpretations of Say's law, he concludes that: 'Both Say's law and the theory of equilibrium income - its intellectual complement and historical rival — can be traced back to a common origin in the Physiocrats and are reunited in post-Keynesian macroeconomics' (Sowell 1972:219). In 1945, Spengler had already laid down the roots of Say's law in the writings of the Physiocrats (Spengler 1945; 1960:161-82), and Sowell noted the statements in the Wealth of Nations of Adam Smith that foreshadowed Say's famous law (Sowell 1972:15-17). A lengthy discussion of Say's law also appears in a later work by Sowell (1974:35-7).

Discussing Turgot's work, Groenewegen observed in 1977 that: 'Turgot's second major comment deals with the problem of monetary leakages from the circular flow and contains the essence of Turgot's account of what became later known as Say's Law' (Groenewegen 1977b:xxiv). In 1971, he had already noted that 'Turgot was probably the first economist who attempted a rigorous demonstration of the improbability of leakages from the circular flow in the form of hoarding' (Groenewegen 1971:338).

In a well-known paper, Baumol distinguished at least eight laws of Say (Baumol 1977). In his view, Say has the priority for the law, and Say's law can be said to have achieved its full codification in 1814, on the occasion of the second edition of the Traité. Baumol's major conclusion is that '...the Say's law discussion was, first and foremost, an examination of the influences that promote long-term economic growth, and not primarily a matter of short-term problems of unemployment and overproduction' (Baumol 1977:160).

W.Thweatt, in a reaction to Baumol's article, argued that 'James Mill, basing himself largely on what he found in the Wealth of Nations, by 1808 had presented a full and balanced discussion of the Law of Markets' (Thweatt 1980:467). Already, one year 
earlier, Thweatt had discussed the early formulation of Say's law and concluded in favour of Mill's priority (Thweatt 1979:92). In recent contributions, Baumol came back to the discussion (Baumol 1999; 2003) and concluded that '...the Law may justly be deemed partly Say's. But it is emphatically not Say's alone (Baumol 1999:204; 2003:47). As I indicated, this dispute can be solved by making the distinction between a naïve, tautological interpretation of Say's law and an advanced interpretation.

E.L.Forget underlines the role of the entrepreneur in the process of self-adjustment that Say attributes to the economy (Forget 1999:174; 2003:60-2). This observation can be looked at as a microeconomic condition for the macroeconomic equilibrium á la Say and the full-employment postulate. In his penetrating study, Kates concludes that the macroeconomic interpretation of the originators of the law of markets boils down 'to deny flatly that failure of effective demand was a cause of recessions and unemployment' (Kates 1998:216).

As already pointed out, our view on Say's law is independent of full-employment in the economy.

1 Underlined in the original.

\section{Notes}

2 Now in the Say archives of the Bibliothèque National in Paris. 


\title{
4 \\ Thomas Tooke's Legacy to Monetary Economics
}

\author{
Matthew Smith
}

Among nineteenth-century classical economists, only David Ricardo (1772-1823) and Henry Thornton (1760-1815) rival Thomas Tooke (1774-1858) for influence on the development of monetary economics. The large-scale empirical analysis contained in Tooke and Newmarch's monumental six volume History of Prices (1838-1857) has clearly been an invaluable source for economists as well as economic historians. ${ }^{1}$ But it is Tooke's novel banking school ideas, which were most coherently presented in his classic pamphlet, An Inquiry into the Currency Principle (1844), that have enjoyed a lasting influence on monetary thought. In broad terms, Tooke's influence was exerted on the development of monetary economics in two different theoretical traditions. Firstly, Tooke's banking school ideas had a constructive influence on the development of monetary thought in the classical tradition. In the nineteenth century this line of influence ran through fellow members of the Banking School, from John Fullarton and James Wilson, to J.S.Mill and to Marx. The rehabilitation of the classical approach in the second half of the twentieth century, principally as a result of the work of Sraffa $(1951 ; 1960)$, has revived this line of influence. Secondly, Tooke's banking school criticisms of the classical economists' quantity theory exerted an important influence on the reconstruction of the quantity approach to money in the marginalist tradition. In this tradition Wicksell and Marshall stand out as the two most important progenitors of twentieth century monetary thought. ${ }^{2}$ In particular, Tooke's contributions significantly assisted Wicksell and, to a lesser extent, Marshall, in developing their seminal monetary theories within the framework of the then newly founded marginal analysis. Apart from these two broad lines of influence, Tooke's banking school ideas had a more general impact on monetary policy debates in Britain, Continental Europe and the United States of America. ${ }^{3}$

This inquiry is concerned with Tooke's lasting legacy to monetary theory rather than with his contributions to banking policy and, therefore, focuses on the two main lines of influence identified above. The first section examines Tooke's influence on nineteenth century monetary theory in the classical tradition. It is shown that Tooke's banking school ideas particularly exerted a considerable influence on J.S.Mill and Marx in the development of their respective monetary analyses, especially in respect to the proposed relationship between the interest rate and the rate of profit. The following section then examines Tooke's influence on the early development of monetary theory in the marginalist tradition. This section shows that Tooke's criticisms of the classical economists' quantity theory of money had a significant influence on Wicksell and, to a lesser extent, Marshall, in the development of their pioneering monetary theories. The final section locates Tooke's main legacy to contemporary monetary thought. 


\section{Tooke's Constructive Influence on Nineteenth Century Monetary Theory in the Classical Tradition}

The reception of Tooke's banking school ideas was divided between critics from the Currency School and new adherents who formed the Banking School. Among the Currency School, Tooke's strongest critic was Torrens (1840; 1844; 1848 and 1858), who set out to expose Tooke's banking school views as 'grand Tookean Fallacies'. ${ }^{4}$ Tooke dealt with most of Torrens' criticisms in volume IV of History of Prices (1848a: esp. x, 171-209). However, criticism of Tooke was more than balanced by support from a number of contemporary writers inspired by his banking school ideas. Chief among these was Fullarton (1845:19-20), who made it clear that his renowned publication, On the Regulation of Currencies (1845), was written with the aim of contributing toward the 'completeness' and 'consistency' of Tooke's banking school theory. Based on Tooke's ideas, Fullarton (1845), in particular, further developed the 'law of reflux' and significantly advanced the analysis of 'hoarding' behaviour. Another adherent to Tooke's banking school views was James Wilson, inaugural editor of the Economist, and author of Capital, Currency and Banking (1847), a collection of articles on banking policy issues published in the years 1845-1847. Fullarton and Wilson were leading members of the Banking School, closely subscribing to Tooke's position and strongly defending it against Torrens and other Currency School critics. ${ }^{5}$ Tooke's contributions were also well received by the prominent banker and writer, J.W.Gilbart. A peripheral member of the Banking School, Gilbart did not subscribe to a lot of Tooke's constructive theory, but he did earnestly support his criticisms of the 'currency principle' and the Bank Charter Act of $1844 .^{6}$

The most eminent contemporary to support Tooke's opposition to the Bank Charter Act of 1844 was J.S.Mill. In a famous review article published in the Westminster Review (1844b), Mill lent considerable support to Tooke's banking school position against criticism by Torrens (1844). Mill (1844b:579-80) showed himself to be an admirer of Tooke, praising him 'as an authority of the highest order'. Indeed, from his earliest writings, Mill's position on monetary questions was much influenced by Tooke. In particular, as is shown below, Mill adopted Tooke's unorthodox position on the relationship between the interest rate and the profit rate. Tooke's banking school ideas also exerted a considerable influence on Marx's monetary analysis and, connectedly, the position he developed on the relationship between interest and the profit rate. In Marx's most elaborate writings on money and interest in Part V of volume III of Capital (1894), ${ }^{7}$ there are numerous, mostly favourable, references to Tooke (and Fullarton). ${ }^{8}$ Marx devoted a whole chapter to critically appraising the views of the banking school on the distinction between 'currency' and 'capital'. As was Marx's method, the formulation of his monetary analysis proceeded from a critical study of the contributions of those from whom he derived the most revelation. The esteem in which Marx held Tooke was well expressed in a letter to Engels, written a few days after Tooke's death, when he referred to him as 'the last English economist of any value' (1858:284). 


\section{J.S.Mill}

Tooke's influence on J.S.Mill's monetary writings is first apparent in the article, 'Paper Currency-Commercial Distress', published in the Parliamentary Review, Session of 1826, in which Mill endeavoured to explain the causes of the financial crisis of 1825-26. Mill's notion of 'over-trading', which was at the centre of his explanation, was evidently influenced by Tooke's authoritative account of the crisis in his Considerations on the State of the Currency (1826). ${ }^{10}$ A more important early influence on Mill was Tooke's theory of the rate of interest in its relationship with the profit rate, articulated in Section I of the Considerations (1826). What was significant about Tooke's theory was that it dissented from the 'orthodox' position established by Adam Smith (1776, I. ix. 4-5citing book, chapter and paragraph numbers) and, then, affirmed by David Ricardo (1821:363-4), that the money rate of interest was ultimately governed by the rate of profit on productively employed capital, so that lasting changes in the normal rate of profit could be inferred from observing long-run changes in the 'average' rate of interest. The 'orthodox' position entailed that in the long-run the money rate was ultimately determined by those 'real' forces in the system of production which were specified as determining the normal (or natural) rate of profit. ${ }^{11}$ Tooke challenged this position by arguing that the 'average' rate of interest can be explained by factors operating in the financial system independent of the rate of profit so that the interest rate could permanently change in relation to the profit rate. ${ }^{12}$ Mill basically adopted Tooke's approach in his essay 'On Profits and Interest', written in 1829-30 though not published until 1844 in Essays on Some Unsettled Questions of Political Economy. Much of the explanation provided in this essay was subsequently incorporated into Mill's Principles of Political Economy (cf. 1871 [1848]:405-21, 637-50).

Whereas Tooke appears to have rejected Ricardo's theory of profit, Mill adopted a version of it. ${ }^{13}$ In his essay 'On Profits and Interest', Mill (1829-30:90-106) provided a Ricardian explanation of the normal rate of profit, essentially arguing that its level depended on 'real' forces determining the real wage of labour. ${ }^{14}$ In accordance with the common position of classical economists, including Tooke, Mill conceived that the normal rate of profit resolved itself into two parts: the rate of interest and a 'compensation' for the risk and trouble of productively employing capital, which he called, the 'wages of superintendence'. ${ }^{15}$ Adopting Tooke's (1826:11-12) position, Mill treated the compensation for risk and trouble as the residual part and the interest rate as the autonomous part of the profit rate: 'it would be decidedly more correct, that the wages of superintendence are regulated by the rate of interest, or are equal to profits minus interest' (1829-30:108). In Mill's (1829-30) analysis, the general rate of profit is a maximum limit to the 'average' rate of interest, with the interest rate determined by forces operating in the financial system independent of the profit rate. Inspired by Tooke's (1826) dissenting position, Mill developed a conception that allowed him to argue:

....although the rate of profit is one of the elements which combine to determine the rate of interest, the latter is also acted upon by causes 
peculiar to itself, and may either rise of fall, both temporarily and permanently, while the general rate of profit remains unchanged.

(Mill 1829-30:114)

In explaining the rate of interest, Mill closely followed Tooke's approach of classifying different generic groups of lenders and borrowers that determine the supply of and demand for loan capital and, then, to consider how these groups behave in relation to the determination of the rate of interest. Just like Tooke, Mill divided borrowers into 'productive' borrowers, who employ capital with the prospect of earning profits, and 'unproductive' borrowers, who used funds to finance unproductive expenditures beyond their income. It is evident that by unproductive expenditure, Mill (1829-30:111), following Tooke (1826:19-20), meant expenditure that was not applied to reproduction and, therefore, had no prospect of generating a commercial return. The major borrower of this kind was the national government. With respect to classifying lenders, whereas Tooke (1826:13-19) identified different groups of lenders in terms of the 'trouble and risk' they were willing to accept, Mill (1826:109-10) classified lenders according to their institutional role in the financial market: into those who effectively acted as intermediaries in the financial market and those who are non-professional investors (the 'monied class'). In this regard, Tooke's analysis incorporated a notion of 'liquidity preference' in terms of the risk-return profile of assets demanded in relation to those supplied that is missing in Mill's analysis. Nevertheless, they both conceived that the 'average' rate of interest was explained by reference to politico-institutional factors that determined demand and supply conditions in the market for loan (or 'disposable') capital. Thus, similar to Tooke, Mill argued that a major reason for a permanent change in the rate of interest in relation to the rate of profit was changes in 'unproductive' borrowing by the government to finance war-related expenditures. Hence, Mill (1829-30:112-14) agreed with Tooke's $(1826: 7-8,11)$ thesis that the substantial increase in British government debt to finance the long-running French Wars (1793-1815) permanently raised the rate of interest in relation to the rate of profit. ${ }^{16}$ In addition, Mill followed Tooke in arguing that an increase in the supply of loan capital in relation to its demand would tend to cause a decline in the money rate of interest in relation to the rate of profit. However, whereas Tooke linked an excess supply of loan capital to speculative behaviour in the financial market in order to explain financial crisis, Mill linked it to the institutional structure of the capital market. Mill (1829-30:112-17; 1871 [1848]:638-41) maintained that with a growing proportion of national wealth going to the 'monied class', the amount of disposable capital on the loan market would progressively grow over time and have the tendency of lowering the 'average' rate of interest, an institutional development which he believed would be facilitated by strong growth in deposit banking. In this respect, a major difference in Mill's analysis over Tooke's concerned the role of banks. While Tooke regarded banks as passive middlemen between lenders and borrowers, Mill (1829-30:114-17) argued that the institutional development of deposit banking would tend to lower the 'average' rate of interest over time by the more efficient mobilisation of idle funds and, progressively, to increase the supply of disposable capital. ${ }^{17}$ But, overall, Mill's analysis of interest and profit owed a great debt to Tooke.

As previously indicated, Tooke's banking school ideas also exerted a significant influence on the development of J.S.Mill's monetary thought. In support of Tooke's 
position in the Currency-Banking School debates, Mill (1844b:592) largely agreed with the argument that the quantity of banknotes in circulation, especially country banknotes, was the consequence rather than the cause of variations in prices. Mill (1844b:591-3) also adopted Tooke's argument that normally an increase in the general price level was the result of speculative activity accommodated by credit and independent of the quantity of banknotes in circulation. ${ }^{18}$ Based on his interpretation of Tooke's (1844) 'dualcirculation' framework, Mill (1844b:588-9; also see 1871 [1848]:532-6, 652-6) argued that an increase in the quantity of money could only raise the price level if there was an increase in the 'purchasing power of the community' enabled by an increase in the 'aggregate money incomes of the community'. ${ }^{19}$ Nevertheless, consistent with Tooke's viewpoint, Mill (1844b:590-2) maintained that in a convertible system of currency, it was only at 'speculative times' when confidence was running high that a 'new' purchasing power over commodities could be created by an increased facility of credit. Moreover, Mill (1844b:594-6) acutely appreciated that Tooke's denial of the banking system's power to influence prices was based on a refutation of the 'common opinion' that a lowering of the rate of interest conferred an increased power of purchasing which provided the stimulus to commodity speculation. While Mill did not indicate approval of this argument, following Tooke's reasoning, he instead claimed that the 'mode of issuing and recalling' banknotes had an important bearing on the stability of the loan market. From this standpoint, Mill (1844b:596-8) argued that the 'mode of issuing and recalling' contemplated under the 1844 Bank Act would tend to have a destabilising effect on the loan market.

The influence of Tooke's banking school ideas is most evident in Book III of Mill's Principles of Political Economy (1871 [1848]), in which there are numerous citations and quotations from Tooke's works, all favourable. ${ }^{20}$ It is true that in the Principles Mill softened his opposition to the Bank Charter Act of 1844 and advanced a version of the quantity theory of money. Nevertheless, the influence of the banking school is evident in the careful manner in which Mill restated the classical quantity theory and the heavy qualifications he placed on its application. ${ }^{21}$ Mill believed that the quantity theory was most applicable to a purely metallic system of currency or one with an inconvertible paper currency (see 1871 [1848]:495-6, 542-55). For him, it had only limited application to Britain's highly developed monetary system in which credit played a key role in financing business transactions. Developing Tooke's view, Mill (1871 [1848]: 523-41) argued that credit was the major facilitator of 'purchasing power', responsible for accommodating most variations in the price level. However, while Mill accepted much of Tooke's argument denying the power of the Bank of England and other banks to arbitrarily increase the quantity of banknotes in circulation, he did not fully subscribe to Tooke's conception of 'endogenous money' (cf. Wicksell 1898:85-7). ${ }^{22}$ Mill (1871 [1848]:653-4) maintained that when markets were in a 'quiescent state' in which 'producers and dealers do not need more than the usual accommodation from bankers and other money lenders' the 'law of reflux' would ensure that banknotes in circulation did not increase beyond the public's demand. But when markets were in a 'speculative state' in which the expectation of a profitable rise in prices caused producers and dealers to unduly expand their operations by means of 'a more than ordinary use of their credit', Mill (1871 [1848]:654-6) indicated that the 'law of reflux' would fail to prevent banks from autonomously increasing their issue of banknotes and extending the speculation. 
Nevertheless, as indicated above, Mill's exposition of the anatomy of a speculative-based rise in prices, which eventually collapses and leads to 'commercial revulsion', conforms closely to Tooke's long established explanation. Overall, then, despite the 'eclecticism' of Mill's monetary theory, it is evident he was much influenced by Tooke's banking school ideas.

\section{Marx}

In contrast to Mill, Marx incorporated much of Tooke's banking school theory into his own monetary analysis without qualification. Thus, Marx (1859:169-87; 1894:454-7, 546-51) fully accepted Tooke's main argument that the quantity of money in circulation was endogenously determined by prices together with the volume of output. Furthermore, Marx (1894:443-60, 528-30) essentially constructed his analysis of money and banking on the basis of Tooke's 'dual circulation' framework, distinguishing between monetary circulation which facilitated the 'expenditure of revenue' from that which facilitated the 'transfer of capital' ${ }^{23}$ Following Tooke, Marx maintained that the circulation of money promoting the 'expenditure of revenues' involved transactions between 'consumers and retail merchants'; while that promoting the 'transfer of capital' involved transactions between 'dealers and producers'. Whereas the amount of money which facilitated the 'transfer of expenditure' circulated 'outside the banks' walls', the amount of money which facilitated the 'transfer of capital' circulated 'inside the banks' walls'. However, in adopting this approach, Marx (1894:442-6) was critical of Tooke and the Banking School for confounding capital in the form of credit (and 'currency') with 'real' capital employed in production. Specifically, Marx was critical of Tooke for his tendency to regard only those transactions facilitated 'outside the banks' walls' as involving the circulation of money in the form of coin and banknotes while treating those transactions which are facilitated 'inside the banks' wall' through deposit transfers (and bills of exchange) as requiring only a money reserve to enable the circulation of capital. ${ }^{24}$ Marx believed Tooke overlooked the relationship between the two spheres of circulation, in which the same money - though circulating in different forms - can perform both the function of consumption expenditure and the purchase of intermediate products by merchant traders. ${ }^{25}$ Marx therefore believed that Tooke's distinction between 'currency' and 'capital' was wrongheaded:

...a certain quantity of money circulates in the transactions between dealers as well as in the transactions between consumers and dealers. It is, therefore, equally currency in both functions... To reduce the difference between circulation as circulation of revenue and circulation of capital into a difference between currency and capital is, therefore, altogether wrong.

(Marx 1894:443-4)

For this reason Marx disagreed with Tooke's position that while matters of currency could exert a temporary influence on the rate of interest, in the long-run, the 'average' rate was 'governed entirely by the supply of, and demand for, [disposable] capital as resulting from circumstances independent of the currency' (Tooke 1826:23n.; 1838, 
II:361n.). In this particular respect, Marx more firmly established a position in which the 'average' rate of interest is determined by monetary forces in the financial market independent of conditions of production. This position is closely connected to Marx's (1894:420-1, 514-19) criticism of the Currency School for confounding capital in the form of credit (and 'currency') with 'real' capital employed in production. Marx (1894:485-501) claimed that the main factors which influenced the demand for loan capital and its expansion were connected with the nature and organisation of the financial system independent of the amount of 'real' capital employed in production (see Panico 1988:74-7). In all, despite the differences mentioned, Tooke's 'dual circulation' framework was an important foundation upon which Marx developed his own analysis of the operation of the financial system.

The dissenting positions of Tooke and J.S.Mill on the interest-profit relationship in the 1820s heavily influenced Marx in developing a conception of the rate of interest as an autonomous variable, determined by forces independent of the rate of profit. Within Marx's 'surplus' approach to value and distribution the normal rate of profit is determined by the real wage for a given technique of production. The normal rate of profit so determined by 'real' forces was conceived by Marx (1894:358-60, 370-9) to be divided into two component parts: the 'average' rate of interest going to the lender (or 'money-capitalist') and the profit of enterprise going to the productive borrower (or 'industrialcapitalist'). Of these two component parts, Marx treated the 'average' rate of interest as the autonomous part, which could permanently establish levels up to the 'maximum limit' set by the normal rate of profit and, therefore, he regarded the profit of enterprise as the residual part (see Pivetti 1991:66-9). On the basis of this constraint, Marx developed upon the arguments of Tooke and Mill to explain the 'average' rate of interest by reference to a complex set of economic, institutional and conventional factors that governed the operation of the financial system, including the monetary authorities. ${ }^{26}$ In this regard, a distinctive feature of Marx's explanation of money interest was that industrial capitalists, insofar as they are borrowers of capital, and, money capitalists, are seen to be antagonists, each with an interest in obtaining a larger portion of profits at the expense of the other. Marx therefore conceived that the abovementioned factors explaining the level of the 'average' rate of interest, and thereby determining the division of profit between 'interest' and 'profit of enterprise', reflected the balance of power existing between these two kinds of capitalists.

According to Marx the 'average' rate of interest 'cannot be determined by any law' and, hence, 'there is no such thing as a natural rate of interest in the sense in which economists speak of a natural rate of profit and a natural rate of wages' (1894:362; also see 364-5). Instead, Marx believed that the 'average' rate of interest was in fact the 'average' of rates of interest on long-term loans over the business cycle, rates which are determined at any point in time by the supply of and demand for loan capital and independent of competitive forces operating in the production system. In this regard, Marx believed the rate of interest was conventional in character: 'there is no other method of determining [the interest rate] than by the opinion of borrowers and lenders in general; for right or wrong, in this respect, are only what common consent makes so' (Marx 1894:362-3). Among those monetary factors which Marx believed entered into the conventional determination of the rate of interest was the discount policy of the Bank of England and, acknowledging 'the greater or lesser approximate equalization of the rate of 
interest in the world market', he contended that there was a 'direct influence exerted by the world market on establishing the rate of interest, irrespective of the economic conditions of the country' (1894:364 n. $68,358,367-8)$. With respect to the 'average' rate of interest, Marx (1894:364) referred to the influence of conventional factors like 'customs' and 'juristic tradition'. In explaining why the 'average' rate of interest varied independently of the rate of profit, Marx also referred to arguments employed by Tooke and Mill. Hence, Marx referred approvingly to the arguments that 'many borrow without any view to productive employment' and that the expanding 'class of rentiers' in England would increase the growth of loan capital supplied to the financial market (1894:361-2). More particularly, Marx agreed with Mill that the rate of interest would systematically fall in relation to the rate of profit with:

...the development of the credit system and the attendant ever-growing control of industrialists and merchants over the money savings of all classes of society that is effected through the bankers, and the progressive concentration of these savings in amounts which can serve as moneycapital.

(Marx 1894:362)

Within his elaborate monetary analysis, Marx (1894:420-4) argued that this institutional development of the banking system, especially that associated with the proliferation of large-scale deposit banking, would bring about a progressive concentration of the financial system's cash reserves, enabling banks to expand the amount of loans in proportion to 'reserve funds'. Marx (1894:558) contended that against this development the purpose of the regulatory provisions of the Bank Charter Act of 1844 'was to make money dear' and, thereby, to improve the profitability of English bankers. Along the same lines as Tooke (1848a:347-8; 1848b, Qs 5386-8:422; 1857, vol V:535-6), Marx argued that the decentralisation of British bullion reserves, which occurred as a result of the 1844 Bank Act, caused 'continual large fluctuations' in the rate of interest, with the effect of sustaining a higher 'average' rate of interest. ${ }^{27}$ He clearly believed that the 1844 Bank Act was an institutional change that reflected a shift in the balance of power from industrial capitalists to money capitalists, especially to bankers (see Marx 1894:560-4).

Overall, Marx's elaborate monetary analysis was built on the foundation of banking school theory that was principally developed by Tooke. In particular, Marx's conception of the rate of interest as an autonomous variable in relation to the rate of profit clearly owes a great debt to Tooke, directly as well as via J.S. Mill

\section{Tooke's Critical Influence on Monetary Thought in the Marginal Tradition}

Tooke's influence on the development of monetary analysis in the marginal tradition has largely gone unnoticed in the literature. Yet, as mentioned in the introduction above, the two major pioneers of twentieth century monetary theory, Marshall and Wicksell, were appreciative of Tooke's illuminating criticisms of the classical economists' quantity theory of money. In the preface to his Interest and Prices, Wicksell wrote that 'in the 
criticisms [of the quantity theory] by the school of Tooke there is much that is correct and instructive' (1898: xxiii). Furthermore, in volume II of Lectures on Political Economy (1906), Wicksell included among the most important writings on money and prices, Tooke's Inquiry (1844) and his History of Prices (1838-1857) ${ }^{28}$ There are numerous references to Tooke by Wicksell in these two works, both of an approving and critical nature. ${ }^{29}$ Given his practice of rarely citing sources, it is significant that Marshall referred to Tooke on two occasions in the Official Papers (1926)-Marshall's evidence to several parliamentary committees and containing his most extensive dissertations on monetary questions. $^{30}$ Moreover, C.R.Fay (1960:35), junior lecturer at Cambridge, relates how Marshall told him:

[T] hat after long years of thought he had come to the conclusion that in the great currency controversy of Tooke versus Ricardo, Tooke was more right than Ricardo, in token whereof he lent me for the space of 6 years (i.e. to the outbreak of World War I) his second copy of Tooke's 'History of Prices', then a rare six-volume work.

\section{Wicksell}

In the construction of his monetary analysis, Wicksell benefited from Tooke in two particular respects. Firstly, Tooke's criticisms of the classicals' quantity theory focused Wicksell's mind on the need to provide a plausible 'transmission mechanism' by which the banking system could autonomously regulate the quantity of money in circulation. This is evident in the discussion by Wicksell $(1898: 81-101 ; 1906: 182-7)$ of Tooke's rejection of any systematic connection between the rate of interest, spending and the price level. Wicksell's 'transmission mechanism' essentially relied on a demand function for loans, elastic with respect to interest, as derived from a saving-investment analysis based on the new marginal theory of capital and distribution. ${ }^{31}$ On the basis of this demand function for loans, Wicksell (1898:102-56; 1906:190-208) argued that the banking system could regulate the quantity of money (and volume of credit-funds) by altering the rate of interest on loans in relation to the 'natural' rate of interest (or normal profit rate) at which the demand for savings is equal to the supply of saving at full-employment output. Hence, in Wicksell's monetary analysis, the banking system can autonomously increase (contract) the quantity of money through increased (reduced) lending, by lowering (raising) the loan rate and making it profitable for firms to borrow more (less) funds for capital expenditure. With the resulting increase (reduction) in monetary expenditure, the demand for money would eventually rise (decline) to absorb its exogenous supply. It is true that from the standpoint of his monetary analysis, Wicksell (1898:43-7; 1906:182-8) criticised Tooke's banking school position. ${ }^{32}$ But, importantly, Tooke's alternative views helped Wicksell to clarify the theoretical issues in constructing a plausible version of the quantity theory of money consistent with marginal economics. ${ }^{33}$ Moreover, on the basis of his 'transmission mechanism', Wicksell (1898:110) was able to contemplate the notion of 'endogenous money' in what he called 'an elastic monetary system', in which:

...the supply of money is more and more inclined to accommodate itself to the level of demand...in our ideal state every payment, and 
consequently every loan, is accomplished by means of cheques or giro facilities. It is then no longer possible to refer to the supply of money as an independent magnitude, differing from the demand for money... The 'supply of money' is thus furnished by the demand itself.

For Wicksell (1898), the main implication of an 'elastic monetary system' was that the money rate of interest could deviate from the natural rate 'for a long time' with a considerable 'cumulative' effect on the price level.

Secondly, Tooke assisted Wicksell in developing an explanation of price variations consistent with the facts. In this regard, Wicksell accepted Tooke's empirically-based observations on the actual movement of money, credit, interest and the price level in relation to each other, notwithstanding that they lay behind much of Tooke's objections to the classical economists' quantity theory. They consisted of the following observations: (i) There is a strong correlation between actual movements in the general level of prices and the rate of interest (i.e. the 'Gibson Paradox'). ${ }^{34}$ (ii) An increase in the price level is usually accompanied by an expansion in credit and a rise in the velocity of circulation of currency; and a decline in the price level, vice versa (Wicksell 1906:173-4, 184-5), (iii) A rise and fall in the price level usually precedes an increase and decrease respectively in the quantity of paper currency issued by the banking system (Wicksell 1906:182-3).

Wicksell believed that a plausible explanation of money and prices needed to conform to these stylised facts. As is well known, in Wicksell's monetary analysis, price movements are explained by reference to deviations between the actual money rate of interest on long-term loans (ultimately regulated by the 'discount rate' of the monetary authorities) and the 'natural' rate of interest. Based on this notion, the explanation of 'cumulative' price movements developed by Wicksell (1898:164-177; 1906:200-216) conformed closely to Tooke's 'facts'. In particular, it is significant that Wicksell (see 1906:202-5) adopted the 'trailing rate' doctrine in order that his explanation conformed to the 'Gibson Paradox' (cf. Ellis 1934:300-8). On the basis of this doctrine, Wicksell (1898:166-8; 1906:205-7) argued that the main cause of price variations was not exogenous changes in the money supply but rather 'real' factors affecting technical conditions of production and, thereby the natural rate of interest, in conjunction with slowness in the operation of monetary forces, including monetary policy, which brings about adjustment in the money rate of interest.

Through this important influence on Wicksell, Tooke has left a legacy to traditional monetary analysis. Needless to say, the influence of Wicksell on modern monetary thought is enormous, exerted chiefly through the Swedish and Austrian Schools and, from the late-1920s, through members of the Cambridge School (see Laidler 1991:1469).

\section{Marshall}

It was mainly through the writings of J.S.Mill that Tooke and the Banking School exerted an influence on Marshall. ${ }^{35}$ This line of influence is apparent in the emphasis that Marshall placed on the demand for money and the process by which exogenous changes in the supply of money could affect monetary expenditure and the price level. In this 
regard, Marshall's 'cash balance' version of the quantity theory focuses attention on the motives for holding money and the monetary transmission process. Nevertheless, like Wicksell, Marshall's 'transmission mechanism' relied heavily on the demand for loan capital as an inverse function of the rate of interest. The precursor to Wicksell, it was in fact Marshall who first explained price movements by reference to deviations of the money rate of interest (as regulated by the 'discount rate' of the monetary authorities) from the 'real' rate corresponding to equilibrium between the demand for and supply of savings. ${ }^{36}$ Marshall was also able to explain variations in the price level broadly consistent with Tooke's 'facts'. While Marshall (see 1926:49-52, 194, 274) believed that monetary disturbances were the original cause of most price variations, interestingly, he argued that the phenomenon of the 'Gibson Paradox' was attributable to 'real' factors which affected what he called the 'state of business confidence' and, thereby, the demand for liquidity. Furthermore, it is significant that Marshall's explanation of price variations is based heavily on a conception of 'trade cycles' that he developed in The Economics of Industry (Marshall and Marshall 1879 [1997]:152-7) from Overstone as well as Bagehot (see Bridel 1987:48). ${ }^{37}$ It is evident from his writings that much of Overstone's description of the cyclical variation in business activity and prices was derived from Tooke's empirical-based explanations of economic crises. ${ }^{38}$ In general, the influence of Tooke and the Banking School on Marshall is manifested in what his biographer has described as Marshall's 'complex views' on the quantity theory which admitted that besides the quantity of money, the price level was affected by many 'real' factors (Groenewegen 1995:349-50).

Marshall's influence on the formation of modern monetary thought is vast. His analysis pre-dated and, indeed, influenced Wicksell (cf. 1898:76). Nevertheless, in published works, Wicksell's monetary analysis is more systematically worked out than Marshall's. This was because most of Marshall's substantive monetary thought is contained in his parliamentary evidence to the Royal Commissions on the Depression of Trade and Industry (1886) and on the Value of Gold and Silver (1887-88), subsequently published in the Official Papers (1926:1-195; also Marshall 1996:65-77). Marshall's lasting influence on twentieth century monetary economics was principally exerted through the 'oral tradition' of his teaching, by which he provided the foundations for the development of monetary thought by the Cambridge School, consisting of Robertson, Hawtrey and his outstanding pupils, Pigou, Lavington and Keynes (see Bridel 1987). The far-reaching nature of Marshall's influence on the development of modern monetary analysis is especially manifest in Keynes' contributions in the 1930s.

\section{Tooke's Lasting Legacy}

Tooke's influence on the development of monetary economics has been underestimated. It was shown in the first section above that Tooke's novel banking school ideas exerted a constructive influence on J.S.Mill and Marx. In particular, Marx developed Tooke's banking school ideas to provide an elaborate analysis of the operation of a capitalist economy's financial system. It can be said that many of Tooke's original ideas were kept alive in Marx's monetary analysis in volume III of Capital (1894). Unfortunately, and no doubt partly because much of it was in the form of unfinished notes, Marx's monetary 
analysis did not receive a great deal of attention. ${ }^{39}$ Apart from his position on the relationship between interest and profit, Mill only partially incorporated Tooke's banking school ideas into his most enduring work, the Principles (1871 [1848]). Nevertheless, Tooke's influence on Mill proved highly significant because it mainly concerned the 'transmission mechanism' of monetary policy and the role of the interest rate, which, through Mill, exerted an important influence on the next generation of monetary theorists, most notably, Marshall. As discussed in the second section above, Tooke more directly exerted an influence on Wicksell. In this respect, it has not been sufficiently appreciated that Wicksell and Marshall, pioneers of twentieth century monetary thought, greatly benefited from Tooke's criticisms of the classical economists' quantity theory of money in the development of their own monetary theories within the apparatus of the new marginal (or 'supply and demand') analysis. However, the main constructive elements of Tooke's banking school theory, in particular, his conception of 'endogenous money', were submerged, largely because they were not compatible with the quantity of money approach which dominated monetary theory.

There has been a renewed interest in Tooke's banking school ideas in recent times. This interest has stemmed mainly from 'post-Keynesian' writers concerned with advancing the notion of 'endogenous money' against the traditional view that the quantity of money is exogenously controlled by the monetary authorities. ${ }^{40}$ These writers have tended to concentrate on Tooke's role in pioneering the notion of 'endogenous money' (see Moore 1988:5; Wray 1990:xiii, 102-10). Moreover, Tooke's view that monetary policy is effectively conducted through operations that directly influence the level of short-term interest rates rather than through control of the quantity of money is now commonly accepted by central bankers. ${ }^{41}$ There has also been much interest in Tooke's broader contributions by writers more concerned with the development of theories of money and distribution in the analytical approach of the classical economists and Marx as revived in the second half of the twentieth century, principally by Sraffa (1960). ${ }^{42}$ As is shown below, within the framework of this 'modern' classical analysis, Tooke's banking school ideas can make an important positive contribution to contemporary monetary thought that goes well beyond the concept of 'endogenous money'.

While Tooke's conception of 'endogenous money' represents an important contribution to developing an alternative to the quantity theory approach, in our view his most important legacy lies with the dissenting position he took on the relationship between the money rate of interest and the rate of profit and his notion that the rate of interest constitutes part of the normal cost of production of commodities. As was shown in the first section above, Tooke's 'dissenting position' initiated the development of analysis toward a conception of the rate of interest as an autonomous variable in the classical tradition. This conception obtains its full force when, as Tooke proposed, the long-run 'average' rate of interest governs the normal rate of profit, as based on treating interest as a normal money cost of production. In the classical approach to (relative) prices and distribution articulated by Sraffa (1960) this conception can be the basis of a 'monetary explanation of distribution' in which the normal distribution of income between wages and profits is seen to be mainly determined by the level of the money rate of interest. It begins with the assumptions that the real wage is not determined by, and normally stands above, the subsistence requirement of workers, and that the given technique of production ensures the economic system produces a positive surplus. Within 
a Sraffian framework, normal prices and distribution can then be solved by taking the normal rate of profit as the exogenous distributive variable so that the (surplus) real wage is determined as a residual. Treated as the exogenous distributive variable in the determination of distribution and prices, the normal rate of profit can then be logically conceived to be governed by the money rate of interest. According to this conception the normal rate of profit is determined by two autonomous components: the (long-term) money rate of interest, being the 'opportunity cost' of capital in financial form, plus a normal remuneration for the 'risk and trouble' of productively employing capital (see Pivetti 1991:20-26). Hence, consistent with Tooke's notion, a lasting change in the rate of interest will, given the normal remuneration for 'risk and trouble', cause a sympathetic change in the normal rate of profit.

The monetary explanation of distribution is most relevant to a fiat-based monetary system of modern capitalism in which monetary values are not tied to any producedcommodity standard. ${ }^{43}$ In such a monetary system money prices are conceived within the Sraffian framework to be normalised by a given (homogenous) money wage, determined independently through wage-bargaining. As a component of normal money costs of production, a lasting increase (reduction) in the money rate of interest will, for a given technique, cause enterprises to raise (lower) money prices - the general price level-in relation to the given money wage in order to earn higher (lower) normal rates of profit on capital consistent with free competition. The resulting increase (reduction) in the pricewage ratio means that the real wage declines (increases), associated with a redistribution of a given level of income from wages (profits) to profits (wages). This change in distribution will involve a change in relative prices. Hence, according to this explanation, the money rate of interest exerts a lasting influence on the normal distribution of income, relative prices and the general price level (see Pivetti 1991:20-41). With regard to the price level, Tooke's argument that as a part of the normal money cost of production, the long-run 'average' rate of interest exerts a positive causal influence on the long-run price level entirely accords with this explanation of distribution and prices. ${ }^{44}$ In addition, Tooke's fundamental view that causality runs from the rate of interest to the price level and, then, for a given level of normal output, to an endogenously determined quantity of money, can be sustained in this analysis. Furthermore, by incorporating the Keynesian theory of output into the classical analysis of the determination of distribution and prices, it is possible to consider the influence of the rate of interest on economic activity. ${ }^{45}$

The manner of determination of the level of interest rates is clearly pivotal to the monetary explanation of distribution. An unprejudiced observation of the facts suggest that the general level of interest rates is actually determined by the monetary policy of the central banking authority, chiefly through its direct control over short-term rates on liquid funds in the financial system. The longstanding interest-rate policy of the monetary authorities appears to depend on a combination of policy objectives and constraints of a social, economic and political nature, all of which can only be ascertained by reference to the concrete historical situation under consideration. According to this approach, the normal distribution of income between wages and profits is then explained by consideration of the complex set of socio-economic, politico-institutional and conventional circumstances that over a 'long' period of time (an 'epoch') determines the interest-rate policy of the monetary authorities as well as determining money wage behaviour (see Pivetti 1991:10-17; Smith 1996a:39-46). 
But however interest-rate policy is explained, the most important implication of the monetary explanation of distribution is that the interest-rate policy of the monetary authorities can exert a lasting influence on the distribution of income, and, thereby, on the level of output and employment as well as the price level (see Pivetti 1991:38-46). This represents a dramatic departure from traditional theory, which supposes that monetary policy can have a temporary but not a lasting influence on 'real' economic variables in the system of production. The traditional position stems from the conception that the money rate of interest is ultimately determined by those 'real' forces specified to determine the normal rate of profit (or 'natural' rate of interest). It should be emphasised that this traditional position applies whether one supposes that the quantity of money is endogenously determined by demand (i.e. theories of 'endogenous money') or adopts the quantity theory approach to money. Once it is acknowledged that monetary forces, including monetary policy, can exert their influence on a capitalist economy through their effect on the money rate of interest, long-run money neutrality is seen to be the consequence of the traditional view that the money rate of interest must adjust to the normal rate of profit to restore long-run equilibrium. The implication for economic theory is clear: long-run money neutrality can only be overcome in a theory of value and distribution that can logically accommodate the conception that the money rate of interest systematically governs the normal rate of profit, as originally suggested by Tooke. As shown above, this conception can be logically sustained within the classical approach to value and distribution in the form of the 'monetary explanation of distribution'. Hence Tooke's main legacy to economics lies with his contribution to the overcoming of longrun money neutrality, within the framework of a 'modern' classical analysis.

\section{Notes}

1 William Newmarch was Tooke's coauthor in volumes V and VI of History of Prices (1857). Initially, Tooke built his reputation as an empirical economist, with an expertise in the cause of price movements (see Malthus 1823:214; Torrens 1829:ix, xii). Of Tooke's History of Prices (1838-57), Jevons wrote that it is 'a unique work, of which we can hardly overestimate the value' (1865:119). Economic historians who have greatly benefited from Tooke's History, include Clapham (1930; 1932), Fetter (1965a), Hilton (1977), King (1936) and Morgan (1965).

2 Another important progenitor who does not appear to have been much influenced by Tooke was Irving Fisher.

3 As discussed in Smith (2003:54-6), chiefly through the agency of Bagehot (1873), Tooke's banking school views exerted a long-term influence on the development of British banking policy in the last quarter of the nineteenth century. The French historian of money and credit, Rist, held that in Europe 'Tooke's ideas became extremely popular' (1940:181). He maintained that in France 'the advocates both of monopoly and competition in banking based their arguments on Tooke'; while, in Germany, 'Adolf Wagner popularised Tooke's ideas in a book which has become a classic' (Rist 1940:181), titled Beiträge zur Lehre von den Banken (1857). Also see Wicksell (1898:38-50). With respect to the United States of America, Tooke's banking school ideas exerted a considerable influence on Laughlin (1903; see esp. Chs. VII-IX), a major authority in debates over 'bimetallism' and a trenchant critic of the quantity theory. On Laughlin's views, see Girton and Roper (1978) and Skaggs (1995).

4 Other critics of Tooke included Clay (1844), Johnson (1856) and Arbuthnot (1857). But Torrens was the major defender of the Currency School position, criticising all Banking 
School supporters, notably, Fullarton, James Wilson and J.S.Mill. It is beyond the scope of this work to properly assess Torrens' criticisms and their impact on public opinion.

Nevertheless, in short, it can be argued that being mainly based on a re-assertion of the Currency School position, Torrens' criticisms were not particularly penetrating. However, for a sympathetic account of Torrens' critique of the Banking School, see Robbins (1958:121-43).

5 Another principal member of the Banking School was Tooke's protegè and coauthor of volumes V and VI of History (1857), Newmarch, who in particular put forward the banking school position in evidence to the 1857 House of Commons Select Committee on the Bank Acts (Newmarch 1857).

6 See, in particular, Gilbart $(1841 ; 1849,1: 113-151)$.

7 Posthumously published, much of volume III of Capital (1894) consisted of unfinished notes written in the mid-1860s and 'orderly' arranged by its editor, F.Engels (see editor's preface, Marx 1894:2-5). As Panico (1988:47-9, 197 n. 1) has pointed out, these writings have in fact received very little attention in the literature.

8 According to the incomplete 'Name Index' there are twenty-four page references in this volume to Tooke and eleven to Fullarton. In other works by Marx, Tooke is cited on several occasions in A Contribution to a Critique of Political Economy $(1859: 98,178-9,185-7)$ and, sporadically, in Parts I and II of Theories of the Surplus Approach (1861-1863). Though not generously acknowledged by Marx, J.S.Mill was also a major influence on the formulation of his monetary thought (see Marx 1859:191-2; 1867 [1986]:125 n. 1; 1894:389, 398, 519, 575, 878; also see Panico 1988:56-9, 96-7).

9 This is chapter XXVIII of volume III of Capital (1894:442-60).

10 In Mill's article there are no less than six references to Tooke's Considerations (see Mill 1826:76-7, 86 n. 1, 92n., 97n., 109n., 111). Tooke's explanation of the 1825-26 crisis was highly influential at the time, with a number of references by parliamentary speakers to the authority of his pamphlet (see 2 Hansard, xiv:134-5, 222-3, 273; and also Smith 1996b:xvixxvii).

11 In Adam Smith, these 'real' forces imprecisely consisted of an array of socio-institutional and technical factors that determined conditions of competition and economic development; while in Ricardo they consisted in a precise manner of the real wage in conjunction with the dominant technique of production.

12 Tooke wrote ' $[\mathrm{M}] \mathrm{y}$ only purpose, at present, is to inquire in what respect the rate of interest is an index of the rate of profit, and how far the former depends upon the latter' (1826:6). Another economist who rejected the orthodox position was Joplin (1823:62-7), arguing that 'the profits of trade are regulated by the interest of money'. However, Joplin's explanation for his position is not very convincing and does not appear to have exerted much influence.

13 On Tooke's rejection of Ricardo's theory of the rate of profit, see Smith (2002:334-6).

14 In short, Mill argued that '[S] upposing, therefore, that the actual comforts of the labourer remain the same, profits will fall or rise, according as the population, or improvements in the production of food and other necessaries, advance fastest' (1829-30:106). He followed the Ricardian view that there was tendency for the rate of profit to decline with the 'progress of society' because, with diminishing returns in agriculture, the growth in population would tend to raise the price of necessaries. On the other hand, Mill recognised that this tendency could be mitigated by technological 'improvements in agriculture, and in the production of those manufactured articles which the labourers consume' (Mill 1829-30:106). However, as has been variously shown by Bharadwaj (1989), Dobb (1973:126-31) and de Vivo (1984), Mill was not very faithful to the 'core' of Ricardo's theory.

15 In the Principles Mill (1871[1848]:407, 637) divided profits into three parts: interest as the remuneration for 'abstinence', 'insurance' as the remuneration for risk and 'wages of superintendence' as the remuneration for 'exertion' or 'trouble'. The treatment of interest as the remuneration for 'abstinence' clearly represents Mill's attempt to incorporate Senior's 
notion into his analysis, an element that must reduce the force of any arguments that the rate of interest is determined by monetary forces. It is also evident that Mill regarded the element of insurance to be determined independently of interest by the risks usually connected with the employment of capital in a particular line of business. He therefore conceived that profits less insurance resolved itself into interest and 'wages of superintendence'.

16 Subsequently in the Principles, Mill (1871[1848]:643) referred to the large 'absorption' of disposable capital in the construction of railways, which occurred during the 'railway boom' of the mid-1840s, as a cause of a higher 'average' rate of interest. In addition, on the supply side, Mill (1871 [1848]:642, 646-7) maintained - as Tooke and Newmarch (1857, vol. $\mathrm{V}: 597)$ did - that the substantial increase in the supply of gold which followed the gold discoveries of the late- $1840 \mathrm{~s}$, increased the supply of loan capital and, thereby, tended to lower the rate of interest.

17 As will be discussed below, Marx took up this theme, though from a different standpoint.

18 Under the influence of Tooke's early writings, Mill had in fact taken up this view in his above-mentioned article, 'Paper Currency_Commercial Distress' (1826).

19 On Tooke's 'dual-circulation' framework, see Smith (2001:32-6).

20 See Mill (1871[1848]:521n., 533-5, 536n., 554, 648, 652-5, 665). There are also numerous references to Fullarton (1845) by Mill (1871 [1848]:498, 500n., 537, 652-5, 668-70, 675).

21 An important aspect of Mill's articulation of the quantity theory is a clear restatement of the classical notion that in the long-run the 'Value of money' is determined by the 'cost of production' of gold so that the quantity theory only concerns short-run variations in the price level around its 'average' level as fixed to the gold standard (see 1871 [1848]:499-506). In this manner Mill makes it clear that his monetary analysis is entirely consistent with the classical approach to value. With regard to his qualification of the quantity theory, Mill (1871 [1848]:490-8, 524-5) maintained that an increase in the quantity of money would raise prices only if, other things being the same, it constituted an increase in the quantity of money in circulation, by which he meant that it facilitated an increase in spending on commodities. Mill's apparent apprehension about the quantity theory is likely to have emanated from concerns about what in modern parlance is called the 'transmission mechanism' as most prominently brought to his attention by the banking school writings of Tooke and Fullarton.

22 On Tooke's conception of 'endogenous money', see Smith (2001:36-42).

23 For an illuminating reconstruction of Marx's analysis, see Panico (1988:61-70).

24 While there is an element of truth in Marx's criticism, it is evident Tooke was aware that banknotes were used to settle transactions between 'dealers and producers'. For example, Tooke (1844:35) discusses how banknotes were still commonly used in much rural trade.

25 Marx (1894:443-4) uses the example of money received in the form of banknotes and coins by retail merchants in payment for consumer products. This same money is revenue to the retail merchant, which is deposited in a bank and is used to pay for intermediate products (i.e. capital) through cheques drawn on the retailer's bank deposit.

26 See, in particular, Marx (1894:358-69) and also Panico (1988:70-4).

27 While the evidence shows that the amplitude of fluctuations in the rate of interest definitely increased, it does not support Marx's other contention that the rate of interest was 'on average' higher after the inception of the 1844 Bank Act than before it. It might be noted that the argument over the centralisation of bullion reserves under control of the Bank of England raged in England during the 1860s until settled by Bagehot (1873) (see Fetter 1965a:255$83)$.

28 In addition, Fullarton's On the Regulation of Currencies (1845) is listed by Wicksell (1906:127).

29 See Wicksell (1898:36, 43-6, 82-92, 99-101, 112; 1906:127, 161, 172-5, 182, 186-7, 194, 202). 
30 See Marshall $(1926: 4-6,59)$. There are also three references to Tooke on historical questions in Marshall's last work, Money, Credit and Commerce (1923:22, 54n., 306).

31 As well as Marshall and J.B.Clark, Wicksell was in fact instrumental in the development of the marginalist theory of capital and distribution. In Value, Capital and Rent (1893) and in Volume I of Lectures on Political Economy (1901), Wicksell developed his theory from the 'Austrian' approach to capital of Böhm-Bawerk (see Pivetti 1990).

32 On Wicksell's criticisms of Tooke, see Pivetti (1991:81-6).

33 In this regard it has not been sufficiently appreciated in the literature that Wicksell gained as much from Tooke and the Banking School as he did from the classical quantity theorists.

34 Of this statistical relationship Wicksell wrote ' $[\mathrm{T}]$ he correctness of this observation is beyond dispute; later statistics have frequently confirmed this fact' (1906:182). Also see Wicksell (1898:88).

35 On Mill's considerable influence on Marshall, see Groenewegen (1995:145-9, 154-8).

36 On Marshall's monetary analysis and his explanation of the general level of prices, see Bridel (1987:7-24) and Eshag (1963). On the possible influence of Marshall on Wicksell, it is evident that Wicksell (see 1898:46, 76) closely read much of Marshall's contributions on monetary questions to government inquiries. Thus, on the question of how the quantity of gold in the banks influences the level of prices, Wicksell referred to Marshall's evidence to the Royal Commission on the Value of Gold and Silver (1887-88) as '[B]y far the most valuable contribution towards a solution of this question' (1898:76).

37 Marshall and Marshall (1879 [1997]:153) actually quote Overstone (1837:31) on the 'established cycle' of trade.

38 On fluctuations in trade and prices, Overstone (see 1840:87, 109; 'Appendix A' 147-8, 'Appendix D' 150-2) heavily cites the authority of Tooke's History of Prices (1838).

39 See Panico's (1988:47-9) instructive discussion on this neglect in the literature, even by Marxists.

40 A renewed interest in the notion of 'endogenous money' was sparked by Kaldor (1970; $1982 b)$ as a response to 'monetarism'. Friedman's (1970:52) reference to Kaldor (1970) as a 'Johnny-come-lately' in pointing out 'that changes in the money supply must be regarded as the result, not the cause, of changes in economic activity' is thrown into relief by consideration of Tooke's contributions made over one hundred years earlier. For a survey of 'post-Keynesian' writers who have followed up the notion of 'endogenous money', see Rochon (1999).

41 See Goodhart (1989a:303-11, 322-6; 1989b:210-11), Borio (1997) and Blinder (1998).

42 See Caminati (1981), Panico (1988:21-45), Pivetti (1991:74-86; 1998).

43 For an account of this explanation in a gold-money economy, see Smith (1996a).

44 See Pivetti (1991:38-9). However, this relationship cannot be supposed to exist in the goldstandard British economy of Tooke's day (see Smith 1996a:47).

$45 \mathrm{On}$ the incorporation of the Keynesian 'principle of effective demand' for determining normal output into the classical approach to value and distribution, see Garegnani (197778:61-3), Kurz (1985), Ciccone (1986) and Trezzini (1995). 


\title{
5 \\ William Thomas Thornton and John Stuart Mill
}

\author{
A Victorian Friendship \\ Mark Donoghue ${ }^{*}$
}

In candour, sincerity, and singleness of mind, few men come near him.

J.S.Mill on W.T.Thornton

[T] he best, truest, noblest of friends...

W.T.Thornton on J.S.Mill ${ }^{* *}$

\section{Introduction}

William Thornton's friendship with the 'Victorian sage' overlapped with what has become known as 'the third, mature stage' in Mill's life journey (Robson 1989:7). This final phase of his life has, as Lipkes (1999:3) correctly notes, 'received comparatively little attention' from intellectual historians, although it saw Mill's re-emergence from seclusion following the death in 1858 of his beloved wife, Harriet Taylor and covered his association with the last classical economists, the Blackheath Park circle, an exclusive group of economists who met over Sunday dinner at Mill's Blackheath Park residence when he was in London. It also included the continuation and ripening of his close friendship and collaborative relationship with William Thomas Thornton.

Mill and Thornton influenced each other in a number of important ways. Mill became something of a father figure to Thornton, whose own father had died shortly before his first birthday. Mill assisted the younger man in establishing his credentials in London's literary circles and helped to advance his professional career at India House. The paternalistic position Mill assumed towards his close friend resembled that of his own father towards him. Yet, as Mirowski and Tradewell correctly remind us:

Thornton was no martinet, no mere stalking horse for Mill. The fact he was his own man is what endeared him to Mill-let us not forget, the author of On Liberty as well as Principles of Political Economy. The author of the former text argued that truth was not found in consensus, but derived from the process of individual dissent.

(Mirowski and Tradewell 1999:40) 
As the two men's personal friendship and intellectual collaboration developed, Thornton became an important figure in Mill's life. Mill appreciated the personal qualities and intellectual abilities of the younger man, whose work not only helped to crystallise Mill's developing ideas in several areas but also influenced the direction of his thinking. No less important was Thornton's central role in Mill's personal life during the period following Harriet Taylor's death in 1858. In a sense, Thornton came to fill the void left by her death and Mill often turned to him for emotional support.

The aim of this chapter is to explore the development of the professional and personal relationship between Thornton and Mill, to evaluate the reciprocal nature of their intellectual partnership and to set it in the broader context of the contemporary debates that occurred in several fields of mutual interest to both men. We discuss the beginnings of their friendship and collaboration at the London branch of the East India Company in Leadenhall Street. Following sections present biographical material, some of it related to the exaggerated claim Thornton made in a biographical fragment prepared later in life: that his friendship with Mill, from beginning to end, never entailed 'misunderstanding of any kind' (Thornton 1873:36). The final substantive section reviews the extent to which Mill advanced Thornton's authorial career and examines how much Thornton's own work on political economy, peasant proprietorship, and industrial relations helped to shape Mill's developing views on these subjects. Some concluding remarks follow.

\section{Leadenhall Street Days}

On a summer's day in early August 1836, young William Thomas Thornton 'entered a service which was to be the work of his life by obtaining a clerkship in the East India House'. ${ }^{1} \mathrm{He}$ joined the 'Honourable Company' during its heyday. Its prestige in the Far East was unrivalled (although in a little more than two decades it would be fighting for its survival).

Thornton had only recently returned to England from the Levant, where he had been employed for five years on the staff of the Consul General of Constantinople, John Cartwright. Family connections had secured his appointment to the East India Company, although the vacancy itself had been created by the death of James Mill, the head of the Examiner's Office and the father of John Stuart Mill. Later in life, Thornton recalled the circumstances surrounding his appointment to the Company:

The death of Mr. Mill senior, in 1836, had occasioned a vacancy at the bottom of the examiner's office, to which I was appointed through the kindness of Sir James Carnac, then Chairman of the Company, in whose gift it was. Within a few months, however, I was transferred to a newlycreated [marine] branch of the secretary's office.

(Thornton 1873:34)

At the time, of course, Thornton could not have been aware of the way James Mill was unwittingly shaping his future by bringing him into direct contact with his son, John Stuart Mill, who had joined the East India Company as a clerk in 1823. The two men's 
lives were destined to become intertwined, both professionally and personally, although their friendship did not commence, on Thornton's account, until early 1846.

\section{The Mills: Father and Son}

The rigorous education that Mill received from his father and the circumstances of his 1823 appointment to the East India Company's Examiner's Office, in which his father also had a direct hand, may help to explain why Mill played a key role in advancing Thornton's professional and authorial careers.

Mill's Autobiography provides an extraordinary account of the muchmaligned childhood education he received from his father, James Mill. At age three, he began studying Greek and was soon reading Aesop's Fables and by the time he was eight he had read many of the Greek classics, including 'the whole of Herodotus, and Xenophon's Cyropaedia and Memorials of Socrates; some of the lives of the philosophers by Diogenes Laertius; part of Lucian, and Isocrates Ad Demonicum and Ad Nicoclem' (Mill [1873] 1989:28). 'The only thing besides Greek that I learnt as a lesson in this part of my childhood', Mill tells us, 'Was arithmetic', including Euclid, 'and somewhat later, algebra', all of which he imbibed 'under my father's direction' (ibid: 69). James Mill's ambitious experiment continued with the addition of lessons in Latin. 'From my eighth to my twelfth year', Mill wrote, 'I remember reading...the Bucolics of Virgil, and the first six books of the Aneid; all Horace except the Epodes; the fables of Phaedrus; the first five books of Livy; all Sallust...' (ibid: $31-2$ ).

At age twelve, Mill entered what he called 'another and more advanced stage in my course of instruction', which included studying 'the Latin treatises on the scholastic logic' and political economy, notably 'Ricardo's great work'. Indeed, he received personal instruction in the fledgling science from Ricardo himself (ibid: 36, 42). His education would not, of course, have been complete without instruction in utilitarian philosophy, and this he received in person from the father of utilitarianism, Jeremy Bentham (see ibid: 65-69). James Mill once confided in a letter to Bentham, that he saw his son as 'a successor worthy of us both'.

Mill's account of his childhood education is so full of compact detail that it is impossible in a short space to convey the depth and breadth of his reading. Robson (1989:5) accurately remarks on 'the staggering list of books' Mill devoured between the ages of three and thirteen, after which his 'formal lessons' ceased. James Mill had prepared his eldest son's education from his birth in the hope of creating 'a competent and diligent reformer, a proper successor to himself and Jeremy Bentham, a utilitarian messiah' (ibid: 4). Throughout his formative years, his constant companion was his father, working 'hard himself, sharing with the boy his writing hours, his walks and his talks, offering guidance with instruction and leaving delight to take care of itself' (ibid.). As the passage suggests, James Mill was the initial guiding force in his son's intellectual and moral development. ${ }^{2}$

In 1823, John Stuart Mill was appointed to the East India Company's Examiner's Office as a junior clerk, the 'lowest level in the clerical establishment of the Examiner's Office' (Moir 1990:xiii). James Mill had himself recently obtained promotion to Assistant Examiner in that office, and he was able to use his position to secure his son's 
appointment. ${ }^{3} \mathrm{He}$ could thus determine the future direction of his son's professional career in much the same way that he had planned and shaped his son's early education, all of which suggests more a 'prolongation of [the] father's celebrated tutelage than the first moves towards independence' (ibid: xvi). Indeed, Mill himself acknowledged as much in his Autobiography:

[M]y professional occupation and status for the next thirty five years of my life were decided by my father's obtaining for me an appointment from the East India Company...immediately under himself.

(Mill [1873] 1989:78)

Mill quickly rose through the ranks of the imperial civil service. His father played a key role in his advancement, although Moir notes that the younger Mill's talents as a civil servant 'soon won the support and approval of the Company directors' (Moir 1990:xiv). After five years of drafting despatches in the Political and Public Departments, ${ }^{4}$ Mill was transferred, in 1828, to the Examiner's Office, promoted to the position of fourth assistant, and required to perform 'more demanding intellectual duties' (ibid: xv). He rose to become second examiner and then first examiner in, respectively, February and July, 1836. James Mill died in the same year. The younger Mill's rapid advancement through the civil service ranks came to a halt, and he was not again promoted until March 1856, when he was appointed Chief Examiner. ${ }^{5}$

\section{Thornton and Mill at the Company}

When Thornton joined the Company as a junior clerk in August 1836, Mill held the position of first assistant examiner in the correspondence department. Thornton was very much junior. Although the two men were now working at the same establishment in Leadenhall Street, the social rigidities of Victorian England and their mutual shyness meant that for a decade the two men 'seldom [came] into contact, scarcely ever spoke, and generally passed each other without any mark of recognition when [they] happened to meet in or out of doors' (Thornton 1873:34).

Thornton left no personal record of the duties he performed as a Company clerk during the course of a working day. However, in the obituary notice of Mill that he wrote for the Examiner, he compared the terms and conditions of Mill's employment at the East India Company with those of its other junior clerks:

According to the ordinary course of things in those days, the newlyappointed junior would have had nothing to do, except a little abstracting, indexing, and searching, or pretending to search, into records; but young Mill was almost immediately set to indite despatches to the governments of the three Indian Presidencies, on what, in India House phraseology, were distinguished as 'political' subjects - subjects, that is, for the most part growing out of the relations of the said governments with 'native' states or foreign potentates. This continued to be his business almost to the last. 
An examination of the despatch books preserved in the Oriental and India Office Library suggests that Thornton did not draft any despatches in the early stage of his career. (At least, he did not sign off on any.) It seems reasonable to assume, therefore, that his daily routine revolved around more mundane clerical and administrative tasks, such as filing documents, retrieving correspondence and writing précis.

In any case, Thornton was transferred, in December 1837, to the newly created Marine Branch of the Secretary's Office. The move rapidly improved his financial position, and, following the mandatory unsalaried probation period, his annual income rose to a respectable $£ 500$.

Thornton remained in this position for the next decade and might have held it throughout his Company career if, in the winter of 1846, he had not taken the initiative of sending Mill a copy of his recently published book titled Over-Population and its Remedy: or, an enquiry into the extent and causes of the distress prevailing among the labouring classes of the British Islands (Thornton, 1846).

Thornton never forgot the significance of what followed. As he recalled some years later, Mill approached him 'a day or two afterwards [and] came into my room to thank me for [the book]'. ${ }^{6}$ There ensued a 'half-hour conversation', which marked the beginning of an 'intimate friendship, of which I feel that I am not unduly boasting in declaring it to have been equally sincere and fervent on both sides' (Thornton 1873:345). From that time, he wrote:

a day seldom passed for the next ten or twelve years, without, if I did not go into his room, his coming into mine, often telling me as he entered, that he had nothing particular to say; but that, having a few minutes to spare, he thought we might as well have a little talk. And what talks we have had on such occasions, and on what various subjects! And not infrequently, too, when the room was Mill's, Grote, the historian, would join us, first announcing his advent by a peculiar and ever welcome rat-tat with his walking-Stick on the door.

(ibid.: 35)

Unfortunately, further details of Thornton's and Mill's workplace conversations have not survived. Their subsequent correspondence, however, does contain useful information on a range of topics of mutual interest, such as political economy, continental travel, utilitarianism, peasant proprietorship and poetry. From the beginning, their friendship was based on a mutual respect for each other's intellectual qualities, although on appropriate occasions Thornton deferred to the more famous man. ${ }^{7}$ The two men's lives were bound together in an intense camaraderie which was only severed when Mill died in 1873.

Mill was instrumental in advancing Thornton's career at the East India Company. At mid-century, Thornton was still serving as a clerk, a junior position with little prospect of promotion. At the beginning of 1856, however, Mill recommended him for the position of assistant examiner in the newly created Public Works Department (Mill 1991:97). Some years later Thornton recorded the part Mill played in securing his promotion: 
When, in 1856, [Mill] became examiner, he had made it, as I have been since assured by the then Chairman of the East India Company, a condition of his acceptance of the post [of Chief Examiner of Indian Correspondence] that I, whose name very likely the Chairman had never before heard, should be associated with him as one of his assistant examiners; and I was placed, in consequence, in charge of the Public Works Department.

(Thornton 1873:35)

Under Mill's general supervision, Thornton was responsible for the daily operation of the Public Works Department and for the preparation of public works despatches. In the mid$1850 \mathrm{~s}$, however, Thornton was unable to discharge his official duties because a mysterious illness, he later recalled, 'for nearly a year absolutely incapacitated me from mental labour'. Thornton faced the prospect of an early and unscheduled retirement when Mill came to his rescue and quietly discharged 'the whole of my official duties...for the space of twelve months, in addition to his own' (Thornton 1873:35). In practical terms, this kindness involved Mill's preparing 'some forty-eight Public Works drafts between May 1857 and April 1858, after which Thornton recovered his health and gradually resumed his regular duties' (Moir 1990:xxxii). ${ }^{8}$

Mill gave Thornton more help in 1858, when he was promoted to the senior administrative position of Secretary of the India Office's Department of Public Works, which afforded him 'the modest prosperity of a colonial bureaucrat of a middling rank' (Mirowski and Tradewell 1999:43). The appointment might not have materialised had it not been for Mill's personal kindness and his generous endorsement of the younger man.

In brief, Mill became, in a sense, a substitute father to Thornton. Robson (1989:10) explains this relationship in terms of the 'Oedipal desire to take over from one's father'. Supporting such an interpretation is what Moir calls Mill's own 'paternal position towards his younger brother', George Grote Mill, who obtained a junior clerkship in the Examiner's Office in April 1844, largely on the strength of a testimonial given by Mill. In 1848, however, Grote was 'obliged to take a long period of sick leave and eventually to retire altogether in March 1850' (Moir 1990:xix). He died in 1853 in Madeira.

What is particularly striking about George Grote's appointment and short career, according to Moir, is that it bears such a 'close resemblance to J.S.Mill's own early career with the Company...even to the extent of employing phrases of recommendation in his testimonial which almost seem to mimic what James Mill had told the Company directors about his own qualities and attainments some twenty years earlier' (ibid.). Despite the obvious dangers in claiming that Thornton came to occupy the place of Mill's younger brother after his retirement and untimely death, the curious resonances seem to reinforce the picture of Thornton serving an experimental apprenticeship under Mill's tutelage, receiving instruction and gaining experience in the drafting of despatches until he could handle such heavier responsibilities himself. 


\title{
The Best, Truest, Noblest of Friends
}

Thornton recalled later in life that his 'own friendship with [Mill] was, from first to last, never once ruffled by difference or misunderstanding of any kind' (Thornton 1873:36). This statement was an exaggeration. From time to time tensions arose between the two men. But affection, support and respect were more often evident.

\section{Some Vexations}

On one occasion, Thornton carelessly '[took] the liberty of addressing one [poem] to [Mill] by name' in his book Zohráb: or, a Midsummer Day's Dream, and other poems (Thornton 1854). ${ }^{9}$ Mill, who was a very private person, felt slighted by the cavalier reference. He confronted his friend, sought an explanation and an apology, both of which he received (though Mill deemed the apology 'Very insufficient'). Mill's anger stemmed in part from his low opinion of the work, which he saw as little more than 'better than common'.

Then, having discussed the matter with his wife, Harriet Taylor, who had earlier reproached Thornton over the same incident, Mill took up the cudgels again. The tone of his letter to Harriet Taylor is rancorous:

\begin{abstract}
With regard to Thornton I do not think what you say too severe- - he has suddenly plumped down to the place of a quite common person in my estimation, when I thought he was a good deal better. There are in the book itself many proofs of excessive, even ridiculous vanity, not much the better for being, as in his case it is, disappointed vanity. He is far from the first instance I have known of inordinate vanity under very modest externals. His misjudgement of me is so less than you supposed, as he has not put in any flattery proprement dit, but the fact itself is a piece of flattery which he must have thought would be agreeable or he would not have taken so impertinent a liberty. There are so few people of whom one can think even as well as I did of him, that I feel this a loss, \& am like you angry with him for it.
\end{abstract}

(Mill 1972, 14:139-40)

Clearly Harriet Taylor, highly jealous of Mill's friends and determined to isolate him from them, had orchestrated Mill's stinging and self-righteous reply. ${ }^{10}$ Yet such irritations sometimes arise between close friends. Mill and Thornton had occasional quarrels too and moments of mutual dissatisfaction. But Mill was not the sort of person to harbour a grudge, and having administered the rebuke, he forgave his friend and let the matter rest. If anything, their attachment seemed to grow stronger over time, particularly in Mill's final decade. ${ }^{11}$

Soon after Mill's death in 1873, Thornton prepared a moving tribute in which he spoke candidly of the man and his personality. On Mill's 1858 retirement from public life, a group of his India House colleagues had arranged to present him with a handsome 
silver inkstand as a 'token of high admiration and esteem, and warm personal regard' (Mill 1972, 15:570n.). Mill, who did not feel comfortable about receiving public compliments, was upset when he learned of the plan and 'quite resolved not to be made the subject of them' (Thornton 1873:36). Thornton, who had originally proposed the idea, told his readers of making arrangements for the testimonial to be delivered secretly 'to $\mathrm{Mr}$ Mill's house at Blackheath' and placed in his drawing room. The 'plan succeeded...mainly due to Miss Helen Taylor's good offices' (ibid: 37). This incident makes clear once again Mill's determination to retire quietly and gracefully from public office. He was 'from first to last' a private person.

\section{Mill's Retirement}

In 1858, the administration of the East India Company's territories was transferred to the Crown. The Company's dissolution was the catalyst for Mill's decision to retire from his official position in the home establishment, although during the first six months of the year he had been fighting for its survival on the grounds that it was a model of good government (Moir 1993). In a letter to Henry Chapman on 8 July 1858, he remarked:

The East India Company has fought its last battle, and I have been in the thick of the fight. The Company is to be abolished, but we have succeeded in getting nearly all the principles which we contended for, adopted in constituting the new government, and our original assailants feel themselves much more beaten than we do. The change though not so bad as at first seemed probable, is still, in my opinion, much for the worse.

(Mill 1972, 15:560)

Although Mill 'never again sought or occupied an official position in the home government of British India', he retained a lively interest in India House affairs (Moir 1990:xxxix). Thornton, who had been promoted to the position of Secretary of the India Office's Department of Public Works, kept his friend informed of news, personal views and other snippets of information on the India Office. For example, in an illuminating letter Thornton wrote to Mill on 8 January 1869, he characterised Sir Stafford Northcote as a person of little resolve. At the same time, he referred approvingly to the recent appointment of the Duke of Argyll as Secretary of State for India:

[W]e seem to have made a good exchange of Sir S.Northcote for the Duke of Argyll. It is impossible to be much in contact with the former without liking him, but I never before met with a man of so much capacity joined with so little force of character. Over and over again, he would...[give] up his own judgement in deference to the noisy opposition of men as incapable of judging of anything as Mills or Macnaughten. Now the Duke of Argyll looks and speaks as if he had a will as well as an opinion of his own.... [W] hat we, office men, desire above all things in a Secretary of State is that he should preside over this council instead of letting them rule over him.

(Donoghue 2000:335) 
The Duke of Argyll, who served between 1868 and 1874, acknowledged Thornton's support in connection with the establishment of a new railway network in the state of Punjab, north-west India (see Argyll 1906:274). Thornton later dedicated his Indian Public Works, and Cognate Indian Topics (1875) to Argyll, and, as an acknowledgement of loyal and distinguished service to the India Office, the Duke recommended Thornton for the Companion of the Order of the Bath.

A few months after his retirement, Mill's beloved wife, Harriet Taylor, passed away. His grief left him no energy to carry on. He fell into a chasm of gloom and withdrew from society. Thornton was the first person outside of his immediate family with whom Mill shared his grief. From the Hotel d'Europe, Avignon, he wrote:

It is doubtful if I shall ever be fit for anything public or private, again. The spring of my life is broken. But I shall fulfil her wishes by not giving up the attempt to do something useful, and I am not quite alone. I have with me her daughter, the one person besides my self who most loved her and whom she most loved, and we help each other to bear what is inevitable.

$\left(\right.$ Mill 1972, 15:574) ${ }^{12}$

\section{The Last Years}

With Thornton's support, however, Mill gradually regained the will to live and he reemerged from seclusion in the early 1860 s. Indeed, the 1860 s proved to be a particularly engaging decade for Mill. He entered political life and won the seat of Westminster in the general election of 1865 , although he lost the seat in the next election in 1868. Thornton saw his defeat as a blessing in disguise. '[Y]our last letter', he wrote in a letter to Mill on 8 January 1869 ,

has throughout it a ring of such genuine satisfaction at your emancipation from parliamentary drudgery that it is impossible for me to feel any further regret on your personal account in respect of the Westminster election.... [Although] there is much work of the highest importance to be done in the House of Commons which no one can do as well as yourself if at all, there is at least equally important work for you out of the House, and work which it gives me much more pleasure to fancy you engaged upon.

(Donoghue 2000:334)

Thornton was referring to Mill's continuing work aimed at the 'improvement of mankind', in which he had taken more than a passing interest. ${ }^{13}$

Indeed, in his final decade, Mill gathered around him a small, loyal band of followers who showed a commitment to the dissemination of his ideas and a devotion to the improvement of mankind. Thornton was a pivotal member of this group, which came to be known as the Blackheath Park circle. ${ }^{14}$ He had remained very close to Mill and, to some extent, helped to fill the void left by Harriet's death (see Lipkes 1999:118-19, 158).

Mill, having purchased a cottage at Mt Veran in the south of France so as to be nearer the Avignon cemetery where Harriet was buried, was spending less and less time at 
Blackheath Park. Thornton, by now deeply attached to Mill and Helen Taylor, Mill's stepdaughter, was a regular guest at Avignon. At one point, Helen, who seems to have inherited her mother's strong personality, ${ }^{15}$ took it upon herself to supervise the renovation of the cottage. ${ }^{16}$ From Avignon in mid-January 1869 , Mill wrote to Thornton with news that 'Helen says your room is not finished yet, because as she is an architect and master mason all in one, she is carrying on the improvements very slowly, not letting the attention to them interfere too much with her work' (Mill 1972, 17:1549.) ${ }^{17}$. Mill died on 7 May $1873 .{ }^{18}$ In a letter to Helen Taylor from his London residence two days later, Thornton described the depth of his feeling towards Mill:

Forgive me for presuming to intrude upon your affliction. From what $\mathrm{Mr}$ [Leonard] Courtney tells me I fear that before this reaches you, all may be over. I do not write to offer condolence. My own feeling at the idea of losing the best, truest, noblest of friends tells me only too well what a mere impertinence that would be. But possibly you may feel the need of other assistance and cooperation than any immediately at hand. If so, I desire to say, though I trust you do not require to be told, that there are no services which I can render which you may not command. May God help you to endure this fearful blow.

(Thornton to Helen Taylor, 9 May 1873) ${ }^{19}$

The passage makes clear, in addition to the deep sense of loss Thornton felt after the death of his dear friend, that the two men had enjoyed a mutually warm friendship nurtured over many years. Their letters, which always began 'My dear Mill' and 'Dear Thornton', reveal the depth of their bond. They also show that Thornton, far from being a passive bystander in their intellectual discourse, often initiated a topic of discussion, providing direction and substance to it in a variety of ways. Indeed, as Mill's biographer Alexander Bain observes: 'one of Mill's chief friendships in later years was with Thornton, who differed from him in a great many things, but the differences were of the kind to bring into lively exercise Mill's argumentative powers' (Bain 1882:173-4.)

\section{Thornton's Wrongful Claims and Rightful Dues}

From the late 1840s onward, Mill played an important part in advancing Thornton as a student of and writer on political economy and social philosophy. The interplay of the two men's ideas and personal reactions form an interesting sidebar to the history of Victorian thought.

\section{A Plea for Peasant Proprietorship}

In 1848, Thornton published his second book, A Plea for Peasant Proprietorship, in which he proposed a limited scheme for resettling Irish cottiers on wasteland, with ownership passing to them after reclamation. Mill, who read the proof sheets, incorporated some of the factual evidence into the 1848 and 1849 editions of his Principles of Political Economy. He was particularly interested in Thornton's study of 
peasant properties in the Channel Islands. ${ }^{20} \mathrm{He}$ made the following attribution to 'Mr William Thornton, in his Plea for Peasant Proprietors, a book which, by the excellence both of its materials and of its execution deserves to be regarded as the standard work on that side of the question' (Mill [1848, 1849, 1871] 1965, 2:272). Mill's biographer, Alexander Bain, once said that it was William Thornton who 'first awakened him [Mill] to the question of peasant properties' (Bain 1882:82n.).

Between October 1846 and January 1847, Mill published a series of articles on the 'Irish Land Question' in the Morning Chronicle. In one, he acknowledged that his plan for Ireland had been 'anticipated...in the excellent work of Mr. William Thornton' (see Kinzer 2001:55).

Thornton's letters to Mill in the 1860s and 1870s also contain information on peasant proprietorship. In October 1869 he wrote to his friend in the south of France describing the peasant properties he had visited during the course of one of his walking tours in Europe. In that letter, he explained that the peasant properties in Europe were not comparable to those found in Britain, adding:

I took the railway to St. Nicolas... and then walked back for six miles through the thick of its peasant properties - I am sorry to say the reality did not in all respects come up to my expectations. ...They are not to be compared with those which one sees either on well-tilled English farms, nor in other parts of Belgium.

(Donoghue 2000:336)

All this he summarised for Mill's benefit, thinking that what he had seen on his 'rambles' was sufficient for both men to 'cite in confirmation of our theories' (ibid: 332, 336-7).

With Mill's help, Thornton began to make inroads into London literary circles. On 12 February 1850, Mill wrote to William Hickson, the editor of the Westminster Review, recommending Thornton as a potential contributor to the journal and sending a copy of a recent paper (Mill 1972, 14:47). Impressed with its content, Hickson agreed to publish it under the title 'Equity Reform; the Probate Courts'.

At about this time, Mill also nominated Thornton for membership in the Political Economy Club. He thus met and later became friends with several prominent economists of the day. The most important connection he formed through Mill was with John Elliot Cairnes (1823-1875), the holder of the political economy chair at University College, Dublin. ${ }^{21}$ Although Cairnes often found himself in disagreement with Thornton, he admired his intellectual qualities and appreciated his camaraderie.

However, Thornton and Cairnes did not establish a close and spontaneous friendship for some time. In a letter to Cairnes on 3 October 1864, Mill provided an assessment of Thornton's character: 'Thornton will be much pleased by your feeling towards him, and will, I am sure, fully reciprocate it. He is a person I particularly respect and like. In candour, sincerity, and singleness of mind, few men come near him' (Mill 1972, 15:958). The inference is that Mill was trying to stage manage their relationship. Indeed, the formal tone of the two letters that Thornton wrote to Cairnes, dated 16 and 23 August 1866, suggests that they continued to 'keep each other at arms length' for a period after their first contact (see Donoghue 2000:327). However, the two men gradually warmed to one another, and by late 1866 Thornton had seized the initiative and dispensed with the 
'ceremonious prefix...Mr.' when addressing Cairnes in his letters. The tone of subsequent letters was more convivial.

Thornton's letters to Cairnes focus almost exclusively on economic matters. They capture Thornton's cautious personal reaction to the public reception of his Fortnightly Review articles on value and distribution theory and contain an exchange of views on economic methodology and the scientific claims of political economy. ${ }^{22}$ He also took an interest in the welfare of the Cairnes family. Cairnes himself was in his late forties when his health had begun to deteriorate. In a letter he wrote to Mill on 22 September 1872, Thornton showed deep concern at a deterioration in Cairnes's physical condition: 'I dined with Cairnes a few days ago. Every time I see him I find him more helpless. Mrs Cairnes is obliged now to lift the food to his mouth' (Donoghue 2000:339) ${ }^{23}$. The serious atmosphere of the Thornton-Cairnes letters contrasts with the Mill-Thornton letters' lighthearted talk about travel, mutual friends, India House gossip and social outings. Perhaps the subject most frequently discussed in Thornton's letters to Mill was travel. He provided detailed accounts of his 'rambles' in Europe and suggested places for Mill and Helen Taylor to visit on their own holidays. He often spent extended periods abroad, alone, restoring his health, during which he would catch up on his reading. Carlyle's History of the French Revolution was a personal favourite. Reading it made him 'burst out laughing wherever and in whatever company [he] might be', as he found Carlyle's 'grim humour...perfectly irresistible' (ibid: 337-8).

\section{On Labour}

In early January 1869, Thornton wrote to Mill saying that he 'had the delight of being able to write 'The End' on the last page of my M.S.[manuscript]' (ibid: 334). ${ }^{24}$ That manuscript was, of course, On Labour, Its wrongful claims and rightful dues; Its actual present and possible future. Published in instalments in the Westminster Review and the Fortnightly Review between 1864 and 1868, the book eventually appeared in February 1869 and immediately caused a great stir in political economy circles.

When the reviews of On Labour began to appear in the newspapers and periodicals of the day, Thornton was dismayed. He had every reason to fret about the frosty public reception of his book, as even the better reviews were grudging in their praise. ${ }^{25}$ On 26 March 1869, in a letter to Cairnes, by now his close friend, Thornton wrote:

As yet the only fair notice of the [book], besides one entirely commendatory in the Star, has been in the London Review-a journal I am afraid with too little circulation to do me any good. I am a little nervous about the treatment I shall get from the Saturday [Review]. If my critics would only not misrepresent me I should not care what they said. They could not be more severe than I should like them to be upon my errors, but to have your critics' inventions ascribed to you and then to be condemned for them is a little trying, and after having received that treatment from the Pall Mall, I feel scarcely safe in any quarter.

(Donoghue 2000:328-30) 
With considerable relief, Thornton learned of Mill's intention to review the book for the Edinburgh Review. In early October 1867, Mill, having read the instalments of On Labour as they appeared in the Fortnightly Review, had written Thornton to say he liked it (Mill 1972, 16:1518). Later that month, after returning from a 'delightful' summer trip to Europe, Thornton had acknowledged Mill's letter and thanked him for his careful and favourable reading of the Fortnightly Review articles:

Whenever I write I always have the fear of you before my eyes, for of course there is no opinion of what I do that I value half as much as I do yours, and to find this time so much hearty sympathy and commendation mingled with your adverse criticism is all the more gratifying from having been little expected.

(Donoghue 2000:332-3)

In early 1869, Mill approached Henry Reeve, the editor of the Edinburgh Review, about the possibility of reviewing On Labour.

Would it suit the 'Edinburgh Review' to take an article from me on Mr. Thornton's book on Labour? The book is of great ability; and, though there is much of it with which I do not agree, I think it is a really important contribution to political economy, as well as to the particular subject of which it treats. My object would be to recommend the book to the consideration of thinkers, pointing out at the same time how far, and in what, I think it erroneous.

(Mill 1972, 17:1574-5)

In the event, however, Mill withdrew his offer to the Edinburgh Review. ${ }^{26}$ In a letter to Cairnes on 26 March 1869, Thornton confirmed Mill's decision 'to review me in the Fortnightly instead of the Edinburgh, [of] which on the whole I am glad' (Donoghue 2000:329).

In a separate letter, Mill solicited Cairnes's own opinion of the book.

I shall be very desirous of knowing whether you agree with my judgement of the book from the purely scientific point of view. I feel pretty sure you will concur in what I have written on the so-called wages fund, a subject on which I expressed myself in my political economy as inaccurately as other people, and which I have only within the last two or three years seen in its proper light. On the other subject on which you think Thornton vulnerable, the losing sight of the population principle, it would have been better, perhaps, if he had added a few pages on the relation of that question to his doctrine.

(Mill 1972, 17:1587-8)

This passage clarifies two points. First, Mill, who went to considerable trouble with the review, was eager to promote a book he thought deserving of attention. Second, he appears to accept Thornton's criticism of the wage-fund doctrine, foreshadowing his so- 
called recantation of that doctrine, which would be part of his May 1869 Fortnightly Review article on Thornton's book. ${ }^{27}$ This change in his view, although not as radical as has often been thought, was an important episode in the history of economic thought at a time when critics were attacking classical political economy from several sides.

Some years later, Cairnes rekindled the wage-fund controversy with Thornton. He expressed misgivings over Mill's recantation of the wage-fund doctrine (Cairnes 1874:214). Conceding that the old conception of a fixed wage-fund was inadequate, he argued that the wage-fund involved no pre-determination as rigid as Thornton suggested (see Donoghue 1998:400-402, for further discussion). After Cairnes's death (in 1875), Thornton published his final contribution to the debate; in it he admitted that he and Cairnes differed little over the wage-fund doctrine, despite their earlier disagreement (see Thornton 1879).

Mill also had a high regard for Thornton's economic analysis of trade unions. In the preface to the last edition of the Principles of Political Economy (1871), he referred readers to On Labour for 'some instructive discussion...on the influence of strikes and Trade Unions on wages, by which additional light has been thrown on these subjects' (Mill [1848, 1849, 1871] 1965, 2:xciv). In the famous chapter 'On the Probable Futurity of the Labouring Classes', Mill made an important textual change in which he set about clarifying the mechanism by which trade unions could raise the wages of their members. In the last edition of the Principles of Political Economy, the passage reads:

If they could [combine effectively], they might doubtless succeed in diminishing the hours of labour, and obtaining the same wages for less work. They would also have a limited power of obtaining by combination an increase of general wages at the expense of profits. But the limits of this power are narrow; and were they to attempt to strain it beyond those limits, this could only be accomplished by keeping a part of their number permanently out of employment. As support from the public charity would of course be refused those who could get work and would not accept it, they would be thrown for support upon the trades union of which they were members; and the work-people collectively would be no better off than before, having to support the same numbers out of the same aggregate wages. In this way, however, the class would have its attention forcibly drawn to the fact of a superfluity of numbers, and to the necessity, if they would have higher wages, of proportioning the supply of labour to the demand.

(Mill [1848, 1849, 1871] 1965, 3:929-30, emphasis added) ${ }^{28}$

This passage clarifies at least two things. First, the change softens the impact of the inexorable laws of supply and demand and confidently predicts successful wage outcomes by way of labour combination, a view Mill attributes to Thornton in his review of On Labour (Mill [1869] 1967, 5:644). Second, the negotiated wage is the outcome of a bargain between unions and employers, which settles 'the division of proceeds between employer and the labourers'. Nevertheless, Mill recommends an upper limit to wage claims because 'wages might be so high as to leave no profit to the capitalist, or not 
enough to compensate him for the anxieties and risks of trade; and in that case labourers would be killing the goose to get at the eggs' (ibid: 645, 657).

In a letter to Henry Reeve in March 1869, Mill directly referred to Thornton's discussion of the latter point:

On these points, I think Mr Thornton has fully made out his case. [H]e condemns some of the aims and rules of trades-unions; and is quite alive to their liability to carry their legitimate aims (rise of wages and diminished hours of work) to a length which may injure both themselves and their employers by driving trade elsewhere. For the correction of evil he looks to the lessons of experience and increased intelligence; and to amicable discussion between the parties. In these various opinions I entirely agree, and I should feel bound to express them in anything I write on the subject.

(Mill 1972, 17:1576)

Significantly, in his Fortnightly Review article, published in May 1869, Mill recommended that unions moderate their wage claims lest they 'produce a fall in wages, or a loss of employment, to other labourers, their fellow countrymen' or drive wages 'so high as to leave no profit to the capitalist, or not enough to compensate him for the anxieties and risks of trade'. Such a course of action 'Would destroy, or drive elsewhere, the particular branch of industry in which the [wage] rise takes place' (Mill [1869] 1967, 5:657-8, 662). Thornton's economic analysis of trade unions certainly had a telling effect on Mill. It had become clear to him that trade unions, in certain circumstances, could act as a countervailing force, making the operation of the labour market both more efficient and more equitable by promoting more aggressive bargaining over wages among labour market contestants.

Thornton's views on industrial co-partnership and profit-sharing schemes also captured the essence of Mill's own thinking on cooperation. Indeed, this part of Thornton's writings on labour relations particularly appealed to Mill. In a letter to Henry Reeve, editor of the Edinburgh Review, Mill said of On Labour, 'I agree generally in its conclusions, respecting trade-unions, co-operation, and the ultimate future of labour' (Mill 1972, 17:1574-75). And in his review of the book, he evaluated Thornton's account of various forms of industrial cooperation as simply the most 'compact and comprehensive' exposition available at the time, and described the conversion of the existing system of industrial relations, based on collective bargaining, to one in which industrial partnership prevailed as the 'true euthanasia of Trades' Unionism', where 'the whole body of work-people [would] have a direct interest in the profits of the enterprise'. In due course, this system would transform itself again and 'prepare...the working class for a form of co-operation still more equal and complete' (Mill [1869] 1967, 5:666).

Overall, Thornton's On Labour was of major significance for developments in labour economics during the late nineteenth century, not least because of its influence on Mill. It both crystallised Mill's developing ideas on unionism and cooperation and influenced the direction of his thinking on the subject (see Donoghue 1999, for further discussion). 


\section{'Anti-Utilitarianism'}

Following the success of On Labour, Thornton turned his hand, in the early 1870 s, to the pursuit of metaphysical and ethical subjects. It was a brief and largely unsuccessful digression that involved him in yet another intellectual dispute with Mill and Cairnes.

In a Fortnightly Review article titled 'Anti-Utilitarianism', Thornton (1870b) railed against the principles of utilitarianism, labelling them as wrong. He rejected the utilitarians' view that 'the morality of actions depends wholly and solely on their consequences [and] that the motive has nothing to do with the morality of an action'. According to Thornton, calculating the consequences of an action in order to determine its morality is impossible because 'we can seldom, if ever, be quite sure what will be the result of our conduct'. 'Meaning to cure, we may only too probably kill; meaning to kill, we may not impossibly cure' (ibid: 329). In short, he attempted to demonstrate, using a series of 'extreme and imaginary cases', that utilitarianism would justify what existing morality condemned and condemn what existing morality recognised as virtuous (see Lipkes 1999:124-26, for further discussion).

This frontal attack on one of the central tenets of Mill's system of philosophy did not tempt Mill himself to enter this controversy publicly (Everett 1939:222-23). However, J.E.Cairnes, Mill's leading disciple, did mention the challenge in a private letter to Mill on 10 September 1870, dismissing Thornton's article as 'the weakest thing of his, I think, that I have ever read. He might at least have mastered the distinction between "intention" and "motive" before undertaking to refute utilitarianism' (Lipkes 1999:210). In his reply to Cairnes on 15 September 1870, Mill agreed and evaluated 'Anti-Utilitarianism' in the following way:

Thornton's article is, as you say, very weak; but metaphysical subjects are not among his strong points. You have laid your finger very precisely upon one of the principal of his many fallacies. All he says is answered by anticipation in Bentham's Introduction to Morals and Legislation, and in my father's Fragment on MacKintosh.

(Mill 1972, 17:1765)

Thornton had written the article as part of a planned book. ${ }^{29}$ He felt sufficiently anxious about Mill's likely chilly response to it that, while holidaying with his wife and daughter outside London, he wrote to his close friend on 22 September 1872:

[My] own immediate literary labour is, I am rejoiced to say, very nearly completed. I am in the last chapter and have not I believe more than a dozen pages to write. ...One instalment of my book, the chapter on Huxleyism is to appear in October's Contemporary [Review]. I shall be rather nervously anxious for your and Miss Taylor's judgement upon it.

(Donoghue 2000:339-40)

In the last letter Mill wrote to his friend before his death, he congratulated Thornton 'on so nearly having finished your book. It is sure to interest me whether I agree with it or 
not' (Mill 1972, 17:1913). Mill had a considerable tolerance for the philosophical deviations of those with whom he shared political and social sympathies, and Thornton fitted this description perfectly.

\section{Concluding Remarks}

In early 1846, Thornton and Mill began what would become a close and lasting friendship. Apart from Thornton's twelve-month period of recuperation in the mid-1850s, during which Mill performed his friend's official duties at the East India Company, the two men met every day at work until mid-1858 when Mill retired from the Indian civil service. Although no correspondence between the two friends survives from this period, their published writings and Mill's private letters reveal the depth of their attachment. Even the redoubtable Harriet, who tried to isolate Mill from his friends, eventually accepted Thornton as having a unique place in their lives. Helen Taylor, Harriet's daughter, doted on Thornton, and he kept up a separate correspondence with her that is notable for its warmth and spontaneity. Thornton and Mill did, of course, occasionally quarrel, but they never seriously jeopardised their attachment.

Reinforcing the sense of the personal bond that had developed between them was the moral support each extended the other in times of family bereavement and serious illness. In the period after Harriet's death in 1858, Thornton, in a sense, came to replace her as a stable, candid, and trustworthy presence in Mill's life (Lipkes 1999:118-119). On other occasions, the Mill family rallied behind Thornton, lending him moral support in an hour of need. Examples include Thornton's mysterious illness in the mid-1850s, the lifethreatening lung complaint of his son, Edward Zohrab, in 1860 and the death of his daughter, Evelyn Danvers, in 1876.

Mirowski and Tradewell (1999:33) remind us that Mill had 'few friends; and fewer still whom he regarded comfortably as intellectual equals'. Thornton was an exception. The warm and generous comments Mill made about his friend's scholarship and friendship attest to his high regard for Thornton. Yet, surprisingly, the bulk of Mill's biographers have not discussed his friendship with Thornton.

Several prominent nineteenth century intellectuals did, however, leave sketches of that friendship, revealing the depth of the bond. Alexander Bain, Mill's biographer and close friend, once remarked that 'one of Mill's chief friendships in later years was with [William] Thornton'. Even the irascible Leslie Stephen, who had made several uncharitable remarks about Thornton on other occasions, conceded that 'the excellent W.T.Thornton... was one of the few friends who communicated freely with [Mill] during his seclusion' (Lipkes 1999:118-19).

Another significant aspect of the Mill-Thornton relationship that has received relatively little attention is the nature of their intellectual collaboration. From the time of their first discussion in India House in early 1846, both men realised that they shared intellectual concerns and preoccupations. Although Mill's influence on the younger man's authorial and professional careers was pervasive, the direction of the effect and the mutual exchange of ideas was clear. It is well known that Mill solicited views from congenial minds and benefited from criticism of his own. He was tolerant of the alternative thoughts of individuals with whom he shared political and social sympathies. 
As we have seen, Thornton was no passive bystander in the intellectual dialogue. More often than not he initiated a topic of discussion, providing direction and substance to it in many ways. His strictures on the fledgling science of political economy were important for developments in that discipline in the last third of the nineteenth century. In particular, the importance of his association with the controversy over the classical wagefund doctrine carried political implications with regard to the methods, aims and legitimacy of organised labour. Thornton's writings in these areas certainly helped to shape Mill's own thinking on these subjects during the 1860s. Thornton also contributed to the rehabilitation of peasant proprietorship in the nineteenth century. Indeed, the shift in Mill's position on the Irish Land Question in the mid-1840s - from one in favour of the adoption of large-scale English farming as a model for Irish agriculture to one that advocated the reclamation of wastelands and the settlement of peasant proprietors on them-owed much to Thornton's work.

Mill once described Thornton, in a letter to Henry Fawcett, as a 'superior man on many points, [but] on others he feels with the herd' (Mill 1972, 15:777). He was referring both to Thornton's unpredictable 'mental constitution' and to the quality of his thinking on a wide range of subjects. Yet it was his unpredictable intellectual disposition that endeared him to Mill and to the Mill circle. To be sure, Thornton's work never lacked criticism. John Stuart Mill, for one, remonstrated with his friends in private correspondence over Thornton's contributions, but he never discouraged his literary endeavours or censored his views. Indeed, from the beginning of their friendship, Mill saw a kindred spirit in Thornton with his taste for controversy, his 'excess receptivity for paradox', and his tendency to 'swim against the stream'.

\section{Notes}

* I thank Keith Forster, Peter Groenewegen, Jeff Lipkes, David Reisman, John Whitaker, Mike White and anonymous referees for extremely useful comments and suggestions on an earlier version of this chapter. I am solely responsible for any remaining shortcomings.

** The first quote is taken from a letter John Stuart Mill wrote to John Elliot Cairnes in early October 1864 and is published in The Later Letters of John Stuart Mill, 1849-1873 (Mill 1972, 15:958). The second quote is taken from a letter William Thornton wrote to Helen Taylor, J.S.Mill's stepdaughter, on the sad occasion of Mill's death. The unpublished letter is preserved in the Mill-Taylor Collection, British Library of Economic and Political Science, and is dated 9 May 1873.

1 According to the records of the East India Company, now preserved in the Oriental and India Office Library, Thornton joined the Company on 2 August 1836. The official record of Thornton's appointment is as follows: 'Resolved with reference to the Courts' Resolution of the 27 ulto, that Mr William Thomas Thornton be appointed Junior Clerk in the Established branch of the Examiner's Office on probation for one year, under the Regulations of the 9 March 1831' (L/AG/30/12). East India House was the name given to the London headquarters of the East India Company in Leadenhall Street.

2 James Mill's educational practices have, by and large, come in for harsh criticism from social historians. For example, Carlisle (1991:14) argues that 'his was certainly an educational experiment that entailed the emotional and social deprivation of its subject'. Robson (1989:5) provides a more balanced assessment: '[W] hat is almost universally overlooked is the pleasure Mill took in his learning'. Robson continues by noting, '[A]nyone feeling tempted to tears or rage about Mill's education should glance... at other personal accounts of 
childhood education in the nineteenth century, which are marked by woeful memories of neglect, boredom and very often of brutality, especially at public schools'.

3 The controversial nature of both James Mill's promotion and his son's appointment is discussed at some length by Moir (1990:xiii-xiv).

4 The Court Minutes explain that it proved possible to employ J.S.Mill 'in preparing drafts of despatches, instead of performing the duties usually assigned to persons of his standing' because of 'the great pains bestowed on his education' coupled with his own 'acquirements which are far in advance of his age' (Moir 1990:xiii).

5 For an excellent discussion of the progress of Mill's career in the Indian civil service, see Moir (1990).

6 In the first and second editions of the Principles of Political Economy (Mill [1848, 1849, 1871] 1965), Mill praised Thornton's Over-Population and its Remedy. He saw Thornton's proposed project, entailing the colonisation of Irish wastelands by indigenous peasants, as 'distinguished from most others by its rational treatment of the great questions affecting the economical condition of the labouring classes' (Mill [1848, 1849, 1871] 1965, 3:997, cf. 996-1002).

7 Thornton was, however, an independent thinker, as he showed when be published his criticism of the classical theory of value. It was a direct challenge to Mill's authority. Thornton did, however, declare that he felt 'a little as Saul of Tarsus might have felt if, while sitting at the feet of Gamaliel, he had suddenly found himself compelled by a sense of duty to contradict his master' (Thornton 1870a:62).

8 On 13 March 1857, in a letter to Edwin Chadwick, Mill lamented that he was 'too busy' to continue with his own writing, 'having all Thornton's work to do in addition to my own' (Mill 1972, 15:528).

9 The dedication reads: 'To John Stuart Mill, Esq. In Imitation of an Epistle of Horace to Maecenas, ibid: 132-149, with the Latin of Horace on facing pages'. Here Thornton is suggesting that his own relationship with Mill resembled that between Horace and his patron Maecenas, who introduced Horace into his privileged circle of political and literary associates in Rome.

10 This contretemps is further evidence of Mill's unusually strong attachment to Harriet, which led one contemporary reviewer to quip: 'Mill had no great faith in a God. He had unbounded confidence in a goddess' (Mill 1972, 14:xxiii).

11 Thornton's warm relationship with Mill and his family can also be gauged by the fact that Harriet Taylor herself made him trustee of her first husband's estate (Mill 1972, 15:504, n. $5)$.

12 Mill also asked Thornton to place an obituary notice in several London newspapers (Mill 1972, 15:575).

13 Robson (1989:14) provides a concise summary of Mill's lifelong commitment to the 'improvement of mankind'. It was manifested in 'selfless dedication and energy and a sense of engaging in battle against forces of evil armed with unreason and entrenched in traditional strongholds. This programme was theological in force, if agnostic in creed, and its most evident engine was moral.'

14 The Blackheath Park circle comprised only economists, although a wide range of views on political economy and on other subjects existed within the group. The loyalists, John Elliot Cairnes - Mill's anointed heir - and Henry Fawcett - the blind defender of the faith — were largely responsible for the dissemination of Mill's economic doctrines in the public domain. The dissidents - William Thornton and T. E.Cliffe Leslie-railed against classical political economy, and their criticisms led Mill to modify some of his views on economic subjects, much to Cairnes's chagrin.

15 Lipkes (1999:76) remarks wryly that Mill 'was a Taylor-made man'.

16 In a letter Thornton wrote to Mill on 8 January 1869, he mentioned having heard 'great things from Mr Hare of Miss Taylor's architectural achievements' (Donoghue 2000:335). 
17 From Avignon in October 1862, Thornton wrote Henry Fawcett a long letter in which he provided a detailed description of Mill's way of life. In it, he remarked, 'Two of the lower rooms are the drawing-room and sitting-room, the third is my bedroom, at the window of which, looking into the garden, I am now writing' (Elliot 1910, 1:261-2).

18 In a codicil to his last will, Mill appointed Thornton one of his executors and trustees. In his deed of gift, Mill bequeathed one thousand pounds to Thornton. He also appointed Thornton his literary executor in the event Helen Taylor did not survive him (Mill 1991, 32:328-36).

19 The letter, in which this passage appeared, is now preserved in the Mill-Taylor Collection, British Library of Economic and Political Science. Helen Taylor was fond of Thornton, and they kept up a regular correspondence with each other.

20 Mill praised Thornton's book in a letter to John Elliot Cairnes, to whom he sent his personal copy (Mill 1972, 15:930, 948-9). Mill later encouraged Thornton to publish a second edition of the book, which duly arrived in 1874 with two additional chapters, one titled the 'Social and Moral Effects of Peasant Proprietorship' and the other 'Ireland: a Forecast from 1873' (Thornton 1874).

21 It is not known precisely when Thornton met Cairnes, but on the available evidence it seems likely that they first met in the early to mid-1860s.

22 Cairnes, having published a treatise titled Character and Logical Method of Political Economy in 1857, had established a reputation as an expert on this subject.

23 In some of his own letters to Cairnes, Mill refers to 'very recent intelligence' reports received from Thornton containing news of Cairnes's health (see Mill 1972, 16:1283; 17:1909).

24 Mill wrote back to congratulate Thornton on bringing his book 'to a happy termination' (Mill 1972, 17:1547).

25 For discussion of the reviews of Thornton's On Labour, see White (1994a) and Mirowski and Tradewell (1999).

26 Economist George Rickards wrote a scathing review of On Labour for the Edinburgh Review (see Mill 1972, 17:1576 n. 3).

27 Briefly, Thornton rejected the assumption made by 'those who affirm the wages fund [doctrine]' that there is a fixed or pre-determined wage-fund from which workers are remunerated.

28 In the first six editions the italicized passage read: 'But if they aimed at obtaining actually higher wages than the rate fixed by demand and supply - the rate which distributed the whole circulating capital of the country among the entire working population...'.

29 The article was eventually published in Thornton's 1873 book titled Old-Fashioned Ethics and Common-Sense Metaphysics.

30 Events would prove him right. In 'Natural Rights and Abstract Justice', a follow-up article to 'Anti-Utilitarianism', he remarked, 'I feel that I must have incurred in philosophic quarters a sort of civil contempt, which I am very desirous of removing, and which will, I trust, be somewhat diminished on my proceeding to explain how few and elementary are the rights that I propose for naturalisation' (Thornton, 1871:359). His proposal met with trenchant criticism from one reviewer, who said that 'Mr. Thornton's doctrine of abstract indefeasible rights...is connected with some of the crudest theorising about the social contract which has ever been printed' (Simcox 1873:192). 


\section{6 \\ A Grin Without a Cat \\ W.S.Jevons' Elusive Equilibrium \\ Michael V.White}

The notion of getting into equilibrium is a metaphor based on space to explain a process which takes place in time.

Joan Robinson (1978b:12)

In the Preface to the first edition of his Theory of Political Economy (hereafter TPE), W.Stanley Jevons noted that, in chapter IV, he had 'alluded' to the 'cardinal difficulty with the whole theory' (Jevons 1871:x; 1970:45). As Jevons did not make a habit of advertising the problems he recognised with his marginalist theory, the reference indicates that he considered the cardinal difficulty to be a matter of substantive concern. Because it was only alluded to, however, it was not clearly identified. The purpose of this chapter is twofold. The first is to argue that the difficulty consisted in explaining how an equilibrium is attained in a market period and that Jevons was unable to do so. It has since been observed that the failure of post-classical (or neo-classical) theory to provide 'a rigorous basis for believing that equilibrium can be achieved or maintained if disturbed' is a 'major lacuna in economic analysis' (Fisher 1987:26). While that lacuna was evident to Jevons, the second purpose of the chapter is to show how he obscured both the presence and the significance of the problem with a series of rhetorical devices in TPE.

The core of Jevons' difficulty turned on the relationship between the marginal utility theory and 'the laws of supply and demand' in a market period. One of Jevons' principal arguments in TPE was that, with the utility theory, he had, for the first time, provided a rigorous theoretical explanation for the laws that, as 'facts', recorded 'actual' market phenomena. This meant, in turn, Jevons claimed, that the theory was Verified' in the functioning of actual markets (Jevons 1970:43, 148). To explain the attainment of equilibrium with the theory, Jevons depicted a representative transactor adjusting purchases in a sequence of disequilibrium transactions with a given exchange ratio (or market price). The problem was that, for Jevons, the laws of supply and demand entailed that every transaction would change the price. The attainment of equilibrium could not, therefore, occur as any transaction would change one of the data of the equilibrium position. Unable to solve the problem, Jevons produced a confusing account of market period trading in TPE. ${ }^{1}$ On the one hand, he gave the impression at a number of places that he could explain how equilibrium was attained through adjustments with disequilibrium transactions. At the same time, he alluded to the problem, but failed to clearly identify it. He did not make clear, therefore, that his account was restricted to the depiction of equilibrium outcomes, the attainment of which he could not explain. He then 
resorted to the argument that all market transactions could be depicted as occurring at equilibrium and attempted to defend that result, principally by drawing on a number of arguments from mechanics and natural philosophy (physics). Jevons had initially developed his marginalist analysis using a series of mechanical metaphors. The basic exchange equilibrium condition, for example, was derived from that for a lever in static equilibrium. In explaining that derivation in $T P E$, Jevons defended his analysis by referring to the principle of virtual velocities from (variational) mechanics, which argued that all outcomes in a system could be explained in terms of equilibrium. It was consistent with his only alluding to the attainment problem, however, that the significance of the principle of virtual velocities was not clearly explained.

The analysis is presented in five sections. The first considers Jevons' discussion of market period trading in Chapter IV of TPE, where he argued that the marginalist theory was practically verified in actual markets. The second section then explains his difficulty with equilibrium. The following section discusses the passages where Jevons alluded to the problem, while the fourth section considers the lever analogy and the reference to the principle of virtual velocities. It is concluded that Jevons' confusing discussion of his theory and its relevance for explaining events in actual markets was a deliberate rhetorical strategy, designed to avoid a clear discussion of his equilibrium problem. The fifth section shows how the context in which TPE was written explains why Jevons adopted that strategy.

\section{Market Period Trading}

Jevons' discussion of trading (or exchange) in a market period in Chapter IV of TPE assumed a 'theoretically perfect' market which was characterised by six conditions:

(i) the ratio of exchange 'between any two persons should be known to all the others';

(ii) transactions were motivated purely by self-interest and the maximisation of utility;

(iii) 'perfectly free competition' prevailed so that 'anyone will exchange with anyone else';

(iv) there were no conspiracies for withholding supplies to increase prices;

(v) commodities were homogeneous;

(vi) there was a single price (or ratio of exchange) 'at any moment' (Jevons 1970:133-4, $136-7)^{2}$.

The uniform price was 'a general law of the utmost importance in economics', which, in the second edition, was labelled 'the law of indifference...in the same open market, at any moment, there cannot be two prices for the same kind of article' (Jevons 1970:13 7). ${ }^{3}$ The archetypal market used to illustrate the argument was that for wholesale commodities, such as cotton and coal, or financial instruments, such as stocks (ibid.: 132). In those markets, Jevons asserted, brokers established the prevailing price: 'The theoretical conception of a perfect market is more or less completely carried out in practice. It is the work of brokers in any extensive market to organise exchange, so that every purchase shall be made with the most thorough acquaintance with the conditions of the trade... It is only thus that a definite market price can be ascertained at every moment, and varied according to the frequent news capable of affecting buyers and sellers' (ibid.: 133, 134). 
This meant that constantly changing prices were consistent with the law of indifference: 'Though the price of the same commodity must be uniform at any one moment, it may vary from moment to moment, and must be conceived as in a state of continual change' (ibid.: 137). The key analytical role attributed to brokers was further illustrated when Jevons, in effect, defined a market in terms of the law:

By a market I shall mean two or more persons dealing in two or more commodities, whose stocks of those commodities and intentions of exchanging are known to all... It is only so far as this community of knowledge extends that the market extends. Any persons who are not acquainted at the moment with the prevailing ratio of exchange, or whose stocks are not available for want of communication, must not be considered part of the market.

(Ibid.: 133)

It was a peculiar argument. With no trading within a spread of buy and sell offers by transactors, the maximisation assumption entailed that all trades took place at equilibrium. Yet there was no explanation for how brokers would establish a uniform price and certainly not at every moment of trading (Fusfeld 1990). The figure of brokers thus acted as a deus ex machina, analogous to that of the auctioneer in later post-classical theory. It should be noted, however, that Jevons' notion of perfect competition was quite different from that of the later theory in two important respects. The first was that he did not depict all transactors as price-takers in TPE. As was explained in TPE, with continuous trading in a market period, any set of trades would change the price: 'In theory, this effect of exchange upon the ratio of exchange must be conceived to exist in some degree, however small may be the purchases concerned' (Jevons 1970:138). The second difference with the later theory concerned the knowledge of transactors. Jevons defined a market as 'theoretically perfect only when all traders have perfect knowledge of the conditions of supply and demand and the consequent ratio of exchange' (ibid.: 134). This perfect knowledge, however, entailed that participants had that information at any moment and not that they had complete knowledge of future events, even on the same day. Jevons made this clear in a note added to the second edition when, discussing the law of indifference and how the theory was 'verified in practice', he referred to

New York stock markets, where it is the practice to sell stocks by auction in successive lots, without disclosing the total amount to be put up. When the amount offered begins to exceed what was expected, then each successive lot brings a less price, and those who bought the earlier lots suffer. But if the amount offered is small, the early buyers have the advantage. Such an auction sale only exhibits in miniature what is constantly going on in the markets generally on a large scale.

(Ibid.: 137n.)

Jevons' statement that perfect markets were to be found more or less completely carried out in practice, indicates that he acknowledged there were some exceptions. Four can be identified in TPE, two of which concerned traders in specialised commodity or financial 
markets. The first concerned indivisible and heterogeneous commodities for which there were a small number of transactors (White 2001). The second was that speculators could manipulate market outcomes through, for example, the use of corners. Changes in prices would then bear 'no proper relation to the existing supplies', producing 'unnatural ratios of exchange'. The solution was state intervention in the form, for example, of regulations requiring information to be posted regarding the amount of stocks to be traded on a particular day (Jevons 1970:133-4). The third exception concerned the law of indifference when Jevons referred to "[S] uch differences as may practically occur arise from extraneous circumstances such as the defective credit of purchasers, their imperfect knowledge of the markets, and so on' (ibid.: 137). This was, however, the only acknowledgement Jevons made in TPE regarding such divergences. While John Stuart Mill and J.E.Cairnes regarded price dispersion as the rule in retail (but not wholesale) markets, ${ }^{4}$ Jevons treated dispersion as an exception which required little attention.

The fourth exception to the conditions required by the theory concerned the behaviour of final consumers. At a number of points in TPE, Jevons discussed whether all 'individuals' would behave as required by the theory in adjusting their purchases in a continuous (marginalist) maximising manner as prices changed (Jevons 1970:86, 108-9, 119, 135-6). He acknowledged that some ('many' at one point-ibid.: 86-although he usually referred to one or a few individuals) would not do so: 'We cannot usually observe any precise and continuous variation in the wants and deeds of an individual, because the actions of extraneous motives, or what would seem to be caprice, overwhelms minute tendencies'. However, because he assumed that behaviour was normally distributed (according to the law of error) purchasers would, on average, behave in the requisite manner. So, for example, if the price of a commodity increased,

a single individual...probably continues his ordinary consumption until accident directs his attention to a rise in price, and he then, perhaps, discontinues the use of the article altogether for a time. But the aggregate or what is the same, the average consumption of a large community will be found to vary continuously or nearly so. The most minute tendencies make themselves apparent in a wide average. Thus, our laws of economics will be theoretically true in the case of individuals, and practically true in the case of large aggregates; but the general principles will be the same, whatever the extent of the trading body considered.

(Ibid.: 135)

Indeed, the way in which particular individuals behaved was virtually irrelevant: 'the movement of trade and industry depends on averages and aggregates, not on the whims of individuals' (ibid.: 136). Due to the law of error, 'accidental and disturbing causes will operate, in the long run, as often in one direction as the other, so as to neutralise each other' (ibid.: 86). The use of that assumption entailed that consumers' behaviour was independent, which marked a significant break with the interdependent behaviour assumed by earlier economists such as Adam Smith and Nassau Senior.

The effect of Jevons' discussion of possible exceptions to perfect markets was to reinforce his claim that such markets could be taken as the rule. The law of indifference was crucial because it governed the possibility of equilibrium trades and hence the 
material welfare maximisation results that, Jevons claimed, followed from 'perfect freedom of exchange':

so far as is consistent with the inequality of wealth in every community, all commodities are distributed by exchange so as to produce the maximum of benefit... No one is ever required to give what he more desires for what he less desires, so that perfect freedom of exchange must be to the advantage of all.

(Jevons 1970:171; also 173)

It was, however, in explaining the attainment of an equilibrium position that Jevons realised he faced the cardinal difficulty with the whole theory.

\section{The Equilibrium Problem}

The analysis of market period trading in chapter IV of TPE was designed to show that the facts of the laws of supply and demand could be explained by the marginal utility theory. For two representative transactors trading commodities $x$ and $y$, the basic equilibrium exchange condition was $ø x / \psi y=d y / d x=y / x$, where: $\varnothing x / \psi y$ is the ratio of the final degree of utility for the two commodities; $d y / d x$ is the marginal exchange ratio; $y / x$ is the market exchange ratio. In Chapter $\mathrm{V}$ of TPE, Jevons added a price ratio for the two commodities to the equilibrium condition, so that $y / x=p_{1} / p_{2}$-where $p_{1}, P_{2}$ are the Prices of $x, y$ measured in gold (Jevons 1970:141-4, 204). As has often been noted, this is basically the same condition for consumer equilibrium that can be found in today's microeconomics textbooks. In Chapter IV, Jevons argued that, with the market exchange ratio given at any moment by the law of indifference, the theory depicted an equilibrium between supply and demand:

We may regard $x$ as the quantity demanded on the one side and supplied on the other; similarly, $y$ is the quantity supplied on the one side and demanded on the other. Now, when we hold the two equations to be simultaneously true, we assume that the $x$ and $y$ of one equation equal those of the other. The laws of supply and demand are thus a result of what seems to me the true theory of value or exchange.

(Jevons 1970:144)

In the section of the chapter immediately preceding that analysis, Jevons had discussed how the equilibrium maximisation point could be reached, using a utility diagram for a representative transactor (Jevons 1970:140).

The transactor held a stock of commodity $b$ (the supply), exchanging units of it for those of commodity $a$ (the demand). The final degree of utility function for $a(p r)$, was 'measured' from left to right. The corresponding function for $b\left(p^{\prime} r^{\prime}\right)$, reversed and superimposed on that for a, was measured from right to left. Acquisition of the unit $a a^{\prime}$ would produce a net utility gain $\left(a^{\prime} d>a c\right)$ and exchange would continue until the equilibrium point $q$. Transactions would not persistently take place to the right of $q$ as 
there would be a net utility loss $\left(e b^{\prime}<f b\right)$. In representing disequilibrium transactions, the diagram showed how utility was maximised at equilibrium: 'Exchange will thus go on until each party has obtained all the benefit that is possible, and loss of utility would result if more were exchanged. Both parties, then, rest in satisfaction and equilibrium, and the degrees of utility have come to their level, as it were.' It is important for the

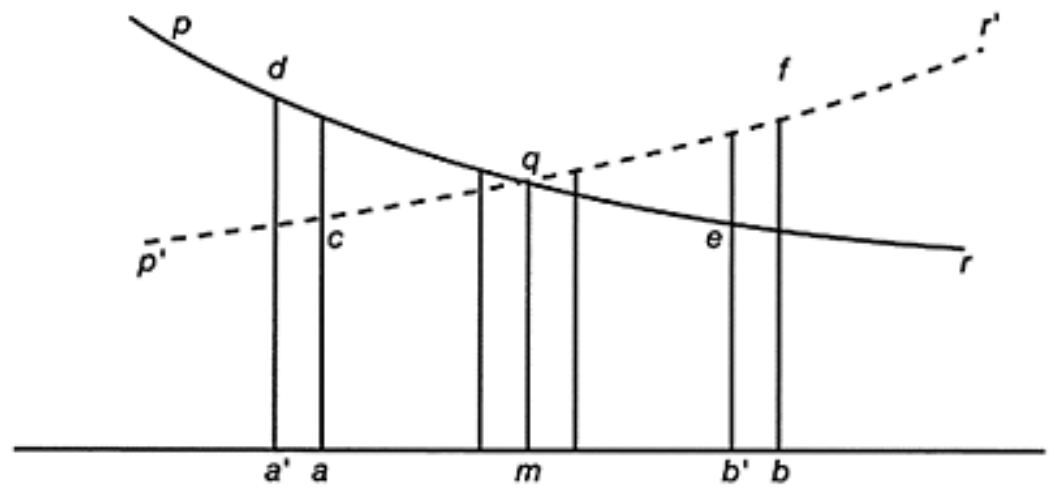

\section{Figure 6.1 Equilibrium for Market Exchange}

Source: Jevons 1970: p. 140

analysis below to note that, although Jevons acknowledged that the theory dealt with 'infinitely small quantities' of commodities, his discussion also referred to finite quantities, such as ten pounds of corn (Jevons 1970:140).

The depiction of adjustment to equilibrium with a given exchange ratio appears, at first sight, to be consistent with references, elsewhere in the same chapter, to 'the conditions of a great market where vast quantities of some stock are available, so that any one small trader will not appreciably affect the ratio of exchange'. In such cases, the equilibrium condition 'accurately represents the position of an individual consumer with regard to the aggregate trade of a large community, since he must buy at the current prices, which he cannot in any appreciable degree affect' (ibid.: 150-1). The argument was, however, misleading. As was noted above, Jevons made clear that any set of trades, represented by the behaviour of a representative transactor, would change the ratio and, therefore, 'the conditions of utility' (ibid.: 137). This resulted in Jevons' difficulty: adjustment towards an equilibrium in a series of disequilibrium transactions would induce a parameter shift (the price) and hence a new equilibrium position. Any convergence to an equilibrium through disequilibrium transactions would be akin to chasing a will o' the wisp. Nor was the problem restricted to transactions by a group of traders. As was noted above, Jevons argued that, in theory, any trade would change the ratio. Even when he referred to an individual consumer whose transactions could not appreciably affect the price (see above), he acknowledged in the same paragraph that 'the smallest purchasers do affect the market in some degree' (ibid.: 151).

One possible solution to the problem can be found in Jevons' discussion, elsewhere, of the properties of the laws of supply and demand. Although he insisted that the marginalist 
theory provided the analytical basis for the laws, he did not explain their meaning in TPE. An account can be found, however, in the record of his mid-1870s lectures at Owens College (Black 1973-81:vi, 81-2), the Political Economy primer (Jevons 1878:99-100) and the unfinished Principles of Economics (Jevons 1905: Ch. 9). The laws were summarised in the primer as follows: 'a rise of price tends to produce a greater supply and a less demand; a fall of price tends to produce a less supply and a greater demand. Conversely, an increase of supply or a decrease of demand tends to lower price, and a decrease of supply or an increase of demand to raise price' (Jevons 1878:99). For Jevons, the laws were empirical phenomena or facts that were the result of a complex of causal factors in market trading. Because of that complexity, there was little to be gained analytically in drawing supply and demand functions as the facts were known (White 1989; 2003). Jevons argued, however, that it was possible, in principle, to explain the primary factors driving transactors' behaviour by the marginal utility theory, assuming that other factors could be put to one side. ${ }^{5}$ In terms of Figure 6.1, changes in demand and supply with the respective price and quantity outcomes could be represented and explained by shifts in the utility functions. The difficulty was, however, to explain how an equilibrium could be attained.

In the Principles, Jevons argued that the laws 'are in no sense ultimate, natural, or invariable laws, but only expressions of the general course of phenomena exhibited in commerce when there are many buyers and sellers'. The market characteristics necessary for the laws were the same as those for perfect competition in TPE (Jevons 1905:56, 57). Consistent with TPE, the summary of the laws indicated that any change in demand or supply would change the price, producing an equilibrium: 'The whole problem of value is supposed to be summed up in this equation, that the value will be adjusted to the point at which the quantity demanded is equal to the quantity offered' (Black 1973-81:vi, 81-2; see also Jevons 1878:99-100). The record of the Owens College lectures acknowledged that it was difficult to explain how the equation of demand and supply occurred, 'except the higgling of the market achieves it' (Black 1973-81:vi, 82). While the primer also referred to higgling as settling the price at a 'Butter Cross' in a 'market town', Jevons claimed there that all transactions took place at equilibrium:

The [market] price must be such that the quantity demanded at any time is equal to the quantity supplied.

The market price will be such that the demand at that price will equal the supply at that price. The quantity of butter or any other commodity that is sold must equal what is bought, because it is not sold until it is bought; but the price will settle itself accordingly.

(Jevons 1878:100)

This was a peculiar claim-all transactions took place at equilibrium because, by definition, what was bought must equal what was sold. Here, Jevons was repeating an argument made by John Stuart Mill in 1869 when he rejected part of William Thornton's critique of the role of the laws of supply and demand in explaining price formation. In his On Labour (1869), Thornton had argued that, on a market day, most trading took place at disequilibrium positions. Disequilibrium was indicated by unsold inventories that provided a signal for sellers to adjust prices in a series of steps. Reviewing Thornton's 
text, Mill claimed that inventories should not be regarded as part of the market supply, an argument which, in effect, made demand and supply equal for all trades. As J.E. Cairnes explained to Mill, that explanation for equilibrium was a tautology (a 'truism'), a point Mill conceded (White 1994a:161-2).

Jevons also appeared to refer to Mill's tautology in $T P E$ when claiming that 'it is not difficult to find practical illustrations which will show how [the marginalist theory of exchange] is verified in the actual working of a great market. The ordinary laws of supply and demand, when properly stated, are the practical manifestation of the theory' (Jevons 1970:148). Referring to Thornton's critique and to Mill's review, Jevons claimed (quite misleadingly) that he not only accepted Thornton's 'View' but would 'carry it further':

The [marginalist] theory consists in carrying out this view to the point of asserting that it is only comparatively insignificant quantities of supply and demand which are at any moment operative on the ratio of exchange. This is practically verified by what takes place in any very large marketsay that of the Consolidated Three Per Cent Annuities... Now the theory [asserts]...that the market price of the funds is affected from hour to hour not by the enormous amounts which might be bought or sold at extreme prices, but by the comparatively insignificant amounts which are being bought or sold at the existing prices. A change of price is always occasioned by the overbalancing of the inclinations of those who will or will not sell just about the point at which prices stand. When Consols are at $93^{1 / 2}$, and business is in a tranquil state, it matters not how many buyers there are at 93 , or sellers at 94 . They are really off the market.

(Jevons 1970:149-50)

In the context of the references to Thornton and Mill, this statement had the effect of claiming that stocks could be ignored when explaining an equilibrium between demand and supply. If that was consistent with the definition of equilibrium in his primer, Jevons had also confirmed that comparatively insignificant transactions would change the price. However, he then gave the impression that the theory could deal with disequilibrium transactions:

When the price of funds is very steady and the market quiescent, it means that the stocks are distributed among holders in such a way that the exchange of more or less at the prevailing price is a matter of indifference.

In practice, no market ever long fulfils the theoretical conditions of equilibrium, because, from the various accidents of life and business, there are sure to be people every day compelled to sell, or having sudden inducements to buy. There is nearly always, again, the influence of prospective supply or demand, depending on the political intelligence of the moment. Speculation complicates the action of the laws of supply and demand in a high degree, but does not in the least degree arrest their 
action or alter their nature. We shall never have a science of economics unless we learn to discern the operation of law even among the most perplexing complications and apparent interruptions.

(Jevons 1970:150)

It might be suggested that the ambiguous statements regarding price-taking and the possibility of accounting for disequilibrium transactions simply reflected confusion on Jevons' part. There are, however, two reasons for concluding that he was fully aware of the equilibrium attainment problem. The first is that, when he referred to the cardinal difficulty with the whole theory in the Preface to the first edition, Jevons wrote that he had alluded to the problem in the section of Chapter IV on the 'Ratio of Exchange' (Jevons 1871:91-5), which was retitled 'The Law of Indifference' in the second edition (Jevons 1970:136-9). In that section, having discussed the law of indifference and how prices 'must be conceived in a state of continual change', Jevons added: 'Theoretically speaking, it would not usually be possible to buy two portions of the same commodity successively at the same ratio of exchange, because no sooner would the first portion have been bought than the conditions of utility would have been altered'. He reiterated the point in the same paragraph: 'In theory this effect of exchange upon the ratio of exchange must be conceived to exist in some degree, however small may be the purchases made' (ibid.: 137, 138). This seems to be a reference to the attainment problem. It remained an allusion, however, because Jevons did not make clear to the reader that the point entailed that he could not explain how an equilibrium was attained.

The second reason for concluding that Jevons was aware of the attainment problem was the way he proceeded, in the same section, to defend his basic equilibrium exchange condition against the criticism that it was unsatisfactory because it was not possible to derive a total integral of utility from it (Jevons 1871:93-5; 1970:138-9). Following a restatement of that critique by a reviewer of the first edition, Jevons added a further defence in a new section in the second edition (Jevons 1970:144-7). That discussion was clear in that the problem (the absence of integration) was identified and a defence provided. It does not appear, therefore, that Jevons was referring to the integration criticism when he wrote of alluding to the central difficulty in the 1871 Preface.

The integration criticism was quite distinct from the attainment problem in that the latter was pertinent with or without integration. Jevons' defence of the integration criticism is important to consider here, however, because of its implications for his difficulty. His defence turned on using metaphors from mechanics and natural philosophy. That is not surprising, as the discussion in the second edition made clear how the basic equilibrium condition was derived from that for a lever in static equilibrium. The significance of the metaphors was not simply that they provided a defence against the integration criticism but, more importantly, that they also provided a rationale for treating all trades as equilibrium transactions in a market period. It will be convenient to first discuss Jevons' comments in the first edition of TPE. The following section will consider the further defence added to the second edition. 


\section{Statics and Dynamics}

When Jevons referred to 'the cardinal difficulty with the whole theory' in the Preface to the first edition of TPE, he added that, '[S]o able a mathematician as my friend Professor Barker, of Owens College, has had the kindness to examine some of the proof-sheets carefully; but he is not, therefore, to be held responsible for the correctness of any part of the work' (Jevons 1970:45). The reason for the qualification was that Barker, professor of mathematics at the College, objected to Jevons' basic conditions for equilibrium in exchange. As Jevons subsequently noted in a letter to George Darwin, Barker insisted that the conditions 'are (or at any rate ought to be) differential equations demanding integration, whereas I hold that, though deduced by the use of differentials, they are simply algebraic equations. The problem, as I regard it, is a [statical] one' (Black 197381:iv, 87). Harriet, Jevons' wife, later recalled a sharp disagreement on the matter: 'Mr. Jevons showed him several of the proofs and I remember quite well the argument they had over one page, but Mr. Jevons said he could not put it otherwise than he had, nor could he see that it was wrong' (Konekamp 1982:398). ${ }^{6}$

In the first edition, Jevons' discussion of his 'ratio of exchange' as a 'differential coefficient' turned on the difference between statics and dynamics used in mechanics as he outlined his defence in three steps. The first was to acknowledge that his approach was limited in that the mathematics could not depict the dynamics or motion of the system:

The real condition of industry is one of perpetual motion and change. Commodities are being continually manufactured and exchanged and consumed. If we wished to have a complete solution of the problem in all its natural complexity, we should have to treat it as a problem of motiona problem of dynamics.

(Jevons 1970:138)

This was confusing. Chapter IV examined a market period with a parametric commodity stock at the beginning of the period. The reference here to production, exchange and consumption referred to an analysis of a series of market periods tending toward, or oscillating around, a long-period equilibrium position as in Chapter V (White 2003). The 'complete solution' would presumably entail a mathematical analysis of the adjustment toward the long-period equilibrium. Jevons noted, however, that such an analysis was not 'within our power' (Jevons 1970:138).

The second step was to acknowledge that the analysis could, therefore, deal only with statics:

It is only as a purely statical problem that I can venture to treat the action of exchange. Holders of commodities will be regarded not as continuously passing on these commodities in streams of trade, but as possessing certain fixed amounts which they exchange until they come to equilibrium.

(Ibid.: 138) 
With the reference to transactors possessing certain fixed amounts, this step switched the argument to that for a market period. The static analysis of exchange included the process of adjustment to equilibrium. It appeared, therefore, to allow for the possibility of disequilibrium transactions. The final step, however, indicated that an adjustment process was precluded:

It is much more easy to determine the point at which a pendulum will come to rest than to calculate the velocity at which it will move when displaced from that point of rest. Just so, it is a far more easy task to lay down the conditions under which trade is completed and interchange ceases, than to attempt to ascertain at what rate trade will go on when equilibrium is not attained.

(Ibid.)

It was on this basis that Jevons justified his use of a differential coefficient equilibrium condition. If the analysis depicted dynamics, he would require 'differential equations, which would have to be integrated'. That was not necessary, however, 'in the statical view of the question' (ibid.). Given the law of indifference, 'the last increments in an act of exchange must be exchanged in the same ratio as the whole quantities exchanged'. With infinitely small units of a commodity, all transactions would take place at a (momentary) exchange ratio (ibid.: 139).

It was a confusing discussion. Shifting, without clarification, from a long period to a market period, the upshot of the discussion was that the mathematical analysis could not depict transactors 'possessing certain fixed amounts of commodities which they exchange until they come to equilibrium', as Jevons had claimed in the second step of his argument. Instead, the analysis was consistent only with the equilibrium condition where 'trade is completed and interchange ceases'. The reader, however, was given the impression that the analysis could deal with disequilibrium trades, because the next section of the chapter contained Jevons' diagram of crossed and superimposed utility functions for a single transactor with the discussion of how exchange would continue until equilibrium was attained (see above). That was followed with a section on 'The Symbolic Statement of the Theory' (Jevons 1970:141-4) where, criticising Mill's analysis of supply and demand, Jevons claimed that 'our theory is perfectly consistent with the laws of supply and demand' (ibid.: 143). Exchange was depicted in terms of an equilibrium condition for two transactors. At one point, however, Jevons acknowledged that each transactor 'must...derive equal utility from the final increments, otherwise it will be for his interest to exchange either more or less, and he will disturb the conditions of exchange' (ibid.: 142). Once again, he had alluded to the attainment problem but failed to explain its significance for his claim about the analytical compatibility between the utility theory and the laws of supply and demand. 


\section{Virtual Realities}

In the Preface to the first edition of TPE, Jevons noted that his

theory of economy...presents a close analogy to the science of statical mechanics, and the laws of exchange are found to resemble the laws of equilibrium of a lever as determined by the principle of virtual velocities. The nature of wealth and value is explained by the consideration of indefinitely small amounts of pleasure and pain, just as the theory of statics is made to rest upon the equation of indefinitely small amounts of energy.

(Jevons 1970:44)

In the second edition, when defending the basic equilibrium exchange condition against the integration criticism, he explained the analogy in some detail (ibid.: 144-7), referring to the following diagram from one of the 'best modern

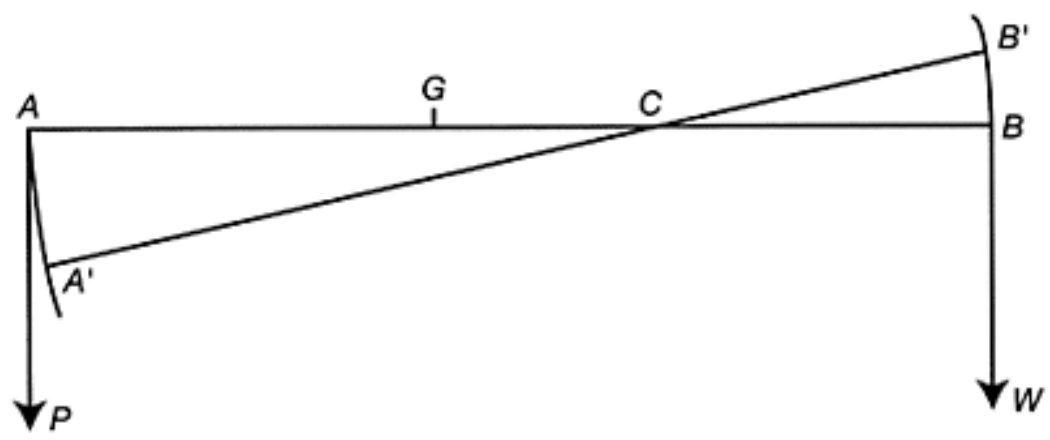

Figure 6.2 Equilibrium for a Lever

Source: Magnus 1875: p. 128

elementary' treatments of mechanics, Philip Magnus' Lessons in Elementary Mechanics (ibid.: 144; Magnus 1875:128).

$A B$ is a lever turning, without friction, about the fulcrum C. $P$ is a force applied at $A$, while $W$ is the force exerted (or resistance overcome) at $B$. If the lever turns through the arc $\mathrm{ACA}^{\prime}$, the work done by $P=P . A A^{\prime}$ and the work done by $W=W . B B^{\prime}$. For equilibrium, the work is equivalent, such that $P . A C=W \cdot B C$, or $W / P=A C / B C$. Hence, $W / P=A A^{\prime} / B B^{\prime}=A C / B C$. The ratio of the point masses $(W / P)$ is inversely proportional to both the ratio of the arcs of displacement $\left(A A^{\prime} / B B^{\prime}\right)$ and the ratio of point distances from the fulcrum $(A C / B C)$. With an infinitesimally small displacement, the equilibrium condition was 'exactly similar in form to...[that for] the theory of value' (Jevons 1970:145), so that

$W / P=A A^{\prime} / B B^{\prime}=A C / B C$ 
$\varnothing x / \psi y=d y / d x=y / x$

The final degrees of utility corresponded to the forces, the marginal exchange to the displacement arcs and the exchange ratio to the distance of the point masses from the fulcrum (see Jevons' diagram, Jevons 1970:146).

Jevons' familiarity with the theory of the lever, used as the basic theoretical explanation for a balance, was the result of his training and work as a chemist and, especially, as a gold assayer at the Sydney Mint while in Australia (1854-59). Utilising that experience, at the beginning of 1861 he began work on a number of entries for a Dictionary of Chemistry, the first of which, 'Balance', provided a detailed examination of the practice of using balances in chemistry, coupled with an explanation of the theory of the balance in terms of a lever (Jevons 1863$).^{7}$ The entry opened as follows:

Chemistry being concerned with the relative masses or quantities of the elements which compose all known substances, and the weight or force of gravitation of a body being the only practicable measure of its mass or quantity of matter, the balance, which shows the equality of two weights, and may hence determine the ratio of all commensurable weights, is the chemist's most important instrument.

(Jevons 1863:481)

Jevons had derived his marginalist theory of behaviour in 1860 from the representation of behaviour as a mechanics of balancing gravitational forces in Richard Jennings' Natural Elements of Political Economy (1855; see White 1994b). The quotation above suggests how he was then able to both adapt and extend Jennings' analysis in formulating the theory of exchange with the lever analogy. The discussion of the balance in TPE was, however, different from that in the chemistry Dictionary in two important respects. The first was Jevons' reference to 'indefinitely small amounts of pleasure and pain' as akin to 'indefinitely small amounts of energy' (Jevons 1970:44). This was in line with Magnus' discussion (Magnus 1875:125) but had only became part of Jevons' language from the mid-1860s (White 2004). The second and more important difference here was the use of the principle of virtual velocities. Jevons argued that, although it was 'disguise[d]' in 'elementary works', the principle was 'the real foundation of the science' of mechanics. He summarised it as follows:

if any number of forces be in equilibrium at one or more points of a rigid body, and if this body receive an infinitely small displacement, the algebraic sum of the products of each force into its displacement is equal to zero. In the case of a lever of the first order, this amounts to saying that one force multiplied into its displacement will be neutralized by the other force multiplied into its negative displacement.

(Jevons 1970:145)

Without further explanation, it might seem that this was much the same argument as in the chemistry Dictionary, where the condition of static equilibrium for a balance was explained as 'the sum of the moments of forces on one side [is] equal to that on the other' (Jevons 1863:487). The only difference might appear to be that the argument in TPE 
depended on infinitesimally small changes, whereas the Dictionary entry (and, as Jevons noted in TPE, Magnus' account) dealt with finite changes. The principle of virtual velocities, however, was a general balancing principle that was supposed to apply to all mechanical systems.

Jevons' initial formulation of the balance metaphor drew on two principal theoretical sources. The first was the treatment of the calculus by Augustus De Morgan, whose classes Jevons had attended at University College, London, when he returned from Australia in 1859 (Black 1973-81:ii, 403). ${ }^{8}$ The second was S.D.Poisson's Treatise on Mechanics (1833), an influential exposition of the French tradition of variational mechanics which, in referring to the work of J.L.d'Alembert and J.L.Lagrange, stressed the principle of virtual velocities (Poisson 1842 [1833], vol I:58-71; Grattan-Guinness 1990b:318, 325-7). Jevons referred to Poisson's text in the chemistry Dictionary and in TPE when discussing the lever (Jevons 1863:489; 1970:147). He could also have read a discussion of virtual velocities in the chapter 'Application to Mechanics' in De Morgan's Differential and Integral Calculus. Like Poisson, De Morgan discussed the principle by referring to d'Alembert, arguing that it should be treated as an 'axiomatic truth' (De Morgan 1842b:501; see also De Morgan 1842a:478).

The significance of the principle of virtual velocities in the variational mechanics tradition was the (problematic) claim that, with d'Alembert's action-reaction principle, all dynamic problems could be analysed in terms of statics and hence in terms of equilibrium. ${ }^{9}$ As Poisson noted, the principle 'implies...that there is constantly an equilibrium between the given forces' (Poisson 1842 [1833], vol. II:3). De Morgan made the same point when referring to 'D'Alembert's principle': 'every problem of motion, of which the circumstances are known, may be reduced...to one of equilibrium: that is to say, the properties of the actual variations which do take place may be investigated by means of the simple changes of place, without reference to time, which might be made in a system of rest' (De Morgan 1842b:510). Jevons used the principle to argue that, because the lever displacements depicted 'imaginary infinitesimal quantities', there was no requirement to integrate his basic equilibrium condition-'there is no effect to be summed up' (Jevons 1970:147). The unstated import of the reference to the principle, however, was that it provided a rationale for treating all transactions as equilibrium outcomes in a market period. This was consistent with the way he referred to Mill's equilibrium tautology in the same chapter. In both cases, Jevons failed to explain the significance of his argument where marginal trades in the basic equilibrium condition $(d y / d x)$ were virtual transactions that only existed in an imaginary form.

In the discussion of statics and dynamics in the first edition of TPE and the explanation of the lever added in the second, Jevons' defence of his basic equilibrium exchange condition was dominated by the question of whether it required integration. The significance of the principle of virtual velocities was presented only in that context. The integration question was, however, something of a side-show. The unstated role of the principle was that it provided a means to sidestep his cardinal difficulty in that it provided a justification for treating all transactions as equilibrium outcomes. It was symptomatic of Jevons' references to the attainment problem, however, that the full implications of his reference to virtual velocities were not clearly explained. 


\section{Thornton's Revenge}

Jevons' references to his difficulty read like an elaborate game with the reader of TPE. On the one hand, he remarked that he had alluded to the problem and presented a series of clues to identify it. On the other hand, he did not clearly identify the problem and gave the impression that disequilibrium trades posed no difficulty for his analysis. A possible explanation for that rhetorical strategy is that, convinced he had found the truth, Jevons simply refused to clearly discuss any substantive difficulties he had identified with the theory. While this point is relevant, it would, if taken alone, reduce the explanation to a particular Jevons character trait. Consideration of the context in which TPE was written, however, provides a broader perspective to explain Jevons' peculiar treatment of the attainment problem.

Although it is not clear when Jevons recognised the problem, the available textual evidence suggests that it occurred between 1862, when the 'Brief Account' of his theory was written, and late 1870, when he began working on the text of TPE. In the Brief Account, he referred to the properties of his equilibrium exchange condition with 'infinitely small quantities of commodities':

The ratio of the increments of the commodities... would be indeterminate but for the existence of a law that all quantities of the same commodity, being uniform in kind, must be exchanged at the same rate. The last increments, then, must be exchanged, in the ratio of the whole quantities exchanged. To explain in ordinary words how the adjustment takes place under this condition is almost impossible.

(Jevons 1866 [1862]:284)

While that statement might be taken as an indicator of the attainment problem, it seems more likely that it simply referred to the difficulty in explaining the adjustment without the diagram used in TPE (Figure 6.1 above). That reading is supported by Jevons' preceding comment that '[W]hether the exchange will take place or not can only be ascertained by estimating the utility of the objects on either side, which is done by integrating the appropriate functions as limits. A balance of utility on both sides will lead to an exchange' (ibid.: 284). A subsequent remark also indicates that, in 1862, Jevons saw no difficulty in referring to integration. ${ }^{10}$ It should also be noted that a number of arguments in TPE required a utility integral. The discussion of the gains from international trade in Chapter IV, for example, was conducted in terms of the total utility of a nation (Jevons 1970:172-4). ${ }^{11}$ The diagrams used to illustrate the argument appear to date from the early 1860 s. $^{12}$ The adjustment-to-equilibrium diagram, which probably dates from the same period (White 1989:486), also requires an integral if finite quantities were referred to, as in TPE. Taken together, these references suggest that, when he initially formulated the theory, Jevons saw no difficulty in referring to a total integral of utility.

In TPE, however, Jevons claimed that his approach was built on 'the fearless consideration of infinitely small quantities' (Jevons 1970:78) and that, although 
the mind often hesitates and is perplexed in making a choice of great importance... [the theory] seldom involves the comparison of quantities differing much in amount. The theory turns upon those critical points where pleasures are nearly, if not quite, equal. I never attempt to estimate the whole pleasure gained by purchasing a commodity.

(Ibid.: 84-5)

If that statement reflected Jevons' defence of his basic equilibrium exchange condition and hence the attainment problem, the last sentence was clearly incorrect (see above). While this provided another source of confusion in understanding Jevons' argument, it indicates that he was unable to make all aspects of his previous analysis consistent with the stress on infinitesimals in TPE.

The attainment problem associated with disequilibrium trades had particular relevance in the context in which Jevons came to write TPE. As was noted above, in 1869 William Thornton's On Labour had attacked the relevance of references to the laws of supply and demand for explaining price formation. Focussing on trading during a market day (within a market period), Thornton defined an equilibrium as the trading cease-point that occurred when all commodity stocks were sold or a sellers' reservation price was reached. He argued that, if demand and supply were defined as the prices at which the purchasers and sellers were prepared, respectively, to trade different quantities, references to demand and supply could, in themselves, explain little about how the equilibrium position was reached. The process of price adjustment required an explanation of market coordination that depended on the interdependent behaviour of heterogeneous sellers with different access to credit facilities, experience and, therefore, knowledge. The signal for price adjustment during the day was the existence of unsold stocks, which meant that most trades occurred at disequilibrium ('intermediate') positions (Thornton 1869:43-77; see White 1994a:151-7).

If Thornton had introduced the question of how an equilibrium position was to be explained by coordination in a market, his focus on disequilibrium trading created a substantive difficulty for those who then attempted to restore the laws of supply and demand to the principal explanatory role in a market period. While dismissing Thornton's critique, in the first set of (quantity-function) supply and demand diagrams published in English, the engineer H.C.Fleeming Jenkin was confronted with an equilibrium attainment problem. Although the precise rationale for the shapes of his diagrams was unclear, Jenkin acknowledged that the demand curve for trading on a market day required a given set of expectations as a parameter. Disequilibrium trades would change the expectations and shift the function (Jenkin 1870:153-5). Jenkin then asserted that, with a uniform price set at any moment by market specialists, all trades during the day took place at equilibrium ('at each moment the...law of supply and demand holds good'ibid.: 156).

Jevons subsequently acknowledged that he had written up TPE for publication in part because Jenkin's article made no mention of Jevons' utility theory that had been discussed in the exchange of letters between them in 1868 (Jevons 1911:1vii; Black 1973-81:iii, 166-78). The terms of the debate over Thornton's critique also left their mark on Jevons' discussion of market period trading in Chapter IV of TPE. In part this was evident from a number of references to Thornton (Jevons 1970:148-9, 158-9) and 
the focus on trading within a day during a market period. Less obvious were two effects of Jenkin's analysis. First, the engineer's discussion of indeterminacy in exchange with an indivisible commodity appears to have prompted Jevons' reassessment of his own analysis of that topic (White 2001). Second, in TPE, Jevons adopted Jenkin's tactic of claiming that market specialists (brokers) set a uniform price at any moment. In both cases, the tactic was used to sidestep an attainment problem that followed the attempt to depict or explain the laws of supply and demand in a functional form. The manifestation of Jevons' problem was different from Jenkin's because he did not use supply and demand functions. Nevertheless, it had the same basis in disequilibrium trades shifting a parameter. Jevons' initial failure to identify the problem, his inconsistent arguments in TPE regarding references to total utility and his use of market specialists to set a uniform price at any moment, might suggest that Jevons identified his particular indeterminacy problem after reading Jenkin's article. The inconsistencies noted above in TPE regarding references to total utility could thus reflect the way in which Jevons hurriedly wrote up $T P E$ to establish his own contribution to the debate over the laws of supply and demand.

Whether Jevons recognised his attainment problem before or after reading Jenkin's article, it was a serious liability in the wake of Thornton's critique. In TPE, the most positive comment that Jevons felt able to make about On Labour was the following:

Though Mr Thornton's objections [to explanations of price formation in terms of the laws of supply and demand] are mostly beside the question, his remarks have served to show that the action of the laws of supply and demand was inadequately explained by previous economists. What constitutes the demand and the supply was not carefully enough investigated.

(Jevons 1970:149)

While Jevons attributed a positive, albeit limited, role to On Labour, it was extraordinary to claim that Thornton's analysis was 'mostly beside the question'. Thornton had argued that references to the laws of supply and demand could not provide a substantive explanation for the adjustment to equilibrium in a market period, and that was precisely the problem that Jevons could not solve within his own framework. It was that context that seems to explain, in large part, his rhetorical strategy in TPE of alluding to, but refusing to explain, the cardinal difficulty of the whole theory.

\section{Conclusions}

Although the problem of the attainment of equilibrium has continued to dog postclassical theory (Fisher 1987), ${ }^{13}$ the secondary literature on TPE has devoted little attention to identifying Jevons' difficulty and hence to explaining why he only alluded to, rather than clearly explained, the problem. In part, this is because the problem was simply ignored. Knut Wicksell, for example, while using Jevons' crossed and superimposed utility diagrams to represent the trans-actions of a representative actor, simply assumed that 'on the market one price or a proportion of exchange between every two 
commodities establishes itself within a short time for each commodity in which afterwards the bulk of transactions are done' (Wicksell 1954 [1893]:58-9, 70-1).

A second strand in the literature read Jevons' distinction between statics and dynamics to make it consistent with later, quite different, arguments. This approach first appeared in the exchange between Francis Y.Edgeworth and Ladislaus von Bortkiewicz regarding the validity of Walras' tatonnement explanation for equilibrium. Noting Jevons' use of virtual velocities, Edgeworth insisted that the account in TPE was restricted to a 'static' depiction of an equilibrium position and that Jevons had used the term 'dynamics' to refer to the adjustment process by which an equilibrium was attained (Edgeworth 1889:435; 1891:13-14). Bortkiewicz, writing under Walras' 'close supervision' (Bridel and Huck 2002:527), noted that Jevons had used the term statics when referring to transactors exchanging 'until they come to equilibrium'. This was, he argued, the same process that had now been explained by Walras' tatonnement (Bortkiewicz 1890:85-6). Edgeworth, however, simply refused to discuss the quotation to which Bortkiewicz had drawn attention. While Bortkiewicz and Walras were strictly correct, where Edgeworth was not, in noting how Jevons had used the term statics, the acrimonious exchange failed to explain Jevons' argument. Further confusion followed nearly a century later in an account which, in replicating Edgeworth's reading of the meaning of statics and dynamics in TPE and referring to Jevons' defence of differential coefficients, suggested that " $[\mathrm{b}]$ ehind this "statical view of the question" there must be a dynamic process of trading. What Jevons had in mind is a piecemeal exchange process' of recontracting and arbitrage (Negishi 1982:222, 226; see also Creedy 1986:44-5; Dome 1994:95-7). TPE's exchange theory is then represented by an Edgeworth-Bowley box where recontracting explains the "law of indifference ...that plays the role of the equilibrium condition for Jevons... Demand equals supply trivially, since the quantity of a commodity given by person A is equal to the quantity received by another person B' (Negishi 1994:xx). Putting to one side that Jevons did not refer to recontracting, which is inconsistent with his discussion of market-day trading, ${ }^{14}$ this misunderstands his distinction between statics and dynamics. In TPE, dynamics referred to the relation between a long period and a series of market periods. Statics included an explanation of an adjustment to equilibrium (although Jevons was unable to do so). Any attempt to represent Jevons' analysis in terms of an Edgeworth-Bowley box (see also Creedy 1992:128-39) thus erases his particular distinction between statics and dynamics as well as his depiction of equilibrium prevailing at any moment in a market period.

The importance of paying close attention to Jevons' language is not simply to locate the reference points for, and hence the meaning of, particular categories. It is also essential for unravelling the ways in which he attempted to deal with his cardinal difficulty. Although Jevons explicitly used the tautological definition of equilibrium in his primer (was it a tale for children?), the use of momentary equilibria in TPE seems to have been an attempt to evade the attainment problem, rather than a belief that disequilibrium transactions were irrelevant in 'actual' markets. In noting Jevons' references to actual markets, a third strand of commentary has suggested he drew a clear (and apparently unproblematic) distinction between the theoretical analysis of equilibrium and a real world of disequilibrium trading (Ekelund and Thommesen 1989:583-4; Schabas 1990:90; Peart 1998). Those accounts do not, however, satisfactorily explain why Jevons insisted that the theoretical conception of a perfect 
market is more or less completely carried out in practice. Nor do they clarify the analytical roles of brokers and the principle of virtual velocities in his analysis. The problem here, at least in part, seems to be an implicit assumption when reading TPE that Jevons provided a transparent story of market trading, devoid of rhetorical guile. To this extent, Jevons' strategy of only alluding to his equilibrium attainment problem, so as to obscure its presence and significance, was successful.

\section{Notes}

* While the usual caveat on responsibility applies, I thank Sam Bostaph, Robert Dixon, Dietrich Fausten, Ivor Grattan-Guinness, Geoff Harcourt, Prue Kerr, John King, Harro Maas, Bert Mosselmans, Norton Wise and anonymous referees for helpful discussion and suggestions.

1 Chapter IV of TPE is concerned with a market period analysis, where the stock of commodities to be traded is given at the start of each period. Chapter V set out a long-period analysis where, with changes in production levels, market period prices fluctuate around or tend toward, a long-period position, characterised in terms of the cost of production. Jevons did not explain this periodisation (which entails his use of the classical method) in TPE and the analysis is also difficult to understand because of his peculiar definition of cost of production. For discussion, see White (2003; 2004).

2 Jevons' use of the calculus also required that commodities were infinitely divisible. The difficulties this created for his analysis, put to one side here, are considered in White (2001).

3 In the first edition, the law was referred to as the principle of uniformity (Jevons 1871:99). All emphases in material cited here appear in the original texts.

4 See the discussion and references in White (1994a:152).

5 The other factors included speculation, the distribution of income and wealth (demand) and transaction costs (supply).

6 Barker's particular objection (Konekamp 1982:398) was to the statement of the equilibrium condition as $\Delta y / \Delta x=y / x$ or $\Delta y=y / x$. $\Delta x$ (Jevons 1871:99; 1970:141). The same criticism was made in an unsigned review of the first edition published in the Saturday Review (Black 1973-81:vii, 152-7).

7 See also the discussion in Maas (2001: Ch. 7), which considers Jevons' more general use of the balance metaphor in his political economy.

8 Jevons had also attended De Morgan's classes before he left for Australia. See the discussion of Jevons' mathematics with regard to De Morgan in Grattan-Guinness (2002) and Black (1972).

9 Smith and Wise (1989:372-7), Wise (1989:289-91), Grattan-Guinness (1990a: 276-83). See also the discussion of the significance of virtual velocities as a general balancing principle in Poisson 1842 [1833], vol. I:531-65.

10 ' $[\mathrm{T}]$ hough the exchanges be regulated by equations, there cannot be equality in the whole utilities gained and lost, which are found by integrating the functions of utility of the respective commodities before and after exchange' (Jevons 1866[1862]: 285).

11 See also Figure 7 in Jevons (1970:160). That diagram was particularly problematic for Jevons as it referred to an indivisible commodity (see White 2001).

12 This is indicated by some notes in the Jevons Archive (John Rylands University Library of Manchester, JA 6/23/68-70) where the two separate aggregate utility diagrams in TPE appear on a single diagram. The handwriting suggests that the notes were written in the early- to mid-1860s.

13 See also Trevor Swan's reference to "Virtual" displacements' (characterised, with a further Dodgsonian metaphor, as 'a grin without a cat') in post-classical growth theory (Swan 1956:351) and the apposite commentary in Harcourt (1972:34-9).

14 See, for example, Jevons' discussion of the New York Stock Exchange, cited above. 


\title{
7 \\ Henry George on Property Rights in Land and Land Value
}

\author{
Equal and Private, or Common and Public?
}

John Pullen*

\section{Introduction}

Henry George's case for land-value taxation-whether it be a 'single tax' or a major component of a tax package-appears to have been based on four interconnected arguments:

(1) the community-created argument, i.e. the idea that increases in land value are created by the community, not by individual owners or developers, and that therefore, invoking a Lockean or labour theory of property rights, should belong to the community, not to individuals.

(2) the unearned-increment argument, i.e. the idea that, as a corollary of (1), increases in land value are not earned by the individual land owner, and therefore, on Lockean grounds, the individual has no moral right to appropriate them.

(3) the fiscal-expediency argument, i.e. the idea that a land-value tax is relatively easy and cheap to collect (compared with other taxes), is difficult to evade, and generally accords with the ability to pay.

(4) the right-to-land argument, i.e. the idea that land (including everything that is provided by nature) ought to belong equally or in common to all human beings.

This present chapter is concerned with the fourth argument, and discusses in particular George's use of the terms 'equal' and 'common' in the context of the right to own land. It asks whether a distinction between the 'equal and private right to land or land value' and the 'common and public right to land or land value' was intended by George, and whether such a distinction is valid. It is a contention of this chapter that an important theoretical distinction can be made, and should have been made by George, between 'common public ownership of land' and 'equal private ownership of land', and that this theoretical distinction has implications for the practical implementation and political acceptability of his policy of land-value taxation.

By concentrating in this chapter on George's philosophy of natural rights, it is not meant to imply that his natural-rights argument is either a sufficient or even a principal justification for a policy of land-value taxation. Although George gave great emphasis to the natural-rights argument and seems to have regarded it as a sufficient justification, he also at times (as noted below) made use of the utilitarian or consequentialist argument that the taxation of land values would be a major stimulus to economic growth. 
However, the fact that George gave so much emphasis to the concept of natural rights has meant that this aspect of his thought, and in particular, his views on equal versus common rights, has not received much attention from economist critics who regard the question of natural rights as a normative issue that lies outside the province of economics. Alfred Marshall, for example, who was prone to offer the occasional normative judgement of his own, described George as a 'poet' rather than 'a scientific thinker', and appears not to have bothered to make a serious and public attack on George's concept of the natural right to land (see Groenewegen 1995).

\section{Preliminary Definitions}

The expression 'common property' is used in this chapter to describe a situation where an asset is owned by a government or public authority, rather than by private individuals or private companies or non-government institutions. 'Common property' could also be described as 'public property' or 'collective property' or 'state ownership'. 'Examples would be civic buildings, such as a Town Hall; publicly-owned infrastructures, such as dams or bridges; and publicly-owned educational and recreational facilities, such as schools and swimming pools. They are the common property of the people as a whole, collectively owned by the community (however defined), not owned by the people taken individually. The members of the society would not be regarded as having individual property rights in such public assets. They would not have the legal power to claim a particular portion of the Town Hall, or a portion of the value of the Town Hall, as their individual private property. They could not sell or bequeath a portion of it. If they emigrated, they would not expect to be able to sell their portion of the Town Hall to the society.

The expression 'private property' or 'private ownership' is used in this chapter to refer to a situation where something is owned by an individual person or organization. The owner has the right to use and dispose of the property and' to deny that right to others, although this right is not necessarily absolute. It might be restricted by regulations relating to town planning, public health, environmental protection, taxation, etc. ${ }^{2}$

The expression 'equal private property in land or land value' is used to refer to a situation where the land or the land value of a society is distributed equally amongst the members of the society.

The term 'private' does of course have other meanings. For example, the phrase 'private enterprise' refers to a situation characterized by the operation of market forces, without government intervention. The implementation of George's reforms would obviously require a considerable role for government. As a referee of this chapter has noted, the reforms would be contrived, sanctioned and enforced by government. George did not suggest that they would come about through the unaided forces of private enterprise. But the fact that George relied upon strong and radical action by government to implement his reforms does not necessarily mean that his reforms should be classified as socialist, or anti-capitalist, or anti-private-enterprise. The question is too large to be treated adequately within the limits of this present chapter, but it could be said that in a society where private ownership of land value is the norm, it is easy to think of it as a right established independently of government, to overlook the role that governments 
have played in the past, and continue to play, in sanctioning and perpetuating their current property systems.

\section{George's use of 'Equal' and 'Common'}

Throughout George's writings, correspondence and reported speeches, there are abundant references to equal and common rights to land or land value. However, George does not appear to have undertaken a systematic discussion of a possible distinction between common rights and equal rights. The terms seem to have been used either synonymously, or in the sense that one automatically follows the other.

For example, in Progress and Poverty, 1879, he stated that 'equality of rights' would be achieved by 'declaring all land public property, and letting it out to the highest bidders' (George [1879] 1956:403-4). This implies that the act of declaring all land public property, or the realization of the 'common right to land' (George [1879] 1956:407), will in effect mean that the equal rights to land have also been realized.

A similar nexus between common and equal is presented in The Irish Land Question ([1881] 1953a). The term 'common property' occurs frequently, along with expressions having a similar meaning, such as 'belongs to the whole people'. For example,

The land of Ireland...belongs to the whole people who at the time exist upon it (p. 37)

the land of Ireland belongs to the people of Ireland (p. 38)

9)

the land of Ireland... [should] be resumed by the whole people (pp. 38-

the land belongs rightfully to the people (p. 39)

The only true and just solution...is to make all the land the common property of all the people (p. 53)

land is of natural right common property (p. 63)

land is rightfully common property (p. 64).

However, interspersed with these assertions of common rights, there are references to equal rights, for example:

Since, then, all the Irish people have the same equal right to life, it follows that they must all have the same equal right to the land of Ireland (p. 36)

the right of each one of the people of Ireland to an equal share in the land of Ireland is equal and inalienable (p. 37).

Similarly, in a conversation with D.D.Field, published in 1885 , George made use of the concepts of equal right to land and common right to land without indicating that he intended a conceptual difference. For example, he spoke of 'the equal right to land', 'equality of natural opportunities', and 'the equal right of all to the bounty of their Creator' (pp. 13-14); and he argued that the equal right to land is a prerequisite for the realization of the rights proclaimed in the Declaration of Independence: 
the equal right to life, liberty and the pursuit of happiness, does it not necessarily involve the equal right to land, without which neither life, liberty, nor the freedom to pursue happiness is possible?

(Field and George [1885] 1936:14)

But he also stated that the value of land should be 'appropriated to the common benefit' (p. 15), and the following quotation shows that, for George, equal rights to land would be realized when land is made common property - 'the property of the whole people':

by treating all land as the property of the whole people, we would make the whole people the landlords, and the individual users the tenants of all, thus securing to each his equal right.

(Field and George [1885] 1936:15)

This apparently synonymous use of 'equal' and 'common' can also be seen in an address entitled 'Justice the Object-Taxation the Means' delivered in San Francisco on February 4, 1890, just prior to his departure from America for a lecture tour of Australia. He referred, for example, to 'the great truth... that every child born comes into this world having equal rights with all to the use of the earth' (George [1890] 1947:2). He also referred to 'the equal right to that element which is the basis of production; that element which is indispensable to human life; that element which is man's standing place, his storehouse, his reservoir...' (George [1890] 1947:5). But in the same address he stated that the land value of a community should be common property:

We should take for the use of the community the value of land... It belongs to the community because the growth of the community produces it

(George [1890] 1947:15)

In an address, entitled 'Thy Kingdom Come', delivered in Glasgow on April 28, 1899, George again referred to equal rights and common rights. He stated that 'we are all here equally the children of the one Father, equally entitled to share His bounty', and he argued that land-value taxation could secure 'the equal rights of all' to the land, but he also indicated that the revenue from the land-value tax would be used as 'common expenditure', and would be the fund from which the 'common needs' of society would be supplied (George [1889] 1936:10, 12-13). This implies that, in his reform programme, the land-tax revenue would be the property of society as a whole, rather than being distributed equally to all as their private property. It suggests that George intended that equal rights to land value, and common property in land value, were to be conflated, and that equality of rights to land would be fully satisfied when land value became common property and was used for common purposes.

In A Perplexed Philosopher ([1892] 1937), George stated that his reform (viz. taxation of land values) will restore to men their 'equal rights', but in the same paragraph declared that this reform will be 'taking for the use of the state that which rightfully belongs to the state', which implies that land value would thereby become common or public or state property, rather than the equal private property of individuals. The 'abolition of unequal 
rights to land' would be achieved, not by sharing the land value equally amongst all, but by making it the property of the state (George [1892] 1937:208-9).

In A Perplexed Philosopher George made use of the expression 'joint rights', contrasting them with equal rights: 'the rights of men to the use of land are not joint rights: they are equal rights' (George [1892] 1937:33), but his discussion of equal rights and joint rights does not contribute significantly to an understanding of his use of equal and common. He used the analogy of rooms in a club to explain his notion of equal rights:

When men have equal rights to a thing, as for instance to the rooms and appurtenances of a club of which they are members, each has a right to use all or any part of the thing that no other one of them is using.

(George [1892] 1937:33)

However, this analogy does not clarify the meaning of equal rights when applied to land. The right to use a room not occupied by another member of the club is not an 'equal right' in the sense in which George elsewhere used that expression when referring to the equal right to land and/or land value. One member might be occupying the largest or best room while others might have to put up with much inferior rooms. This situation could hardly be described as one of equal rights. His concept of joint rights was explained thus:

where men have joint rights to a thing, as for instance to a sum of money held to their joint credit, then the consent of all the others is required for the use of the thing or of any part of it, by any one of them.

(George [1892] 1937:33)

This notion of joint rights does not coincide with the notion of common public property as discussed in this chapter.

This lack of clarity and precision in George's use of 'equal' and 'common' is also evident in his reply to the encyclical of Pope Leo XIII. For example, in one place he argued that land value should be taken 'for the state' but elsewhere he proclaimed 'equal rights to land', and asserted that the revenue from land-value taxation 'goes equally to each member of society' ([1891] 1953b:8, 13, 16).

The above quotations suggest that further analysis and clarification by George would have been helpful on the question of whether land (and land value) should be held in equal private ownership or in common public ownership, i.e. whether land (and land value) should be a distributive good or a collective good. ${ }^{3}$

\section{George's Argument Against Private Ownership of Land and for Common Ownership of Land and Land Value}

George argued that land should be common or public property, rather than private property. This argument was based on his claim that the 'rightful basis of property' is human labour or exertion. 
that which a man makes or produces is his own, as against all the worldto enjoy or to destroy, to use, to exchange, or to give. No one else can rightfully claim it, and his exclusive right to it involves no wrong to any one else. Thus there is to everything produced by human exertion a clear and indisputable title to exclusive possession and enjoyment which is perfectly consistent with justice, as it descends from the original producer in whom it vested by natural law.

(George [1879] 1956:334)

The principle thus enunciated would for most people be uncontroversial and readily acceptable. However, it becomes controversial when George interprets it as the only justification for private property:

this [i.e. labour] is not only the original source from which all ideas of exclusive ownership arise...but it is necessarily the only source...there is no other natural right from which any other title can be derived... Nature acknowledges no ownership or control in man save as the result of exertion ... She recognizes no claim but that of labor.

(George [1879] 1956:334-5)

The laws of nature are the decrees of the Creator. There is written in them no recognition of any right save that of labor... Hence, as nature gives only to labor, the exertion of labor in production is the only title to exclusive possession... This right of ownership that springs from labor excludes the possibility of any other right of ownership.

(George [1879] 1956:336)

From the premise that labour is the only legitimate basis for private property, George concluded that no one 'can rightfully claim exclusive ownership in land', and declared private property in land to be unjust:

Whatever may be said for the institution of private property in land, it is therefore plain that it cannot be defended on the score of justice... There is on earth no power which can rightfully make a grant of exclusive ownership in land.

(George [1879] 1956:337-9)

private property in land has no warrant in justice, but stands condemned as the denial of natural right.

(George [1879] 1956:403)

He asserted that labour gives a right to what is produced on the land, but gives 'no right to the land itself' (George [1879] 1956:343). In his view, recognition of individual rights to land would give moral sanction to the ownership of an entire nation or the entire world by one person (George [1879] 1956:343, 345). He concluded: 
Equity...does not permit private property in land, since that would involve the right of some to deny to others the use of land.

(George [1892] 1937:18)

In addition to this a priori argument based on his perception of natural rights, George supported his case against private property in land by a utilitarian or consequentialist argument. He held that private property in land has led in the past, and will continue to lead in the future, to a very unequal distribution of land, which would result in great misery and poverty for those who owned little or no land. He argued that even if the land is initially divided into equal portions, it would sooner or later be transformed into very unequal portions through buying and selling, bankruptcies, inheritance, and (in some societies) through force and fraud.

From this rejection of the right of private property in land, George concluded that land should become common property.

We have weighed every objection, and seen that neither on the ground of equity or expediency is there anything to deter us from making land common property by confiscating rent.

(George [1879] 1956:403)

we must therefore substitute for the individual ownership of land a common ownership... We must make land common property.

(George [1879] 1956:328)

the only remedy for the unjust distribution of wealth is in making land common property.

(George [1879] 1956:329)

land is not the rightful property of any individual...the land belongs...to all the people.

(Field and George [1885] 1936:11-12)

However, although George clearly advocated common public ownership of land in principle, he did not advocate confiscation of existing private property by legislative enactment. Confiscation by formal legislation 'Would involve a needless shock to present customs and habits of thought' (George [1879] 1956:404). It would meet with strong political opposition from existing holders of titles to private property in land that have been conferred and sanctioned by positive law. ${ }^{4}$ As is well known, he avoided the problems involved in a wholesale formal abolition of private property rights in land by proposing to transfer only the value of the land (by means of a land-value tax) to public ownership, leaving existing land titles intact.

Some commentators might praise this as estimable pragmatic flexibility and as a commendable willingness to compromise principles for the sake of political expediency; others might condemn it as a weak abandonment of principles.

But George believed that his reform programme would not involve any backing-away from principles; on the contrary it would in effect result in a full realization of his 
fundamental principle that private property in land should be abolished and all land made common property. He argued that to make land common property it was not necessary to nationalize it. In his view the essential and defining characteristic of any private property right is the right to own and use the value of the property. Therefore, in his view, the levying of a land-value tax equal to the full value of the land would alter the essential nature of private property rights in land. By transferring ownership of the land value to the state, it would transform land from private property into public property. Existing title holders would be left with what George called 'possession' rather than property. They might be pleased to continue to regard the land they hold as private property, and could be allowed in positive law to do so, but they would in fact have only the shell of private property, not the kernel:

I do not propose either to purchase or to confiscate private property in land. The first would be unjust; the second, needless. Let the individuals who now hold it still retain, if they want to, possession of what they are pleased to call their land. Let them continue to call it their land. Let them buy and sell, and bequeath and devise it. We may safely leave them the shell, if we take the kernel. It is not necessary to confiscate land; it is only necessary to confiscate rent.

(George [1879] 1956:405)

It has been argued elsewhere that George was mistaken in thinking that private property in land is converted to common property by means of a land-value tax, and mistaken in thinking that the title remaining to the holder becomes one of mere private possession rather than private property. ${ }^{5}$ It has also been argued that this mistake has unnecessarily alienated, and continues to alienate, those who insist on the social and political significance of private property in land, and has contributed to the inability of Georgist policies to achieve lasting and widespread acceptance (Pullen 2001).

\section{The Case for Equal Private Ownership of Land and Land Value}

The case for equal private ownership (as opposed to common public ownership) of land and land value can be argued at the level of philosophical principles and at the level of political expediency. George argued from the a priori principles that land is provided by Nature and by God for the benefit of mankind in common, and that by the act of labouring on the land an individual person is justified in claiming private property rights in any products made from the land, or any improvements made on the land. However, as critics have noted, this argument is difficult to sustain. Unless there is a legitimate right of private ownership in the portion of the land that the individual wishes to use, there can be no legitimate private right of property or possession in the products or improvements. The usual example of the potter and the clay illustrates the point. If the potter does not have the right as an individual to own and use the clay, how can he or she be justified in claiming private property in the finished product? George addressed this problem in The Condition of Labor, when he considered the argument of those who say that 'if private property in land be not just, then private property in the products of labor is not just' 
([1891] 1953b:29). He answered that argument by asserting that the right of an individual to land is merely a right of 'temporary possession' ([1891] 1953b:30). But this answer is not entirely convincing. If the individual's right to land is one of mere private possession, not a right of private property, then it is difficult to see how the right to the products made by labouring on that land can be more than a right of 'temporary possession'. Furthermore, if a right to exclusive private property or possession of a parcel of land cannot be claimed by any one individual, then how can society as a whole claim that right, given that society is a collection of individuals? And still further, if the only justifiable basis for property rights is the act of labouring, then the claim that land belongs to mankind in common, or to society as a whole, cannot be sustained, because the land has not been produced by the labour of mankind in common or the labour of society as a whole.

If the right of private property in what is produced by labour from land is defensible, it logically requires two premises, or two principles of property, viz. (1) a labour principle according to which each individual person has a private property right in what that person produces by labouring; and (2) a land principle according to which each individual person has a private property right in land.

George rejected the land principle, frequently asserting that private property in land should be abolished and converted into common property. However, while denying the right of individuals to own land, he asserted their right to possess or use land with the proviso that that right is not an unlimited right, but is an equal right, and one that is limited by the equal rights of others to possess or use land.

The right of each in the use of land is... a direct, original right, which he holds of himself, and not by the gift or consent of the others.

(George [1892] 1937:33)

The equal right of all men to the use of land is as clear as their equal right to breathe the air - it is a right proclaimed by the fact of their existence... If we are all here by the equal permission of the Creator, we are all here... with an equal right to the $u$ se of all that nature so impartially offers.

(George [1879] 1956:338; italics added)

George's distinction between, on the one hand, the equal right to private property in land, and on the other hand, the equal right to private possession or use of land-he denied the former and asserted the latter-appears to be fundamental to an understanding of George's position on property rights. However, it is open to criticism. In the first place, as already noted, his distinction between private property in land and private possession of land hinges on the disputable view that the taking away of land value by means of a land-value tax will take away the essence of property and convert property into possession.

Secondly, George's view that a person's right to use land is 'a direct, original right, which he holds of himself appears to contradict his argument that the right to own what has been produced from land arises entirely from the act of labour. If a person's right to use land is 'a direct, original right', it is a right that exists independently of, and prior to, the right that arises from labour. There must therefore be not one, but two, premises or 
principles if the right to the produce of labour is to be sustained. The right to the produce of labour must logically be invalid if not accompanied by a right to use land.

These criticisms could have been avoided by George, without weakening his case for land-value taxation, if he had been prepared to accept the principle of equal private property in land. But instead of qualifying the principle of private property in land by the addition of the word 'equal', and redefining the principle as the principle of equal private property in land, he chose to deny the principle of private property in land, and to substitute the principle of common property in land. Instead of asserting a principle of equal private property in land, he preferred to enunciate a principle of no private property in land.

He seems to have rejected the principle of equal private ownership of land for two reasons:

(1) He realized (quite rightly) that it would not be feasible to divide land into equal physical portions. However, this difficulty or impossibility of giving practical effect to the principle is not a sufficient reason for rejecting the principle.

(2) He apparently was convinced that private property in land must inevitably lead to inequalities in the ownership of land: 'in the nature of things unequal ownership of land is inseparable from recognition of individual property in land'.

(George [1879] 1956:329)

\section{Disposing of the Land-Tax Revenue}

In discussing how to dispose of the land-tax revenue George generally stated or implied it would be spent on public works and social services provided by government. Occasionally, he mentioned the possibility of distributing the land-tax revenue as a grant or dividend to private individuals. For example, the following exchange occurred between George and D.D.Field:

F. To what purpose do you contemplate that the money raised by your scheme of taxation should be applied?

G. To the ordinary expenses of government, and such purposes as the supplying of water, of light, of power, the running of railways, the maintenance of public parks, libraries, colleges, and kindred institutions, and such other beneficial objects as may from time to time suggest themselves; to the care of the sick and needy, the support of widows and orphans, and, I am inclined to think, to the payment of a fixed sum to every citizen when he came to a certain age.

F. Do you contemplate that money raised by taxation should be expended for the support of the citizen?

G. I see no reason why it should not be.

F. Would you have him fed and clothed at the public expense?

G. Not necessarily; but I think a payment might well be made to the citizen when he came to the age at which active powers decline that would enable him to feed and clothe himself for the remainder of his life....

F. If I understand this explanation of your scheme, it is this,... that the proceeds of the tax should be applied, not only to purposes of government, but to any other purpose that 
the legislature from time to time may think desirable, even to dividing them among the people at so much a head.

$\mathrm{G}$. That is substantially correct.

(Field and George [1885] 1936:15-16)

In this exchange George seems to have been proposing that a portion of the land-tax revenue be made available as a grant or pension to the elderly. To that extent, land-tax revenue would become individual private property rather than common public property. ${ }^{6}$ His responses show that he was not opposed in principle to the idea of distributing the land-tax revenue to individuals by means of direct grants or a national dividend, and thereby converting the land-tax revenue into private property; but the idea does not figure prominently in George's writings and, when it is mentioned, it is described as a welfare service for the needy, not as a personal right. ${ }^{7}$ There is no suggestion that, as a standard policy, the land-tax revenue be distributed equally to all the members of the society as their natural right, irrespective of their financial needs.

In other words, George seems, as a general rule, to have regarded the tax-collected land value as common or collective property, to be spent by the government for what it perceives to be common or collective purposes. For example, in Social Problems, first published in 1884, he spoke of applying the land-tax revenue to 'securing such common benefits and providing such public conveniences as advancing civilization may call for' (George [1884] 1932:183; italics added). The use of a portion of the land-tax revenue as grants to private individuals seems to have been regarded as an exception to that general rule. ${ }^{8}$

George believed that the revenue from the land-value tax would be more than sufficient for all the needs of government. A difference of opinion occurred amongst Georgists on whether the land-value tax should be levied in full or only to the extent required by the needs of government. George described himself as an 'unlimited' single taxer who would take the full land value in tax, rather than a 'limited' single taxer who would take only enough for the government's needs. A limited single tax would mean that some of the land value would be left in the hands of the landowners - which, according to Georgist principles, would be unjust. With an unlimited single tax there would be a problem of what to do with the surplus. George argued that if more revenue were collected than was needed by government, it would encourage inefficiency in public administration, provide temptation to corruption, and result in an unnecessary and undesirable increase in 'the role of government, leading to demoralisation'. It is possible that George regarded a per capita national dividend as a solution to that problem: 'if it were to appear that further extension of the functions of government would involve demoralisation, then the surplus revenue might be divided per capita' (Field and George [1885] 1936:11).

But if, as later critics argued, he had overestimated the revenue potential of the landvalue tax, and/or underestimated the needs of government, then there might not be a surplus, and the case for privatising some of the revenue as per capita grants would be weakened or destroyed. Having rejected the right of private property in land itself, and having maintained that the land must be common property, he was consistent in asserting that the land value must also be common property and should be used in ways that would promote the common good. 
The crucial question that George did not address with regard to land and land value is: do they belong to all human beings in common, or to all human beings equally? He did not discuss the relative merits of equal private ownership and common public ownership of the land value. He seems to have assumed without doubt that land value is a collective rather than a distributive good. The answer to that unasked question is important not only at a philosophical and moral level; it also has important practical implications for the manner in which the revenue generated by a land-value tax is disbursed. If land is regarded as a common asset, then it would be logical to use the revenue as a source, if not the sole source, of finance for public works and community services that promote the common good. But if land is regarded as a natural resource to which all people have an equal right, then it would be logical to distribute the revenue in the form of an equal periodical share or grant to every person (children as well as adults), and to look to other sources for the revenue for public works and community services. ${ }^{9}$

A periodical distribution of the revenue would guarantee strong electoral support for the scheme and (more importantly) strong electoral opposition to any attempt by any subsequent government to abolish it. Previous legislative attempts to collect betterment have suffered from the fact that well-organized and vocal pressure groups have opposed the legislation, while its benefits have been too amorphous and too diffused over the community at large to create a strong and bipartisan body of voters aware of their vested interests in supporting it. The same fate awaits a land-value tax that does not quickly generate widespread and identifiable benefits. Political weakness has led to the demise of schemes for land-value taxation or betterment collection in the past; ${ }^{10}$ but a scheme that incorporated periodic equal distribution of the revenue of the land-value tax would generate unassailable political pressure for its own retention.

Although a land-value tax, the proceeds of which are distributed as an equal periodic grant, is logically and morally defensible as an expression of the equal (rather than the common) rights of all to land, it would probably be rejected by those who see it as a case of 'getting something for nothing' and as therefore morally reprehensible in itself and likely to lead to orgies of self-indulgence by the recipients. ${ }^{11}$ This objection could perhaps be overcome by distributing the tax revenue, not in cash, but as supplements to individual superannuation (retirement) accounts or by linking it to welfare disbursements. The amount of revenue periodically disbursed could be taken into consideration when assessing the needs of welfare recipients, and could therefore reduce the government's welfare bill.

The possibility of regarding the land-tax revenue as the private property of the individual members of society, and distributing it equally and periodically to all eligible members, ${ }^{12}$ does therefore merit serious consideration. There would appear to be no insuperable practical difficulties in implementing such a scheme.

A land-value tax under which increments in land value were distributed equally as land tax dividends, and as a result of which some individuals would receive more in land tax dividends that they paid in land tax, would be similar (at least in its consequences if not in its theoretical basis) to the 'public grants economy' advocated by Kenneth Boulding, to the negative income tax proposed by Milton Friedman, ${ }^{13}$ and to the idea of a national dividend proposed by writers such as James Meade, André Gorz and David Purdy as a solution to the problem of long-term technological unemployment. ${ }^{14}$ If the tax revenue is distributed in this manner, the scheme could be described as, and would in 
effect be, incremental-land-value-equalization. ${ }^{15}$ Increments in a society's land values would become equal private property rather than common property. If the land-tax revenue is absorbed into general government revenue, it is in effect socialized or nationalized. If it is distributed equally to everyone, it remains private property, and becomes equal private property rather than common public property. The land itself would not be divided physically in equal portions, but the land value would be owned privately and equally. It would be neither the private property of the few nor the common property of the state. This would appear to be an important distinction both ideologically and practically. ${ }^{16}$

In the absence of explicit textual evidence, we can only speculate on George's reasons for not considering and not advocating the equal private ownership of the revenue from the land-value tax as a standard policy. No reason is immediately obvious. One possible reason might be that if the revenue from a land-value tax is distributed into equal individual ownership instead of being absorbed into government revenue, it will not be available to finance public works and services, and could therefore not be the single tax. Land-tax revenue that is distributed equally to everyone will alleviate the need for some government-financed works and services - it might, for example, take the place of some welfare benefits and social services - but there will be other functions of government that require tax revenue (for example, to finance 'public goods', such as defence and the administration of justice). To cater for such public or collective goods, and at the same time to maintain the singleness of the Single Tax, it would be necessary either for the land-tax revenue not to be fully distributed, or for the recipients of the distributed revenue to refund some portion of it to the government for public-goods purposes.

Another possible reason for George's failure or unwillingness to consider a policy of distributing the land-tax revenue to everyone equally might be that, having vehemently rejected the institution of private property in land and land value, he automatically inferred that equal private property in land and land value would also have to be rejected. He seems not to have considered that the economic and social evils that he had attributed to private property in land and land value might be due, not to private property in land and land value as such, but to the inequality of its distribution.

Additionally, this failure or unwillingness could have been due to the fact that, having realized (correctly) that in practice ${ }^{17}$ an equal private distribution of the land itself would be difficult (or even impossible) to set up and to maintain, he automatically ruled out any consideration of an equal private distribution of the land value (as collected by a landvalue tax), whereas, on the contrary, the factors that militate against an equal private distribution of the land do not apply to an equal private distribution of the land value. Inequality would occur in the distribution and private ownership of the revenue from the land-value tax only if the public authorities made a deliberate decision not to share it equally, but to distribute it amongst individuals or groups according to criteria other than the criterion of equality.

\section{The Singleness of the Single Tax}

George did not initially give great emphasis to the idea that the land-value tax should be the single tax, ${ }^{18}$ but, later, after being persuaded by others, he enthusiastically promoted 
the notion and slogan of the 'Single Tax' ${ }^{19}$ It was thought that a single tax would have wide public appeal. In George's time, the principal source of tax revenue was indirect taxes on commodities, i.e. customs and excise duties, which being regressive taxes impacted particularly on lower-income groups. It is understandable therefore that George's proposal for a single tax on land received enthusiastic support from members of the lower-income and non-landowning members of society, who interpreted the proposal as one which would shift the tax burden from themselves to landowners and under which they would not have to pay any tax. George appeared to accept without question the view - sanctioned by Ricardo and Classical Political Economy - that a tax on land must fall entirely on the landowners, and could not be passed on to tenants in the form of higher rents. ${ }^{20}$ It is hard to say whether the popular support for Henry George emanated from the logical force of his theory or from its appeal to the vested interests of the majority.

George's view that the land-value tax should be the single tax was based on the argument that all other taxes unjustly take from individual persons or companies what they have produced by their labour, and what therefore rightfully belongs to them as individuals, not to the state. Land value, he argued, is created by society as a whole, and therefore society is entitled to take it by taxation, but is not entitled to take anything else by taxation.

This argument for a single tax can be challenged on a number of grounds. It can be argued that part of what is produced by labour and capital is also caused by society-for example, through its cultural heritage and its expenditure on public works and services (health, education, etc.), and that therefore society would be justified in recouping some of its needed revenue through taxes on wages and profits. Land is not the only factor that receives an 'unearned increment' from the actions of persons other than the owner of the factor. It can also be argued that land values are not always created entirely by society; for example, some of the increases in land value that occur when a residential development is undertaken might be attributable to the labour and capital of the developers. Furthermore, even if, for the sake of argument, it was agreed that land values are created entirely by society and that wages and profits are created entirely by individuals, there would still be no moral or economic reason for the land-value tax to be the only tax. If voters freely and democratically decide that they want their government to provide more public works and services than can be financed by a land-value tax, they would surely be justified in supporting legislation to impose taxes on income or consumption.

\section{An Attempted Summary of George's Views on Equal Private Ownership and Common Public Ownership of Land and Land Value}

George's views on property rights in land and land value are difficult to summarize because he did not provide a formal, systematic and comprehensive treatment of the topic. From his many references in his many publications and reported speeches, his position would seem to depend on four considerations:

- whether he was referring to land or to land value;

- whether he was discussing theoretical principles or practical applications; 
- whether the issue was one of property or one of possession;

- whether the land and/or land value should be either owned and used equally by all individuals as their private property, or owned and used by the state for the common benefit.

With regard to land itself, he argued that in principle land should be made the common property of the society, because private ownership of land leads to inequality, poverty and misery. But in practice he proposed to abolish private ownership of land and convert it to public ownership, not by legislative enactment, but by the fiscal measure of landvalue taxation. He believed that this fiscal measure would change private property into private possession, although existing holders might continue to think of their titles as private property. An equal division of land (as private property or as private possession) would not in practice be desirable or possible.

With regard to land value, the general tenor of his statements was that, as a matter of sound principle and good practice, the revenue collected by means of a land-value tax should be common public property and used for works and services of common benefit. Occasionally, he mentioned the possibility that some of the revenue might be distributed as a welfare benefit to the needy; thus, in effect, it would become their private property. But this possibility did not figure prominently in his reform programme. Nor did the programme consider the possibility or practicality of an equal private sharing of the revenue as a standard policy or as an equal right.

\section{Conclusion}

George's main aim was to attack the institutions that led to widespread poverty in the midst of progress. The main target of his attack was the private ownership of land. If he had directed his attack instead at the unequal private ownership of land, and had not felt it necessary to oppose the deep-seated and almost universal attachment to private property in land, the academic standing and popular acceptance of his ideas might be very different today. In the nineteenth century, in countries where the main source of tax revenue was customs and excise duties ${ }^{21}$ (which were assumed to be passed forward in the form of higher prices, and therefore paid by consumers), and where most people were not landowners, the promise that only landowners would pay tax (which according to the conventional economic wisdom of the time could not be passed forward) was sure to engender wide popular support. Today, in those societies where many people are either landowners, or mortgagors in the process of buying land, or aspiring land buyers, the promise of a regular national dividend might have more electoral appeal than a single (and heavy) land-value tax the revenue from which, even if spent on useful public works, might not bring obvious benefits to the life of the average citizen.

George's policy of common or public ownership of land is seen by many as a policy of land nationalization and as a first step towards socialism and communism. It appeals to those whose political ideology inclines towards socialism, but is anathema to those of the opposite political persuasion. A policy that promises equal private ownership of land value might achieve greater support. Whether or not it would enjoy majority support would depend to a large extent on whether the majority receive more in dividend than they pay in tax. 
In 1890 George predicted it would not be long before the civilized world came to acknowledge the equal rights of all to the use of the earth.

The currents of the time are setting in our favour. At last - at last we can say with certainty that it will only be a little while before all over the English-speaking world, and then, not long after, over the rest of the civilized world, the great truth will be acknowledged that every child born comes into this world having equal rights with all to the use of the earth.

(George [1890] 1947:2)

Over 100 years later the world is no closer to acknowledging equal rights to land than it was in 1890, and no closer to implementing policies that would give effect to equal rights to land. George's name and policies are less widely known and less popular than they were in 1890. Many suggestions have been advanced to explain the failure of his 1890 prediction. The fact that he advocated common public ownership of land and land value rather than equal private ownership, and the fact that he did not recognize the political repercussions of that position, could be significant elements of that explanation.

\section{Appendix: Schematic Summary of Henry George's Views on the Ownership of Land and Land Value}

\section{Land}

- private property

-rejected in principle, because in practice it leads to inequality and misery

- equal private property

-not explicitly considered in principle, because unworkable in practice

- common public property

-acceptable in principle, but in practice achieved by a fiscal measure (land-value taxation), not by legislative abolition of private property

\section{Land Value: Distribution of the Revenue from a Land-Value Tax}

- discretionary private property: distributed as welfare payments (e.g. pensions) on a needs basis

-acceptable in principle, but not a prominent nor a standard feature of his reform programme

- equal private property: distributed on a rights basis to each person as an equal national dividend 
- common public property: distributed by the government for public works and public services of common benefit

-the standard policy; endorsed in principle and practice

\section{Notes}

* The assistance of two anonymous referees is gratefully acknowledged.

1 In this paper the terms 'ownership' and 'property' are used as synonyms.

2 Opinions differ as to whether, or at what point, restrictive regulations in the use of private property amount to a negation of private property.

3 In suggesting that George's use of 'equal' and 'common' is in need of clarification, it is not meant that his general policy position was ambiguous or internally inconsistent. George of course would have denied any ambiguity. It is quite clear that his first-best option was for the government to own the land (i.e. common public ownership of land), and for the public revenue raised by leasing the land to private individuals (persons or companies) to be used for common public purposes (e.g. schools, roads, ...). It is also clear that, recognising the political impracticality of doing away with existing private land titles, his second-best option was to retain the existing private land titles, but to take away by taxation the value of the privately held land - thus creating a situation that he preferred to call private possession rather than private property - and to use the land-tax revenue for public purposes. This policy position might not be universally acceptable, but it was neither ambiguous nor selfcontradictory.

4 A further argument - not mentioned by George - against legislative confiscation is that it would have little chance of being implemented in a society where most people are landowners.

5 Just as George's distinction between possession and ownership of land was left unclear and unconvincing, so also was his distinction between possession and use. As a referee of this paper has observed, in some contexts George seems to use 'possession' as a synonym for 'use'; in others, he seems to use 'possession' to mean what is left of the institution of private property in land after the land value has been removed by taxation; and elsewhere, 'use' seems to be applied to what the land-holder, whether owner or mere possessor, is doing with the land. This creates problems of interpretation. When George spoke of the 'right to land' it is not immediately obvious whether he had in mind the right to own and use land, or the right merely to possess and have access to it in order to use it without owning it.

6 It is not clear from the above quotation whether 'the care of the sick and needy, the support of widows and orphans' would be in the form of publicly funded institutions, such as hospitals, nursing homes and orphanages, or whether it would take the form of direct grants to individuals. If the latter, then it would represent a privatisation of the land-tax revenue.

7 George claimed that we all have the right to an 'equal share' of the land - see, for example, the quotation from George [1881] (1953a:37), cited above. But in that context his term 'equal share' seems intended to mean not an equal portion of the land itself, but an equal sharing in the benefits of the public goods and services - such as roads, bridges, schools, defence, and the justice system - that are financed from the revenue of the land-value tax. $\mathrm{He}$ does not appear to have advocated, as a consistent and leading principle, that the revenue from the land tax should be shared out equally in the form of per capita grants. As a referee of this chapter has noted, there would be no contradiction if George had argued for common public ownership of land, but equal private ownership of the land value. It would have been possible for George (or anyone else) to combine in one policy the common public ownership of land with the equal private ownership of land value. This situation could arise, for example, if the state nationalized the land, leased it to private persons or firms, and then 
distributed the lease revenue equally on a per capita basis. But George did not choose to adopt this policy, for reasons discussed elsewhere in this chapter.

8 A referee of this chapter has suggested that George's preference for spending the land-tax revenue on public works and services instead of distributing land value in equal shares to private citizens could have been influenced by an unstated belief that the equal shares would somehow be redistributed unequally - a point that George had explicitly made as an argument against an equal distribution of the land itself (see above).

9 This view is admittedly based on the assumption that there is a logical link between equal rights to land value and equal shares in land value - an assumption that some might wish to challenge.

10 For example, in Great Britain, the Land Commission Act of 1967, and, in New South Wales (Australia), the Land Development Contribution Management Act of 1970. Both of these schemes were intended to tax for public purposes the increases in land value arising from rezoning, but both were not perceived by a majority of voters to provide them with any direct individual benefit, and both succumbed to the collective opposition from landowners who perceived (quite correctly) that they would suffer considerable economic harm.

11 George does not appear to have discussed explicitly the question of whether distribution of the land value to every citizen might involve demoralization for the recipients. But in speaking of a related policy_ pensions for the widowed, sick and aged, he said:

All prating that is heard from some quarters about its hurting the common people to give them what they do not work for is humbug. The truth is, that anything that injures self-respect, degrades, does harm, but if you give it as a right, as something to which every citizen is entitled, it does not degrade.

(George [1885] 1938:24)

12 Eligibility criteria would involve factors such as age, citizenship, nationality, permanency of residence, etc.

13 Boulding (1982:10). Boulding stated: 'It is a little surprising that Friedman has not been more enthusiastic about land rent and land value taxation which would seem to fit in well with his general philosophy'.

14 Meade (1993:405-10) has proposed a 'tax-free Social Dividend or national dividend or Basic Income or... Citizen's Income' to be paid 'to every citizen regardless of whether they are in work or unemployed... [and] regardless of all circumstances other than age'. Gorz (1982:41) has proposed 'a social income guaranteed for life', and Purdy (1988:193-5) proposes a 'basic income' that is 'an unconditionally guaranteed minimum income' that would be independent of current employment status and independent of other income.

\section{There are some similarities between the ideas of these three writers and the idea of a national dividend financed by land-value taxation, but in noting these similarities it is not intended to imply influences or priorities. As stated above, a national dividend financed by land- value taxation was not put forward by George as a standard component of his proposed policy.}

15 The term 'incremental land value equalization scheme' gives expression to the principle of equal rights to land, and to the logical and moral link between equal ownership and equal benefit. It would be more politically acceptable than 'land-value tax'. One of the reasons for the inability of George's policy to maintain widespread support was that as a general rule he insisted on applying the land-value tax to the current value of land (without compensation to 
existing owners) rather than to increments in land value after a base date set in the enabling legislation, as proposed by John Stuart Mill.

16 George argued that landowners had no moral right either to the unearned increments that had accrued on their land in the past, or to any unearned increments that they expected to accrue in the future; and, therefore, they had no moral right to any compensation if some or all of those past or expected increments are taken away by land-value taxation. To compensate them, he argued, would be equivalent to paying compensation to a thief whose ill-gotten gains are confiscated by the police. Also, as John King (1988:102) asks: 'Can I legitimately expect compensation when a slave I acquired innocently is emancipated, or the stolen goods I bought in good faith are repossessed? Compensation from whom?' George was not prepared as a general rule to admit exceptions or concessions in the case of a buyer who purchases land just before the introduction of the land-tax legislation, and whose purchase price reflects the market's estimate of future increments in land value. This rather extreme application of the principle of land-value taxation alienates those who regard it as unfair and arbitrary confiscation.

17 Recognition of the practical impediments to an equal private distribution of land does not rule out recognition of the principle of equal private distribution of land.

18 The term 'single tax' occurred only on a few occasions in Progress and Poverty, and was not capitalized as the 'Single Tax'.

19 In New South Wales (Australia), his early supporters were organized under the name of Single Tax Leagues.

20 'all economists are agreed that taxes on land values irrespective of improvement or use...must be paid by the owner and cannot be shifted by him on the user' (George [1891] 1953b:13n.). But, according to Groenewegen, Ricardo's view of the incidence of land tax 'is now no longer acceptable to tax economists... it is now agreed that all taxes are in principle shiftable...rent and taxes on rent can be passed on, depending on the state of competition...supply and demand elasticities will determine the actual incidence of the tax' (1979c:10-11). And, according to King (1988:92), George's analysis of distribution 'rested upon a theoretical fallacy - that the landowner was the residual claimant — and had been refuted in practice by the rapid growth of non-rent property incomes'.

21 For example, in Australia in 1901-1902, customs and excise duties raised 63\% of total taxes. See Groenewegen (1979a:60). 


\title{
8 \\ Groenewegen's Marshall
}

\author{
A Review \\ Milton Friedman
}

Peter Groenewegen's magnificent biography of Alfred Marshall provides a veritable mountain of detailed evidence on the development and contributions of a remarkable and complex human being during his long life. Groenewegen has left no stone unturned that might conceal the remotest detail of Marshall's background and life. Truly a labor of love, no effort has been spared to assure that it is complete and balanced. The result is an 800-page text that "everyone who is fascinated (and what economist is not?) by the extraordinary enigma of Marshall's character and the qualities which made his pupils regard him as incomparably great, must read,' as Austin Robinson (1948:123) said of Mary Paley Marshall's posthumously published What I Remember.

As a long-time Marshallian, I am one of those who believe that Marshall was an 'incomparably great' economist. The cry 'it's all in Marshall' still rings true with respect to price theory. At the same time, I have long had doubts about Marshall's qualities as a human being. Groenewegen provides ample evidence to confirm or resolve those doubts, and is remarkably evenhanded in doing so.

Readers less interested than I am in Marshall as an economist may find the book overdetailed, but they too will find much to reward them, even if they skip everything about his economic scholarship. The book will unquestionably be the standard source for any future scholars of the economist whose Principles of Economics dominated the teaching of price theory from its first publication in 1890 until well into the twentieth century.

I believe that Marshall was at his peak, both as economist and human being, when he was a young Fellow at St. Johns from age 24 to 35, the period that Groenewegen labels his 'economic apprenticeship'-another example of Schumpeter's generalization that the third decade is 'golden' for a scholar. The hard analytical structure of the Principles dates from that period, including the bulk of the Mathematical Appendix; so does the privately circulated (by Henry Sidgwick, not Marshall) The Pure Theory of Foreign Trade and the Pure Theory of Domestic Values; and so also the excellent little book, authored jointly with his wife, Mary Paley Marshall, The Economics of Industry, which Marshall suppressed when The Principles was published, giving the title to an abridgement of the Principles, even though large parts of the earlier book found their way into the Principles and later writings. I believe that the first, or possibly the third, edition of the Principles was the best of the lot, and that revisions in later editions raised considerably the ratio of mush to analytical content in order to meet criticisms of such non-economists as Sidney and Beatrice Webb and to satisfy Marshall's desire to appeal to business men and educated laymen. (In 'The Marshallian Demand Curve', I rationalized two passages in later editions of the Principles that I interpreted as inconsistent with Marshall's earlier 
work on demand theory on the grounds that they were written 'some twenty years after the fundamental analysis... had been completed' (Friedman 1949:494).

As a human being too, Marshall shows up best during his apprenticeship years. He made many close friends during this period, most of whom (including John Neville Keynes) he alienated as the decades went on until in his later years, 'relatives, work and some recent students [including John Maynard Keynes], counted for more with him than former friends of school and college, regrettable though that absence seemed occasionally in old age' (see Ch. 18, 'The Friend', quote from p. 697).

Marshall 'actively participated [in the 70s] in advancing the rights of women to education at the university' (p. 100), and 'he was part of the team of Cambridge academics who lectured to women when from 1870 Cambridge opened its doors to female students on an informal basis' (p. 270). Mary Paley, a member of the initial class at newly established Newnham College for women, was one of Marshall's students. Her 'own account of their "courtship" showed that she took initiatives in this' (p. 228). After their engagement, Marshall undertook to collaborate with her on a book that she had contracted to write and that became The Economics of Industry.

Marshall's attitude on feminine education changed drastically over time. Initially, women were not granted Cambridge degrees. As pressure for granting Cambridge degrees to women increased, Marshall became one of the strongest opponents, in the process alienating some of the friends with whom he had joined in the $1870 \mathrm{~s}$ in promoting womens' education. Chapter 14, 'A Feminist Manque', tells this story in great detail.

Many readers will find Chapter 8, 'The Husband (1877-1924) in an Unusual Partnership' (pp. 223-67), the most fascinating chapter in the book. In his obituary of Mary Paley Marshall, John Maynard Keynes (1944:276; the first part of this quote is quoted by Groenewegen on p. 223) described the marriage as

an intellectual partnership...based on profound dependence on the one side (he could not live a day without her) and, on the other, deep devotion and admiration, which was increased and not impaired by extreme discernment... Neither in Alfred's lifetime nor afterwards did she ever ask, or expect, anything for herself. It was always in the forefront of her thought that she must not be a trouble to anyone.

Austin Robinson (1948:123-4) is less generous in his review of Mary Paley Marshall's memoir:

Mary Marshall was enslaved to forty years of self-denying servitude to Alfred: the 'foolometer' by which he measured the popular intelligibility of his writing, the organizer of his materials, the breakwater between himself and the irritations of life. And then, when Alfred died in 1924, ...Mary Marshall's glorious rediscovery of the world. ...I suspect that the last twenty years [of her life] were in many ways the happiest of all. ...Why indeed...did Alfred make a slave of this great woman and not a colleague? 
Groenewegen's final paragraph gives an excellent panorama of the riches in this book (p. 791):

This was the mixture which made Marshall. It produced a great economist and a cautious reformer. It created a scientist diligently seeking after truth but capable of hiding both his parental antecedents and his embarrassing place of birth. It created the moralist who unashamedly preached the worth, as aids to character building, of good consumption habits and general standards of living but who feared the social consequences of 'modern women' being given the vote or a Cambridge degree. It formed the leader of a profession who laid down generous rules for the treatment of predecessors, but who, if need be, was willing to hurl himself into the controversy to protect both his own good name and his principles. ... Often humourless, pedantic, vain, selfish, ungenerous, even egotistical, he could at the same time be sensitive to the needs of others, courageous in his support of unpopular causes, generous of both time and money to advance teaching and students in the subject he professed and to which he made a lasting contribution in his writing. Much can still be learned in what to adopt and what to reject from the man and his life. In this sense, Marshall remains a soaring eagle.

\section{Note}

This review of Groenewegen (1995) first appeared in the Journal of Economic Literature, 34 (December 1996):1989-91. It is reprinted with permission of the American Economic Association and Professor Friedman. 


\title{
9 New Orientations in Marshallian Studies
}

\author{
Giacomo Becattini*
}

\section{A Turning Point in Marshall Studies?}

Anyone wondering, no more than 10-12 years ago, whether it might be possible for Alfred Marshall's thought to emerge from the niche-a most prominent niche, to be sure - assigned to him in current economics and, accordingly, history of economic thought handbooks, so that it could return once more to occupy a major position in 'viva' theoretical reflection and/or 'field' research in economics, would surely have concluded: no, this is inconceivable, because Marshall, for all his merits, belongs to the prehistory of contemporary economic analysis.

Certainly, there were isolated economists, including a number of renowned figures, who would not have endorsed that judgement (Shackle, Coase, Georgescu-Roegen, or Loasby, to cite just a few, but this list could be extended), because they felt Marshall's thought held considerable unexpressed potential. But overall, economic analysis pursued avenues of exploration that made a return to the Marshallian approach to economics highly improbable. The great season of Marx was coming to an end, David Ricardo was still holding his own on the market very satisfactorily, the Sraffa papers were the object of careful scrutiny, and Friedrick Von Hayek was looming larger and larger on the horizon.

That Marshall had now been sidelined was a point of view shared, albeit with different motivations, both by mainstream neoclassical economics, whose irritation with that 'good analytical economist ashamed of analysis' had already been expressed by Samuelson (1967). One special case was that of the Italian Marxists, willing to be 'receptive' to an economist who, although most definitely 'bourgeois,' did have the virtue of addressing the real problems of capitalism (Becattini 1981). But overall, I must stress, Marshall was considered to stand outside the central stream of scientific progress in economics.

Those who were in Cambridge in 1990 will have a vivid memory of the curious 'intellectual climate' of the celebration of the centenary of Principles $;{ }^{1}$ the atmosphere was so strained as to prompt Austin Robinson to complain that the Cambridge milieu was imbued with a profound distaste, bordering on disrespect, for the author who was being commemorated. $^{2}$

Well now, it seems to me that barely a decade later, the situation has changed considerably. Today, the name and ideas of Marshall are encountered more and more frequently in economic literature, predominantly in a favourable tone. Suffice it to say that four years ago, in Nice, a conference was held that was entirely devoted to Marshallian economic thought and that a book by Tiziano Raffaelli on Marshall's 
Evolutionary Economics, which I take the liberty of defining as 'important', has been recently issued by Routledge (Arena and Quéré 2003; Raffaelli 2003).

All this, it should be noted, is not merely an impulsive response to some anniversary: rather, it has arisen above all because investigation into the 'real' economic phenomena of our time, especially in the area of industrial and development economics, has revived Marshallian concepts such as the formerly execrated external-internal economies, and makes widespread use of 'pregnant' images such as the 'industrial atmosphere' which are inevitably 'dialectical' and fuzzy. This revival, this re-entry of the Marshallian æeuvre into mainstream economic circles, is thus not only unexpected but also worthy of considerable attention, in particular on account of the path that has led to its restoration.

\section{The Bases for the Return of the 'White Elephant"}

Naturally this return of Marshall in the wake of research on 'the industry of today' would not have sparked such a wave of curiosity as it did, had it not been for several new developments in studies on the history of economic thought and in economic analysis itself. I will briefly mention a few of these.

Let us first and foremost chart the major novelties in studies on the life and thought of Marshall. I have already mentioned the 1990 Cambridge Conference, but several other conferences on Marshall were held in the period between 1990 and 1992 (to commemorate the hundred and fiftieth anniversary of his birth). The materials and/or proceedings have already been published (cf. Whitaker 1990a; McWilliams-Tullberg 1990; Dardi, Gallegati and Pesciarelli 1991-1992) and readers thus have a chance to delve into a wealth of fascinating partial explorations. This notwithstanding, I would argue that the most significant advancements have been achieved elsewhere.

I believe that the scene has changed as a result of the impact made, essentially, by six publications, which enabled a fairly vast community of scholars to gain access to a whole range of very important Marshall papers that for years had long been quite out of reach, consultable only by the aficionados of Cambridge UK, and more specifically of the Marshall Library.

Two of these, the magnificent biography of Marshall (Groenewegen 1995) and the splendid critical edition of the Marshall correspondence (Whitaker 1996), which amounted to an overall total of 2,000 pages (roughly), constitute the first extensive and solid basis for the Marshall revival that I aim to focus on here.

Taken together, these two works make clear that if the life and work of a scholar is projected onto the society of the scholar's day, then a different array of questions may arise as compared to those that come to mind when approaching the works of great scientists through the more commonplace routes, i.e. through the theoretical queries and on-going debates of the given scientific discipline. A careful inspection of the life of an author, accompanied by clarification of the historical context, provides help in 'positioning' the different parts of a scholar's work - even the more strictly scientific sections - according to the importance and role the author and or other scholars of the time attributed to such parts. ${ }^{4}$ And it is precisely this 'contextualization' that is required if one seeks to reconstruct the 'internal line of the author's arguments' and understand what educated readers of the day saw —or did not see—in the works in question. ${ }^{5}$ 
As a further complement to the two above-mentioned fundamental works, which constitute in their own right the indispensable premise for the turning point I intend to describe here, I would add, albeit on a slightly different plane, the critical edition of several manuscripts dating from Marshall's youth: his early economic writings edited by Whitaker (Whitaker $1975^{6}$ ) and the philosophical manuscripts edited by Raffaelli (Raffaelli $1994^{7}$ ). These may be extended to a couple of other works, although of somewhat lesser importance: in particular his Lectures to Women (Raffaelli, Biagini and McWilliams-Tullberg 1995), and a second collection of official documents edited by P. Groenewegen (Groenewegen 1996), which followed J.M.Keynes's 1926 collection (Keynes 1926).

The overall body of these publications, plus a number of others that will not be mentioned here, ${ }^{8}$ present us with a Marshall who, in my estimation, is considerably different from the image that has been enshrined in economic textbooks and in books on the history of economic thought. Sufficiently different, I would argue, as to prompt the need for an overall reappraisal. Of course, it would be beyond the scope of this chapter to engage in such a reappraisal here: I would nevertheless like to outline the main lines along which it could be developed.

Many new issues are raised in the above cited works, but I think that one in particular, the republication of his early philosophical manuscripts, contains the crux, as it were, of the re-reading of Marshall to which I am alluding.

\section{The Crux of the Revisitation of Marshall}

If I cast my mind back today to the six Marshallian anomalies of four years ago (Becattini 2000), I come to the conclusion that, basically, they can all be contained in the first one: man as an entity that is diversified over space and variable over time as a function of the circumstances in which he lives.

As Marshall states in the most passionate and explicit text, the inaugural lecture in Cambridge in 1885:

The chief fault, then, in English economists at the beginning of the century was...that they regarded man, as, so to speak, a constant quantity, and gave themselves little trouble to study its variations. The people whom they knew were chiefly city men; and they took it for granted tacitly that other Englishmen were very much like those they knew in the city... They were aware that the inhabitants of other countries had peculiarities of their own; but they regarded such differences, when they thought of them at all, as superficial and sure to be removed as soon as other nations had got to know that better way which Englishmen were ready to teach them... This did little harm as they treated of money and foreign trade, but great harm when they treated of the relations between the different industrial classes. It led them to regard labour simply as a commodity without throwing themselves into the point of view of the workman; without allowing for his human passions, his instincts and habits, his sympathies and antipathies, his class jealousies and class 
adhesiveness, his want of knowledge and the opportunities for free and vigorous action. They (the English economists) therefore attributed to the forces of supply and demand a much more mechanical and regular action than they actually have... The socialists were men who felt intensely, and who knew something about the hidden springs of human action of which the economists took no account. Buried among their wild rhapsodies there where shrewd observations and pregnant suggestions from which philosophers and economists had much to learn.

(Pigou 1925:155-6)

Now, these statements are extremely clear and unmistakably show Marshall distancing himself both from classical-Ricardian thought and from incipient marginalism. Yet very few economists have given due attention to these words.

If this, for Marshall, is social reality, then nothing short of - and nothing less general than - a science of society can succeed in deciphering it. Economic science in the strict sense is merely, let us say, the best armed and most highly trained 'imperial guard' of a whole army of scholars whose goal is 'intellectual appropriation' but also, at the same time, 'practical government' of the constant flux of social phenomena.

In Marshall's day, conditions were not yet ripe for economic knowledge to be recognized as a definite part of a general science of society that had yet to be formulated. Nevertheless, his conviction that observation and reflection, conducted with scientific rigour and philosophical breadth of mind, would sooner or later usher in the moment when such a science could be established is, to my mind, incontestable. Likewise, there can be no doubt at all as to which category Marshall felt would play a pivotal role in the moral sciences: human character, in which all the drives, both objective and subjective, towards social change are intermeshed and transmitted, or undergo metamorphoses and sublimation:

Social science or the reasoned history of man, for the two things are the same, is working its way towards a fundamental unity; just as is being done by physical science, or which is the same thing, by the reasoned history of natural phenomena. Physical science is seeking her hidden unity in the forces that govern molecular movement; social science is seeking her unity in the forces of human character. To that all history tends; from that proceeds all prediction, all guidance for the future.

(Pigou 1925:299-300)

There are, I would say, three main elements that should be highlighted: the centrality attributed to human character, its complexity and the extent to which it is affected by the circumstances of historical development. Little effort is required to perceive that what underlies these elements are the torments and failure of the Millian ethological project. In the eyes of Marshall's contemporaries, and even more so of his successors, this was the crucial point that marked out this part of Marshall's work as dated and obsolete, whereas I regard it as essential - unresolved and problematic though it may be. Consequently, this passage and many other comments of a similar nature scattered through Marshall's work 
were ignored, and Marshall was ascribed, lock, stock and barrel, to triumphant marginalism.

\begin{abstract}
Despite some remarkable exceptions, the reading of Marshall as a second generation marginalist remained the 'basic' interpretation until no more than a few years ago. It was not until 1994, with the critical edition of the philosophical manuscripts, that the foundations for a change of direction were laid. Guided by Raffaelli in the meanders of an enormously complex philosophical landscape, at the centre of which stood the explosion of Darwinian evolutionism and the invasion of Britain by non Euclidean geometry, we are led to realize how vast and how deeply rooted those Marshallian outpourings were.
\end{abstract}

(Raffaelli 1994)

The key text of a group of papers, a text which, although closed up in some inaccessible drawer, runs right through the whole life of Marshall is Ye Machine. Re-read today, with hindsight, it would not be exaggerated to define this work as setting the fundamental coordinates of Marshall's thought.

This, then, is the node of nodes: the comparative evolution of human character and the institutions begotten by humankind.

\title{
Industry and Character
}

The automaton Marshall shapes in the aforementioned manuscript as he reflects on the functioning of the human mind is adequately decomposed and logically recomposed in Raffaelli's commentary, and I see no better way of acquainting the reader with its working than to refer the reader to those texts. However, on a few points, which constitute the crux of my argument, I would like to go into matters in greater depth, although unfortunately my observations will remain bereft of the logical framework in which they are meant to be understood.

What is character? Or, to use today's terminology, what is personality? In the Victorian and Edwardian era, much was written on this theme, so central to nineteenthcentury British thought. But scant attention was devoted to rigour in dealing with this topic, so that it never went beyond a level we might call para-journalistic. Yet, strange though it may seem, ${ }^{9}$ some of the explanatory remarks that seem quite crucial to a solution of this puzzle are to be found precisely in the paper Ye Machine dug up by Raffaelli.

What is the central point? It is the idea, really quite trivial today but much less so around 1870 , that the mind creates routines consisting of what the individual finds to be successful answers to the problems he has encountered, and then utilizes these routines automatically. ${ }^{10}$ While this process on the one hand builds up a mounting store of routines ready for use-some incorporated in machines, tools and handbooks, others preserved as practical, productive and moral know-how in the minds of men-on the other, it frees up, shall we say, a 'potential of new thought' that can be of use in excogitating new solutions to new problems The complex of routines, only partly 
appropriable and appropriated, represents the essential nucleus of the 'capital' of mankind. But the most important result of this process lies in the growing release of mental energies.

Character is thus the result of our own personal experiences, of the experiences of the race $^{11}$ and, more generally, of the species; it is a complex and stratified phenomenon, endowed with a fixed or given part, and with a tool capable of setting itself a broadening range of ever new problems and of working out a constant supply of new solutions. The system of ends, or needs, that are recognized by the agent is correspondingly complex and variable. It is no coincidence that Marshall, unlike his British contemporaries, paid considerable attention to German thought, where the function of utility took much longer to 'dislodge' the theory of needs as the basis of the theory of demand.

Marshall's theory of utility, scoffed at as rudimentary by those who subscribed to the refinements of ophelimity and preferences, did not sweep away all bridges with a hierarchy of needs, which allows consumption to be linked up to social structure and income distribution. Effectively, in the light of GeorgescuRoegen's (1968) critique of the utility function, Marshall's position on consumption and its presuppositions appears today - despite all its limits - to be ahead of its time rather than outdated.

Marshall does not stride ahead by forced marches towards a simplified pattern of human behaviour that would allow it to be treated with mathematical tools. Firmly committed to the idea that action is prompted by a multiplicity of stimuli-high-level and low-level, regular and sporadic, male and female, etc.- he saw some areas of social behaviour that could more easily be isolated from the remainder by the ceteris paribus hypothesis (e.g., money and international trade). In such areas, the classical and neoclassical behavioural hypothesis of maximizing the monetary value of the result of each given operation could be applied more constructively. But he also saw areas (such as the continuum from employed labour to entrepreneurship) in which this might lead to distortions, at times severe, in the interpretation. Overall, it is a conception of social phenomenology in which strictly economic motivations, present in every action to a variable extent, define a very heterogeneous, unstable and discontinuous, field of phenomena. Hence the methodological rule, so alien to neoclassical thought, of proceeding by short chains of deduction. It is indeed remarkable and rather thoughtprovoking to note that along this line one finds Marshall, Keynes and...open, open your eyes, some of the Sraffians! ${ }^{12}$

There are some passages in Marshall's writings, especially his early writings, which have always reminded me of Marx's historical materialism. In Marx, the 'mental' effects of the organization of the production process (a Ford-Taylorist world ante litteram) are concentrated, for the great mass of workers, i.e. for the working class, in the formation of class-consciousness. On the other hand, the problem of ensuring a correspondence between the communist conscience and the planning of the production process is postponed inasmuch as it is said to belong to the 'cuisine of the future'.

In Marshall a different outlook is discerned: the central object is the study of the various organizational forms (Taylorism, payment and incentive systems, etc.) of the social production process, both from the point of view of their economic efficiency and from that of their effects on human character, such effects being multifarious and hard to define. The value of this attitude is well exemplified by Marshall's reception of 
Taylorism: as a counterpart to many dogmatic enthusiasts, stand the rather cautious, reflectively meditated reservations of Marshall.

Naturally these aspects, together with others one might call to mind, are not a fully formed theory - of this, Marshall was well aware-but they do provide us with several important and quite challenging points of reflection, which is no mean consideration in this post-Fordist and post-Central Planning phase, in which, significantly, the so-called cognitive economy holds sway so massively.

A fascinating development of several other points touched on in the manuscript, concerning economic analysis in the strict sense, is offered by Marco Dardi in a paper entitled 'Marshall equilibrium analysis: dynamics in disguise' written for the volume by Arena and Quéré (Dardi 2003).

\section{A Neoclassical Economist Sui Generis}

Armed with the considerations outlined above we can now address the central category of Marshall's economic philosophy: human labour. In the first piece Marshall published, the text of a lecture he gave in 1873 on the Future of the working classes, there is a statement that catches the attention: 'labour is not a punishment for fault: it is a necessity for the formation of character, and therefore, for progress' (Pigou 1925:367). This is not, in contrast to a widespread belief, an instance of typical Victorian moralizing. Quite the opposite: it is the focal point, so to speak, of Marshall's problematicization of social phenomena.

It should be noted that the sentence in question does not refer only to salaried employment, for which the full and complete status of human-ness is claimed - recall the passage cited previously - but also to the entrepreneur, whom Marshall places in a line of continuity and interchangeability with the former, despite the numerous social preconceptions placed in the wheels of such a perspective. ${ }^{13}$ It also expresses a certain vision of the crucial role of 'industrial' activity, seen as human 'industriousness' which, it is well to remember, co-produces the product and the producer.

From this there ensues an immediate conclusion, one that remained latent without ever either totally disappearing or acquiring complete expression throughout Marshall's life: the economist's most valuable contribution to human progress resides, as Marshall sees it, in the formulation of a social system such as can produce, together and jointly, an ever increasing number of commodities and services on the one hand, and ever more 'civilized' men on the other. The full, and good (in the sense of productive and 'educational' ${ }^{14}$ ) utilization of all subjects in social production is, essentially, the summum bonum of the Marshallian market society.

It is not a question of simply maximizing the economic welfare, or welfare tout court, of the present or future generations; rather, it is more a question of the capacity of the system to render active every member of society. Of course, this implies making each member a producer of commodities (goods and services) that can be sold, in the long run, on the market with at least normal profit (the condition for economic reproducibility of the process), but also and above all, making each member a better citizen, better informed, more responsible, endowed with more 'freedom'. 
In other words, the volume and composition of employment produced by society should not be such as to produce simply an increasing amount of profits, wages and revenues, but it should also and most of all be capable of enabling man to 'blossom out. ${ }^{, 15}$ Only in this case can one speak of progress and not simply growth or mere change.

Now, what would standard neoclassical economists of the first decades of the twentieth-century have made of this approach to the social problem? They would have shrugged their shoulders, pointing out that if stated in such terms, the problem was beyond the scope of their investigation as economists.

It would be easy to demonstrate that concern over the effects of social organization on the character of the average man, a concern that came straight from the social criticism of, say, Owen and from the torments of the later Mill, never disappeared from the works of the Cambridge School. Nor did its counterpart in the form of ceaseless-even though at times barely perceptible - reflection on the best social system, not even after the overt repudiation of Victorian ethics and of a substantial portion of Marshall's conceptual apparatus. $^{16}$ This is the leitmotif which, above and beyond the fracas sparked by the clashes between the generations, forges a link connecting the different seasons of Cantabrigian economic thought, at least from Marshall to Robinson (Kahn 1985).

To conclude, the real, underlying raison d'être of the economic analysis of social facts did not reside, as Marshall saw it and in the eyes of the entire Cambridge tradition, in aseptic study of the rational allocation of given resources in a given social system, or an enquiry into the logic of individual choices. Instead, it consisted in finding an answer, however problematic this might turn out to be, to the investigation that sought to spell out what type of general organization of society, or of a determining portion of society, would most successfully - and without noticeably frustrating growth - enable all members of society, even the marginalized and the underprivileged, to release their latent creativity.

How can all this be reconciled with the label of neoclassical economist almost unanimously attributed to Marshall? The answer is simple: it cannot be reconciled.

\section{Industrial Districts and Small Businesses}

One issue on which I may be expected to say a few words is the strange role played by the industrial district in the corpus of Marshall's thought. How it arose is a matter I have addressed more than once in my writings, and I will not repeat myself here. I would merely briefly point out that it sprang from a composite origin: the young Marshall's reflections on the theoretical-methodological themes of non-competitive groups and economic nations, blended with his passion for direct and painstaking observation of social phenomena. The economic conclusion Marshall reached, presumably in the $1870 \mathrm{~s},{ }^{17}$ is the well-known statement that:

Some of the advantages of division of labour can be obtained only in very large factories, but that many of them, more than at first sight appears, can be secured by small factories...if many of them are collected together in the same district.

(Marshall and Marshall 1879 [Macmillan]: 52-3) 
But it is what one may term the ideological aspect of the question that arouses the greatest interest, when set in a more general interpretive perspective such as that adopted here. There are two aspects that need to be taken into account: a) the need to bypass the impediments that stood in the way of wage improvements and which, according to the epigons of classical economists, were explained by the theory of the wage fund and, according to Marx, to the reserve industrial army; b) the parallelism and interdependence between the production process and the educational process.

But let us retrace our steps a moment. The Ricardian approach, which was long suffused throughout political economy, ${ }^{18}$ explained the growth of productive forces in terms of the two-pronged system of investment and technical progress, a phenomenon essentially internal to the process of capitalist accumulation. This meant that civil society, which constituted a sort of passive framework, contained within it an economic mechanism whose operation caused great change and disruption. Marx and Engels had a keen grasp of this 'disruptive' effect, vividly depicting it in the 1848 Communist Manifesto. The engine of change lay precisely in this set-up: expected profits, profits realized, reinvestment of profits, the ensuing frantic and instrumental acceleration of technical progress. Now, the fact that such a mechanism continuously throws society into turmoil by changing the relations between economic and non-economic phenomena was of very little concern to the standard economist of the day. Marx, who took it to heartand how could he fail to do so!- - sterilized the overwhelming majority of its effects, channeling them into the formation of a revolutionary consciousness among the oppressed class.

Well now, when seen in the perspective of the Marshallian district (but not exclusively in this perspective, of course!) the human communities in which every productive apparatus is steeped are, under certain conditions, transformed from the status of passive containers into protagonists. What is the industrial atmosphere, what are the internalexternal (in relation to place) economies, if not a conduit through which the local society makes its influence felt on the productivity of labour, in addition to the well-known effects of accumulation and technical progress?

Now the concept of local society as, let us say, a factor modifying the productivity of labour can be justified only in the light of two major aspects: the above outlined conception of the learning process and the sense of belonging to a place (and not, as is the case with the socialists, to a class) such as one finds in Marshall and, as far as I am aware, in no other major economist of his day. ${ }^{19}$

It is interesting to note that Marshall's learning process overturns - or completes, if considered from a slightly different angle-Marx's early position according to which man is impoverished by the specialization resulting from the increasing technical division of labour. Marshall, interrogating the blue books on this point with no less attention than did Marx, concluded that while it may in some respects be true that specialization decreases the versatility of the subject, in other respects it enables the mind to become more 'refined' by freeing man from heavier and more repetitive tasks.

Thus Marshall's answer is two-pronged. On the one hand, accumulation and technical progress set mankind free (except for a social residuum: how this could be eliminated was to be a baffling impasse that would plague Marshall throughout his life) from the most grueling and boring tasks, allowing an increase in the productivity of all types of labour (salaried, self-employed, entrepreneurial). On the other hand, when the district 
also comes into play, that is to say when there is a synergy between development of the communities and the corresponding production apparatuses, then accumulation and technical progress produce increases in labour productivity that derive neither from investment nor from technical advancement, but rather from the intellectual and moral growth' of all the agents involved in social production. Moreover, in certain conditions perception of the individual interest in the framework of a group interest (the industrial district) promotes the rise of a more mature civic consciousness. Marx had excogitated the formation of class-consciousness; Marshall responded with the formation of a civicconsciousness that evolved, as we will see, into a national-consciousness.

It is now possible to venture an answer to an objection that springs to mind quite spontaneously: if it is true that Marshall ascribed all these valuable qualities to the form describable as the district, why does the term never appear in the subject-index of his books?

My answer is composed of two parts. First and foremost, as the years went by-in fact, as early as 1890-Marshall to some extent became convinced that his externalinternal (in relation to place) economies were beginning to lose ground in favour of those purely internal to the enterprise, and were also losing their strength as they became spatially dispersed and dissipated among the industrial sectors. Secondly, this phenomenon in turn resulted in twofold effects: not only were the small businesses of the districts less protected against competition from the larger businesses, but the sense of belonging also began to change and became more extended: from the county (for instance, Lancashire) to the nation-state (for instance, Britain), so that the unit of analysis of the fundamental process of character formation-which, it is well to remember, ran parallel to the production of commodities - became identified with the nation-state itself. And in fact, in his study of cases of industrial leadership, which invoke 'national characters' as a last analysis factor, he is referring precisely to the nation-state. ${ }^{20}$ However, these arguments by no means lead Marshall to the 'easy' conclusion that there is no room for small and medium businesses in the new industrial situation. ${ }^{21}$ On the contrary, at several points and looking at the issues from several different angles he underlines that there will always be room for a revival of the productive apparatus from the bottom up, because the possibility of drawing on diffuse and latent creativity is indispensable to the regeneration of capitalism. The connection that should be established between the two processes, regeneration from the bottom up and sectorial concentration, each of which expresses a specific requirement of capitalism, is, in Marshall's view-or so I read him - a synergic relation.

\section{Some Research Lines}

What can be concluded from this enquiry? I conclude by giving a few indications for future research.

My first proposal concerns that great book-for such I consider it, as did Andrews (Lee and Earl 1993:119) — that is Industry and Trade. I believe there is still much food for thought to be found in its pages, and I sincerely hope that someone will sponsor a conference focusing on this text. A conference, I would venture to state, that should act as an interface between industrial economics and the history of economic thought. 
The reflection on Marshall's thought I have sought to initiate here has highlighted two important aspects: the parting of ways in the aftermath of Mill and the dissolution of Marshall's message. In my view, both have barely been touched by historians of economic thought; moreover, to the extent that they have been addressed at all, debate has been biased by arbitrarily introduced 'captious' questions that have swayed the natural course of British culture (e.g., the supposed Vulgarity' of the epigons of the classical economists, the emergence of British economic thought from the 'Marshallian mists,' etc.). Surely it is time to revisit the whole issue with a fresh and unprejudiced mind.

The aftermath of Mill — once the attempt by Spencer, Comte and Mill to achieve a synthesis had met with failure-resulted in the splintering of social knowledge into a multiplicity of distinct disciplines, which have since then continued, with some exceptions, to move further and further apart, almost like the break-up of a dying star. Now, the crucial issue that needs to be faced is the following: how positive is this specialization? What risks does it involve? What damage has it caused? It is with some satisfaction that I note a few steps towards addressing this issue within contemporary economics. The tendency towards complacent self-sufficiency has lessened, and less scope is conceded to the tendency to colonize the rest of social knowledge: indeed, I would say that in a thrust to mirror the variety and complexity of social phenomena more closely, present-day economic thought is branching out into a myriad of interconnecting strands. I see something symbolic in the fact that one of the 2002 Nobel prize-winners for economics declares himself to be, first and foremost, a psychologist.

In conclusion, the picture of Alfred Marshall emerging from the Millian-but not only Millian-torments of the early Victorian age is of one whose intellectual outlook diverged from the approach adopted by the bulk of the economists of his age, and above all by the subsequent generations. As opposed to a coarse positivism that became commonplace among economists, ${ }^{22}$ Marshall retained an evolutionary conception in which there was ample space for the role of ideals and human consciousness. ${ }^{23}$ The very acceptance of the market society, which was no less pronounced in Marshall than in his contemporaries, was accompanied by subtle but 'weighty' reservations, increasingly incomprehensible to run-of-the-mill economists.

Over time, this initial discrepancy intensified into an increasing eccentricity of his position with respect to the evolution of twentieth-century economic thought. In Marshall's vision, progress in economics was not so much to be achieved through the study of monetary phenomena or through abstract diatribes on the theory of value or general economic equilibrium, but rather through careful painstaking examination, with an open-minded attitude in true Baconian and Darwinian spirit, of man's countless answers to the everyday problems individuals raise and seek to address. Among the many messages that can be derived from the rereading of Marshall I have proposed, this is perhaps the most important one.

And, last but not least, I would underline the desirability of a critical and dispassionate investigation of what to my mind still remains an insufficiently and poorly explored question, namely the outcomes and the dissolution of the Marshallian approach. ${ }^{24}$ Such a venture could pave the way towards a better understanding of his most amazing return, which is at least partly predicated on the surge of empirical studies on post-war development in Italy. 


\section{Notes}

* A previous Italian edition of this chapter was originally delivered, as invited Lecture, at the $43^{\text {rd }}$ Annual Scientific Meeting (Ferrara, 25-26 October 2002) of the Società Italiana degli Economisti (Italian Economic Association).

1 I wrote extensively about this 'climate' in Becattini (1991b).

2 One of the episodes that struck me particularly during this conference was the paper presented by Phyllis Deane on the Memorandum on the Fiscal Policy of International Trade, dating from 1903, in which Deane, Professor of Economic History at Cambridge, displayed a somewhat scornful attitude to Marshall's economic theories, preferring the 'political jargon'-allow me to call it such — of his opponent, the philosopher and Prime Minister Gerald Balfour. The version of Deane's paper published in MacWilliams-Tullberg (1990) does not reproduce the 'scoffing tone' of the paper she read.

3 Léon Walras wrote to Vilfredo Pareto, in 1892: 'Alfred Marshall ce grand éléphant blanc de l'économie politique.' Cf. Jaffè (1965).

4 On the issue of contextualization, see, as well as the two works mentioned, at least: Jha (1973); Collini, Winch and Burrow (1983); Kadish (1983); Maloney (1985); Loasby (1989, 1999); Deane (2001) and several papers by A.W.Coats.

5 A.Gramsci raised a similar query concerning the interpretation of Marx (Gramsci 1975).

6 These two volumes were of crucial significance in drawing the attention of scholars to Marshall's very early economic works, almost all of which had remained unpublished. With regard to the early Marshall I would also like to mention the fine work by Marco Dardi (1984). However, since this work appeared prior to the interpretive turning point I mention here, it failed to achieve the success which, in my view, it deserved.

7 These manuscripts are, perhaps, no less helpful for an understanding of the Marshall of Principles and Industry and Trade than the Paris philosophical manuscripts for an understanding of the Marx of Capital. T.Raffaelli suggests they are to Principles as The History of Astronomy is to The Wealth of Nations. See the introduction to Raffaelli (2003).

8 E.g., Groenewegen (1990) and various articles in the Marshall Studies Bulletin.

9 Far less strange after Raffaelli's revelation of the surge of studies on this matter in an author like William Clifford, a close friend of Marshall's.

10 It hardly need be stated that Marshall did not engender the concept, fully fledged and raring to go, purely out of his own mind. One has only to consider a writer such as Alexander Bain.

11 It is well known that Marshall ascribed importance to what at that time was meant by 'race'.

12 Cf. Brusco (1989:500): 'I think - he writes at the end of his collection of essays - that the object of economic theorizing - that is, human behavior - requires that the frame of theory be made of short chains; where little by little the many facets of traditions, cultures, customs, styles of life of contemporary civilization, find their place and role.'

13 Some have seen this tentative hypothesis of social mobility as a response to the socialist challenge mentioned earlier and, additionally, as echoing the controversy on non-competitive groups.

14 Marshall's ideas on the educational or detrimental role of social labour emerge in the above mentioned early lecture on 'The future of the working classes' more vividly than elsewhere. See, preferably, the version reproduced in Raffaelli, Biagini and MacWilliams-Tullberg (1995).

15 Almost a return from Ricardo's net product to Smith's gross product.

16 The Economics of Welfare (1920) by A.C.Pigou and The Economics of Fatigue and Unrest (1924) by P.Sargant Florence represent attempts to reply to those questions.

17 Which in effect develops and gives a more precise rendering of certain flashes of brilliant intuition he drew from some of his contemporaries.

18 Marshall sides with the more open approach of Smith.

19 Perhaps there is something of this kind, with reference to the first element, in Carlo Cattaneo (cf. Becattini 2001). 
20 See Book I of Industry and Trade.

21 'Strong individuality, resolution and directness of purpose may enable a multitude of British businesses of moderate size to hold their own against powerful aggregations in all those industries, in which no overmastering technical advantage belong to massive, continuous production: provided these qualities are united with frank willingness to learn from others; and to cooperate genially with others in matters in which unfettered association has large opportunities' (Marshall 1919:584).

22 Also affecting his dearly loved J.Neville Keynes.

23 Significant is the set of authors (Hegel, Goethe and Darwin) who, according to Marshall, pointed nineteenth-century scientific philosophical thought in the right direction.

24 I refer here to the developments of Marshall's thought that were formulated not so much by thinkers such as A.C.Pigou, J.M.Keynes or D.H.Robertson, but rather by D.H.MacGregor, J.S.Chapman, W.T.Layton, P.Sargant Florence, and a long string of figures right up to E.A.G.Robinson and B.Loasby. 


\title{
10 \\ Marshall on India
}

\author{
Tiziano Raffaelli
}

Though Marshall wrote nothing specific on India, his interest in its economic and social problems and history was long-lasting and profound. The Catalogue of the Marshall Library of Economics, compiled by Mary Marshall in 1927, lists 44 books and more than 50 official documents specifically devoted to India, almost all of which belonged to her husband, ${ }^{1}$ and the number of journal articles bound in Marshall's miscellaneous volumes which directly refer to India amounts to 63 titles. $^{2}$ Most of these publications deal with Indian currency and finance and are somehow related to the Indian Currency Committee of 1899, but many items are of more general interest or deal with other subjects (education, women's conditions, transport, the factory system, etc.). Moreover, Marshall seems to have been used to work on Indian issues, as attested by Keynes's well known obituary: '[Marshall] was pleased with his detailed realistic inquiries into Indian problems, and the great rolls of Indian charts, not all of which were published, were always at hand as part of the furniture of his study' (Pigou 1925:53).

Marshall's concern for India is the sequel to a long tradition of British economists who took a close interest in the colony. James and John Stuart Mill, as well as Herman Merivale and William Thornton, worked for the East India Company, which also ran the East India College at Haileybury, where Thomas R.Malthus and Richard Jones taught for many years. Torrens, McCulloch, McLeod, Fawcett, Jevons and many other economists were also involved in debates about Indian economic problems. Land tenure and fiscal and monetary policy were the main issues of colonial policy which required the economists' expertise and advice. At the same time, participation in such debates helped to forge the general thought of British economists on these and related topics. ${ }^{3}$

The limited aim of this chapter is to show that for Marshall India was not simply the main problem of British colonial policy: ${ }^{4}$ rather, it was also a privileged test of the validity of some of his general ideas on the relationship between 'custom' and 'competition' and the possibilities of economic and social progress. Judging from the evidence at our disposal, it seems that the latter role of India's economic problems proved more relevant than the former, mainly because of Marshall's unwillingness to draw conclusions about economic policy issues from the application of analytical tools to incomplete empirical data. After providing an overview, almost in reverse chronological order, of the events and circumstances which repeatedly brought India to Marshall's attention, the chapter focuses on the evolution of his thought, concluding that Marshall's keen interest in Indian affairs was rewarded by the influence which their study exerted on his general views. 
Marshall's best-known intervention on India is the evidence given before the Indian Currency Committee in January and February 1899. Marshall's answers, almost entirely devoted to theoretical discussions of monetary problems, follow the main lines of the evidence he had given 12 years earlier before the Gold and Silver Commission, but with such improvement that he was firmly convinced they constituted 'his best account of the theory of money' (Pigou 1925:53). Openly acknowledging, as usual, ignorance of specific Indian problems, he stated that he had accepted to be questioned by the Commission only because the inquiry concerned 'some broad issues of economic principles' and went 'beyond questions of practical administration' which would have required 'much knowledge of India' (Keynes 1926:267). In his evidence, Marshall expounds his cautious version of the quantity theory of money, endorses the classical theory that interest rates are due to real causes, traces the effects of price variation on income distribution and the economy - reiterating the opinion, held after abandoning the opposite view, that a slow downward movement of prices is better than inflationary tendencies - and maintains the need to adjust the quantity of money to cyclical and seasonal needs. He also insists on the distinction between the gold value of the rupee and its purchasing power, pin-pointing the ambiguity of the term 'depreciation' as he had done before the Gold and Silver Commission. Examining Marshall's answers, Khrishnaswami (1942) underlined the many points of contact with Keynes's later approach to monetary issues. Thus on the specific matter of Indian problems, Marshall states:

a) the expediency — based on the conservative principle that 'the function of a legislator as regards currency is to do as little as possible' (Keynes 1926:292) — of keeping the rupee rate of exchange at 1.4 pounds, as fixed in 1893 after closure of the Indian mint and replacement of traditional silver money with gold-anchored currency; ${ }^{6}$

b) the difficulty of forming an opinion on variations of Indian prices because of the gap between prices in ports trading directly with European markets and those prevailing in the inner part of the country;

c) the usefulness of the Central Bank - similar to those recently instituted in Continental Europe and operating in regime of the gold-exchange-standard - or some other institutional device to buffer price variations and back anti-cyclical policies.

The third proposal-formulated in general terms, because the particular plan 'must lie with those who know more of India, and more of the practical side of banking than I do' (Keynes 1926:324) — would be taken up later by the young Keynes, who can be said to have replaced Marshall as the most eminent economic advisor to the India Office (Moggridge 1992:203). After a few years of employment in the Indian Office itself, Keynes acquired the specific knowledge which was needed to detail the plan of the Indian Central Bank. First in a series of articles and lectures and then in Indian Currency and Finance (1913), Keynes made use of the history and problems of Indian currency to praise the gold-exchange-standard above the more costly and less flexible gold standard. Later on, in the Annexe to the Final Report of the Select Committee on Indian Currency and Finance, he advocated the need of a Central Bank for India, capable of regulating the internal currency and the rate of exchange by selling and buying in the open market 
(Moggridge 1992:224-8). The Annexe had a great impact on Marshall. After repeating once again that his knowledge of India was very poor, he ventured to confess his admiration for the work, stating that he had been 'entranced by it, as a prodigy of constructive work' (Whitaker 1996, III:305) and concluded that 'Verily we old men will have to hang ourselves, if young people can cut their way so straight and with such apparent ease through such great difficulties'. This provides good reasons for believing that Marshall considered Keynes's monetary policy proposals wholly in line with his own monetary theory,

However, it is interesting to notice that Marshall did not put much weight on the analytical and empirical problems of Indian currency, as can be evinced from his correspondence at the time when he was giving his evidence to the Indian Currency Committee. In December 1898 he regretted being busy with 'that detestable subject, Indian Currency' (Whitaker 1996, II:242) and a few months later, keeping an eye on the educational requirements for the Indian Civil Service, ${ }^{7}$ he wrote to Bonar that he considered the subject useful only as a 'peg' for more relevant ones:

I do not want people to study Indian currency! I want them to have studied the economics of industry and trade; fluctuations of commercial prosperity; good and evil of international indebtedness, of paternal policies in railway matters and so on. I am using currency reserves as my peg; because currency reserves happen to be under discussion. But I am never weary of preaching in the wilderness 'the only very important thing to be said about currency is that it is not nearly as important as it looks'.

(Whitaker 1996, II:246)

\section{II}

Fundamental for assessing Marshall's ideas on money, prices and fluctuations, the 1899 evidence is really no more than an episode in the development of Marshall's thinking on India, whose reconstruction requires investigation of other sources.

A precious trace of Marshall's more general interest in Indian affairs is the article published in the September 1892 issue of The Economic Journal in reply to Cunningham's fierce critique of chapters 2 and 3 of Principles, which were later to form Appendix A. Refuting accusations of approximation and superficiality in dealing with economic history, Marshall maintains that his discussion of land tenure systems is based on P.Gavrilovitch Vinogradoff's Villainage in England and Richard Jones's Literary Remains, a work which 'gave a direction' to his understanding of 'the contrast between medieval and Indian tenures on the one hand and modern English on the other' (Guillebaud 1961:73 9n.). Though Marshall read Jones much earlier, ${ }^{8}$ his attention focused on the economic problems of modern India only in 1883-84, when he was teaching Indian cadets at Oxford (Pigou 1925:53; Groenewegen 1995:295). There he met the young Russian historian who was doing archive research for his 'fascinating' book, first published in 1887 and translated into English in 1892.' Disagreement with Cunningham centred on subjects which Marshall had already tackled in similar terms in the Cambridge inaugural lecture, delivered just at the end of his Oxford period; namely 
the relationship between 'custom' and 'competition'-between traditional, routine action and that dictated by the 'equilibration of measurable motives' (Pigou 1925:170) — and the degree of resistance to economic change exerted by customary thought and behaviour.

Vinogradoff's history of the English manor showed that old communal institutions were preserved and partly re-adapted to the needs of the new economic system. The open-field system of cultivation for instance, clearly a relic of the village community and originally functional to its economy, survived in the manorial system but was 'in some degree distorted and warped from its original shape' (Vinogradoff 1968:401). This reconstruction made it clear that custom, far from being fixed and unexplainable, resulted from the action of economic and social forces and was continuously driven to vary by their powerful and changing influence. Vinogradoff's reasoning on the evolution of medieval institutions induced Marshall to reflect that custom, though resistant, is slowly and almost inadvertently re-shaped by economic forces. Thus, in the 1892 article the Russian scholar is said to be one of the historians of medieval times who 'have assigned to custom rather a narrower scope and a rather greater pliability than before' (Guillebaud 1961:738).

However, the author who probably provided the universal key to solve Marshall's theoretical problems was Henry Sumner Maine, who had investigated and compared the socio-economic institutions of India, medieval Europe and the Ancient world. Marshall's early reading of Ancient Law and Village Communities in the East and West is well documented (Groenewegen 1995:167-8), but he went back to Maine's writings in the 1880 s, while rethinking the role of custom in human history. The Marshall Papers show a lasting interest in Maine's work throughout the 1870s and 1880s, when Marshall often referred to Maine's writings on medieval history, transcribing passages from his own copies of Maine's books (Marshall Papers 4/13, 4/17, 4/19). ${ }^{10}$ However, Marshall's notes do not bear clear traces of the change of opinion openly declared in the Economic Journal article, neither do his annotations on Ancient Law. ${ }^{11}$ In the article, Marshall states that the starting point of his studies was 'in the teaching of Henry Maine and others that, since people brought up under the influence of custom have habits of mind not like ours, they are, for that very reason, able to persuade themselves that they are adhering to custom, when they are really modifying it. They adopt different means for attaining their ends from those which we do, and are not nearly as conscious of what they are doing. But I believe that the desire to do what is best for oneself is seldom wholly absent from human nature' (Guillebaud 1961:738). The passage seems implicitly to rely on the concept of 'legal fiction' which in Maine's view was the earliest device for adapting social norms to new needs, before the same task was performed first by equity and then by legislation.

In Ancient Law, the triad of successive devices for amelioration of norms-legal fiction, equity, legislation - is explicitly limited to Western history, but Maine generalises the notion of 'legal fiction' beyond the boundaries of Roman law, where it signified 'a false averment on the part of the plaintiff which the defendant was not allowed to traverse' (Maine 1905:23) and which gave jurisdiction to Roman courts. This happened for instance when the plaintiff declared himself to be a Roman citizen, when in truth he was a foreigner. This fiction resembles those contrived in England by the Queen's Bench in order 'to usurp the jurisdiction of the Common Pleas'. ${ }^{2}$ In all these cases, the fiction was simply a means by which the tribunal extended its jurisdiction beyond its original 
boundaries, but in Maine's wider meaning 'legal fiction' came to signify 'any assumption which conceals, or affects to conceal, the fact that a rule of law has undergone alteration, its letter remaining unchanged, its operation being modified'. English Case-Law and the Roman Responsa Prudentium fall under Maine's concept of legal fiction: 'the fact is in both cases that the law has been wholly changed; the fiction is that it remains what it always was'. 'It is not difficult'-Maine goes on - 'to understand why fictions in all their forms are particularly congenial to the infancy of society. They satisfy the desire for improvement, which is not quite wanting, at the same time that they do not offend the superstitious disrelish for change which is always present. At a particular stage of social progress they are invaluable expedients for overcoming the rigidity of law', as witnessed by the 'fiction of adoption' which, by feigning family ties, modifies and extends the application of family law (Maine 1905:24).

Likewise, the eighth lecture of Early History of Institutions - 'The growth and diffusion of primitive ideas' - emphasises that new ideas, habits and social relations do penetrate even into societies apparently ruled by tradition, but that in order to gain acceptance they have to be dressed in customary clothing. In the same chapter, Maine also concedes that 'the difference between the East and the West, in respect of the different speed at which new ideas are produced, is only a difference of degree' (Maine 1880:226), a statement which Marshall, who always championed continuity, certainly endorsed whole-heartedly. Moreover, Maine's 1875 Rede Lecture, 'The effect of the observation of India on modern European thought', included in subsequent editions of Village Communities in the East and West, ended with a note of confidence about the possibility of Indian progress under British rule: 'It is this principle of progress which we Englishmen are communicating to India' (Maine 1881:238).

The agent of change inherent in human nature is defined by Marshall as 'the desire to do what is best for oneself'. This is almost the same as Maine's 'desire for improvement' and goes back to Smith's 'desire to better one's own condition', which is the secret spring of social change in Wealth of Nations. Starting from recognition of this leading force, whose action often passes unnoticed, the task of the economic historian is to search 'the slender records of medieval customs for subterranean channels of change' (Guillebaud 1961:741). In a long footnote, which is said to be based on Indian evidence, Marshall lists six circumstances which explain why change of custom can easily take place without being openly declared: 1) evasion without breakage; 2) vagueness and elasticity of custom itself; 3) exceptions to customary rules of payment, which are more numerous than usually thought of; 4) external shocks that forcibly disturb economic and social conditions; 5) inapplicability and loss of exact meaning of old customs in the presence of such disturbances; 6) rapidity with which the causes of change are forgotten and new customs acquire prestige.

According to Marshall, these elements of custom variability are particularly effective in the economic sphere, prices and money above all, as he explicitly states in his evidence before the Indian Currency Committee (Keynes 1926:181, 274-5; cf. also Marshall's letter to Edgeworth of 17 June 1886 in Whitaker 1996, I:209). Both the 1899 evidence and the 1892 article, as well as Industry and Trade (see below), place great emphasis on knowledge of the economic conditions of contemporary India as a key to understanding those of the Middle Ages and the evolution of Western societies. This may be one of the reasons why Marshall gathered extensive information on Indian prices, by means not 
only of published statistics, but also directly, asking his brother, who lived in India (Groenewegen 1995:38-9), to collect businessmen's and experts' answers to a questionnaire. ${ }^{13}$ This gives a hint of Marshall's general method of doing economics, in which abstract reasoning was continuously tested and revised through direct acquaintance with the phenomena which it sought to explain.

\section{III}

The novelty of Marshall's opinion on Indian custom emerges by comparison with his earlier writings. On Method and History of Economics, a text probably written at the beginning of the 1870s, shows quite different views on India. Under the influence of Kautz's Geschichtliche Entwickelung der National-Oekonomik, Marshall presents India as a society in which individuals act under the absolute rule of nature, with no margin left for the pursuit of their own aims:

as a consequence, then, of this passive acquiescence in 'Natural' arrangements we have an absence of the habits of the determination of his conduct on the part of each individual so as to obtain most completely his own ends. Men do not seek to 'buy in the cheapest market and sell in the dearest market'. Trade in any broad sense of the word does not exist.

(Groenewegen 1990:13)

This view leads Marshall to criticise Hegel, though not unreservedly, ${ }^{14}$ for beginning his philosophy of history from China, where people at least pay obedience to civil law and political authority, instead of India, where they live under the impersonal and absolute rule of nature.

A similar view of India is to be found in Economics of Industry (1879):

The fixed customs which thus controlled men's lives have been especially powerful in the East. ...In India...custom decides the Caste or rank in society to which a man belongs... [and] regulates the wage of each kind of service, and the price of every commodity with an inflexible rule.

(Marshall and Marshall 1879 [Macmillan]: 44)

The distance from Marshall's later opinion expressed in the inaugural lecture and in his polemics with Cunningham is evident. It seems therefore that the period 1883-84 was decisive in producing a change in Marshall's thought, awakening him to the realisation that the rule of custom is never unchallenged, probably thanks to his contacts with Vinogradoff and further thoughts on Maine.

It may be guessed that acknowledgment of the inextricable interconnection between custom and economic change produced an impact both on Marshall's conception of the economic organon, whose power is exalted in the inaugural lecture, and on that of normal value. When the contraposition between custom and competition becomes less absolute and rigid, the scope of the economic organon is widened (as it is in the inaugural lecture), but at the same time, precisely because it becomes applicable to various historical 
contexts, its action becomes 'relative', as witnessed by the new notion of normal value. The way the latter is defined in Economics of Industry implied perfect competition and absence of any obstacle exerted by custom:

when we speak of Normal values, or Normal prices, or Normal wages, or Normal profits, the particular set of Laws which we have in view are those Laws of human nature and human conduct which are brought into play when competition is perfectly free.

(Marshall and Marshall 1879:66)

Also implied was the possibility of a clear demarcation between custom and competition, but all these assumptions were doomed to disappear in Principles: 'Normal does not mean Competitive. Market prices and Normal prices are alike brought about by a multitude of influences of which some rest on a moral basis and some on a physical; of which some are competitive and some are not' (Marshall 1920b:347-8). This change of opinion is confirmed by Marshall's annotation in the margin of his own copy of the 1886 printing of the earlier book: 'be careful to strike out everything wh. implies that normal value $=$ competitive value' (Whitaker 1975, I:73 n. 21; cf. also Marshall's letter to Clark of 11 November 1902 in Whitaker 1996, II:413). ${ }^{15}$

In accordance with the prominence explicitly awarded in Principles to the dynamic and evolutionary elements of economics (Marshall 1920b:366n.), its logical tools are now employed to explain change rather than stability and equilibrium. When dealing with economic history, the task of economic analysis is to explain genetically those phenomena which historians are wont to attribute to custom: 'to say that any arrangement is due to custom, is little more than to say that we do not know its cause' (Pigou 1925:169). Marshall's aim is to develop a kind of economic analysis which, when refined in the light of the economic facts of modern India, becomes capable of producing the 'solvent' which is needed to understand 'much that is now unintelligible in medieval economic history' (Pigou 1925:171). ${ }^{16}$ The judgement is repeated, with caution, in the third edition of Principles (Marshall 1920b:643n.) and in Industry and Trade, where suggestions derived from the study of India, and

conducted in the spirit of Maitland and Professor Vinogradoff, may explain many of the apparent paradoxes of English medieval history and show that custom is often the gradual result of economic conditions; even where it appears at first sight to be their governing cause, rather than their effect.

(Marshall 1919:798n.)

Once again, prices of harvest and staple commodities (more than wages) are said not to be ruled by tradition, and sudden changes - like famine, plague or flood - are said to undermine the authority of custom. Moreover, as soon as a new custom becomes established, it earns the same prestige as the one it replaced.

In many respects, Marshall's research programme resembles that of the modern neoinstitutionalists, but while the latter seem to set off in pursuit of definitive explanations, Marshall's humbler attitude is to dissect the evolution of economic systems into a 
continuous succession of innovative variations and routine repetitions in which neither of the two elements can be dispensed with: both are always at work and differences of social contexts in respect of progress are largely differences in their mix. Progress implies plasticity rather than dismissal of custom, whose resistance is essential in order for innovation to leave its trace, according to the admirable image of book II, chapter II section 1 of Industry and Trade (Marshall 1919:197-8). To be sure, this is a section that refers to technological innovation, but its general scheme is valid for any evolutionary process, as witnessed by Marshall's cross-reference where he discusses economic and social evolution (Marshall 1919:797). The general model is the Darwinian one of variation and selection, in which custom represents the result of previous selection. ${ }^{17}$

However, in Marshall's juvenile writing on the method and history of economics there is a judgment which, unlike that on the absolute rigidity of Indian custom, was not subverted in his later writings; namely, the idea that the paralysing factor of Indian history is represented by the religious nature of the caste system. While in feudal Europe all the people, though confined to their social status, worshipped the same God, infinitely superior to any human being, and each person was conceived as a subject of absolute, intrinsic value; in India the Brahmins were distinguished from the other castes precisely on religious grounds (Groenewegen 1990:12). In the same vein, in Principles Marshall praised the Christian tradition in which the ecclesiastical career is open and does not constitute a caste prerogative (Marshall 1920b:737). But some weakening even of this dichotomy is implicit in the passages in which Marshall laments similarity between the Indian caste system and the division of labour, which presents some of the aspects of rigidity typical of the former (Marshall 1920b:224-6). The comparison is introduced to underline the need to overcome the evils of divided labour in modern Western society, but, considered from the opposite perspective, it seems to imply that even the ills of India's caste system can be overcome. The persistence of similar institutions throughout the history of different peoples proves their adaptive value and, as in any similar case of traditional persistence, invites the search for a functionalist explanation (Pigou 1925:169). Nevertheless, it is a cause of social backwardness and must be removed to achieve social progress.

\section{IV}

In Marshall's view of progress, the development of market transactions is a factor capable of eliciting innovative faculties in the economic sector, as it was for Smith. Protective duties, though not excluded in principle, are always dangerous since their effect is to slacken rather than rouse human energies (Whitaker 1996, III:268-9, 282-4). The function of trade is to remove hindrances to economic progress; therefore, widening of the market sector, betterment of transport facilities and influx of foreign capital are decisive for Indian development. But the breakthrough depends on the spread of new cultural attitudes and the main help Britain can provide to this process lies in the human qualities of the many able young Englishmen who are sent to India. They do not figure on India's list of imports but are really the most important 'unreckoned' item of its balance of trade (Marshall 1923:134-5). The Indian Civil Service forms a weighty component of Indian imports which is not paid up to its full value. ${ }^{18}$ Paradoxically, even the most 
positivistic Marshallian opinion - the statement that progress depends on the climate (Marshall 1920b: 724-5; Keynes 1926:325; Marshall and Marshall 1879:44) — calls to mind the key role of the human factor: progress is hindered not by the climate itself, but by its negative influence on mental and bodily vigour.

Thus, the wellspring of Indian economic development is, in Marshall's eyes, to be found in a cultural revolution which is both necessary and difficult to attain. This theme is prominent in his correspondence and rests on his personal experience as a teacher. What Indian students lack is not the will to make a go of it when they return to their country, but a feeling of social mission which would induce them to pursue enterprises that can make India great. This marks a decided difference of cultural values in comparison to their Japanese colleagues. The Japanese student in Cambridge 'nearly always asks himself in what way he can strengthen himself to do good service to his country on his return' while 'the best Indian minds seek self-culture, or the barren work of pleading in the Courts [barren of good to the country as is the sand of the sea shore], rather than those creative enterprises which might make their country strong' (Whitaker 1996 III:268, 283). To become a great nation, India needs more people who do not scorn patient work and go home not to make a display of their culture, but to serve their country. Together with disposition to innovate, progress needs a set of values capable of putting that disposition to the right task. Japan's 'quick rise to power' depends on its people's willingness to do good service to their country and 'supports the suggestion, made by the history of past times, that some touch of idealism, religious, patriotic, or artistic can generally be detected at the root of any great outburst of practical energy' (Marshall 1919:161).

\section{$\mathbf{V}$}

This brief survey of Marshall's interventions on India reveals how much it bore on key themes of his social thought. It also suggests that India was a source of inspiration for some of his most profound social and economic ideas. Discussion of Marshall's vision of India throws light on how the subcontinent contributed to shaping and changing Marshall's opinions on relevant points - the relationship between custom and competition - while reinforcing them in other respects - the absolute prominence of the human factor, in particular of cultural values. If one adds to the picture that India provided a litmus-test for Marshall's inductive-deductive method and for his monetary theory, it can be concluded that Marshall's economic thought, like that of many other British economists, was more than occasionally interlaced with Indian economic problems and history.

\section{Notes}

* A former version of this chapter was presented at the meeting of the Associazione Italiana per la Storia del Pensiero Economico, Lecce 2001. I wish to thank K. Caldari for help with aspects relating to the Marshall Archive.

1 Four books were published after 1920 and some of the official documents are probably related to Keynes rather than Marshall I owe this information on the Catalogue to J.K. Whitaker.

2 Seven of them are annotated. 
3 For a general assessment of British economic thought on India see Ambirajan $(1977,1978)$ and Barber (1975).

4 Though 'Marshall was not a staunch imperialist', he was concerned with imperial policy and the future of the British Empire. In particular, he believed that British rule in India should address poverty and repay the country's 'generous' commercial policy towards Britain, i.e. the traditional openness of Indian markets to British goods (Groenewegen 1995:607; Keynes 1926:420).

5 The reason is that 'almost any currency of which the position is certain will do its work fairly well. Frequent changes in its basis disturb expectations, upset reasonable calculations, and infuse a spirit of uncertainty in business. They resemble the frequent wakings of a patient in order to administer sleeping draughts' (Keynes 1926:292).

6 The decision was supported by the Report of the Commission Appointed to Inquire into the Indian Currency (1893). On the Report's consciousness of the contrasting interests which were at stake, and on Marshall's not dissimilar attitude, cf. De Cecco (1979: chapter IV).

7 Marshall was of the general opinion that at least some of its staff needed better training in economics (Keynes 1926:325).

8 On Jones's influence in the years of Marshall's economic apprenticeship see Pigou (1925:296) and Whitaker (1975:II, 264).

9 Remembering their friendly encounter, Mary writes: 'Alfred happened one day to meet Professor Vinogradoff and he was so much fascinated that he asked him to dine with us....I never heard him talk as freely as he did that evening, and I would give much to be able to recall that conversation' (M.P.Marshall 1947:38-9).

10 Maine's books listed in Mary's catalogue of the Marshall Library are: Ancient Law $\left(3^{\text {rd }}\right.$ edn 1866), Early History of Institutions (1875), Village Communities in the East and West ( ${ }^{\text {th }}$ edn 1881), Early Law and Custom (1883) and Popular Government (1885). Marshall's bound volumes of essays also contain three articles by Maine from The Fortnightly Review (1877, 1881 and 1882). All these items are still in the Marshall Library of Economics.

11 Marshall's copy bears a few comments and numerous sidelines on page margins (including the pages discussed below). Several references to Hegel and a comment on India and China - see below - suggest an early date for at least most of the annotations. The other copies of Maine's works listed in the previous note are not annotated.

12 One such device, called 'fiction of a trespass', is described in Smith's Lectures on Jurisprudence (LJ A V.25:280).

13170 pages of such answers by 15 Indians to Marshall's questionnaire about variations in prices, wages and rents are now preserved in the Marshall Papers (4/17).

14 Reservations on this criticism of Hegel are also expressed in a comment to a passage of Ancient Law in which Maine maintains a position similar to that of Marshall, who however, in view of the deep religious feelings of India writes: 'yet Hegel is in some ways right in regarding China as spiritually more backward than India' ( $3{ }^{\text {rd }}$ edition, p. 23. Annotated copy in the Marshall Library of Economics).

15 While Whitaker (1975:I, 73) regrets this change, which deters Marshall from straightforward acceptance of pure equilibrium analysis, Dardi (1984) considers this a new opening towards Marshall's more mature style of economics.

16 These passages are taken from the inaugural lecture where Marshall's new turn of mind on the pliability of custom is already clear: 'If the preponderance of economic motive is strong in one direction, the custom, even while retaining its form, will change its substance, and really give way' (Pigou 1925:170).

17 For the origin and analysis of Marshall's evolutionary model, the reader will forgive me for referring to Raffaelli (2003).

18 This judgment seems to address alleged accusations that the costs of colonial government drained wealth from India and points out the overwhelming benefits that India derives from Britain's rule. 


\title{
11 \\ Alfred Marshall and Grand Social Reform
}

\author{
John K. Whitaker ${ }^{1}$
}

\begin{abstract}
The management by working men of the businesses in which they are themselves employed is neither as efficient nor as free from friction as it would be if we social reformers had been able to arrange the world just to our own liking-Alfred Marshall addressing the Cooperative Congress in 1889.
\end{abstract}

(Pigou 1925:243)

At first glance it is a little surprising to find Alfred Marshall putting himself forward as a social reformer. Even the most casual acquaintance with his mature writings suggests that the reformist element is subdued and that any youthful sympathy for socialist aims was soon abandoned. But it would be wrong to pigeonhole him as a doctrinaire conservative intellectually, or even as a practicing Conservative politically-if anything his political sympathies seem to have lain with the Liberal party, although he was careful to remain above the political fray and maintain an aura of magisterial impartiality. ${ }^{2}$ As Donald Winch, writing of the last quarter of the nineteenth century, justly remarks;

\begin{abstract}
Any differences...between socialists and liberal economists at this time were not so much conceptual as practical; they concerned the extensiveness and seriousness of contemporary abuses, and the pace at which society could be made to move towards new forms of social organisation without attendant loss of benefit from the old. It was only in the context of a debate of this kind that Marshall must be accounted a conservative.
\end{abstract}

(Winch 1969:36)

For his day, Marshall's views on social and economic reform were mildly progressive and not at all extreme, but the kinds of reform he favoured were clearly slow and piecemeal, not fast and sweeping. Despite a strong sympathy for the poor and downtrodden, and despite his self-confessed youthful 'tendency to socialism', it is clear that he was never in sympathy with proposals for revolutionary social change. ${ }^{3}$ Instead, he was an incrementalist who placed his hopes for the future on the evolutionary forces he perceived to be steadily changing social institutions and human attitudes or capabilities. Desirable reform was for him a matter of nudging these forces along in the right direction, and forcible intervention by the state, through legislation or direct governmental action, was far from the only route through which he saw such reform as 
proceeding. Inculcating appropriate individual attitudes, and fostering the development of appropriate private institutions, seemed equally important, if not more important, goals. He saw the economist as playing an important role in both analysing and urging such evolutionary developments. With age, he became increasingly strident in his opposition to proposals for sweeping social and economic change, proposals that centred in his day on the issues of 'socialism' and 'collectivism'. But his attitude to such proposals was already clearly formulated in a little known passage from his paper to the Industrial Remuneration Conference of 1885 that deserves to be quoted in full. ${ }^{4}$

In one sense indeed I am a socialist, for I believe that almost every existing institution must be changed. I hold that the ultimate good of all endeavour is a state of things in which there shall be no rights but only duties; where everyone shall work for the public weal with all his might, expecting no further reward than that he in common with his neighbours shall have whatever is necessary to enable him to work well, and to lead a refined and intellectual life, brightened by pleasures that have in them no taint of waste or extravagance. But I fear that socialists would refuse to admit me into their fold because I believe that change must be slow. /I admit that even now every right-minded man must regard himself rather as the steward than the owner of what the law calls his property. But there are very few directions in which I think it would be safe at present to curtail his legal rights. I admit that Utopian schemes for renovating society do good by raising our ideals, so long as they are only theories. But I think that they do harm when put prematurely into practice: for their failure causes reaction. /Economic institutions are the products of human nature, and cannot change much faster than human nature changes. Education, the raising of our moral and religious ideals, and the growth of the printing press and the telegraph have so changed English human nature that many things which economists rightly considered impossible thirty years ago are possible now. And the rate of change is increasing constantly and rapidly. But we have not now to speculate for the future; we have to act for the present, taking human nature not as it may be, but as it is. /Even as human nature is, an infinitely wise, virtuous, and powerful government could, I will admit, rid us of many of our worse economic evils. But human nature is, unfortunately, to be found in Government as elsewhere; and in consequence Government management, even if perfectly virtuous, is very far from being infinitely wise...wastefulness is the least evil of Government management. A greater evil is that it deadens the self-reliant and inventive faculties, and makes progress slow. But the greatest evil of all is that it tends to undermine political, and through political, social morality.

(Marshall 1885a:173-4)

This passage surely epitomizes the central views on socialism and collectivism that Marshall was to maintain for the remainder of his life. While sympathizing with the ideals of the socialists, and empathizing with the sufferings of the poor, he invariably 
counseled caution in instituting radical social change. It must wait on slow changes in human nature and attitudes. The following passage occurs in all editions of Principles:

Projects for great and sudden changes are now, as ever, foredoomed to fail, and to cause reaction; we cannot move safely, if we move so fast that our new plans of life altogether outrun our instincts. It is true that human nature can be modified: new ideals, new opportunities and new methods of action may, as history shows, alter it very much even in a few generations; and this change in human nature has perhaps never covered so wide an area and moved so fast as in the present generation. But still it is a growth, and therefore gradual; and changes of our social organization must wait on it, and therefore they must be gradual too. /But though they wait on it, they may always keep a little in advance of it, promoting the growth of our higher social nature by giving it always some new and higher work to do, some practical ideal towards which to strive. Thus gradually we may attain to an order of social life, in which the common good overrules individual caprice, even more than it did in the early ages before the sway of individualism had begun.

(Marshall 1920b:751-2)

In Marshall's heyday of the 1880s and 1890s the so-called social question was very much at the centre of public concern and discussion. At issue was the position and future of the working classes, with interest focusing especially on the plights of the 'residuum' of hopeless or incorrigible poor, the aged, the unemployed, the workers in the sweated trades, and the denizens of the squalid urban slums. This was the era of the university settlements which, as at Toynbee Hall in London's East End, involved earnest young undergraduates in social work among the poor, of Charles Booth's pioneering inquiries into London's poverty, of the flourishing Charity Organisation Societies through which the urban middle classes attempted to do for the urban poor what the gentry had traditionally done for their rural dependents. Extension of the suffrage and compulsory education were making it possible to view many workers as full citizens rather than as some separate and alien race to be governed and perhaps feared by the ruling classes. Yet there were fears that the rising political power of the workers and an increasingly aggressive trades unionism, perhaps fuelled by Fabian and Marxist ideals, might provoke destructive changes. To judge Marshall fairly he must be seen in the context of this era.

The present chapter focuses on Marshall's antagonistic views towards proposals for sweeping social and economic reform - 'grand' reform as opposed to the 'petit' or incremental reform he favoured. His views on the latter will be outlined briefly, however, to avoid conveying too negative an overall impression.

The attempt to come to grips with Marshall's views on all these matters has a threefold interest. First, an understanding of these views helps us understand better the full range of his thought. Second, his views were not without influence, given his public stature as an economist and his heavy involvement in government enquiries. Finally, his views were broadly shared, and to a considerable extent illustrate the ethos of the educated and somewhat progressive middle-class public in Britain in the last quarter of the nineteenth century. 


\section{On Socialist Organization}

Marshall's animadversions on 'socialism' span many decades and are directed at a variety of targets. Sometimes, especially in his earlier days, his objection was to the 'wild rhapsodies' of the earlier utopian socialists, such as Owen, Blanc, Saint Simon, or Lassalle. ${ }^{5}$ At other times, and especially around the turn of the century, it was what Marshall on one occasion termed 'administrative socialism' - state control of industrythat was vehemently criticized. ${ }^{6}$ Such administrative socialism had a variety of manifestations. At the ideological end of the spectrum, they ranged from the theoretical tenets of revolutionary Marxism to the incipient nationalization plank in the political platform of social democracy, associated in Britain with Fabianism and the beginnings of the Labour Party. Probably it is ideas of Marxist affiliation that Marshall had in mind in asserting that:

It is from German writers, some who have been of Jewish origin, that the world has received the greater part of the most thoroughgoing of recent propositions for utilizing the property of the world for the benefit of the community with but little reference to the existing incidents of ownership. It is true that on closer examination their work turns out to be less original as well as less profound than at first sight appears: but it derives great power from its dialectical ingenuity, its brilliant style, and in some cases from its wide-reaching though distorted historical learning.

(Marshall 1920b:769, see also, 753 and Whitaker 1996, 1:302-3)

The pragmatic end of the spectrum of possibilities for administrative socialism ranged from the growing tendency in Britain to establish municipally owned utilities to the great extension of state bureaucratic control in 'the semi military organization of Imperial Germany', leading to 'State Socialism'. ' In Industry and Trade (Marshall 1919) a new target appeared: the National Guild movement, a form of syndicalism. Marshall saw this as more suited to the Anglo-Saxon temperament than central control by government would be, and believed that it was rapidly gaining ground at the expense of Fabianism, which had 'made something of a compromise with pure Marxian doctrine'. But, although more in sympathy with the National Guild version of 'socialism', he still regarded it as ill considered and as involving 'grave hazards to social stability and progress'.

Marshall's objection to the utopian socialists was straightforward: they assumed an implausible degree of virtue and unselfishness in the common people and their optimistic schemes would almost never succeed, as past experiments with communist communities showed conclusively. Perhaps, after a long course of human evolution, the world might eventually be ready for such schemes, and meanwhile they had a certain poetic appeal in raising aspirations. But 'irresponsible imagination', however seductive, if put into practice prematurely could only 'tend to the setting aside of methods of progress, the work of which if slow is yet solid' (Marshall 1920b:721-2).

The objection to 'administrative socialism,' or government ownership and control of business, was quite different. This form of socialism was practicable-only too seductively practicable - but its advantages lay wholly on the surface whereas its drawbacks came in subtle but cumulative ways that might long escape attention. 
Marshall's fundamental objection, reiterated in an almost obsessive way in his writings, was that government control would inhibit adaptability and the development of new methods, and thus greatly retard the economic growth needed to alleviate poverty and maintain Britain's industrial leadership: ${ }^{9}$

If governmental control had supplanted that of private enterprise a hundred years ago, there is good reason to suppose that our methods of manufacture now would be about as effective as they were fifty years ago, instead of being four or even six times as efficient as they were then.

(Pigou 1925:338)

The sources of Marshall's firm conviction as to the superior efficiency of the private businessman and the inevitable sinking of government enterprise into bureaucratic lethargy and addiction to routine remain obscure. He makes some attempt to sketch a theory of governmental bureaucracy and ministerial control but it does not go far. The case is, he seems to imply, either obvious or conclusively demonstrated by history. ${ }^{10} \mathrm{~A}$ scepticism about governmental, or even joint-stock, control of economic activity might have derived from the views of Smith and his Classical successors, or from blatant examples of free-wheeling American corruption. Possibly a growing awareness that an easily misled general membership of a trade union or a cooperative society might not select its leaders wisely was projected onto the larger political scene with its increasingly democratic electorate. On the other hand, municipal enterprises-gasworks, tramways, and so on-were proving themselves, although Marshall was not prone to lavish praise on them. The successful private business, owned and managed by a skillful, farseeing, innovative, and humane businessman, was doubtless a paragon of free enterprise, the proven survivor of a testing evolutionary struggle. But not all private businesses were like that. Moreover, the large joint-stock company, growing to industrial dominance in Marshall's later years, posed many of the same problems as did government enterprise, a point to be returned to below.

At a deeper level, Marshall saw reliance on free enterprise as important not merely for economic progress, but also for its evolutionary effects in developing intrinsically valuable traits among the populace:

I am convinced that, so soon as collectivist control had spread so far as to narrow considerably the field left for free enterprise, the pressure of bureaucratic methods would impair not only the springs of material wealth, but also many of those higher qualities of human nature, the strengthening of which should be the chief aim of social endeavour.

(Pigou 1925:334)

The grounds for Marshall's vehement belief in the character-building virtues of free enterprise remain even more vague than those for his belief in its superior long-term economic efficiency. Competition might develop rationality, initiative, foresight, and so on, but it is difficult to see how it will inculcate the altruistic or 'chivalric' virtues on which he placed much reliance for future social development. ${ }^{11}$ 
Marshall was fundamentally more sympathetic to the syndicalist National Guild ideas than to proposals for direct government control. The plan he said 'puts into the forefront the dignity of the worker, whether with hand or head, as a man: it claims thus to evoke his full energies and give them free play'. It is 'on a different intellectual level from those which regard the whole produce of industry as belonging to the operatives; and think but lightly of any work that is not manual'. Nevertheless, it still had the fundamental failing of making no provision for the continuance of economic progress and took 'little thought for its dependence on deep insight, on farseeing foresight, on sound judgment in selecting new developments of technique and organization, and the courage of leaders of industry in taking selected risks on their own shoulders' (Marshall 1919:658, 651).

G.D.H.Cole, one of the theorists of the movement, was accused of following 'in the paths of St. Simon, Fourier and other early socialists of noble character and vivid poetic imagination' and of assuming the task of regulation to be 'as simple as it would be if all men were as unselfish and earnest as the writer himself; the vast difficulties of modern business organization are so completely left out of account as to imply that they have never been seriously studied' (Marshall 1919:660n.). Thus, in a way, the wheel has turned full circle back to the perils and infeasibility of utopianism in the absence of a prior transformation of human nature.

\section{On Financial Socialism}

In Marshall's day, progressive taxation for social welfare purposes was widely viewed as socialistic, and Marshall himself referred to it on one occasion as 'financial socialism'. ${ }^{12}$ His attitude towards this form of socialism was much more favourable than his reaction to organizational socialism and of the form 'Why should the Devil have the best tunes?':

On the financial side, Socialism may be rapacious, predatory, blind to the importance of security in business and contemptuous of public good faith. But these tendencies lie on the surface: they provoke powerful opposition and reaction; and personally I fear them less than those which are more insidious. In moderation they are even beneficial in my opinion. For poverty crushes character: and though the earning of great wealth generally strengthens character, the spending of it by those who have not earned it, whether men or women, is not nearly an unmixed good. A cautious movement toward enriching the poor at the expense of the rich seems to me not to cease to be beneficial, merely because socialists say it is a step in their direction.

(Pigou 1925:462-3) $)^{13}$

Indeed, in an ironical echo of Henry George, who was hardly one of Marshall's heroes and had been widely denounced in his day as a socialist, Marshall saw the failure to tax capital gains on land - that is, the unearned increment - as a 'sustained social injustice', the remedying of which through taxation would be 'anti-socialistic'! However, he was not prepared to accept any 'abstract or "metaphysical" principle' about the right to a 
specific share in the product, or the just income (Marshall 1919:463; Pigou 1925:252, 389-90).

Marshall's case for redistribution was a pragmatic one, resting partly on a simple Benthamite comparison of utilities but mainly on an evolutionist desire to better the conditions of the poor in order to facilitate their self-improvement as workers, parents and citizens. Except perhaps for those in dire need, redistribution was to take the form of tax-financed provision of education, improved surroundings, and social services, not handouts. Taxation would be progressive but most workers would still pay some taxes.

Any sudden large increase in taxation might be unsettling to the well-to-do, who could only be squeezed so far 'Without danger to freedom and to social order; and without impairing the springs of initiative, enterprise and energy' (Pigou 1925:366). When it came to the effects of taxation on the supply of effort Marshall was fairly optimistic, believing that relative incomes were more important stimuli than absolute incomes because of the large emulative or display element in consumption and the use of money income as a yardstick of relative achievement. Similar considerations presumably applied to effects of capital taxation on the incentive to save, although the risk of inducing emigration was greater for capital than for labour. However, capital would be unlikely to emigrate merely because of moderate taxes so long as enterprise was encouraged and tax receipts were devoted to purposes that made society more agreeable by increasing social and human capital. In any case, shift working would permit considerable economies in the use of capital. Continued reliance for accumulation on the middle and upper classes would remain necessary — neither skilled workers nor the state (a 'brave borrower') could be expected to make adequate provision for the future. But the necessity for saving to sustain economic growth had come to seem less pressing, at least by the turn of the century. ${ }^{14}$ 'Britain's capital...grows fast relatively to her area, and a small check to its growth would but postpone a little the day when most of her new accumulations are exported' (Marshall 1920b:463). Thus, cautious redistribution could be accomplished without a severe threat to growth and could play an important part in the sustained struggle to improve the lot of the poorer members of society. Success in this struggle would have important long-term consequences in raising the ranks of the skilled workers and reducing the ranks of the unskilled, thereby reducing the inequality of incomes as well as raising their absolute levels. In turn, workers' horizons would be expanded and self-improvement encouraged. But, meanwhile, there was a danger in exaggerating the immediate possibilities for redistribution and the extent to which it could benefit the poor. As Marshall delighted in pointing out, many skilled workers would lose from a move to absolute equality of incomes. ${ }^{15}$

\section{Fostering Enterprise}

Enterprise, not capital, lay at the heart of Marshall's concerns about 'socialism'. In a pregnant passage he remarks:

But all socialist schemes, and especially those which are directly or indirectly of German origin, seem to be vitiated by want of attention to the analysis which the economists of the modern age have made of the 
functions of the undertaker of business enterprises. They seem to think too much of competition as the exploiting of labour by capital, of the poor by the wealthy, and too little of it as the constant experiment by the ablest men for their several tasks, each trying to discover a new way in which to attain some important end. They still retain the language of the older economists, in which the employer, or undertaker, and the capitalist are spoken of as though they were for all practical purposes, the same people.

(Pigou 1925:283-4)

The growing tendency of business to operate on borrowed capital allowed a separation of questions of wealth distribution and saving incentives from those of industrial leadership - the 'getting the right men into the right places, and giving them a free hand and sufficient incitement to exert themselves to the utmost' (Pigou 1925:282). Industrial leadership and the pioneering of new methods were incomparably the more important needs, since capital but not knowledge could easily be replaced (Pigou 1925:338). Existing inequalities were by no means essential for sustaining adequate industrial leadership, and were in one way inimical to it by excluding able sons of the poor from higher functions, and thereby failing to use the most important untapped resource for industrial progress: in fact 'THE Waste Product' of industry (Pigou 1925:229). The younger economists of the day 'in whom the Anglo-Saxon spirit is stronger'-prominent among them F.A.Walker and Marshall himself-were anxious to disentangle the case for free enterprise as a spur to business activity from the case for 'such institutions as tend to maintain extreme inequalities of wealth' (Pigou 1925:290). But socialists, with their tendency to think of an inherent conflict between labour and capital, tended to confound the two issues, perverting 'reasonable dissatisfaction' with the existing distributions of income and wealth into agitation for 'ill considered measures of reform' (Pigou 1925:328).

In his later years - the theme is fundamental to his Industry and Trade but remained submerged in his Principles - the rise to industrial dominance of large joint stock companies seemed to Marshall to alter the situation fundamentally. On the one hand, it threatened the survival of pioneering small private businesses, the traditional breeding ground of new products and production methods. On the other hand, it democratized the ownership of business by opening it up to the small shareholder, and also democratized the career of management by freeing it from the necessity of investing capital in the business or possessing family connections. The resulting tension called for a precarious balance to be maintained between small and large businesses. Large businesses enjoyed economies of scale that might crush innovative small businesses before their new ideas could establish a secure foothold. But — especially given a separation of ownership from managerial control-large businesses could easily lose dynamism and stagnate into bureaucratic lethargy, suffering many of the drawbacks Marshall had attributed to government-controlled business. New developments might alleviate this, but might also apply to the government alternative. Management might become a recognized and organized profession, with members striving for the acclaim of their peers; an organized research division might successfully substitute for the discoveries of the lone inventor; and 'scientific management' (Taylorism) might reconcile tight internal control with large scale. Nevertheless, the continuing existence of a sector of small innovative private 
businesses remained for Marshall a vital requirement for the continuing productivity improvement he urgently desired. ${ }^{16}$ This improvement, it should be stressed, was important not so much as an end in itself but rather as a necessary means to the improvement of society - to the alleviation of brutalizing poverty and the opening up to all citizens of possibilities for the widening of intellectual, moral and social horizons: in fact to the establishment of the kind of society envisaged in his 1873 paper 'The Future of the Working Classes' (Pigou 1925:101-18). However, in later life a growing concern for threats to Britain's international competitiveness and political standing did come to reinforce Marshall's concern for the more immediate importance of steadily rising productivity.

\section{A Middle Way?}

Marshall's search was for a middle way that would permit escape 'on the one hand, from the cruelty and waste of irresponsible competition and the licentious use of wealth, and on the other from the tyranny and spiritual death of an ironbound socialism' (Pigou 1925:291). In this middle way the state would have important functions to perform in effecting 'social ameliorations that are not fully within the range of private effort' (Pigou 1925:333). The kinds of government intervention that Marshall had in mind can be indicated briefly. Perhaps the most important was the provision of universal education to a certain level and possibilities for further technical training, since many poorer parents might lack the will, the incentive, or the means, to provide an adequate education and training for their children. Government also had an important part to play in regulating and improving the physical surroundings of the working classes, both at work and away from work. Town planning, including provision of parks for recreation and elimination of unsanitary housing, was something Marshall harped on frequently. Provision of a basic safety net for the poorest - deserving or undeserving-was accepted by him as a government responsibility, but more generous treatment for the deserving poor was generally best left to more discriminating private arrangements which would he hoped embody working class input. The publication of accurate information, produced or collected by government, remained his main hope for avoiding exaggerated business cycles and their attendant social and economic costs.

When it came to improving the character and social environment of the working classes, he saw the task as one more suited to private initiatives than to government action, and urged it as a moral and social duty for the middle and upper classes as well as for the workers' leaders. Early in his career as an economist, Marshall had entertained the hope that through involvement in trade unions and the cooperative movement, the working classes might elevate themselves by acquiring a wider and clearer understanding of economic possibilities and a willingness to sacrifice individual interest to collective benefit. This hope eventually languished, leaving to the social consciences of the better off the main onus for prodding along an elevation of the working classes. However, in the aftermath of World War I, with its greatly enlarged government involvement in the economy, Industry and Trade saw more hope for a voluntary collaboration of government, management and unions in the management of industry, and thus more hope for labour as a progressive force in the economy. 
But the more fundamental source of social improvement in Marshall's eyes was economic growth itself. His evolutionary view of human nature led him to believe that increasing relaxation of economic constraints pressing on the poor would naturally bring about a widening of their horizons, an increased willingness to sacrifice for their children, a greater willingness to defer consumption, an elevation of taste, and so on. All this would come about without the need for conscious intervention, although if well timed and aimed such intervention might expedite the underlying evolutionary trend. ${ }^{17} \mathrm{He}$ was much less concerned with how the national product yielded by current resources and knowledge was distributed than with fostering the expansion of knowledge and resources so as to enlarge national product in the future.

Fundamentally it was Marshall's belief in the ability of economic growth to yield widespread social improvement that underlay his hostility towards any socialistic proposals that might affect economic growth adversely. As he wrote to Benjamin Kidd on 6 June 1894:

I cordially agree with you that the true danger of socialism lies in its tendency to destroy the constructive force of variation \& selection: \& that in the permanent interests of the race we cannot afford to diminish suffering by means that appreciably choke up the springs of vigour.

(Whitaker 1996, 2:114)

The weakness of such a position is that it advocates the toleration of evident current evils on the promise that all will come right in the end. It treads a fine line between recommending caution in altering the status quo and regarding the status quo as optimal for its time.

Marshall's cautious support for progressive taxation and for various expansions of government's role in society, especially in education and urban improvement, were doubtless somewhat in advance of the general sentiments of his age and perhaps justify viewing him as a 'small "s" socialist' (Groenewegen 1995:571). But his overriding concern for sustained productivity growth, allied with his rather romantic idealization of the ever-pioneering businessman, led him to defend private enterprise vehemently against collectivist threats of all kinds. In this mode he sometimes appears as more the defender of existing conditions than the social reformer he had once claimed to be.

\section{Notes}

1 Since Peter Groenewegen has already dealt ably, extensively and accurately with Marshall's broad views on social policy and social reform (1995:570-617, also 294-5, 353-71, 449-58, $507-16,726-30,790-1)$ the present essay might appear otiose. But some value may still attach to a more narrowly focused and sharply outlined consideration of Marshall's hostile reactions toward proposals for radical social change. Fry (1976) and Elliott (1990) provide useful overviews of Marshall's views, while McWilliams-Tullberg (1975) and Becattini (1991a) concentrate, respectively, on Marshall's earliest and latest attitudes towards social change. This chapter has benefited from suggestions by Tiziano Raffaelli and two referees.

2 See Groenewegen (1995:609-12) on the question of Marshall's political leanings and for a characterization of him as a classical liberal. 
3 On Marshall's somewhat problematic early tendency to socialism see McWilliams-Tullberg (1975).

4 Slashes replace paragraph breaks. It should be emphasized that Marshall was addressing an audience many of whose members were radically inclined.

5 See Marshall (1920b:763, 766), Pigou (1925:156). Of the early socialist writers, Marshall thought best of Lassalle although he venerated Owen's noble spirit: see Whitaker (1975: vol. 2:11, 13, 37-9); A. and M.P.Marshall (1879:218).

6 The distinction between administrative and financial socialism (the latter term is invoked below) was made by Marshall in a 1909 letter to Lord Reay: see Pigou (1925:462).

7 See Marshall (1919:666, 850-1), Pigou (1925:276), Marshall (1920b:753).

8 Marshall (1919:651, 656-60). Quotations are from pp. 658, 656, respectively. For a detailed account of the National Guild movement see Reckitt and Bechofer (1918).

9 At one point, even protectionism is viewed as socialistic because it 'gives first place to those businessmen who are "expert" at hoodwinking officials, the legislature and the public' Pigou $(1925: 462)$.

10 On bureaucracy see Marshall (1919:666-72), Pigou (1925:337-9). Also see Marshall's letters of 23, 31 March 1891 to The Times concerning the Post Office, reproduced in Coase (1961) or Whitaker (1996: vol.2, 19-25).

$11 \mathrm{~A}$ key to resolving this conundrum lies in the recognition that Marshall saw free enterprise as leading to combination as well as competition and that 'constructive' combination'constructive' was one of his favourite favourable epithets - could bring about important social changes. The theme is prominent in Marshall (1919). See also Pigou (1925:323-46).

12 See note 6 above.

13 For other instances of Marshall's approval of redistribution see Pigou (1925:228, 366), Marshall (1920b:713-4, 802). His willingness to condone progressivity of taxation seems to have increased with age, perhaps in line with a reduced hostility of public sentiment towards it. See Groenewegen (1995:596-8).

14 After the 1914-18 war and the resulting loss of foreign assets the need to maintain accumulation had come to seem more pressing. See Marshall (1919:vii, 649-50) for example.

15 For illustration of the points made in this paragraph see Pigou (1925:283, 328, 331, 346, 366), Marshall (1919:648, 650-1, 663-4), Marshall (1920b:712-4, 803).

16 These themes are developed at length in Whitaker $(1999,2002)$.

17 Among Marshall's hoped for evolutionary developments was an increased willingness of women to devote themselves to social duties and the family hearth. For a full consideration of Marshall's misogynistic tendencies see Groenewegen (1995:493-530). 


\title{
12 \\ History and Theory in Marshall
}

\author{
Neil Hart
}

In his inaugural lecture, presented at the University of Sydney in June 1981, Peter Groenewegen (1982a:14) emphasised the importance of history to students of economics, arguing that is was essential that economists be 'historiate' as well as numerate. Without theory there could be no science, but without history there would be no antidote to the over-abstraction otherwise likely to be associated with theory, and with equilibrium theory in particular. Groenewegen illustrated the significance of the struggle between 'history' and 'equilibrium' through an examination of the seminal works of Adam Smith, Karl Marx and Alfred Marshall. In an interpretation of Smith's writing that diverged markedly from that of commentators such as Hollander (1973), Blaug (1964) and Samuelson (1977), Groenewegen concluded that Smith's solution to the history versus equilibrium issue was to refrain from using the concept of equilibrium mechanically. ${ }^{1}$ Marx's solution, most commended by Groenewegen, was to use mathematics and equilibrium analysis, but to offset the clearly understood limitations of this analysis with recourse to history and statistics.

The struggle to find the balance between history and theory is most clearly observed in Groenewegen's account of Marshall's writings, where it is concluded that Marshall the economic historian came to be defeated by Marshall the equilibrium theorist. This is a most interesting observation, given that Marshall's own inaugural lecture, presented almost one hundred years earlier, contained reflections on the role of history and theory that are not dissimilar in many important respects to those found in Groenewegen's lecture. This chapter considers further the intended role of equilibrium theory in Marshall's Principles of Economics, ${ }^{2}$ and concludes that the nature and significance of Marshall's 'history versus theory' dilemma was much misunderstood by Marshall's critics and followers alike. Somewhat paradoxically, Marshall the acclaimed equilibrium theorist, is revealed through his own writings as a strong critic of much of what came to represent the foundations of equilibrium analysis.

Discussion in the chapter is organised as follows. The next section presents some observations on the role of history and theory as revealed in Marshall's inaugural lecture and some other of his early writings. This is followed by an outline of the intended role of theory in the Principles, both in terms of equilibrium and 'economic biology'. Marshall's long-period analysis is then examined, because this is a context in which the 'history versus equilibrium' struggle is most directly observable. The Marshallian position on the role of equilibrium theory is then considered, followed by some concluding comments on the history versus equilibrium theme in Groenewegen's lecture.

Before proceeding, it is useful to follow Groenewegen (1982a) and set Marshall's struggle to avoid the temptation of over-indulgence in abstract theorising in the context of 
Marshall's story about his patron-saint, as recounted by his favourite student, J.M.Keynes:

\begin{abstract}
About the time that I first resolved to make as thorough a study as I could of Political Economy (the word economics was not then invented) I saw in a shop-window a small oil painting [of a man's face with a strikingly gaunt and wistful expression, as of one 'down and out'] and bought it for a few shillings. I set it up there above the chimney-piece in my room in college and thenceforward called it my patron saint, and devoted myself to trying how to fit men like that for heaven. Meanwhile I got a good deal interested in the semi-mathematical side of pure Economics, and was afraid of becoming a mere thinker. But a glance at my patron saint seemed to call me back to the right path. That was particularly useful after I had been diverted from the study of ultimate aims to the questions about Bimetallism, etc., which at one time were dominant. I despised them, but the 'instinct of the chase' tempted me towards them.
\end{abstract}

(Keynes 1924:37-8)

\title{
History and Theory: Marshall's Inaugural Lecture
}

The importance of combining knowledge of history with the application of theory formed the principal message in Marshall's inaugural lecture, this lecture being occasioned by his election to the professorship at Cambridge in 1885. In his lecture, Marshall (1885b) endeavoured to provide a 'short account' of what he judged to be the province of the economist. The theme was developed through a consideration of examples that illustrated the dangers associated with hastily applied abstract theorising that ignored history and statistics. At the same time Marshall cautioned that facts by themselves were silent and warned against the notion perpetuated by some of the 'hangers-on of the science' who in Marshall's judgement believed that the solution to economic difficulties was to discard all theories and revert to the 'direct teaching of facts'. Marshall's discussion led him to acclaim that part of the Historical School's contribution that had traced the history of economic habits and institutions as representing 'one of the great achievements of our age' (Marshall 1885b:165). At the same time, he was highly critical of what he termed the 'extreme wing' of the Historical School of economics, characterised as urging economists to reason directly from facts to facts without the intervention of any formal theory. ${ }^{3}$

In his inaugural lecture, Marshall defended his early nineteenth century predecessors from the charge that they were theorists who neglected history and statistics; an 'English fault' that many of Marshall's contemporaries claimed to be redressing through the 'discovery' of the importance of supplementing and guiding deduction by induction. On the contrary, Marshall (1885b:153) argued that most of the earlier nineteenth-century contributors were 'practical men' who 'wrote economic histories that are in their own way at least equal to anything that has been done since'. The perception of over indulgence in abstract reasoning could be attributed almost solely to the faults and virtues of the 'masterful genius' David Ricardo, who, along with his followers, had 'neglected a 
large group of facts'. More importantly, they had employed a method of studying facts that Marshall associated with the mathematical-physical group of sciences at the beginning of the nineteenth century. These sciences, according to Marshall, had in common the characteristic that the subject matter is constant and unchanged in all countries and in all ages. By applying this method to the relations between the different industrial classes in particular, Marshall argued that Ricardo and his less able followers were led to deduce misleading inferences from the facts:

They therefore attributed to the forces of supply and demand a much more mechanical and regular action than they actually have; and laid down laws with regard to profits and wages that did not really hold even for England in their own time. But their most vital fault was that they did not see how liable to change are the habits and institutions of industry. In particular they did not see that the poverty of the poor is the chief cause of that weakness and inefficiency which are the cause of their poverty: they had not the faith, that modern economists have, in the possibility of a vast improvement in the condition of the working classes.

(Marshall 1885b:155)

The analysis of history and statistics required a different method, one capable of encompassing the changing inner character and outward institutions of 'man'. In a theme to be repeated frequently in his later writings, Marshall saw the emerging science of biology, with its perception of 'organic growth', as providing the foundations of such an approach. In Marshall's judgement, the interest in biological notions by practical economists had not arisen primarily from attacks on a particular economic doctrine or writers. Rather the application of biology to economics was seen as reflecting the evolving nature of the subject matter of a science, and part of a general movement of all moral and historical sciences: "At last the speculations of biology made a great stride forward: its discoveries fascinated the attention of all men as those of physics had done in earlier years'.

A clear insight into Marshall's preferred methodological position emerges from his inaugural lecture. To yield useful deductions, economics had to combine theory with the facts, as revealed through history and statistics. However the mechanical analysis associated with 'mathematical-physical' sciences did not provide the vehicle though which such analysis could be usefully constructed. Rather, it was from the 'speculations of biology', with the emphasis on evolutionary change, that the organon of economic theory had ultimately to be assembled.

Given the emergence and widespread acceptance of evolution as a scientific principle in the second half of the nineteenth century, it is not surprising that Marshall was attracted to the concept as he journeyed from the mathematical to the moral sciences during the 1860s. Marshall had no formal training in biology, a'shortcoming' he was to lament. However he claimed to have worked through Charles Darwin's Origin of the Species by 1867 , and was clearly attracted to the writings of Herbert Spencer. Marshall's recollections of the significance of both Darwin and Spencer to intellectual pursuits during this period were clearly indicated in his 1904 Daily Chronicle memorial to Spencer: 
There is probably no one who gave as strong a stimulus to the thoughts of the younger Cambridge graduates thirty years or forty years ago as he [Herbert Spencer]. He opened out a new world of promise; he set men on high enterprise in many diverse directions; and though he may have regulated English intellectual work less than Mill did, I believe he did much more towards increasing its utility. He has, perhaps, been more largely read and exercised a greater influence on the Continent than any other recent English thinker except Darwin.

(Daily Chronicle, 23 November 1904; as repr. in Pigou 1925:507)

Initially, Marshall's interest in the speculations of biology was largely in the context of his philosophical investigations into issues such as the nature of knowledge. ${ }^{4}$ Marshall's reading of philosophy led his thinking to be strongly influenced by writers such as Immanuel Kant and G.W.F.Hegel, and significantly, by the principle of continuity later to be associated directly with the Darwinian motto of continuity. During his formative years in his chosen profession, the possibilities of applying these concepts to economic reasoning was also reinforced by a number of books, such as Plutology by the Australian writer William Edward Hearn (1864), where the notion of evolution was applied to various aspects of the social sciences. ${ }^{5}$ In addition, like many of his aspiring contemporaries, Marshall studied in Germany $(1868,1870-71)$ under the tutelage of members of the historical school, with the work of Karl Knies, Friedrich List, Wilhelm Roscher, Gustav Schmoller and others favourably referred to in his own writings. ${ }^{6}$ Most significantly, the historical school made frequent use of the social organism metaphor in their work, being particularly strongly influenced by Herbert Spencer and his followers.

However, as can be clearly observed from Whitaker's (1975) edited volumes, the biological mode of thinking rarely surfaces directly in Marshall's early contributions to economics. Some indications as to its intended role in Marshall's writings may be observed in Marshall and Marshall (1879), particularly in the brief discussions of methodological issues and of increasing returns and industrial organisation where Spencer's influence in particular begins to emerge. However, it was not until the publication of the first edition of the Principles in 1890 that a significant operational role for 'economic biology' is suggested in Marshall's writings, a role that was to undergo somewhat of a transformation during the successive editions of the Principles over the following three decades. ${ }^{7}$

\section{The Nature and Role of Theory in Marshall's Principles}

The readers who shared Marshall's estimation as to the importance of history to economic analysis would have been delighted by the inclusion of the long chapter titled 'The Growth of Free Industry and Enterprise' prominently placed in Book I, Chapter II of the first edition of the Principles. While the interpretation placed on some of the evolving events may be open to debate, the intention was clearly to place the analysis that was to follow in some form of historical context. The significance of this historical material to the early editions of the Principles is stated clearly by Marshall in the following passage from an article of his that appeared in the Economic Journal in 1898: 
Complaints have been made that my first Book keeps the reader too long from entering on the new work before him. But it is needed from my point of view. The chapters on the Growth of the Free Industry and of Economic Science are no doubt long, in spite of their being wholly inadequate if regarded as sketches of economic history. Their aim is different It is to emphasise, as the keynote of the treatise, the notion that economic problems are not mechanical, but concerned with organic life and growth. In combination with the following chapters on Scope and Method they claim to offer a view continuous with that of the classical tradition, but differing in the stress laid on this element of life-growth.

(Marshall 1898a:8)

This passage clearly fits well with the discussion in Marshall's inaugural lecture, and adds substance to some of the references to the nature of economic change outlined in the Preface to the first edition of the Principles. However, as part of a significant rearrangement of the text of the fifth edition (1907), the detailed historical chapter describing the growth of industry was relegated to an appendix (along with the following four chapters dealing with the growth of economic thought and the scope and method of economics). As C.W. Guillebaud (1942:336) justly observed, this rearrangement had the 'regrettable result' of dethroning the long and interesting chapter, resulting in a loss of historical perspective in the Principles. The chapter written to emphasise that economic problems are not mechanical, but concerned with organic life and growth, had now been relegated to an appendix, no longer warranting a place in the main body of the Principles.

In terms of the methodological approach underlying the theoretical structure being constructed in the Principles, the 'Darwinian' motto, Natura non facit saltum (Nature does not make a leap), attached to the first and subsequent editions of Marshall's Principles, would no doubt also have attracted the attention of those eager to apply the 'new way of thinking' to the social sciences. ${ }^{8}$ In the Preface to the first edition of the Principles, Marshall states that it is the 'Principle of Continuity' (attributed chiefly to Herbert Spencer and Hegel) that affected, more than any other, the substance of the views developed in the Principles. Reference is also made to the importance of time, being itself absolutely continuous and at the centre of the chief difficulty of almost every economic problem.

However, the reader of Marshall's Principles anticipating a treatise founded on notions of economic biology may have been somewhat taken aback by references to the role of equilibrium theory in the Preface to the first edition:

As, in spite of the great differences in form between birds and quadrupeds,
there is one Fundamental Idea running through all their frames, so the
general theory of the equilibrium of demand and supply is a Fundamental
Idea running through the frames of all the various parts of the central
problem of Distribution and Exchange.

(Principles: viii)

The application of mechanical notions of equilibrium to the analysis of events that are acknowledged to be continuous in time would appear to be somewhat of a retreat from 
the methodological position espoused in Marshall's inaugural lecture, In that lecture the static method was deemed to be incompatible with meaningful analysis of historical facts. The challenge Marshall had set himself therefore was to convince his readers that, at least in its 'introductory' stages, mechanical equilibrium analogies can shed some light on a complex evolving economic system. Before proceeding to consider Marshall's challenge further, brief comment on the nature of 'economic biology' in the Principles is warranted.

Much of the 'economic biology' in (the later editions of) Marshall's Principles is to be found in those sections in the second half of Book IV concerned with industrial organisation. Here Marshall seeks to extend Adam Smith's insights into the relationship between the division of labour and (dynamic) economic efficiency to consider more closely how the organisation of business is shaped by the interrelationships between specialisation, competition, and the transfer of knowledge. In order to develop this analysis, Marshall at times drew heavily on the ideas of Darwin, Spencer and their many followers. The following passage from Book IV is illustrative of how Marshall attempted to proceed:

Before Adam Smith's book had yet found many readers, biologists were already beginning to make great advances towards understanding the real nature of the differences in organization which separate the higher from the lower animals; and before two more generations had elapsed, Malthus' historical account of man's struggle for existence started Darwin on that inquiry as to the effects of the struggle for existence in the animal and vegetable world, which issued in his discovery of the selective influence constantly played by it. Since that time biology has more than repaid her debt; and economists have in their turn owed much to the many profound analogies which have been discovered between social and especially industrial organization on the one side and the physical organization of the higher animals on the other. ... This central unit is set forth in the general rule, to which there are not very many exceptions, that the development of the organism, whether social or physical, involves an increasing subdivision of functions between its separate parts, and on the other a more intimate connection between them. Each part gets to be less selfsufficient, to depend for its well-being more and more on other parts, so that any disorder in any of a highly-developed organism will affect other parts also.

(Principles: $240-1)$

While Marshall's application of 'economic biology' may at times be judged to be rather rudimentary and incomplete, fertile avenues for further development of this approach are readily observed, particularly when Book IV of the Principles is read in conjunction with the much neglected Industry and Trade (Marshall 1920a). ${ }^{9}$

However, despite the prominent role accorded to 'economic biology' in Book IV of the Principles, Marshall in the opening passages in Book V again contends that in order to prepare the way for 'advanced study', we should first look at a 'simpler balancing of forces' that are analogous to the 'mechanical equilibrium of a stone hanging from an 
elastic string, or a number of balls resting against one another in a basin' (Principles: 324). Characteristically Marshall concedes that the analogy has serious limitations, because in real life economic oscillations are seldom as rhythmical as those of a stone hanging from a string. It was recognised that demand and supply schedules do not in practice remain unchanged for a long time together, but are constantly being changed. Every change in them alters the equilibrium amount and the equilibrium price, and thus 'gives new positions to the centres about which the amount and the price tend to oscillate' (Principles: 346-7). Despite these qualifications, the equilibrium analogies are recurrently used as an expository device in the analysis presented in Book V of the Principles. At the same time the defence of mechanical notions of equilibrium as a tool in the construction of economic analysis becomes more pronounced in the preface to the later editions of the Principles. By the time we reach the eighth edition, both the defence of equilibrium analysis, and at the same time the importance of 'economic biology', are firmly established in Marshall's scheme:

The Mecca of the economist lies in economic biology rather than in economic dynamics. But biological conceptions are more complex than those of mechanics; a volume on Foundations must therefore give a relatively large place to mechanical analogies; and frequent use is made of the term 'equilibrium' which suggests something of statical analogy. ...This fact, combined with the predominant attention paid in the present volume to the normal conditions of life in the modern age, has suggested the notion that its central idea is 'statical', rather than 'dynamical'. But in fact it is concerned throughout with the forces that cause movement: and its key-note is that of dynamics, rather than statics.

(Principles: xiv)

Marshall attempted to 'clarify' aspects of what he believed to be the relationship between 'economic biology' and equilibrium analysis in the aptly titled 'Mechanical and Biological Analogies in Economics'. Here Marshall (1898b: 313-14) reiterates his contention that economic reasoning in its 'early stages' should 'start on methods analogous to those of physical statics'. In this context Marshall proposed that demand and supply were thought of as crude forces pressing against one another tending towards a mechanical equilibrium. However, with the progress of economics, economic reasoning should become 'more biological in tone'; with the reader once more reminded that economic biology is the 'Mecca of the economist'. Most significantly, in the concluding stages of this article, Marshall (1898b:318) attempts to establish a role for 'equilibrium' within the 'more biological' stage of analysis, by suggesting that, 'this balance or equilibrium had to be conceived not as between crude mechanical forces, but as between organic forces of life and decay'. However, the relevance of this 'equilibrium' between decline and growth to the wider explanation of evolutionary change in industrial organisation is not convincingly clarified by Marshall, an ambiguity which is at the core of the analytical difficulties encountered in Book V of the Principles. These difficulties become most apparent as Marshall's time-period analysis progressed to the long-period context, where the struggle to reconcile equilibrium positions with economic events which were acknowledged to be continuous in time becomes most apparent. It is here that 
mechanical forces based on logical time are confronted most directly with 'organic' processes which exist in historical time.

\section{Marshall's Long-Period Equilibrium Versus History}

In his evaluation of Marshall's contribution to economics, Shackle (1965:36) concluded that Marshall's peculiar triumph is his 'creation of a unity out of the conceptions of equilibrium and of evolution'. However, as is most clearly observed in Marshall's longperiod analysis, Marshall himself would not agree with Shackle's conclusion. Rather, the equilibrium analogies used by Marshall, which sought to abstract from history, became increasingly incompatible with the economic biology that had formed the basis of much of the analysis of industrial organisation in Book IV of the Principles.

In the long-period, as distinct from the shorter time periods, suppliers are able to adjust their scale of production in response to a change in demand. Consistent with Marshall's analysis of business organisation in Book IV of the Principles, the likelihood and significance of increasing returns to scale is therefore at the centre of Marshall's long-period equilibrium theory. From the analysis in Book IV, two very important features of increasing returns must be emphasised. Firstly, the source of increasing returns is likely to be a combination of both internal and external economies. Secondly, increasing returns do not emerge from technical relationships embodied in a predetermined production function. Instead they emerge as a result of an evolving process of reorganisation, both at the individual firm and industry domains. This is an endogenous process arising from the efficiency gains associated with specialisation and adaptation, together with the transfer and sharing of knowledge. ${ }^{10}$

From his observations of industry, Marshall had concluded that while increasing returns were widespread and played a key role in industrial expansion, monopolisation was not the natural outcome of this process. He was particularly critical of writers (such as the much respected Cournot) who had, in his judgement, followed their mathematics boldly without realising that their premises led to the conclusion that monopoly was the outcome of industries characterised by individual firms with command over internal economies. ${ }^{11}$ Not surprisingly, Marshall's attempt to reconcile the existence of increasing returns with the generation of long-period normal equilibrium prices involved an appeal to an analogy from the emerging science of biology. The analogy likened the growth process of firms to the growth of trees in a forest; 'the full life of a firm seldom lasts very long', as the firm is likely 'ere long quickly to decay' having lost the 'exceptional energy which enabled it to rise' (Principles: 287). It is nature, by pressing 'on the private business by limiting the length of the life of its original founders, and by limiting even more narrowly the part of their lives in which their faculties retain full vigor' which Marshall argues breaks the nexus between increasing returns and the tendency towards monopoly (Principles: 316 ).

Marshall's biological analogy would imply that, at any point in time, an industry would be characterised by having some firms in their ascending phase, and others in their descending phase. Consequently, and in stark contrast to subsequent 'Marshallian' approaches, the notion of the 'marginal' or 'equilibrium' firm could not have any operational role in the derivation of long-period normal supply conditions. It is in this 
context that Marshall introduced his theoretical construct of the representative firm. The representative firm is 'representative' of an industry in the sense that it has 'normal access to the economies, external and internal, which belong to the aggregate volume of production' (Principles: 317, emphasis added). Importantly, it is the expenses of the representative firm that Marshall uses when the normal supply schedule of an industry is being derived. As a result of a gradual increase in demand, the representative firm could be expected to increase in size, and to have an increase in both internal and external economies at its disposal, indicating declining long-period industry supply prices (Principles: 460).

Marshall's representative firm therefore was constructed partly as a vehicle through which the outcomes of organic processes that characterised the evolution of business organisations could be represented at a point in logical time at which industry equilibrium was somehow attained. ${ }^{12}$ However, at this juncture, Marshall becomes disturbed by the incompatibility of demand and supply analysis with the representation of events which are continuous in time. If accepted, Marshall's long-period equilibrium theory implies that any point on a long-period supply curve reflects the general conditions of an industry consisting of individual producers situated at various stages of their life-cycle. As Marshall (1898b:318) stated, it was necessary for readers of his Principles to interpret equilibrium 'not as a balance of crude mechanical forces', but rather 'as between the organic forces of life and decay'. The critical dilemma that emerges therefore is how to interpret movements along the long-period supply curve occasioned by shifts in the demand curve. The nature of this dilemma, together with its immense importance to Marshall's analysis, is most effectively represented in the following passage from Principles:

It must however be admitted that this theory is out of touch with real conditions of life, in so far as it assumes that, if the normal production of a commodity increases and afterwards again diminishes to its old amount, the demand price and the supply price will return to their old positions for that amount... For, when any casual disturbance has caused a great increase in the production of any commodity, and thereby has led to the introduction of extensive economies, these economies are not readily lost. Developments of mechanical appliances, of division of labour and of the means of transport, and improved organisation of all kinds, when they have been once obtained are not readily abandoned.

$$
\text { (Principles: 807-8) }{ }^{13}
$$

The method by which Marshall sought to explain the establishment of long-period equilibrium challenged the operational validity of the equilibrium analogies from which the analysis was being formed. Mechanical depictions of equilibrium permitted movements along supply schedules and between equilibrium positions. Biological notions of life and decay on the other hand introduced the notion of irreversibilities associated with economic processes that proceeded in historical time. The damaging implications to static equilibrium analysis were clearly recognised by Marshall: 
The Statical theory of equilibrium is only an introduction to economic studies; and it is barely even an introduction to the study of progress and development of industries which show a tendency to increasing return. Its limitations are so constantly overlooked, especially by those who approach it from an abstract point of view, that there is a danger in throwing it into definite form at all.

(Principles: 461$)^{14}$

The long-period analysis in the Principles had clearly confirmed its author's forewarning that theory based on mechanical notions of equilibrium was unlikely to provide a useful framework in which to analyse historical events which were continuous in time.

Marshall hoped to provide a more satisfactory framework in which economic studies could proceed in a 'second volume' of Principles, but the promised volume failed to eventuate. ${ }^{15}$ In the meantime, and despite the clearly stated reservations, the equilibrium analogies continued to play a significant role in the successive editions of Principles. To some extent, Marshall's struggle to commit to a consistent methodological approach can be understood in the context of potentially conflicting endeavours in the purpose of his analysis. As Groenewegen's (1995) insightful account of Marshall's life and career highlights, Marshall's journey to political economy was driven by a desire to provide an economic base to make general human improvement possible. The theoretical structure of Marshall's Principles was therefore intended to provide an 'engine of discovery' to investigate the possibilities of economic progress. In a world characterised by complexity and continuous change, the biological mode of reasoning represented a very fertile route to follow. At the same time, however, Marshall was attempting to establish economics as a distinct 'science', and was therefore concerned to present his subject in a way which emphasised the unity of its principles (Loasby 1989:71-2). Here the much simpler mechanical equilibrium analogies appeared to provide a more easily understandable framework in which logical conclusions could be derived and examined. To the extent that Marshall chose to follow this pathway, the conclusion that in the end equilibrium defeated history in Marshall's economics is justified (Groenewegen 1982a:13).

\section{The Marshallian Response: The Rejection of History}

While equilibrium analogies continued to play an important role in Marshall's economic theory, it is clear that Marshall was unable to remain totally committed to equilibrium analysis. The limitations of equilibrium theorising continued to be emphasised in successive editions of the Principles, as were the calls for economic theory to progress more towards biological conceptualisations of economic events. However, as depicted by Groenewegen (1982a:13-14), Marshall's history versus equilibrium dilemma was forgotten under the reign of Marshall's successor to the Chair at Cambridge. The defeat of history became a rout as A.C.Pigou and his followers set about the task of refining Marshall's equilibrium theory in such a way that history became divorced from economic analysis. In this setting, the focus of long-period analysis became limited to those causal factors leading to decreasing long-period average costs that were consistent with attainment of 'competitive equilibrium'. This in turn saw a shift in emphasis away from 
Marshall's representation of increasing returns as arising from a combination of internal and external economies that were part of an endogenous process of business organisation. ${ }^{16}$ Instead, Pigou emphasised the significance of narrowly defined external economies, despite the protests of early critics such as Allyn Young (1913) and Dennis Robertson (1924) ${ }^{17}$. Marshall's representation of competition as an activity became submerged in definitions of market structure that were amenable to analysis through the models that were being constructed to replace the ambiguities associated with the complex world Marshall had sought to examine.

Pigou's reaction to Piero Sraffa's (1926) 'destructive contribution' to the cost controversies of the late 1920s is illustrative of how far the Marshallian way of thinking had departed from that of Marshall. Sraffa's critique had demonstrated decisively the serious logical difficulties associated with deriving long-period supply functions in the context of competitive equilibrium when increasing returns prevail. Pigou's $(1927 ; 1928)$ reaction was to further retreat into the confines of static analysis, emphasising the role of external economies and constructing the equilibrium firm concept from what he believed to be the remnants of Marshall's representative firm. Marshall's representative firm was reinterpreted by Pigou (1927:195) as one for which, under competitive conditions, there is, at each scale of aggregate output, a certain optimum size, beyond which no further internal economies were available. Pigou (1928:239-40) pictured an industry operating under 'competitive conditions' in which, in a manner partly similar to Marshall's 'trees in the forest' analogy, some firms were expanding, while others were declining. However Pigou protested that the situation analysed by Marshall, where the industry as a whole was in equilibrium without individual firms necessarily being so, was 'highly complicated'; and as a result, Pigou introduced the now familiar concept of the equilibrium firm:

It implies that there can exist some one firm, which, whenever the industry as a whole is in equilibrium, in the sense that it is producing a regular output $y$ in response to a normal supply price $p$, will itself also individually be in equilibrium with a regular output $x_{\mathrm{r}}$.

(Pigou 1928:239-40)

Subsequently, Pigou's 'some one equilibrium firm' was replaced by 'each individual firm'. Each firm existed in a state of equilibrium in concert with industry equilibrium, and the endowment of predetermined production functions enabled them to escape the 'biological' processes that had shaped Marshall's individual firms. Following the work of Joan Robinson (1933) in particular, the equilibrium firm was to find a place beyond the confines of perfect competition. However as Robinson was to later conclude, the market structure and firms in the theories being developed were far removed from what could be found in reality:

The Economics of Imperfect Competition was a scholastic book. It was directed to analyse the slogans of the text-books of twenty years ago: 'price tends to equal marginal cost' and 'wages equal the marginal product of labour'; and it treated of text-book questions, such as comparison of the price and output of a commodity under conditions of 
monopoly and of competition, demand and costs being given. The assumptions which were adequate (or which I hoped were adequate) for dealing with such questions are by no means a suitable basis for an analysis of the problems of prices, production and distribution which present themselves in reality.

(Robinson 1953a:166) $^{18}$

At the same time as the Marshallians were embarking on the static equilibrium path, Frank Knight (1921:14) had argued that 'notable progress in the right direction' had resulted from 'a sharper separation of the theoretical portion of economics from the empirical portion, and towards the clearer formulation of premises'. In reaching this position, Knight had been influenced by the 'young Austrian economist', Joseph Schumpeter, who had proposed a fundamental distinction between statics and dynamics, with the former belonging to the realms of 'pure theory'. In this scheme, Marshall's theory with its appeal to biological analogies and search for 'realism' failed the tests of pure theory as it did not achieve the unity and clarity of the work of Walras or Pareto. Knight's views on the 'shortcomings' of Marshall's approach were stated as follows:

But Marshall himself has adopted a cautious, almost anti-theoretical attitude towards fundamentals; he refuses to lay down and follow rigidly defined hypotheses, but insists on sticking as closely as possible to concrete reality and discussing 'representative' conditions as opposed to limiting tendencies. The gain in correctness and realism is in our opinion more than offset by the obscurity, vagueness and unsystematic character of the discussion, the inevitable consequence of burying fundamentals in an overwhelming mass of qualifications and detail.

(Knight 1921:15)

In Knight's carefully defined regime of perfect competition, it was readily conceded that the category of pure decreasing costs (i.e. those consistent with competitive equilibrium) was indeed an 'empty economic box'. However, the decreasing costs that Marshall was concerned with had no role to play in the static (pure) theory of price, belonging instead to the separate domain of dynamics. From this methodological standpoint, the 'solution' to the ambiguities in Marshall's long-period reconciliation exercise was to purge dynamics from the theory of equilibrium price.

These developments are symptomatic of the fact that by the end of the 1920s mainstream economic theory had turned its back on the 'biological' way of representing economic processes, and instead had reverted fully to the ways of the 'mathematicalphysical group of sciences'. Equilibrium had defeated history and realism of analysis became subservient to the requirements of 'pure theory'.

\section{Joan Robinson's Contribution}

Discussion of the history versus equilibrium theme would not be complete without reference to Joan Robinson's contributions, to which Groenewegen's inaugural lecture is 
dedicated. As noted above, Joan Robinson played a very significant part in the development of the early Marshallian approach to equilibrium theory, but then subsequently rejected this approach to economic reasoning in her reconsideration of the relevance of the imperfect competition model. This rejection was based firmly on the contention that equilibrium analysis upon which 'neoclassical' theory was founded was incapable of considering historical time and had distanced itself from reality. This view is expressed most clearly in her conclusion to the aptly titled 'History versus Equilibrium':

The lack of a comprehendible treatment of historical time, and failure to specify the rules of the game in the type of economy under discussion, make the theoretical apparatus offered in neoclassical textbooks useless for the analysis of contemporary problems, both in the micro and macro spheres.

(Robinson 1974:126)

In looking back at the cost controversies of the 1920s, Robinson (1974:132) concluded that Pigou had emptied history out of Marshall and reduced the analysis to a twodimensional scheme. Robinson's misgivings about the use of equilibrium analogies became more evident with her involvement in the 'Keynesian revolution', from which she concluded that: 'As soon as the uncertainty of expectations that guide economic behaviour is admitted, equilibrium drops out of the argument and history takes its place'. No sense could be made of movements towards, or between, equilibrium positions. In Robinson's judgement, modern general equilibrium theorists had become, to borrow Marshall's words, 'mere thinkers', and their analysis of no relevance to practical problems:

Some theorists, even among those who reject general equilibrium as useless, praise its logical elegance and completeness. A system of simultaneous equations need not specify any date nor does its solution involve history. But if any proposition drawn from it is applied to an economy inhabited by human beings, it immediately becomes selfcontradictory. Human life does not exist outside history and no one has correct foresight of his own future behaviour, let alone the behaviour of all the individuals which will impinge on his. I do not think that it is right to praise the logical elegance of a system which becomes selfcontradictory when it is applied to the question that it was designed to answer,

(Robinson 1974:127-8) ${ }^{19}$

It can be seen that Robinson shared Marshall's views on the importance of history to economics, and developed an understanding of the nature of the history versus equilibrium dilemma originating from Marshall's writings. However, unlike Marshall, Robinson came to view equilibrium analogies as being incompatible with history, and therefore called for the abandonment of equilibrium analysis in economics. 


\section{Concluding Comments}

In his inaugural lecture, Marshall emphasised that the analysis of economic events required both the study of history and the application of theory. He had reasoned that economic theory must move away from the 'mathematical-physical' sciences with the emphasis on static equilibrium analogies, and to embrace instead 'biological' approaches to analysing complex 'organic' systems. The unresolved struggle between 'economic biology' and mechanical notions of equilibrium is a major and often misunderstood legacy of Marshall's Principles. Marshall was unable to escape the constraints of static equilibrium analysis, and consequently, the union he sought to establish between theory and history was not achieved.

The importance of combining theory and history in economic analysis is echoed in Groenewegen's own inaugural lecture. Like Marshall's, Groenewegen's lecture did not represent an attack on the application of formal theory or mathematical economics. Instead it warns against the dangers of viewing 'history as the opposite to theory'. Groenewegen's own analysis of Marshall's struggle to find the balance between history and theory led him to conclude that the defeat of Marshall the economic historian by Marshall the equilibrium theorist in the longer run had significant and detrimental consequences for economics. From the discussion in this chapter, it can be seen that the 'equilibrium theorist' was undoubtedly the victor in the eyes of the Marshallians who enthusiastically embraced the assignment of removing the 'ambiguities' and 'mass of qualifications' from Marshall's writings, so as to enable the construction of 'pure theory'. Marshall had been well aware of the dangers inherent in travelling along this path, but appeared reluctant to devote time to pursuing the alternative 'economic biology' pathway that he had pronounced as representing the 'Mecca' of the economist. ${ }^{20}$ Instead, mechanical analogies were defended, the associated 'handy tools' were refined and became the inheritance of the generations to follow, and equilibrium analysis become embedded as a dominant metaphor in economic thinking and discourse. In this setting, Marshall's struggle in the Principles was associated with an inability to define terms and theoretical relationships formally enough to clarify logical ambiguities that stood in the way of the refinement of equilibrium analysis and pure theory. As a consequence, the history versus equilibrium dilemma became irrelevant to the development of mainstream economic analysis, and the 'economic biology' pathway was left to be explored by 'nonmainstream' practitioners.

Criticisms of equilibrium analysis inevitably raise questions as to alternative modes of thinking and discourse in economics. Marshall's writings suggest that 'speculations from biology' represent one pathway on which this journey may proceed. This alternative was asserted much more definitively by Marshall's contemporary, Veblen (1898), who called for the construction of economics as 'evolutionary science' along 'Darwinian' lines. Veblen's appeal did, and continues to, attract the attention of a group of economists, variously referred to as belonging to the 'evolutionary' or 'institutionalist' schools of thought. However, despite the impressive progress that has been made in reformulating economic ideas within the context of evolutionary analogies and thought processes, such developments are rarely accorded a respectable place within mainstream economics. ${ }^{21}$ It is, however, of interest to note that Frank Hahn (1991), much respected amongst the architects of general equilibrium theory, has predicted that in the next hundred years 
economics would return to its 'Marshallian affinities' with biology, a prediction finding some support from Kenneth Arrow (1995), another prominent equilibrium theorist. ${ }^{22}$ However, the instutionalised formalism that provides the fertile grounds for equilibrium theory would appear to be a major obstacle to be overcome before such predictions can begin to be realised. In the meantime, Marshall's history versus equilibrium dilemma remains largely unresolved, and in terms of his own assessment, economic theory remains in a rudimentary and preliminary stage of development for as long as the equilibrium analogies borrowed from the (largely pre-twentieth century) 'mathematicalphysical' sciences play a prominent role in economic reasoning.

\section{Notes}

1 Groenewegen (1982a) argued that writers such as Hollander, Blaug and Samuelson had not clearly understood the differences between the 'classical' and 'neoclassical' meanings of general equilibrium, and referred his readers to Walsh and Gram's (1980) study of these differences. Gramm (1980) also presents a critique of the 'equilibrium theorist' interpretation of Adam Smith's contributions.

2 Hereafter cited as the Principles. Unless otherwise noted, all references to the Principles (Marshall 1920b) refer to the eighth edition, published by Macmillan in 1920 (1947 reprint), significantly subtitled, An Introductory Volume.

3 Interestingly, Veblen (1898:375) was also critical of the German historical school to the extent that 'they contented themselves with an enumeration of data and a narrative account of industrial development, and have not presumed to offer a theory of anything or to elaborate their results into a consistent body of knowledge'.

4 See Whitaker (1975:I, 4-19) and Groenewegen (1995:118-130) for an account of this stage in the development of Marshall's thinking. Groenewegen (2001) provides a more detailed overview of the evolutionary elements in Marshall's contributions, while Rafaelli's (2003:336) insightful research clearly links Marshall's early thinking on mental philosophy with the later biological analogies to be found in the Principles.

5 Significantly, Hearn was a foundation professor at Melbourne University (1855) who initially directed his teaching largely to history and political economy. Marshall's appreciation of Plutology is noted by Groenewegen (1988, 2-4), and further discussion of Hearn's contributions can be found in Groenewegen and McFarlane (1990:51-6). As Laurent (2001:23-5) demonstrates, a significant characteristic of Hearn's Plutology is the frequent references to the work of both Darwin and Spencer.

6 Hodgson (2001:95-112) provides an excellent review of the Historical School's important influence on Marshall, a much 'neglected' influence emphasised by Shove (1942) in his centenary evaluation of Marshall's contributions.

7 The changes to be found in the successive editions of Marshall's Principles can be detected by referring to Guillebaud's two volume ninth variorum edition of the Principles (Marshall 1961).

8 Fishburn (1996) provides an informative examination of the Darwinian and Marshallian contexts in which the Natura non facit saltum motto is employed.

9 The richness of Marshall's often neglected insights into the analysis of industrial organisiation is clearly captured in the accounts provided by Andrews (1951), Loasby (1990) and O'Brien (1990). Marshall's analysis of industrial organisation is sadly absent from modern microeconomics textbooks, with Earl (1995) being a notable exception, where a clear distinction is drawn between Marshall's 'evolutionary analysis of the firm' and the later 'marginalist' theories of the firm and markets. 
10 Loasby (1990) provides an excellent account of the principle of continuity in the context of Marshall's approach to industry organisation.

11 See for example the following extract of a letter to A.W.Flux dated 7 March 1898; reproduced in Pigou (1925:406-7, Marshall's emphasis); 'My confidence in Cournot as an economist was shaken when I found that his mathematics re I.R. [Increasing Return] led inevitably to things which do not exist and have no near relation to reality. One of the chief purposes of my Wander-jahre among factories, etc. was to discover how Cournot's premises were wrong'.

12 There remains some debate about the role of the representative firm: for some recent and at times diverging interpretations see Marchionatti (2001), Raffaelli (2001) and Hart (2003).

13 The possibility of 'irreversibilities' because of the existence of returns to scale was raised initially in Pure Theory of Domestic Values, where Marshall warned that extensive economies were not readily lost: 'Developments of mechanical appliances, of division of labour and of organisation of transport, when they have been once obtained are not readily abandoned' (Marshall 1879:202).

14 Allyn Young stood alone amongst the Marshallians in his understanding of Marshall's difficulties:

No analysis of the forces making for economic equilibrium, forces which we might say are tangential at any moment of time, will serve to illume this field, for movements away from equilibrium, departures from previous trends, are characteristic of it. Not much is to be gained by probing in to it to see how increasing returns show themselves in the costs of individual firms and in the prices at which they offer their products.

(Young 1928:533)

15 See Whitaker (1990b) for a discussion of intended content of Marshall's proposed 'second volume'.

16 The view that Marshall assigned the key role to external economies in his attempts to reconcile increasing returns and 'competitive' equilibrium can be found in Pigou (1913; 1927 ; 1928) and Sraffa (1926) and has been an interpretation subsequently promoted by Stigler $(1941 ; 1990)$. However, this interpretation is not consistent with Marshall's own representation of increasing returns in Principles (see for example p. 318). Further discussion of the role of external economies in Marshall's writings can be can be found in Prendergast (1992; 1993) and Hart (1995).

17 Marshall's manuscript notes on his copy of Pigou (1912), reproduced with perceptive commentary in Krishna Bharadwaj (1972), provides useful insights into how Marshall viewed the 'extensions' of his model by Pigou. Pigou's (1912) treatment of decreasing and increasing returns implied that both were due to external factors. Marshall's comments on the end-paper of his copy of Pigou (1912) summarises his rather serious reservations about Pigou's work: 'I incline to think that the marginal supply curve Part II Ch. VII has no reality; I think he [Pigou] overrates the possibilities of the statical method' (Bharadwaj 1972:33).

18 Shove (1933), who had understood what Marshall had attempted to achieve more clearly than his Marshallian colleagues, reached a similar judgement in his review of Joan Robinson's work. Harcourt (1991) provides an insightful account of Shove's interpretation of Marshall's Principles and how this interpretation differed from that of his contemporaries.

19 Robinson's (1974:127) criticisms were not limited to the neoclassical version of general equilibrium, noting that the specification of a self-reproducing or self-expanding system such as that of Sraffa or von Neumann exists in logical time, not history. Kaldor's $(1972 ; 1985)$ writings, inspired directly by Allyn Young's (1928) contributions to the Marshallian cost 
controversies, also became well known as opposing the application of equilibrium analysis to economic analysis.

20 In this context, it is not difficult to share Groenewegen's (1982a:14) appreciation of the aptness of Joan Robinson's (1953b:259) remark 'the more I learn about economics the more I admire Marshall's intellect and the less I like his character'. In similar fashion, Robinson (1978a:144), commenting on problems in understanding the concept of equilibrium, remarks: 'Who was it who understood this bit? Marshall did in his own wicked way. You will notice, if you re-read his Principles, that the thinner is the argument the thicker is the tear gas.'

21 Hodgson (1999) provides an excellent account of the development and major elements of evolutionary economics. Foster and Metcalfe (2001) outlines some of the most important developments in evolutionary economics and suggests directions for future research.

22 These predictions are discussed in Hodgson (1999:45). Hahn argued that the 'pleasures of theorems and proofs' would succumb to 'the uncertain embrace of history and biology', while Arrow is quoted as suggesting that economic theory may well take a path which is analogous to the biological path which 'some economists' bad maintained was a 'more appropriate paradigm' for economics than equilibrium models. 


\section{3 \\ Keynes as a Writer \\ Three Case Studies \\ Rod O'Donnell}

A puzzle surrounds Keynes as a writer. On the one hand, he is variously described as an economist who could write well, as a master of the English language and as a great writer. Harrod (1951:647) declared that Keynes had such a 'supreme mastery of English prose' that some might think that it would be 'as a prose writer that he will be longest remembered'. Johnson $(1977: 90,92)$ observed that Keynes, with his ability to use words 'as an artist', stood out among economists because several of his works could be read 'as literature in their own right'. According to Galbraith (1987:232), Keynes was 'a lucid and resourceful master of English prose', while, for Skidelsky (2000a:xviii), 'Keynes was a masterly user of English [whose] language, logical and robust, could suddenly take wing as his mind soared beyond the strict requirements of his argument'. On the other hand, of all twentieth-century economists, he is the one whose writings are most likely to generate conflicting interpretations, not just of the same book but even of the same chapter or paragraphs. Readers of the secondary literature on Keynes cannot fail to be struck by the extent and durability of the debates concerning the content and meaning of his main writings, be they in economics, philosophy, politics or elsewhere. How is it, then, that someone who is widely regarded as a good writer can apparently also be such an unclear writer? Surely, in matters economic, political or philosophical, part of being a good writer is an ability to convey thought lucidly and unambiguously as well as an ability to convey it gracefully and skilfully? Surely a good writer in these areas should combine clarity with eloquence, sense with sensibility?

Evidently, the puzzle has two sides. One concerns Keynes's qualities as a writer. As regards clarity, for example, is he, generally speaking, a lucid writer, a turbid writer or does he oscillate between the two depending on the work or passage in question? Disagreement there will be, but I suspect a majority of his readers would opt for some version of the last alternative. On the other hand, as regards eloquence, is he, generally speaking, a skilful, engaging, even magnificent wordsmith, or merely an ordinary, pedestrian, workmanlike writer? Here I suspect a much larger proportion of readers, whether sympathetic or hostile, would choose the former. On the other side of the puzzle stand the qualities of Keynes's readers and interpreters, particularly, but not exclusively, in economics. Have they, on the whole, been good, careful and skilled readers, or have they been hasty, sloppy, blinkered or hopeless readers? It obviously helps to be an economist when reading economic writings, but economists are not generally known for their training or interest in reading skills. Nor are they widely known for an ability to set aside their own paradigm or ideology so as to read sympathetically from alternative 
viewpoints; pluralism and respect for alternatives have never been formidable forces on the battlefield of economic ideas. ${ }^{1}$

In this chapter, I offer some reflections on an issue relevant to all readers of Keynes, namely, the interaction between his characteristics as a writer and the clarity of his writings. This topic, which is related to, but distinct from, the study of rhetoric and persuasion in his writings, has received very little attention. By focusing on clarity rather than other issues, my hope is that a greater understanding of Keynes's characteristics as a writer will contribute to better interpretations of his thought, but the hope is not sanguine. $^{2}$

My central proposition is that lack of clarity in Keynes's writings is often due to poor expression or laxity in the use of language. In expanded form, my thesis is as follows:

(i) The thought underlying Keynes's writings is frequently clear and coherent, but, on occasions, its clarity is obscured by certain of his characteristics as a writer.

(ii) These various characteristics may be grouped under the general heading of poor word choice or carelessness in the use of language.

(iii) On such occasions, multiple readings, careful intellectual labour and close textual analysis are required to uncover the clear underlying meaning, as well as the deficiencies in his prose.

(iv) Commentators and scholars who overlook this work can easily slip into poor interpretations of his thought.

I am not, of course, suggesting that all instances of unclear writing in Keynes are due to this cause. Unclear writing may result from poor expression of thought that is actually coherent, from accurate expression of thought that is actually muddled, or from poor expression of muddled thinking. What I am suggesting is that many instances of lack of clarity in Keynes fall into the first category. If this is so, then (ii) necessarily follows from (i), because clear thought that is unclearly expressed must be due to poor or careless use of language. My thesis thus contrasts strongly with Gotti's (1994:158, 177, 183-6) remarkable claims that Keynes's choice of language in the General Theory is careful, intentional and far from haphazard, and that the deliberate variations and inconsistencies in the meanings of his words constitute invitations to readers to supply their own interpretations of his text. ${ }^{3}$

In supporting my thesis, I use arguments based, not on sweeping impressionistic generalisations, but on detailed case-by-case examinations. As the only appropriate investigative procedure for the task at hand, this involves the marshalling of relevant evidence and the drawing of probabilistic conclusions. Where careful analysis uncovers a clear underlying meaning, and identifies the poor expression responsible for the lack of clarity, the probabilities of the conclusions reached will be high, even approaching virtual certainty.

Three case studies are presented. The first comments briefly on an analysis of Keynes's writing by Graves and Hodge, possibly the only close examination of one of his passages by English critics. The other two concern passages taken from his philosophical and economic writings respectively, where misunderstanding is evident in some of the secondary literature. Readers of Keynes will be able to suggest numerous other passages where his meaning is not immediately transparent, and further passages where his meaning is notoriously unclear. Any selection from this lengthy list will be arbitrary to 
some extent. My three cases were chosen, not for their high significance, but because they involve relatively short and self-contained passages, because they provide clear illustrations of my arguments, and because they encompass variations across time (19211940), across disciplines (philosophy and economics) and across styles of writing (academic and popular). Their aim is to demonstrate the confusions and entanglements that arise in Keynes's texts when thought that is actually clear and coherent is muddied by loose or inexact word usage.

\section{Two English Critics Pass Judgment}

While many commentators have delivered asides on Keynes's writing, there appear to be very few studies of Keynes as a writer. A short essay by Johnson (1977) offers glimpses of Keynes as a 'literary craftsman', and certain chapters in Marzola and Silva (1994) offer generalised comments on Keynes's language although the bulk of the book is concerned with methodology and rhetoric. The study on which I shall focus here is a much earlier and more circumscribed investigation by the English critics, Robert Graves and Alan Hodge. Graves was the famous poet, novelist, scholar and one-time professor of poetry at Oxford, while Hodge was an editor, novelist and occasional co-author with Graves. Their book, The Reader over Your Shoulder, first published in 1943 and abridged in 1947, was highly successful, being brought out, after five reprints, in paperback in 1965.

Its object was to advance a range of principles for good English prose, and then to examine the extent to which certain people, eminent in their fields, exemplified these principles in passages taken from one of their popular works in the period 1918-41. Keynes, alongside T.S.Eliot, J.B.Priestley, Bertrand Russell, G.B.Shaw and H.G.Wells, was one of the eminent persons selected, with a passage from How to Pay for the War of 1940 being the subject of analysis. The good English prose principles informing this scrutiny consisted of twenty-five principles of clear statement and sixteen principles of graceful prose. The method used by Graves and Hodge to select passages for examination was idiosyncratic. After deciding that an author was eminent in a field, they proceeded as follows: 'We took up the first popular book, pamphlet or article by him that came our way and read on at our usual speed until we found ourselves bogged in a difficult passage. This passage became the subject of our analysis' (1947:139).

The selected passage from How to Pay for the War begins at the fifth paragraph and runs, with some indicated (and unindicated) omissions, to the end of the first sentence of the twelfth paragraph. ${ }^{4}$ In their reading, Graves and Hodge find thirty-three breaches of the principles of clear statement, and three breaches of the principles of graceful prose. In my view, most of these criticisms are wide of the mark, being either irrelevant, pedantic, trivial or mistaken. At one point, they seem to be overtaken by their enthusiasm to find breaches - having deleted one of Keynes's sentences and inserted a summary sentence of their own, they then criticise Keynes for having committed the sin of 'material omission' in their very own sentence! ${ }^{5}$

Nevertheless, a smaller number of their criticisms do strike home. I agree with them that Keynes's writing in the passage can be faulted for (i) inappropriate word choice, (ii) confused imagery, and (iii) memory strain, though the number of instances seems to me 
to be far fewer than they claim. Obviously, all three deficiencies contribute to difficulty of reading and lack of clarity. One can sort out the muddles by identifying the inappropriate words and their alternatives, by clarifying the images, or by reading on, but it typically takes several readings and some labour to do so.

As an example of poorly expressed imagery, take the first metaphor in Keynes's article. Very few words are spent in developing the image and it is left to the reader to sort out the details (which it is possible to do with some work). The context is the competing wartime demands of the civilian population on the one side, and of the war service departments and the export/import trades on the other. The relevant sentences are as follows.

At present it is hard to say who, if anyone, settles such matters. In the final outcome there seems to be a larger element of chance than of design. It is a case of pull devil, pull baker-with the devil so far on top. ...

On the assumption that our total output is as large as we know how to organise, a definite residual will be left over which is available for civilian consumption. The amount of this residue will certainly be influenced by the reasonable requirements of the civilian population. If an acute shortage develops in a particular direction, baker's pull will become stronger and devil's weaker; and something will be done to allow a larger release. ...

In peacetime, that is to say, the size of the cake depends on the amount of work done. But in wartime the size of the cake is fixed. ...

This is the elementary fact which in a democracy the man in the street must learn to understand if the nation is to act wisely - that the size of the civilian's cake is fixed.

(CW IX:374-5) ${ }^{6}$

The problems with Keynes's treatment are various. The identities of the two protagonists are not made entirely clear at the outset, and it only becomes evident after reading further that the baker represents the civilian workforce which produces domestic output and demands consumption goods and services, while the devil (almost certainly) represents war-related demands on total output, namely, those of the war service departments and import/export requirements. What they are pulling at is also not explicitly described by Keynes, which causes Graves and Hodge to offer a very muddled account. They mostly infer that the devil and the baker are pulling at a cake which represents total output, whereas a careful reading of Keynes's text makes it clear that while the two figures are certainly tugging at total output, only one part of this, the civilian's share, is represented by a cake. They also interpret the phrase 'with the devil so far on top' as meaning 'on top of the cake', whereas it actually means the devil is winning the tug-of-war. Keynes's imagery and prose are also poor because he reveals a characteristic that we will encounter again, a tendency to use the abbreviated form (the cake) ahead of the full description (the civilian's cake). Fortunately, understanding this piece of imagery is not vital to understanding his argument. ${ }^{7}$ 
In short, despite having greatly exaggerated Keynes's deficiencies as a writer, Graves and Hodge have nevertheless performed a service by exploring such deficiencies, and identifying some of the faults with which he may be validly charged.

I now proceed to the two remaining case studies to illustrate my thesis in greater detail. One is from Keynes's main work in philosophy, the Treatise on Probability, the other from his main work in economics, The General Theory. In both cases, I shall argue that his meaning is clear, but that he muddies the waters with unnecessarily loose language. The serious scholar is then obliged to work hard, with several re-readings and possible reference to outside material, to see that Keynes has not actually departed from his underlying meaning but has introduced potential confusion by being careless or lax in his use of language. It should also be noted that while both case studies reveal much about Keynes as a writer and clear up some confusions in the literature, neither lays claim to new insights into his thought.

\section{Limited Logical Insight}

This study concerns passages in the Treatise on Probability where Keynes discusses unknown probabilities and limitations on human insight into logical probability relations. Frank Ramsey, a brilliant thinker in many areas, criticised these paragraphs as selfcontradictory in a 1926 essay which laid the foundations for the subjective theory of probability.

Another argument against Mr Keynes' theory can, I think, be drawn from his inability to adhere to it consistently even in discussing first principles. There is a passage in his chapter on the measurement of probabilities which ...seems to me quite unreconcilable with the view which $\mathrm{Mr}$ Keynes adopts everywhere except in this and another similar passage.

(Ramsey 1978:65-6)

Braithwaite repeated the charge in 1973 in the foreword to the Collected Writings edition of Keynes's book, claiming that in speaking of probability as 'relative in a sense to the principles of human reason', Keynes 'throws over entirely his doctrine of specific objective probability-relations' ( $C W$ VIII:xxi). No explanation is offered for this serious accusation, but presumably, as the editor of the original 1931 edition of Ramsey's writings, he merely accepted Ramsey's position. And, despite intervening argument against Ramsey's view (O’Donnell 1989:64-6), Bateman revives the accusation. He declares that both Ramsey and Braithwaite made unknown probabilities 'a point of departure for illustrating that Keynes's entire conception of probability was untenable', and that they also claimed that Keynes's acknowledgment of limited logical insight constituted 'an acknowledgment that his theory was untenable' (Bateman 1991:109 and n. 2). Subsequently, Bateman (1996:57 n. 34) accepts the accuracy of the accusation by arguing that, in 1931, Keynes referred to this part of Ramsey's critique in a capitulation which saw Keynes abandon the logical theory of probability and accept Ramsey's subjective theory. ${ }^{8}$ 
I shall show that the charge is mistaken, however, and that Keynes's account is not only internally consistent but also conceptually quite straightforward. In this case, while Keynes's writing should certainly carry part of the blame, it is the readings of his critics that are largely at fault. They have not granted him the goodwill, cooperation and intelligence he requested in a different context in 1934 ( $C W$ XIII:470), and as a result have fallen victim to careless readings. With hindsight, one can see how re-wording and re-phrasing at certain points could have forestalled the misunderstandings that have arisen, but careful reading reveals that his words, though sometimes not well-chosen, were sufficient to convey his position to readers prepared to engage fully with his text.

In Keynes's theory, probability consists of a logical relation between virtually any pair of propositions. Since an infinite number of propositions exist, there is an infinite number of probability-relations. For any probability to be known by humans, humans must have sufficient logical insight into the realm of logical relations to perceive the probabilityrelation in question. These probability relations are also called 'secondary propositions'. If humans do not have sufficient logical insight and cannot perceive a probability relation (secondary proposition), then this probability is described as unknown. The theory applies to both individuals and humanity as a whole. Individuals can vary in their powers of logical insight, so that a probability relation may be known to one individual and unknown to another. And all humans are limited because only an omniscient mind endowed with perfect logical insight could know all logical relations. ${ }^{9}$

The passage which Ramsey criticises as contradictory comes from section 12, chapter 3. Since it will be the subject of detailed examination, it is quoted in full

12. To say, then, that a probability is unknown ought to mean that it is unknown to us through our lack of skill in arguing from given evidence. The evidence justifies a certain degree of knowledge, but the weakness of our reasoning power prevents our knowing what this degree is. At the best, in such cases, we only know vaguely with what degree of probability the premises invest the conclusion. That probabilities can be unknown in this sense or known with less distinctness than the argument justifies, is clearly the case. We can through stupidity fail to make any estimate of a probability at all, just as we may through the same cause estimate a probability wrongly. As soon as we distinguish between the degree of belief which it is rational to entertain and the degree of belief actually entertained, we have in effect admitted that the true probability is not known to everybody.

But this admission must not be allowed to carry us too far. Probability is, vide chapter $2(\S 11)$, relative in a sense to the principles of human reason. The degree of probability, which it is rational for $u s$ to entertain, does not presume perfect logical insight, and is relative in part to the secondary propositions which we in fact know; and it is not dependent upon whether more perfect insight is or is not conceivable. It is the degree of probability to which those logical processes lead, of which our minds are capable; or, in the language of chapter 2, which those secondary propositions justify, which we in fact know. If we do not take this view of probability, if we do not limit it in this way and make it, to this extent, 
relative to human powers, we are altogether adrift in the unknown; for we cannot ever know what degree of probability would be justified by the perception of logical relations which we are, and must always be, incapable of comprehending.

(CW VIII:34-5) ${ }^{10}$

The first paragraph comments on the meaning and implications of unknown probability (and vaguely known probability), and is, to my mind, unproblematic. It is the second paragraph which Ramsey accuses of inconsistency. His brief argument (1978:66) may be paraphrased as follows. Keynes's theory holds that (i) between the premises and conclusion of an argument there is only one logical relation and hence only one true secondary proposition, (ii) these logical relations are necessarily independent of the mind, and (iii) we know some probability relations but may not know others. From this, he draws the conclusion, using language based on Keynes's later phrasing, that 'probability relations are not ones which we are incapable of comprehending'. To this point I have no quarrel with Ramsey's summary. But then the accusation of inconsistency arrives, based on the last part of the last sentence. If, as Keynes says, we know some probabilities and hence some logical relations, then Ramsey claims it is 'nonsense' for him to speak of probabilities as being justified by logical relations 'which we are, and must always be, incapable of comprehending'.

What has gone awry here? My diagnosis is that Ramsey's argument is surprisingly weak because he has made the simple mistake of confusing all logical relations with some logical relations. Logical relations are divided by Keynes into two groups- those which we do know (which generate known probabilities), and those which we do not know (which generate unknown probabilities). He does not say we know all probabilityrelations, for his theory 'does not presume perfect logical insight'. In this context, the phrase perfect insight, is not to be equated with accurate insight, but with universal, global or unbounded insight. It is not the case that our insight, by not being perfect, is inaccurate, distorted or deluded; but it is the case that it is limited. Our knowledge of probabilities is restricted to the secondary propositions 'which we in fact know', where 'know', as chapter 2 of the Treatise on Probability explains, refers to true knowledge and not mere belief or opinion. And this group of secondary propositions depends on our powers of logical insight into the realm of logical relations, only a part of which is accessible to us. Knowledge of these secondary propositions is independent of our having perfect logical insight which would render visible all parts of the realm. Thus humans have powers of accurate insight into some logical relations, but lack accurate insight into all such relations. If we insisted that probability theory required perfect (universal) logical insight, we would not be able to generate a theory that underpinned human reasoning and we would be 'altogether adrift in the unknown'. We would be defeated by not being able to know those logical relations which we are currently incapable of comprehending, and which (on the reasonable assumption that humans will never achieve universal insight) we must always be incapable of comprehending.

This is the 'sense' in which probability is relative to 'the principles of human reason'. Human reason is restricted to working with the knowledge we do possess, whether of primary propositions, secondary propositions or even, as chapter 2 allows, of logical axioms. The word 'principles', however, is poorly chosen. As the ensuing explanatory 
sentences indicate, particularly the reference to the 'logical processes... of which our minds are capable', it would have been better to have spoken of the 'powers' or 'scope' of human reason. Above all, Keynes's discussion does not imply that the principles of human reason are different in kind from the principles of logic; it only implies that human reason has limited powers or scope. Thus the reference to human reason is perfectly consistent with the core of his theory, and exactly the opposite of the Ramsey-Braithwaite charge that it constitutes a repudiation of this core.

This interpretation is also consistent with the earlier section to which Keynes refers, section 11 of chapter 2 , quoted in full below.

11. In conclusion, the relativity of knowledge to the individual may be briefly touched on. Some part of knowledge-knowledge of our own existence or of our own sensations - is clearly relative to individual experience. We cannot speak of knowledge absolutely-only of the knowledge of a particular person. Other parts of knowledge-knowledge of the axioms of logic, for example - may seem more objective. But we must admit, I think, that this too is relative to the constitution of the human mind, and that the constitution of the human mind may vary in some degree from man to man. What is self-evident to me and what I really know, may be only a probable belief to you, or may form no part of your rational beliefs at all. And this may be true not only of such things as my existence, but of some logical axioms also. Some men-indeed it is obviously the case-may have a greater power of logical intuition than others. Further, the difference between some kinds of propositions over which human intuition seems to have power, and some over which it has none, may depend wholly upon the constitution of our minds and have no significance for a perfectly objective logic. We can no more assume that all true secondary propositions are or ought to be universally known than that all true primary propositions are known. The perceptions of some relations of probability may be outside the powers of some or all of us.

What we know and what probability we can attribute to our rational beliefs is, therefore, subjective in the sense of being relative to the individuaL But given the body of premises which our subjective powers and circumstances supply to us, and given the kinds of logical relations, upon which arguments can be based and which we have the capacity to perceive, the conclusions, which it is rational for us to draw, stand to these premises in an objective and wholly logical relation. Our logic is concerned with drawing conclusions by a series of steps of certain specified kinds from a limited body of premises.

(CW VIII:18-19)

The distinction that opens this section is between individual and absolute knowledge. This again refers to the scope of knowledge and not its accuracy, that is, to the distinction between some knowledge and all knowledge. Some parts of the totality of knowledgesuch as personal existence and sensations are known only by the individuals concerned, and are not known 'absolutely', where absolutely here means by everyone or universally. 
That this is the meaning to be given to 'absolutely' is evident, firstly, from the contrast between 'absolute knowledge' and 'the knowledge of a particular person', and secondly, from a later sentence which says that not all true primary or secondary propositions are 'universally known', that is, known by everyone. Keynes then turns to other parts of knowledge and introduces the word 'objective'. Readers could be forgiven for thinking that 'objective' here means what it did in the opening pages of the Treatise on Probability when Keynes first advanced his concept of logical probability, namely, that objective means independent of human opinion ( $C W$ VIII:4). However, closer examination reveals that objective in this passage actually means the same as absolute or universal. That is, objective knowledge is known by everyone or known universally, with its counterpart, subjective knowledge, referring to knowledge known by the individual. Other parts of knowledge may seem 'more objective' (or more universally known) but in fact they are not, because what 'I really know' may form 'no part of your rational beliefs at all'. Thus some parts of knowledge are not known to everyone. Included in this knowledge is knowledge of the axioms of logic. That individuals vary in their knowledge is obvious, Keynes says, and this variation may extend to variations in their knowledge of logical axioms. ${ }^{11}$

The cause of such variations is then attributed to variations in the constitution of the human mind between individuals. This again refers to scope and not accuracy-what is known accurately by one person may not be known at all by another. The suggestion is that some individuals have minds whose configuration and properties give them greater capacities for logical insight (regardless of whether these capacities are genetic or instilled by education or experience). Keynes then generalises this proposition to suggest that the constitution of the human mind could place global limits on human logical insight. Although human minds as a whole have power over some logical relations (insight into some secondary propositions), there may be other logical relations which all humans are powerless to see because the human mind is not configured or constituted with sufficient acuity (or capacity for acuity) to perceive all such relations. ${ }^{12}$

This, Keynes says, has no significance for 'a perfectly objective logic'. At this point, a different difficulty is introduced. Some sliding starts to occur in the meaning of the word 'objective' which begins to hover ambiguously between the two meanings previously discussed, neither of which, fortunately, affects the point he is making. If objective still means 'known by everyone', then the restriction of human knowledge to a subset of logical relations has no consequences for the full set of logical relations even if these were known by everyone. And if objective has the meaning of being independent of human opinion, then an objective logic still continues to exist despite human powerlessness to see or know all of it. In the penultimate sentence, Keynes pulls all the threads together and indicates that his concern all along has been with the scope, and not the accuracy, of human insight. Given the premises supplied to us, and given the logical relations we are able to perceive, then our conclusions will be connected to these premises by 'an objective and wholly logical relation'. Now that he has reverted to discussing probability as a logical relation between propositions, Keynes slides back into the initial meaning of objective as independent of human opinion. ${ }^{13}$

Two things are evident, I think, from Keynes's passages. Firstly, they have a coherent meaning which is entirely consistent with the rest of his theory. Indeed, this meaning is a necessary part of his theory once it is assumed that humans do not have unbounded 
insight into an infinite number of logical relations. ${ }^{14}$ Secondly, his exposition and word choice are nevertheless very poor. They contain the seeds of several confusions, quite apart from Ramsey's mistake of confusing all and some. It would have been better, in the sentence which led Ramsey astray (the last sentence of the chapter 3 passage), to have inserted the word 'those' so that it read 'by the perception of those logical relations which we are...incapable of comprehending'. It would also have been less misleading at the start of the same paragraph to have spoken of 'The degrees of probability' rather than 'The degree of probability'. And it would have been far better had Keynes phrased the passages such that the meanings of 'principles', 'perfect', 'absolute' and 'objective' were immediately clear, and there was no sliding between senses of 'objective'. If readers take the trouble to re-read the passages with the suggested changes in mind, the underlying coherence will become clear. ${ }^{15}$

A critic of my reading of these passages might argue that all I have done is changed the meaning of some of Keynes's words to make them fit a preconceived interpretation. To this simplistic criticism, I reply that my reading is not arbitrarily imposed because it possesses a very high degree of consistency. It is consistent with:

(i) the other sentences in these passages,

(ii) other passages in the Treatise on Probability related to these passages, and

(iii) all other parts of Keynes's theory in the Treatise on Probability.

The consistency, in other words, is quite comprehensive. If a critic can produce an alternative reading which has the same level of consistency regarding (i) and (ii), I would accept it as an equally sound interpretation in relation to these two criteria. I strongly doubt that it can be done, but am open to correction. The debate will then come down to how (iii) is to be handled. This involves questions such as (a) how probable is it that Keynes unwittingly contradicted himself over a reasonably lengthy period of re-writing, and (b) how much benefit of the doubt should readers give to authors, or, to borrow again from Keynes's 1934 phrase, how much goodwill, cooperation and intelligence are authors entitled to expect from readers. For my part, I think the probability very low, and I am prepared to grant him considerable (but not unlimited) goodwill and cooperation.

\section{Long-Term Expectations and Confidence}

The final case study focuses on a key aspect of the first two sections of the much discussed chapter 12 of the General Theory, 'The State of Long-Term Expectation'. The aspect is the nature of the relationship between long-term expectations and confidence. These concepts are crucial in Keynes's analysis of uncertainty and form part of his arguments for long-period unemployment equilibria in market economies.

Section I opens the discussion clearly enough and contains no relevant problemsinvestment depends partly on the marginal efficiency of capital (MEC), the MEC depends partly on prospective yields, and prospective yields depend partly on expectations about 'future events, which can only be forecasted with more or less confidence' ( $\mathrm{CW}$ VII:147). Keynes then concludes the section as follows: 
We may sum up the state of psychological expectation which covers the latter [that is, future events which can only be forecasted with more or less confidence] as being the state of long-term expectation;- - distinguished from the short-term expectation [of sales revenue from current production with existing equipment].

(CW VII:147-8)

At this point, it can be inferred that the state of long-term expectation depends on two things - (i) forecasts, with which are associated (ii) degrees or levels of confidence.

Section II then distinguishes these two factors quite explicitly.

The state of long-term expectation, upon which our decisions are based, does not solely depend, therefore, on the most probable forecast we can make. It also depends on the confidence with which we make this forecast - on how highly we rate the likelihood of our best forecast turning out quite wrong. If we expect large changes but are very uncertain as to what precise form these changes will take, then our confidence will be weak.

(CW VII:148)

Again, everything remains clear (leaving aside any questions raised by the intrusion of the word 'probable'). The state of long-term expectation depends on

(i) a forecast (described as the 'most probable' or 'best' forecast), and

(ii) a confidence in this particular forecast.

The next three paragraphs, however, release the hares of potential confusion because they do not stick firmly to the opening script. They continue to talk about confidence and expectations, but in the following terms.

The state of confidence, as they term it, is a matter to which practical men always pay the closest and most anxious attention. But economists have not analysed it carefully and have been content, as a rule, to discuss it in general terms. In particular it has not been made clear that its relevance to economic problems comes in through its important influence on the schedule of the marginal efficiency of capital....

There is, however, not much to be said about the state of confidence $a$ priori. Our conclusions must mainly depend upon the actual observations of markets and business psychology. This is the reason why the ensuing digression is on different level of abstraction from most of this book.

For convenience of exposition we shall assume in the following discussion of the state of confidence that there are no changes in the rate of interest, and we shall write... as if changes in the values of investments were solely due to changes in the expectation of their prospective yields and not at all to changes in the rate of interest....

(CW VII:148-9) 
By continuing to use the word 'confidence', and again placing it in italics, these paragraphs convey the strong impression that they are discussing exactly the same notion of confidence that was outlined in the preceding paragraph.

This, however, is not the case. The key lies in the little phrase, 'as they term it', which is likely to be overlooked on a first reading - partly because of the construction of the sentence in which the pronoun (or abbreviation), 'they', precedes the noun (or full description), 'practical men', partly because the referent of 'it' is not immediately obvious, and partly because the phrase has the appearance of an aside. Its importance, however, lies in the fact that it indicates that the state of confidence is just another name, one that practical men use, for what Keynes has called the state of long-term expectation. The 'it', in Keynes's phrase, refers to the state of long-term expectation, and not to confidence in particular forecasts. Thus the state of long-term expectation and the state of confidence are synonyms. The former is an analytical term introduced as part of economic theory, the latter is an everyday term used by practical people in discussing the same thing in matters relating to business.

Any reader still not convinced by this reading can turn to the proofs of the General Theory. The mid-1934 version of chapter 12 follows the final published version with only a few changes ( $\mathrm{CW}$ XIII:423), one of which, however, happens to concern the paragraphs under discussion. The mid-1934 version of chapter 12 begins as follows:

There is much of great importance which can be said, quite independently of the rate of interest, concerning the state of long-term expectation and the methods by which the prospective yield of investment is estimated by the market, as distinct from the methods by which this prospective yield is capitalised or converted into present value. It is a subject to which practical men always pay the closest and most anxious attention under the name of the state of confidence. But economists have not analysed it carefully and have been content, as a rule, to treat it in general terms. There is, indeed, not much to be said a priori, and our conclusions must mainly depend upon the actual observation of markets and business psychology.

$(C W$ XIV:464-5)

The thought is the same as in the General Theory, but the wording is different. And the wording in the draft puts it beyond reasonable doubt that the state of long-term expectation and the state of confidence are the same thing.

This clarifies another source of possible confusion arising from the title Keynes gave to chapter 12 in the mid-1934 proof. This title was 'The state of long-term expectations (or confidence)' ( $C W$ XIII:423). In the absence of other information, one is grammatically entitled to infer from this wording, either that 'expectations' and 'confidence' are interchangeable so that the expanded rendition of the title would be 'The state of long-term expectations (or the state of long-term confidence)', or that the 'state of long-term expectation' and 'confidence' are equivalent so that the corrected rendering would be 'The state of long-term expectation (or Confidence)'. However, as the quoted text of the chapter indicates, neither of these equivalences is accurate so that we can safely conclude that Keynes worded his title misleadingly. The only abbreviated and 
grammatical way of conveying his meaning is to repeat the word 'of', as in The state of long-term expectation (or of confidence)' in which case the expanded version would read The state of long-term expectation (or the state of confidence)' which corresponds exactly to the content of his chapter. In any event, he avoided this source of confusion in the final version by restricting the chapter title to the 'The state of long-term expectation'.

Given that the state of long-term expectation has two aspects, Keynes would have had several alternative names before him. He could have emphasised confidence, as in 'the state of long-term confidence', but this would not have harmonised well with his distinction between short-term and long-term expectations. Or he could have chosen a more comprehensive name such as 'the state of long-term expectation and confidence', but this is longer and clumsier. In the end, he retained the structure of his opening discussion in which expectations (both short and long) enter first, with degrees of confidence only becoming important subsequently in the context of long-term expectations. ${ }^{16}$

We thus have two different senses of the word 'confidence' in these paragraphs:

(i) confidence in particular forecasts which, when combined with such forecasts, makes up the state of long-term expectation,

(ii) the state of confidence, which is merely a synonym for the state of long-term expectation.

Evidently, confidence in the first sense forms part of confidence in the second sense. The former refers to the conceptual framework within which Keynes develops his economic theory, and is the sense in which the term 'confidence' is best used by those engaging in the analytical discussion of his scientific discourse. The latter is an ordinary language term used by practical people in everyday discourse. ${ }^{17}$

Let me now sum up the results of this investigation into Keynes's untidy prose. The 'state of long-term expectation' and the 'state of confidence' are the same thing, but 'long-term expectation' and 'confidence' are different things which, when combined, comprise the afore-mentioned state. The word 'confidence' tout court has a different meaning from the word 'confidence' in the phrase 'state of confidence'. Likewise, 'expectation' (without qualification) and 'confidence' are not the same thing. If all this is remembered, clarity is achievable in reading Keynes on this topic. But it places very large 'memory strain' on the reader to do so. A simple solution was available, however. None of these problems would have arisen if he had stuck solely to his analytical terminology in which confidence is a component of the state of long-term expectation, and the everyday phrase, the state of confidence, had been relegated to a footnote.

While still using both expressions, however, Keynes tended, from Chapter 12 onwards, to use 'state of confidence' more frequently than 'state of long-term expectation'. ${ }^{18}$ This may have occurred because he feared the important role of confidence might have been downgraded or lost by too frequent reference to 'long-term expectations' or, more prosaically, because the former was easier to write or say than the latter. But he could have made 'the state of long-term expectation' the usual term, and regularly reminded his readers that confidence was an integral component of every such state.

The aim of the above clarification is to help reduce confusion and mistakes in reading Keynes on this topic. Readers who turn to Keynes's own writings during the 1930s can 
now avoid the pitfalls of his lax word usage for themselves. And readers of the secondary literature can be made aware of errors in commentaries and interpretations. Several writers have made the mistake of conflating Keynes's two senses of confidence. Carabelli (1988:198) argues that subjective risk depends on 'what in The General Theory was to be called "the state of confidence"..., that is the confidence in a particular probability judgement'. ${ }^{19}$ Gerrard makes the mistake more than once by claiming that 'long-term expectation has two components: the most probable forecast and the state of confidence' (1995:188, also 190, 193), and that 'prospective returns depend on the state of long-term expectations comprising the most probable forecast and the state of confidence' (1997:187). A similar confusion is evident in Dow and Dow (1985:49) who, even after quoting from the clearer $1934 \mathrm{draft}$, nevertheless refer to 'long-term expectations, and the state of confidence they dwelt on'. Nor is it sufficient to glide over terminological or definitional difficulties by omitting deeper conceptual analysis. Bateman's (1996) interpretation makes confidence a central theme in the development and theoretical structure of the General Theory, but provides little analytical discussion of the concept of confidence and its relationship to expectations, and frequently treats these two concepts as synonyms, as in the claim that before 1933 'there was no necessity for Keynes to turn to confidence, or expectations, about the future, as the final element in pulling [the General Theory] together' (Bateman 1996:78, see also 111, 120-1, 124-7, 139, 166).

In clarifying Keynes's meaning, however, I am not suggesting that his remarks are conceptually unproblematic. He gives no explanation, for example, of how probabilities and levels of confidence are to be combined in forming expectations. If probability is high and confidence is low, for example, is long-term expectation high, medium or low? ${ }^{20}$ Possibly the concepts of certainty equivalence, or of combined judgments of probability and confidence (analogous to those involving probability and weight in the Treatise on Probability), could come to the rescue, but these issues need not detain us here.

\section{Towards a Resolution of the Puzzle}

I began with a puzzle - how could Keynes be widely regarded as a good writer and yet apparently be such an unclear writer in the sense of generating multiple interpretations? The above discussion provides part of the answer at the 'micro scopic' level of individual passages. (A more complete answer requires additional 'macroscopic' arguments concerning Keynes's theory of writing. ${ }^{21}$ )

Clarity was certainly one of Keynes's goals as a writer. In his correspondence and drafts, we can see him striving to express his thoughts more clearly to his readers. But clarity wasn't the only goal, and it sometimes lost ground under pressure from other claims. For example, Keynes is almost always a fluent writer regardless of the nature or topic of his writing, by which I mean that his prose typically flows without disjointedness or interruption. If a sentence has to be re-read, it is usually not because of clumsy construction or grammatical faults (though both occur), but because its meaning is not directly apparent. But while fluency creates greater readability and pleasure, it does not guarantee clarity. On those occasions where clashes between fluency and clarity arise, 
Keynes sometimes seemed to have listened more for fluency than for clarity, more for sound than for sense.

The greatest impediment to clarity in the three case studies is poor, inappropriate or confusing word choice. This is manifest in various forms. One form involves grammatical issues where Graves and Hodge make valid complaints (such as their point that 'Were' is better than 'have been' in 'when men were working harder, they have been able to increase their consumption' (1947:179)). A second form is the use of different expressions to refer to the same thing (the state of long-term expectation and the state of confidence). A third is the use of the same word to refer to different things (confidence and the state of confidence), related to which is the use of the same word in different senses with subsequent sliding between the senses (objective). A fourth is not guarding against alternative meanings of the chosen word (such as perfect in the Treatise on Probability passage which there meant universal but could have meant accurate). A fifth is the confused presentation of imagery - using the abbreviated form (the cake) prior to using the complete form (the civilian's cake). And finally, there is memory strain, which emerges in various ways - having to remember (within the same work or across different writings) that one phrase is a synonym for another, that the same word may have related but different meanings, that the same word may be used in very distinct senses within the space of several pages, that a word is being used in one sense only and not in an equally well-used alternative sense, and that time may need to elapse before an image comes clearly into focus.

Keynes certainly had some awareness that his phrasing and word choices were, at times, inappropriate or incorrect. In the 1930s, after several decades of debates and controversies, admissions of this deficiency emerge in his correspondence regarding the General Theory. In 1935, in reply to Hawtrey's criticisms, he observed, firstly, that 'In any passages in which I seem to regard the adjustment of investment and saving as a process occupying time, I agree with you that I am expressing myself incorrectly and am departing from my own ideas' ( $C W$ XIII:581, emphasis added), and, secondly, that 'When I said my point about sinking funds was primarily theoretical, I should have said primarily 'general'. For I had in general considered that it is of great practical importance' ( $C W$ XIII:616). Hicks drew from him a further admission in 1936, where his occasional practice, noted above, of placing the incomplete form ahead of the full form is evident.

I am afraid that I have here misled you (just as I have misled Pigou...) by omitting a necessary qualification on page 223 of my book. In the passage near the top of page 223 I was not intending to do more than to give an example by which I would lead the reader on to the formal definition which I give a few pages later, on page 226. The accurate definition of rate of interest is on page 226. The illustration on page 223 requires a qualification which I have omitted. ...I ought, of course, to have added this qualification. For it is quite natural to think that what I say on page 223 is meant as a complete definition, and readers tend to substitute it for the formal definition given on page 226 , since it is decidedly simpler.

( $C W \mathrm{XIV}: 76)$ 
And in 1937 he confessed a longstanding habit to Kaldor.

You are, of course, quite right. I meant 'neutral' and not 'unstable'. I have had a habit of using the one word when I meant the other for more years than I can remember. Indeed I used to do it long ago when I was working for the mathematical Tripos, when it was a much more serious offence than now!

$(C W \mathrm{XIV}: 242)$

All four remarks should put us on our guard. They support my criticism of Keynes that, in expressing his thoughts, he was sometimes careless or inattentive in word selection. After careful analysis, one can see, not only how thought which is otherwise quite clear is muddied by poor word choices, but also how easy it is to restore clarity to his writing merely by using more appropriate words. It seems that the exceptionally intelligent Keynes did not have a well-developed capacity for placing himself in the position of his readers, including his more intelligent ones, so as to remove easily avoidable confusions. If, however, after all pleas have been entered, we still accept that authors are ultimately responsible for what and how they have written, then Keynes, I think, can be faulted for not having been more attentive to his use of language from the perspective of its clarity, and for placing too much trust in the ability of his readers to see what he was driving at. A pertinent message regarding Keynes as a writer may be fashioned from one of Graves and Hodge's remarks on J.F.C. Fuller: 'ZThe faults are those of over-confidence in the reader's intelligence and knowledge: it is dangerous to allow such laxity in word usage'. 22

The moral of my story is this. Keynes can be a wonderful, delightful and magnificent writer, but he can also be an exasperatingly unclear writer. If we seek clarity, we should, out of courtesy and respect for his formidable intellect, give him the benefit of the doubt and avoid hasty conclusions. Our initial presumption should be that while he may be confusing, he is not confused. There is typically (but not always) a coherent underlying meaning which is both clear and consistent with the rest of his thought, but which may be made turbid by laxity in word usage. The obscured clarity is recoverable, but only by intellectual labour and careful reading.

\section{Notes}

* This contribution is offered, with deep respect, admiration and gratitude, to Peter Groenewegen whose teaching and support have blessed me greatly, and who has always appreciated the importance of reading authors carefully. I am grateful to Craig Freedman, Wylie Bradford and Sean Turnell for helpful comments and suggestions. In addition, I should like to apologise in advance if the relevant work of any author has been neglected. This chapter has been written under the appalling conditions for research activity that prevail in many Australian universities as a result of federal government policies, such conditions making it impossible to maintain, let alone increase, one's intellectual capital.

1 As many of us lament, the teaching of the history of economic thought, which has always served as a strong antidote to any philistinism in its students and at which Peter Groenewegen excelled, has undergone severe contraction in recent decades. 
2 To avoid misunderstanding, my position is that a number of sound interpretations of Keynes's thought are possible, where 'sound' essentially means consistent with all relevant evidence (see O'Donnell 1991:48-52). I am thus not arguing that there is only one correct interpretation of his thought, as a whole or in large blocks, and any impression to the contrary should be resisted. However, at the level of individual sentences or passages, I am prepared to argue, on occasion and with reasons, that they mean one thing and not another. I am also not arguing that Keynes's characteristics as a writer are the only cause of diversity in interpretations.

3 Although referring to Grice's principles for writers, Gotti (1994:173) does not even entertain the possibility that Keynes failed to fulfil Grice's fourth principle, that an author 'ought to express himself clearly and in an orderly way, avoiding ambiguity and other causes of misunderstanding'.

4 That is, from p. 373 , line 28 to p. 375 , line 20 in $C W$ IX (see note 6).

5 See item 14(c) in Graves and Hodge (1947:180). They also include a form of this sentence in their fair copy version of Keynes's text.

6 All references to the Collected Writings of John Maynard Keynes (Keynes 1971-89) take the form of $C W$ followed by the volume number and page numbers.

7 Had Graves and Hodge continued reading, it would have become even more obvious that 'cake' meant 'civilian's cake'. Section III begins with Keynes saying that 'to calculate the size of the cake which will be left for civilian consumption', we need to estimate maximum domestic output, net imports and the output absorbed by the war effort ( $C W$ IX:381).

8 This last issue has generated considerable controversy among Keynes scholars interested in the links between Keynes's philosophy and his economics. My own view, in brief, is that Keynes did not abandon the conceptual framework of his logical theory of probability in favour of the subjective theory.

9 For further explanation of these aspects of Keynes's logical theory of probability, see O’Donnell 1989:28-66).

10 The fourth sentence of this quotation is incorrectly reproduced in the Collected Writings edition. As the original 1921 edition indicates, the sentence begins with 'That' and not The'.

11 The person in the street, for example, will typically not have the same knowledge of logic, for example, as Bertrand Russell or Alfred Whitehead, the authors of Principia Mathematica.

12 An analogy may be drawn with unaided human eyes and ears which are incapable of seeing and hearing everything that animals can. Readers interested in exploring the axioms of logic issue may consult Part II of the Treatise on Probability (particularly chapters 10, 11, 12), in the course of which Keynes again alludes to unknown probabilities and limited human insight.

13 The distinction between these two senses of objective, in which one refers to what is common to all human consciousness and the other to what lies outside human consciousness, is present in the essays of the Victorian intellectual, Leslie Stephen (1893:138, 142-3).

14 On unknown probability, Bateman passes two peculiar remarks without accompanying explanation. He says that Keynes seems 'perplexed' by the idea (1991:109) and that it is an 'awkward construction' (1996:57 n. 34). In fact, there is nothing perplexing or awkward about it at all in Keynes's theory; nor does Keynes even hint that he found it so. It is a perfectly natural concept within his theory that fits in seamlessly with the rest of the conceptual tapestry. What perplexity or awkwardness can there be in saying that humans have limited logical insight and cannot perceive every member of an infinite set of logical relations? Would it not be far more perplexing and awkward to say the opposite?

15 More comment on the 'constitution of the human mind' might also have dispelled doubt as to the nature of his argument. 
16 This parallels the structure of the Treatise on Probability where probabilities (related to expectations) occupy centre-stage, and the weight of argument (a proxy for confidence in that work) is an important but subsequent consideration.

17 One less important instance of unclear writing occurs in the last paragraph. Keynes says that, given no changes in the interest rate, changes in investments are "solely due to changes in the expectations of their prospective yields'. It would have been more consistent with his analytical framework to have substituted 'states of long-term expectation' for 'expectations', so that the changes he was about to consider embraced both forecasts (or expectations) and their accompanying degrees of confidence.

18 A comparison of Keynes's usage of the two terms, 'state of long-term expectation' and 'state of confidence' is as follows. In Keynes's lectures prior to the General Theory in 1932-35 (Rymes 1987), both terms occur with roughly equal frequency. From the General Theory onwards, however, the latter is used more frequently than the former. In the work itself, subsequent to their introduction in chapter 12, 'state of confidence' (or a similar phrase) occurs five times (pp. 248, 264, 307, 317 and 368), whereas 'state of long-term expectation' occurs only once (p. 246), followed by the hybrid term 'the psychological expectation of future yield from capital assets' (p. 247). 'State of confidence' also dominates in two important exchanges after the General Theory. In his 1938 discussion of Tinbergen, it occurs twice as against once for state of long-term expectation, leaving aside one combination of the two (CW XIV: 287-8, 294, 309); while in his 1938 correspondence with Harrod on economic growth, it is the only term that is used (CW XIV: $321-2,326)$.

19 See also Carabelli $(1988: 198-9,223-4)$ where the same conflation is evident in several sentences.

20 See Hoover (1997:221-2) and Runde (1997:225-6).

21 See O'Donnell (2004).

22 Graves and Hodge (1947:168); I have substituted 'allow such laxity in word usage' for their 'use such brevity'. 


\title{
14 \\ 'The Functionless Investor'
}

\author{
Keynes's Euthanasia of the Rentier Revisited \\ Tony Aspromourgos*
}

One of the more remarkable propositions of Keynes's General Theory is that capitalism without property income is possible. In the opening sentences of the final chapter, two key economic defects of liberal capitalist society are proposed:

The outstanding faults of the economic society in which we live are its failure to provide for full employment and its arbitrary and inequitable distribution of wealth and incomes. The bearing of the foregoing theory on the first of these is obvious. But there are also two important respects in which it is relevant to the second.

(Keynes 1936:372; emphasis added)

The relevance of the descriptive theory of Keynes's book for the abolition of 'unearned' income indeed seems largely to have been ignored in the subsequent development of Keynesian ideas. ${ }^{1}$ The purpose of what follows is to revive Keynes's idea concerning the possibility of systematically pushing the underlying rate of interest towards zero. It seeks to demonstrate that capitalism with a zero pure rate of return is a possible state of the world, which policy could enable (the character of the transition path to such a state is another matter). The achievement of that state would amount to eliminating 'pure property income', in the sense that it would result in a zero return from the mere ownership of property. There would only be returns to definite activities, at least under competitive conditions: labour, risk-bearing, entrepreneurship, and so on. The question considered is whether this outcome is possible in a closed system; its desirability or ethical standing is left almost entirely unexamined.

This analysis involves the supposition that pure property income can be conceived of, separably from other income forms. The meaning of that notion is worth clarifying. Suppose a security issued by a well-ordered state in a closed system, to which there attaches a zero default risk. The yield to maturity - at the current market price for that security, known with certainty by participants in the market-is a riskless rate of return. Suppose further, that relative to the yield to maturity of that riskless security (e.g., a ninety-day Treasury Bill), yields on all other capital assets are determined by the usual gamut of forces: differential risk, price volatility (a particular species of risk), market thinness (because relevant to price volatility, via illiquidity), other differences in the liquidity of assets, expectations of future yields (because relevant to arbitrage of securities of differing maturities), other imperfections of substitutability between financial assets, the costs (including normal profits on capital) of the relevant industries 
(e.g., banking) which intermediate financial assets, imperfections of substitutability between financial and real assets, and similar imperfections among real assets (not least, barriers to entry and exit), and so on. The normal or equilibrium structure of yields will be determined by these factors, with the riskless yield representing the rate of return capturing pure property income. ${ }^{2}$ Every other yield contains elements of risk-bearing, illiquidity, entrepreneurship, monopoly power, and so on. Keynes's notion of euthanasia of the rentier requires this kind of conceptual separability between yield on capital ownership as such, and additional elements of return due to differential characteristics of other assets $v i s-\grave{a}$-vis the riskless asset. ${ }^{3}$

This is to define the pure rate of return by reference to the yield to maturity on a riskless government security; but there are generally more than one such yield at any point of time. Each of the current yields to maturity of government securities of various maturities can be regarded as riskless, in the sense of having income streams and redemption prices that are known with certainty. ${ }^{4}$ In general these various yields to maturity will differ; the yield curve is not always horizontal. Given competition in the securities markets - free entry to and exit from those assets, combined with arbitrage of prices between securities - the relative yields on these securities are understood to be governed by interest rate expectations, differing liquidity characteristics, and relative risks. But how can the different securities issued by a non-defaulting government have differential riskiness? They cannot, if they are intended to be held to maturity. But at least some investors do not intend to hold securities to maturity, and perhaps all investors entertain at least the possibility that they may have to exit before maturity, for reasons currently unforeseen. Hence, the behaviour of investors is governed by expectations of future prices, or equivalently, future interest rates. The two key results which follow from this are: i) longer dated securities are riskier because their prices are more volatile in response to the same interest rate variations; and ii) expectations of a rise in future short rates ceteris paribus steepens the yield curve because they induce holders of securities to switch towards shorter dated paper. Hence there is no unique, riskless rate of return: all zero-defaultrisk paper held to maturity has a zero-risk yield; the fact that longer maturities commonly have higher zero-risk yields is primarily due to the intervention in the relative pricing of securities, of market sentiment concerning the possible consequences of not holding to maturity. The best empirical analogue for 'the' pure rate of return is a short rate to maturity. Furthermore, it would be extremely difficult for policy to simultaneously set more than one interest rate, in a competitive system. The structure of rates is strongly governed by market forces and objective characteristics of securities. To that extent, there is generally only one degree of freedom available to the authorities; and for practical reasons, the rate set is at the short end of the spectrum.

\section{Euthanasia in the General Theory}

The two respects in which Keynes's descriptive theory in the General Theory has a bearing on arbitrary distribution - as mentioned in the opening quotation above - is sketched subsequently by Keynes (GT: 372-7, and prefigured at 220-1). First, he suggests that many who would like to see wealth and income disparities further reduced are deterred partly by a belief 'that the growth of capital depends upon the strength of the 
motive towards individual saving and that for a large proportion of this growth we are dependent on the savings of the rich out of their superfluity'. Keynes's demand-side theory of aggregate activity casts considerable doubt on this traditional view: short of full employment (which he takes to be an unusual condition for a mature capitalist economy ${ }^{5}$ ), accumulation is inhibited not assisted by a low propensity to consume. Hence, 'measures for the redistribution of incomes in a way likely to raise the propensity to consume may prove positively favourable to the growth of capital'. Here he has in mind redistributive taxes, with death duties in particular favoured; 'for there are certain justifications for inequality of incomes which do not apply equally to inequality of inheritances' (GT: 372-4). Without doubt, for Keynes entrepreneurship is the leading species of the former justifications.

Keynes's second and 'much more fundamental inference' concerning distribution goes to the rate of interest:

The justification for a moderately high rate of interest has been found hirherto in the necessity of providing a sufficient inducement to save. But we have shown that the extent of effective saving is necessarily determined by the scale of investment and that the scale of investment is promoted by a low rate of interest....

This points to the capacity to reduce interest to that rate which generates investment of a magnitude equal to the saving gap at full employment. Keynes is confident that this implies lower interest 'than has ruled hitherto' (GT: 375): given his acceptance of an interest-elastic investment demand schedule in the General Theory, combined with his conviction that mature capitalism normally exhibits involuntary unemployment, this naturally follows (insufficient investment to match the full employment saving gap implies a too high interest rate). But this reasoning by itself does not lead compellingly to the possibility of zero pure interest. In effect, Keynes's answer to this is that growth of the capital stock through time can lead to the pure rate of return consistent with the full employment level of investment, approaching zero. He makes very explicit that entrepreneurship including risk-bearing would still have to be remunerated in this situation:

This would not mean that the use of capital instruments would cost almost nothing, but only that the return from them would have to cover little more than their exhaustion by wastage and obsolescence together with some margin to cover risk and the exercise of skill and judgement. In short, the aggregate return from durable goods in the course of their life would... just cover their labour costs of production plus an allowance for risk and the costs of skill and supervision.

(GT: 375 , also 221; cf. $C W$ XXI:412)

This would mean 'the euthanasia of the rentier', or 'the functionless investor' (GT: 376): 'A man would still be free to accumulate his earned income with a view to spending it at a later date. But his accumulation would not grow' (GT: 221). 
Keynes's conception here is articulated in the framework of a rather unclear notion of interest as an index of the 'scarcity' of capital, in some sense. This links back to his vexed and near infamous Chapter 17 (as well as Chapter 16, esp. 216-20)-which perhaps was Keynes's last best effort to lay to rest the ghosts of Hayek's review of the Treatise of Money (1930) (vide Hayek 1931; Mongiovi 1990). That chapter has been most ably clarified by Barens and Caspari (1997); also Kurz (2000), Naldi (2001). Something like this seems intended: supposing two inputs for simplicity (labour and homogeneous capital), then for any given level of labour employment in the aggregate, as the capital stock (notionally) rises, the 'marginal productivity' of the capital input fallsand might be supposed eventually to reach zero. And one of the possible given levels of labour employment - associated with an orthodox equilibrium (or a Keynesian, managed economy) - is the full employment level. This amounts to allowing the possibility of capital satiation in a fully employed economy (Keynes himself speaks of saturation). Hence Keynes looks to a coming abundance of capital to slowly ${ }^{6}$ push pure interest towards zero:

Interest to-day rewards no genuine sacrifice, any more than does the rent
of land. The owner of capital can obtain interest because capital is scarce,
just as the owner of land can obtain rent because land is scarce. But whilst
there may be intrinsic reasons for the scarcity of land, there are no
intrinsic reasons for the scarcity of capital [except if public sector saving
cannot compensate for a lack of sufficient private saving, at full
employment, to bring about the required abundance of capital]....I see,
therefore, the rentier aspect of capitalism as a transitional phase... It will
be, moreover, a great advantage of the order of events which I am
advocating, that the euthanasia of the rentier... will be nothing
sudden,...and will need no revolution.

For Keynes the correct theory of a competitive capitalist economy reveals a way to the abolition of property income, without needing to abolish the property rights which traditionally generate that income. ${ }^{7} \mathrm{He}$ sees 'a gentle and easy death' for pure property income (this being the Oxford English Dictionary's prime definition of 'euthanasia'). Keynes's choice of this metaphor is perhaps connected with his interest in eugenics. Concerning the revival after 1900 of 'negative eugenics' ('decreasing the fertility of the "worst" types of human stock'), Toye (2000:117-8) suggests that 'compulsory sterilization, and even (as some of the medical lunatic fringe of the day recommended) involuntary euthanasia, were the coercive measures of last resort that some negative eugenicists advocated' 8 This suggests how Keynes's exposure to the eugenics literature might have stimulated him to reach for this metaphor; and certainly, euthanasia of 'the functionless investor' largely would be involuntary. 


\section{Keynes and Euthanasia in the 1940s}

The abolition of property income did not remain a mere theoretical speculation for Keynes. His involvement in advising the British government into the post-War period enabled him to pursue, if not euthanasia, at least 'cheap money', in practice. The most notable instance of this is Keynes's contributions as a member of the 1945 National Debt Enquiry - as well as his involvement in wider governmental deliberations around monetary policy, including as a semiofficial Treasury adviser to Chancellor of the Exchequer Hugh Dalton, up until Keynes's death in April 1946 (Howson 1993:98). ${ }^{9}$ The policy he advocated in the Enquiry may appear more moderate than euthanasia - though as has been seen, gradualism was an essential part of Keynes's view. Meade, also a member of the Enquiry, gives expression to his exasperation with Keynes at one pointthough perhaps in any case also providing a legitimate insight into Keynes's make-upcommenting on an out-of-committee discussion between Keynes, himself and Lionel Robbins (who was also on the Enquiry): 'Keynes on the rate of interest showed himself in a typical mood: revolutionary in thought and very cautious in policy' (Howson and Moggridge 1990:46). This was stimulated by Keynes's defending a 3\% interest rate (on long-term 'gilt-edged' debt-Howson 1993:323). Meade's diary entries on Keynes and interest may be read as revealing Meade to have the opposite problem. However intemperate, or irrational, Skidelsky ${ }^{10}$ may regard Keynes's policy views to be here, Meade is essentially at one with him, or perhaps more radical (though not consistently)but more orthodox in his economic theory.

Keynes presented three lectures' to the Enquiry ( $C W$ XXVII:388; Howson 1993:47), his longhand notes for which may be quoted at some length, to suggest some of their flavour:

The optimum rate of interest depends on (a) how much investment one wants, (b) how much reward to saving is socially desirable. The monetary authorities can have any rate of interest they like. ...If, after the war, we need more saving to provide more investment, we have to reduce the rate of interest up to the point of full employment. Thereafter the old rules apply we have to raise the rate of interest to prevent inflation. ... Historically the authorities have always determined the rate at their own sweet will and have been influenced almost entirely by balance of trade reasons and their own counter-liquidity preference. ...Authorities make rate what they like by allowing the public to be as liquid as they wish. ... Thus the reason for offering 3 per cent Savings Bonds are

(a) an inducement to saving as an offset to inflation... but chiefly

(b) a wider complex of the social reasons why the euthanasia of the rentier should not take place just yet.

...The essence of our interest policy should be to give a sufficient immediate reward to saving, so not to run prematurely against public psychology, and meanwhile to keep a free hand. 
(CW XXVII:390-6)

A second paper by Keynes, submitted to the Enquiry committee as a summary of his proposals on post-War public debt management, contains little of direct relevance to euthanasia ( $C W$ XXVII:397, 400). A third and final paper, on the concept of a capital budget, also contains almost nothing of relevance, other than a passing reference to Keynes's 'assumption that the outlets for public investment are not yet nearly saturated' (CW XXVII:410; also 350).

The National Debt Enquiry finally issued two reports - one on post-War monetary policy, one on a possible capital levy (Howson 1993:46). The report on monetary policy, written by the outgoing Permanent Secretary to the Treasury, Richard Hopkins, 'fastened' upon the page 203 statement on the conventionality of interest from the General Theory (quoted directly below), to justify the capacity of monetary policy to set long-term rates (Howson 1993:20-1, 46, 52) ${ }^{11}$ Dalton's subsequent experiment with 'cheaper' money was explicitly aimed at income redistribution, as well as easing public debt burdens (Howson 1993:121-2) — and appears to have been inspired by views of Keynes and Joan Robinson, which were more radical than those of most Labour Party economists on this issue (Howson 1993:88-90, 149, 326-7), Dalton even using Keynes's phrase 'euthanasia of the rentier', in inverted commas, in his diary (29 November 1946; Howson 1993:191, also 149). As Howson (1993:327) sums it up, 'Dalton ...saw himself as using Keynesian monetary policy to pursue socialist objectives.' That policy was overwhelmed by market sentiment by the beginning of 1947 (Howson 1993:122, 190-9, 328-31, 333-4). In effect, interest rate expectations ceased to acquiesce in the low rates, depriving the policy of credibility and thereby rendering it unsustainable. Subsequently, bureaucratic and academic support for the restoration of interest rate policy as an antiinflation instrument ended cheap money as such, in late 1951 (Howson 1988a:273-7, 280 - and this article more generally, on the whole two decade period of cheap money in Britain, from the spring of 1932, including its interconnection with public debt management). As to Keynes himself, the unorthodoxy or radicalism of his position, at least at the theoretical level, is well captured by Meade's somewhat horrified accounts of the 1945 deliberations:

Keynes...goes out of his way to give the maximum stress to the difference between his theory and old-fashioned orthodoxy. I felt definitely uncomfortable at his conclusions. He now almost holds the view that variations in the rate of interest (at any rate when it is as low as 3 per cent) have no effect upon investment. ...[H]e continues to put his ideas on this subject [interest] in the most extreme form.... He...leaves out all qualifications of the Liquidity Preference idea so as to assert unequivocally that neither thrift nor the productivity of capital have any influence over the rate of interest. ...[W]e [Meade and Robbins] intended to counter some of Keynes' more extreme remarks... and his view that the rate of interest should no longer be used to control inflation or deflation. ${ }^{12}$

This account is plausible, to the extent that it is very reminiscent of a strikingly clear statement of the logic whereby pure interest becomes a monetary or conventional 
phenomenon in Keynes's system of thought, eight years earlier in one of his journal articles defending the General Theory:

...the initial novelty [of Keynes's theory] lies in my maintaining that it is not the rate of interest, but the level of incomes which ensures equality between saving and investment. The arguments which lead up to this initial conclusion are independent of my subsequent theory of the rate of interest, and in fact I reached it before I had reached the latter theory. But the result of it was to leave the rate of interest in the air. If the rate of interest is not determined by saving and investment...how is it determined?...[My] resulting theory, whether right or wrong, is exceedingly simple - namely, that the rate of interest on a loan of given quality and maturity has to be established at the level which, in the opinion of those who have the opportunity of choice-i.e. of wealthholders - equalises the attractions of holding idle cash and of holding the loan. It would be true to say that this by itself does not carry us very far. But it gives us firm and intelligible ground from which to proceed. ${ }^{13}$

The other particularly striking statement of the conventionality of the pure rate of interest is in a passage of argument earlier in the General Theory, towards the end of his presentation of the so called monetary theory of the rate of interest:

It is evident...that the rate of interest is a highly psychological phenomenon [202]. ...It might be more accurate, perhaps, to say that the rate of interest is a highly conventional, rather than a highly psychological, phenomenon. For its actual value is largely governed by the prevailing view as to what its value is expected to be. Any level of interest which is accepted with sufficient conviction as likely to be durable will be durable; ...[203]. ...[I]t may fluctuate for decades about a level which is chronically too high for full employment;- particularly if it is the prevailing opinion that the rate of interest is self-adjusting, so that the level established by convention is thought to be rooted in objective grounds much stronger than convention... Such comfort as we can fairly take from more encouraging reflections must be drawn from the hope that, precisely because the convention is not rooted in secure knowledge, it will not be always unduly resistant to a modest measure of persistence and consistency of purpose by the monetary authority.

(GT: 202-4)

This explanation of pure interest as conventional links directly, and deeply, with the notion of distribution as arbitrary, from the opening of Chapter 24: the determination of the actual rate of interest as conventional means precisely that it is arbitrary, in the sense that its value can be other than what it is; there is no essential reason for it to be 'this value' rather than 'that value'; consistent with the equilibrium of the system, it can take any one of a spectrum of values. To the extent that income distribution in a competitive capitalist economy hinges upon the magnitude of that rate of interest, distribution is 
indeed 'arbitrary' (within limits). As the OED indicates, 'an arbitrary rule or practice' ('convention', emphasis added); 'having its origin or sanction merely in an artificial convention of any kind; arbitrarily or artificially determined' ('conventional', emphasis added). From this vantage point, Skidelsky's unjustified comments on Keynes's view of rentier income (n. 10 above) nevertheless do serve to open the question of the relation between Keynes's ethical values and his economic theory. In relation to the particular case of Keynes's views on the undesirability of property income, and their relationship to his (explanatory) theory of interest, the former is an ethical view, and one which Keynes thinks actualizable, at least at some point in the future; the latter is a purely descriptive characterization of actually occurring processes and outcomes, albeit in an abstracted theoretical universe. It is logically impossible for the former proposition to be deducible from the latter descriptive system. But this does not mean that the ethical value is something posited entirely independently of Keynes's understanding of the structure of the actual world. Keynes, like most human beings, is not in the business of positing values, desired states of the world, independently of what he judges to be possible. ${ }^{14}$ His new theory of the equilibration of saving and investment told him there was no unique positive rate of interest which played an essential role in the equilibration of the two in a competitive capitalist economy. The existence of a stable and orderly system was consistent with a spectrum of (pure) interest rate values, of which zero, in general, was one. Hence, his descriptive theory of the capitalist economy told him that capitalism with a zero pure rate of interest was a possible world. It was therefore a world that could be desired, and actualized by policy, under favourable conditions. In short, his descriptive theoretical understanding of the actual world, enabled the value to be, reasonably, entertained and embraced. ${ }^{15}$

But does Keynes's theory really enable pure interest to be drawn towards zero and then kept there, even by a measured and cautious conduct of monetary policy? On the one hand a persistent tendency towards lower and lower interest is posited on the achievement of capital abundance, over time. On the other, policy is posited as capable of enabling an approach towards, and an ultimate achievement of, euthanasia. The former notion is spurious. In any case, Keynes's reconciliation of these two posited views is this: i) the end of capital scarcity is necessary to sustain zero pure interest; ii) policy can engineer the time path to, the arrival at, such capital abundance. The policy engineering can and might involve particular public sector budget balances and activity, on both the public saving and public investment fronts. If the (private) propensity to consume is such as to make private saving at full employment insufficient for the desired time path to capital abundance, 'it will still be possible for communal saving through the agency of the State to be maintained at a level which will allow the growth of capital up to the point where it ceases to be scarce' (GT: 376). With regard to public investment,

...only experience can show how far the common will, embodied in the policy of the State, ought to be directed to increasing and supplementing the inducement to invest... [I]t seems unlikely that the influence of banking policy on the rate of interest will be sufficient by itself to determine an optimum rate of investment. I conceive, therefore, that a somewhat comprehensive socialisation of investment will prove the only means of securing an approximation to full employment; though this need 
not exclude all manner of compromises and of devices by which public authority will cooperate with private initiative.

Since in addition Keynes believes that interest in the money markets will not necessarily gravitate to the zero pure rate associated with capital abundance, monetary policy must actively manage interest rates downward, in line with capital abundance. In summary, Keynes's two fundamental policy objectives - full employment and zero pure property income - are to be simultaneously achieved by fiscal policy assisting in getting the economy to capital abundance in the desired time horizon, while monetary policy coaxes money market expectations down to the resulting sustainable zero pure interest. The fiscal element of this policy combination is as spurious as the link between interest and capital 'scarcity' - though in a coherent reconstruction, fiscal policy may well have a (more straightforward) role to play, as indicated in the penultimate section below.

One other element of Keynes's thinking may be noted. At the end of the introduction above it was argued that there is only one degree of freedom available to monetary authorities, for interest rate setting. However Keynes actually did advocate the authorities setting more than one interest rate, during the mid-1940s deliberations ( $C W$ XXVII:391, 396-400; Moggridge and Howson 1974:239, 242, 244; Howson 1993:47, 323). This may partly be explicable by greater market segmentation then than now. But the more significant logic of this approach seems to be for monetary policy to operate across a range of maturities, to allow the markets greater choice in the maturities they wish to hold. The authorities would issue, for example on a 'tap' basis, at prices/yields of their choosing, with the markets determining the quantities taken up. Any shortfall between the public sector's aggregate funding requirement and the markets' take up of securities would then be monetized (see also Howson 1988a:250, 252, 256-8, 260, 268, 275-6). Fully funding public sector deficits with securities issues is not necessary on this view (and might threaten loss of policy control over interest rates). The structure of rates thus set by the authorities would not be arbitrarily posited, from Keynes's kind of standpoint: it would be formulated with a careful eye to market sentiment concerning term structure.

\section{Sraffa and the Conventionality of Interest}

The element of Keynes's characterization of euthanasia which seems particularly unacceptable in retrospect is the relation between interest and capital scarcity. It is as if capital satiation, in some sense, is to be associated with a zero return, analogous to consumption satiation being associated with zero 'marginal utility'. (Pivetti (2001:108) suggests reasons why this might be implausible in a strictly orthodox framework. $\mathrm{Cf}$. $C W$ XXIX:212.) This is linked with the interestelasticity of investment demand. Together with the multiplier mechanism, this elasticity constitutes the incipient 'IS schedule' in his system, which enabled Hicks (1937) to begin the assimilation of Keynes's theory back into the orthodox vision. These notions were dealt fatal blows by Sraffa's 1960 critique of marginalist capital theory in the framework of a reconstruction of the classical approach to distribution and prices, and the considerable literature which has flowed from that seminal work. ${ }^{16}$ A cogent reconstruction of euthanasia must remove any such 
elements from Keynes's system. From Sraffa's classical perspective, the repudiation of demand-and-supply approaches to functional distribution points to a degree of freedom in the determination of distribution-one distributive variable must be determined independently of technology and prices (though subject to technological and social constraints). Hence in Sraffa's reconstructed classicism there can emerge the notion of yields on capital in production as ultimately regulated by interest rates independently determined in the money markets:

The rate of profits, as a ratio, has a significance which is independent of any prices, and can well be 'given' before the prices are fixed. It is accordingly susceptible of being determined from outside the system of production, in particular by the level of the money rates of interest.

(Sraffa 1960:33)

Following Panico (1988) and Pivetti (1991) — and in agreement with Keynes on this point - we can now conceive of this as involving monetary policy playing the decisive role in those money market outcomes. No recourse to capital scarcity and abundance is required. This removes one of Keynes's reasons for policy gradualism (n. 6 above); but another remains: the need, in order to ensure policy credibility, to appropriately shift likely sticky interest rate expectations. (There are possible ethical reasons for gradualism as well, not considered here.)

By employing Sraffa's classical approach to distribution and prices as a framework for making more sense of what is sound in Keynes's concept of a capitalist society with zero pure property income, space is opened up for the underlying yield on capital assets to be a free variable. It becomes possible for the pure rate of return to take any one among a spectrum of values, subject to social constraints determining minimum real wages imposing an upper bound on profit rates. That is to say, when combined with Keynes's investment/saving equilibration mechanism, such a theoretical framework provides the space for money markets to be essentially autonomous in the determination of the prices and yields of securities. This makes the pure interest rate-though not the structure of yields - 'conventional', in the strict sense that any one among that spectrum of yields is consistent with equilibrium of the system. The particular magnitude which emerges is merely customary. Such a Sraffa-Keynes synthesis removes Keynes's Principle from the uncongenial orthodox framework of simultaneous determination of prices and quantities with market clearing, a framework which denies his theory of output 'oxygen', and relegates it to a theory of short-period fluctuations at most. The clearest manifestation of the difficulties into which Keynes's compromises with orthodox distribution and value theory got him, is the presence of a full employment rate of interest (associated with a well-defined and well-behaved IS schedule) in his system. ${ }^{17}$ But many who regard distribution as alterable by policy also take the 'under-consumptionist' view that redistribution away from non-wage income will increase effective demand and employment. Keynes himself often assumes such reasoning (e.g., GT: 262, 290 on the relative spending propensities of wage earners, rentiers and entrepreneurs). This might seem to entail a well-defined relation between interest and (long-period) output, albeit on radically different grounds to the IS schedule. Not much should be made of this: given the long-term nature of any policy of redistribution along euthanasia lines, it cannot 
conceivably be thought of as a mechanism for full employment equilibration, whatever assistance it might provide to that objective over time (cf. Pivetti 2001:114-15).

As to Sraffa himself, his precise views on interest determination are difficult to discern from his published writings - though the Sraffa manuscripts, considerable selections from which are to be published, will reveal much more (vide Panico 2001, esp. 298-303, with Bellofiore, 2001:366-8; Ranchetti 2001, esp. 320-7). At page 203 of his own copy of the General Theory (quoted in the previous section) Sraffa wrote: "è così che si fa una "teoria" ("this is how one makes a "theory"'). ${ }^{18}$ Is this to be read as an endorsement of the notion of the conventionality of interest - or, as the inverted commas around teoria might suggest, is it rather an ironic dismissal of Keynes's formulation? It does not really matter. It is evident enough that Sraffa shared with Keynes the conviction that the opposite of the traditionally supposed causation between the general rate of profit in production on the one hand, and yields in money and financial markets on the other, was closer to reality. They shared the view that the determination of the latter yields may be conceived of as autonomous with respect to the former. At the same time, Sraffa evidences at least a deep disquiet about whether Keynes's specific formulation of this proposition had adequately escaped the orthodox framework of thought. Ranchetti (2001:327) very well sums up the two layers of Sraffa's stance towards Keynes on this matter:

...the strong objections Sraffa raised against Keynes' notions of the ownrate of interest and liquidity preference prevent one from reading Sraffa's [1960:33] proposition as an endorsement, though implicit and allusive, of the way Keynes related the rate of profits to the rate of interest in Chapter 17. On the other hand, on the more positive side of the matter, the new evidence available clearly confirm[s] a strong agreement between Sraffa and Keynes both on a monetary and conventional determination of the rate of interest and on the direction of the causal nexus between...the money rate of interest... [and] the rate of profits...

This combination of agreement and disagreement with Keynes is compatible with Sraffa's annotation being sincere, or ironic. With regard to the latter interpretation, his apparent view that conventional determination of interest is incapable of a plausible, general or quantitative, theoretical statement-in the manner Keynes pursued, and perhaps not in any manner at all — may lead to the inference that a theory of interest is strictly speaking not possible. After all, to propose that the level of interest is conventional is, in a certain sense, to propose that it is indeterminate. This is something like the conclusion arrived at by Pivetti (1991:135-6) in developing a monetary explanation of distribution following Sraffa's lead:

...interest rate determination amounts to a consideration of the wide range of policy objectives and constraints, under which interest rate policy decisions are taken. ...We believe that...a thorough consideration of the circumstances that have governed the course of interest rates in the major capitalist countries... is bound to lead one to see clearly that interest rate determination is not subject to any general law. 


\section{A Model of Euthanasia with Full Employment}

Because the actual theoretical system of Keynes's General Theory is not entirely congenial to articulating euthanasia, it is useful to provide here a model which better illustrates the conception (drawing on Panico 1993:104-13; Cesaratto, Serrano and Stirati 2003:42-4). While a departure from Keynes's GT model, it retains the essential elements of his theory: long-period output is demand determined; consistent with investment/saving equilibrium, the rate of interest is open to a spectrum of possible equilibrium values (including zero); and interest is determinable independent of the rate of profit in production. No pretensions to generality are made for this model: it is just a simple formal way of cogently illustrating Keynes's policy.

Assume a single commodity, produced by homogeneous labour and circulating capital $-1, \mathrm{v}$ being the required labour and capital per unit of output, per time period (with $\mathrm{v}<1$ for viability). The money price of output $(P)$ is given by,

$$
P=w \mathrm{l} /[1-(1+r) \mathrm{v}]
$$

where $w$ is the money wage. The uniform rates of real wages $(w / P$ and profits $(r)$ are bound together by:

$$
w / P=[1-(1+r) v] / 1
$$

There is a minimum consumption per worker (c), below which the real wage cannot fall - with $c<(1-v) / 1$, for viability and positive profits. Hence the spectrum of feasible values for $r$ is:

$$
[(1-\mathrm{v})-\mathrm{cl}] / \mathrm{v} \geq r \geq 0
$$

Output $(Q)$ is determined by aggregate demand arising from private consumption $(C)$, private investment $(I)$ and government expenditure $(G)$. All wages (after tax, at the rate $t$ ) are spent on consumption, and all net profits (also after tax at rate $t$ ) are saved. (The same applies below, to interest income.) Investment demand is determined by the replacement requirements of the current capital stock $(v Q)$, and the additional capital required by firms' uniform expectation of the growth of demand $\left(g_{e}\right)$ :

$$
\begin{gathered}
I=v\left(1+g_{e}\right) Q \\
Q=C+I+G=(1-t)(w / P) l Q+v\left(1+g_{e}\right) Q+G
\end{gathered}
$$

Substituting equation 2 into equation 5 and rearranging:

$$
Q=G /\left[s-v\left(1+g_{e}\right)\right]
$$

where $s$ is the proportion of gross output not used up in induced consumption: 


$$
s=1-(1-t)[1-(1+r) \mathrm{v}]
$$

the term in square brackets being (pre-tax) real wages per unit of output produced (equation 2 above). The further restriction,

$$
(\mathrm{s}-\mathrm{v}) / \mathrm{v}>g_{e}
$$

which makes the induced demand for output (per unit of output produced) less than unity, is required to ensure a meaningful solution. This assumption, together with the restrictions ensuring that $\mathrm{s}$ is less than unity, guarantees that the multiplier in equation (6) is greater than unity and finite. The money wage may also be taken as given.

Equilibrium requires that expected growth, and the actual growth rates of demand and capacity $(g)$, coincide:

$$
g_{e}=g
$$

Suppose three financial assets - stocks of outside money ( $H$, with no income yield), government bonds $(B)$ and equity in the private capital stock in production $(P K)$, all in money terms - and demand functions for those assets such as to generate desired proportions in which wealth-holders will accept those assets, relative to gross income from production $(P Q)$. In equilibrium, these desired ratios $\left(a_{h}, a_{b}, a_{k}\right)$, a function of yields, will equal the actual ratios $(h, b, v)$ :

$$
\begin{gathered}
a_{h}(r, i)=\mathrm{H} / \mathrm{PQ} \equiv h \\
a_{b}(r, i)=\mathrm{B} / \mathrm{PQ} \equiv b \\
a_{k}(r, i)=\mathrm{PK} / \mathrm{PQ} \equiv \mathrm{v}
\end{gathered}
$$

where $i$ is the yield on bonds, Also in equilibrium, net private investment plus the public sector budget deficit will equal net private saving, here expressed as proportions of gross national income from production:

$$
g v+(d+i b)=(1-t)(i b+r v)
$$

where $d$ is the primary public sector budget deficit - the budget deficit net of public sector interest payments - as a proportion of national income from production. Note that the constancy imposed upon $h$ and $b$ renders public sector budget balance sustainable in the usual sense. Finally, the budget deficit is financed by issue of outside money and issue of government bonds, in proportions $(\gamma, 1-\gamma)$ respectively:

$$
\gamma(d+i b)=h g
$$




\section{$(1-\gamma)(d+i b)=b g$}

Keynes's desired policy outcome in Chapter 24 of the $G T$, full employment with zero pure property income, can be imposed upon this model as a way of closing it, as follows: government exogenously sets the levels of one policy instrument (i) and one objective (g) - interest is set at zero and the growth rate is chosen with a view to workforce growth and the consequent requirements for full employment (the chosen $g$ being assumed consistent with restriction 8 above). With $i$ fixed at zero, $\mathrm{r}$ must adjust to ensure equilibrium between portfolio holders' desired ratio of equities to income and the fixed actual ratio, $\mathrm{v}$ (equation 12). Assume there is a unique and stable equilibrium value of $r$ (presumed positive) which can achieve this, and that it is consistent also with restriction (3). With $r$ thus determined, the money price of output is determined (equation 1), and the proportions in which portfolio holders desire to hold outside money and bonds are determined (the LHSs of equations 10,11). The ratios $h, b$ must therefore conform to these desired proportions, presumed positive. Hence in equations (14) and (15) there remain just two variables to be endogenously determined, $y$ and $d$. Assume the unique solutions for these two policy variables are meaningful (i.e., between zero and unity, though when $i>g$, equilibrium $d$ may take a negative value). With $d$ determined (and stationary along the growth path), $t$ also will be determined: it is the only variable remaining in equation (13). Assuming equilibrium $t$ also is between zero and unity, the multiplier in equation (6) is satisfactorily determined - and the growth of $G$ and $Q$ will be identical. The growth of autonomous demand will be determining the growth rate of output, the former being the instrument by which policy achieves the latter.

This solution takes for granted that the economy can be balanced at full employment, with an absence therefore of inflationary pressures from the demand side. Even if this is acceptable, there remains also the possibility of inflationary pressures from the cost side, from distributional conflicts. This points to the problem of policy assignment once monetary policy is assigned to the objective of zero interest: what instrument is left to be assigned to inflation? ${ }^{19}$ If fiscal policy cannot be assigned to inflation-because inadequate as to impact, or inadequate as to speed, or because constrained by its role in pursuing other objectives - then some other instrument must replace monetary policy as the means to pursuing whatever inflation objective is chosen. If it turns out that no other instrument is available, and hence monetary policy cannot be released from its traditional objective of pursuing inflation, then euthanasia would be compromised. But a continuing need to use monetary policy as an anti-inflationary instrument-though rendering continuous euthanasia impossible-would not necessarily pre-empt a long-run zerointerest policy. A long-run target of zero would be consistent with temporary deviations above zero to counter-inflationary pressures. Indeed, to the extent that the efficacy of interest rate variations in containing inflation occurs via agents' perceiving interest as deviating above its normal value (Pivetti 1991:44-5), this anti-inflationary role can be effected via deviations above any norm for interest, including zero. ${ }^{20}$ Furthermore, in a system with persistent (desired and/or actual) positive inflation, so that nominal and real yields diverge, a policy objective of zero real pure interest would require setting the riskless rate of interest equal to the trend inflation rate, rather than equal to zero-and antiinflationary monetary policy with respect to this positive inflation target would 
require deviations of interest above that positive rate. With divergence between real and nominal yields, Keynes's normative purpose would imply a zero real pure rate, not zero nominal pure rate. Hence Keynes's idea is not so radical as might appear at first glance: empirical estimates of the riskless real interest rate in the late-twentieth century would place it between one and two per cent, so that euthanasia would imply shaving that kind of margin off all yields, across the board.

\section{Concluding Comments}

The two greatest obstacles to the achievement of Keynes's objective on pure interest are the difficulty of finding an alternative instrument for targeting inflation, and the question of where 'the' interest-setting monetary authority is to be found in a globalized world economy. No further comment is necessary with regard to the former. With regard to the latter, the logic of the above analysis lies essentially within the framework of a closed system with a singular monetary authority. In practical effect, this means it applies either to an economy with significantly closed capital markets, or to a closed global system of interacting currency areas, with a single dominant monetary authority able to set the pace for global interest rates. What if one confronts a closed global system with no single monetary authority able to independently impose its will as to interest rates? Then the exogenous setting of 'the' interest rate would be subject to a potentially complex matrix of forces, including not only interactions between a small number of major central banks, but also possibly greater scope for market sentiment to play a decisive role in circumstances where monetary policy, being less than singular, is less than decisive. If these are something like the circumstances we confront today, then a policy of pure property income euthanasia would have to choose for part of its means, whether to go 'back' to relatively closed capital markets - or whether to go 'forward' to a genuinely singular world monetary authority.

\section{Notes}

* The author is indebted to P.D.Groenewegen, M.C.Marcuzzo, R.O'Donnell, F. Ranchetti, M.L.Smith and especially C.Gehrke, as well as anonymous referees, for useful commentswithout thereby implicating any of them in the final product.

1 Exceptions to this are the brief discussions in Dillard (1942a, esp. 66-8, 71-3; 1942b, esp. 351; 1948:159, 279, 332-4), Cortney (1960:208), Lawrence (1960:337-9), Murad (1962:79, 146-8, 176-9), Wright (1962: ch. 5), Lambert (1963b: 502-3, 505-6, 513-14), Letiche (1971:443, citing Turner 1969, on the views of I. G.Blyumin), Opie (1974:79, and a comment in 'Discussion' at 97-8, by J.L. Carr), Robinson (1975:130), Gilbert (1982:221-2), Dillard (1984:429), Sweezey (1985:45-6), Tobin (1985:17), Burkett (1986:629), Fletcher (1987:178-81), Fitzgibbons (1988:181-3), Howson (1988b:46-7), Skidelsky (1988:7, 9, 22), Booth (1989:16), Pivetti (1991:42-3), Chick (1992:42), Skidelsky (1992:565, 569-70; 1997:431-2), Meltzer (1997-98:319) and Naldi (2001:395, n. 10). Notwithstanding its title, Pollin (1997) has virtually nothing to do with Keynes's notion.

2 That is to say, pure property (or rather, capital) income would be the value of society's total income-earning capital multiplied by that riskless yield (putting aside the kind of assets mentioned in n. 3). Keynes (1936:221) himself speaks of 'the pure rate of interest apart from any allowance for risk and the like'. Keynes's object is actually property income from 
capital: in a zero-interest regime private property in scarce natural resources - including, perhaps, scarce labour skills, which might also be regarded as 'property'-would continue to command incomes (Kurz and Salvadori 1995:277-320, and 297 with 330-1). Hereafter the General Theory is cited as GT and the Collected Writings (Keynes 1971-89) as CW with relevant volume number.

3 Some assets may have normal or equilibrium yields lower than the riskless yield, due to relatively desirable differential characteristics - most obviously, money, which (at least for some agents, in some magnitudes) has liquidity characteristics superior to those of a riskless government security. On such assets, wealth-holders may receive a lower pecuniary yield than the pure rate of interest, the difference being the opportunity cost of the relative nonpecuniary advantages of the lower yield asset.

4 Beyond some time horizon, yields to maturity of securities issued by a government regarded 'now' as exhibiting a zero-risk of default cannot truly be regarded as riskless-because the continuation of its non-defaulting character cannot be guaranteed indefinitely into the future. If there were such a thing as a perpetual positive income stream, capitalized at a zero discount rate it would have an infinite present value. But such a riskless perpetual income stream can only exist to the extent that the perpetual existence of such a government can be assured-which is impossible. The same reasoning would apply to other 'perpetual' assets, such as rent-earning renewable natural resources - except that here it would be the impossibility of perpetual certain property title (itself dependent upon perpetual existence of an appropriate polity) which would intervene. In other words, the intervention of default risk or uncertainly of title (beyond some future date), alone would suffice to keep the price of apparently perpetual assets finite.

5 See for example $G T$ : 249-50, 254, 307-8, concerning unemployment as normal. In fact in the very context of the opening discussion of Chapter 24, Keynes (GT: 373) writes further about the impact 'in general' of a rise in the propensity to consume, following this phrase with the parenthetical remark, 'i.e. except in conditions of full employment'. Unemployment is part of the general economic situation.

6 On the following page he speaks of 'our aim of depriving capital of its scarcity-value within one or two generations' (GT: 377). At GT: 220 he says 'within a single generation'.

7 Anthony Crosland's characterization of Keynes, as quoted by Skidelsky (2000a: 498), is useful in this context: 'The truth is that Keynes was strongly hostile to capitalism loosely defined as a system of laissez-faire. But he was not opposed to capitalism, defined as a system of private property and enterprise.' On the origins and development of Keynes's 'cheap money' advocacy in general, see Moggridge and Howson (1974:237-46). The possibility of euthanasia of the rentier (but not the phrase) appears in the extant student notes of Keynes's pre-GT lectures, for 1933 and 1935 (Rymes 1989:127-8, 179-80). A $1933 \mathrm{draft}$ table of contents for the GT has a Chapter 12 entitled 'The Influences of Changes in the Distribution of Income between Rentiers and Earners', clearly implying that rentier income is to be regarded as unearned ( $C W$ XXIX:63). Also, in the published correspondence subsequent to the $G T$ there is one reference, adverse, to the zero-interest proposal-by H.O. Meredith in a letter to Keynes of 15 May 1936. Meredith imputes something like the same idea to Marshall (cf. Hicks 1989:76). Keynes's reply (20 May)—somewhat non-committal in tone on euthanasia as such - does not address the reference to Marshall (CW XXIX:211-14).

8 Keynes himself had no sympathy for coercive negative eugenics (Toye 2000:144).

9 On these matters, see Howson (1993, esp. 18-29, 43-62, 88-90, 126-31, 149-52, 191-2, 323, 326-7). James Meade's diary is a particularly interesting first-hand account (Howson and Moggridge 1990, esp. 45-6, 48-9, 55-6, 59, 61, 63-5, 70, 73, 80-2). Three of Keynes's own papers relating to the Enquiry are at $C W$ (XXVII: 388-413).

10 Skidelsky (2000a:375-8) briefly reports on these matters - citing also $C W$ XXVIII; but $C W$ XXVII is evidently intended. Skidelsky takes D.H.Robertson's side on the theory of the rate 
of interest, asserting that Keynes's position was 'wrong, outside the special circumstances of depression', and adding without any substantiation the remarkable comment:

when Robertson was not there to argue with him he reverted to his extreme views. His hatred of the rentier was proof against economic arguments, because at bottom it was theological, not scientific. The bondholder was, in his mind, nothing but the medieval usurer, or Shylock...

(Skidelsky 2000a:377)

\section{Keynes's 1945-46 position is more complex and subtle than Skidelsky allows or describes.}

11 See also Howson (1993:171, n. 39) for Hopkins' further appeal to the p. 203 statement, in written advice of September 1947 to Treasury and Dalton. This is the same GT page at which Sraffa annotated the comment discussed in the last paragraph of the next section below.

12 Howson and Moggridge (1990:48, 55, 61). In his student notes taken at Keynes's 1934 lectures R.B.Bryce was similarly borrified by Keynes's proposition that the rate of interest has nothing at all to do with the propensity to save, writing: 'But oh this is too damn much!' (Rymes 1989:158).

13 Keynes (1937:250). From this and the following quote it is evident that Keynes is not greatly committed to his General Theory version of 'liquidity preference' or 'monetary' determination of interest; what he is committed to is that interest is not rendered determinate by the equilibration of saving and investment, and is therefore free, within limits, for some kind of determination in the money markets. This is more fully discussed in Panico (1988:102-93) and Pivetti (1991, esp. 8-32, 128-36).

14 Indeed, a good part of the dynamic of western civilization arises from that which was previously thought impossible, coming to be regarded as entirely possible.

15 This does not entail that an antipathy to rentier income neither predated Keynes's formulation of his new theory, nor stimulated the construction of that theory in any measure. (For example, Meltzer 1988:5, 11, 42, 182-3, 185, supposes that Keynes was antagonistic towards rentier income from the 1920s, but lacked a theoretical justification for this belief until the GT.) If either of these possibilities were a fact, this would not in any degree tell against, or for, that theory. In the history of ideas, good theories have been stimulated by bad motives, and bad theories have arisen from good motives.

16 For an overview see Kurz and Salvadori (1995, esp. chs. 5-9, 14) and Garegnani (1990). The notion of a long-run tendency for the rate of profit and/or interest to tend towards zero has a place in classical economics as well (albeit in a very different theoretical framework to that of Keynes), most clearly stated in Ricardo (vide Tucker 1960).

17 For example, GT: 243, 267, 309. The whole Keynes/orthodoxy theoretical dispute could then be trivialized to the issue of whether or not the system would spontaneously gravitate to that rate.

18 Ranchetti (2001:327). I am indebted to J.Halevi for the English translation.

19 Keynes himself in 1937 had advocated 'cheap money and fiscal surpluses' to contain inflationary pressures in a Keynesian-managed economy kept more or less continuously close to its supply constraint (Skidelsky 2000a:503). In 1945 he expressed a measure of fatalism about the potential wage inflation problem-_'One is..., simply because one knows no solution, inclined to turn a blind eye to the wages problem in a full employment economy' (CW XXVII:385) — though how seriously such a passing comment should be 
taken is open to question. In the post-War period 'incomes policies' were commonly offered as an alternative instrument (an idea to which Keynes was not averse).

20 In the 1945-46 deliberations Keynes is evidently partly against using interest rate rises to deal with inflation because of the potential difficulties he perceives in subsequently reversing the variation. Booth (2001:285, n. 3) draws attention to Keynes's consistently arguing in the 1930 s 'that once the long-term rate rose it would be difficult to bring it back down' (also Moggridge and Howson 1974:240). 


\title{
15 \\ Some Reflections on Keynes, Policy and the Second World War
}

\author{
Sean Turnell and G.C.Harcourt
}

I

Though we suspect that Peter Groenewegen, like us, has a preference for the way in which Kalecki independently discovered some of the principal propositions of The General Theory, yet, like all right-minded persons (on the left), his admiration for Keynes, for his writings and the man himself, is very great. Moreover, as Peter is a superb historian of thought and the author of the magisterial biography of Marshall, we thought he would welcome this reading of the third and final volume of Robert Skidelsky's magnificent life of Keynes as our contribution to his Festschrift. It is offered with our respect and affection.

Skidelsky tells us that his objective in the final volume has been to rescue Keynes from the economists and to place him 'in the world of history where he properly belongs' (2000a:xxii). A clarion (if somewhat tongue in cheek) declaration in the turf wars over the 'ownership' of Keynes, it is reminiscent of Kaldor's (1982a:2) claim that 'Keynes was an economic adviser, first and foremost; he was a theoretical economist and the creator of a new intellectual system second'. Of course, the likelihood for success of such a 'rescue', especially from a discipline likely to be protective of one its few recognisable stars, might be in doubt. ${ }^{1}$ Nevertheless, what there can be no doubt about is that, in this monumental biography, Skidelsky establishes Keynes's place in history-proper intellectual domicile or not.

For it is in history, in the realms of policy and practical affairs, that the immense scholarship of Skidelsky's biography is most obviously apparent. There should be no surprise at this. As Skidelsky told The Economist upon the release of the final volume, his biography of Keynes was written 'by an economically literate historian, not by a historically literate economist' (Skidelsky 2000b). Previous reviewers of Skidelsky's volumes, including those with reservations over issues of economic theory contained within them, have been in no doubt about their worth as intellectual, and other, history (see, for example, Presley 1984, Eatwell 1994, Pollard 1994, Laidler 2002, amongst the many),

The concern of the following pages is Skidelsky's portrayal of Keynes's role as policy maker and adviser in the final decade of his life. The specific policy episodes chosen for examination are not, however, the most obvious or even necessarily the most important. There is an enormous literature devoted to the study of Keynes and practical affairs, and it is not the purpose of this review to replicate them. The episodes chosen, rather, are those for which Skidelsky's biography is especially enlightening, those that tend to be 
overlooked but for which Skidelsky's work offers new insights, or simply those aspects of Keynes's policy work that we think are especially interesting or relevant to present debates.

The 1920s and 1930s were the years of Keynes's most public policy advocacy, but it was the Second World War that ushered in his most important policy work. A bold claim perhaps, but one that would be hard to refute in the light of the evidence assembled by Skidelsky in Volume III of the biography. In its opening paragraphs, Skidelsky tells us that in 'his narrower, and subordinate sphere, Keynes rivalled Churchill. He was, in fact, the Churchill of war finance and post war financial planning' (2000a: $x v)$. This was despite the fact that Keynes held no official position during the war, remaining throughout 'an unpaid, part-time adviser to the Chancellor of the Exchequer' (2000a: $x v$ ). To foreigners, Keynes was not only the de facto Chancellor of the Exchequer, but 'President of the Board of Trade as well' (2000a: $x v)$. Keynes's influence was based on personal and intellectual authority, but it was no less real for this.

Skidelsky tells us that he had wanted the original subtitle of Volume III to be 'The Economist as Prince', to juxtapose Keynes the theorist, with Keynes the statesman of the war years (2000a: xv). But when it appeared (in the UK) in October 2000, the volume did not bear this subtitle. Instead, the more pugilistic 'Fighting for Britain' was substituted. Meanwhile, by the time Volume III was published in the United States a year later, yet another change had been made-'Fighting for Freedom' graces the covers of the American edition. Behind all of this lay a tale, and some controversy besides.

Skidelsky chose 'Fighting for Britain' because to label otherwise would hide Keynes's contribution to Britain's survival in the Second World War-a survival that was more precarious than is often supposed. The story is 'above all else, about Keynes's patriotism' (2000a: $x v$ ). Churchill's war was against the totalitarian powers. Keynes's war was in the provision of the wherewithal for this, but it was also 'to preserve Britain as a Great Power against the United States' (2000a:xv). It did not end in victory. In helping to defeat the totalitarian powers, 'Britain lost both Empire and Greatness' (2000a:xv).

\section{III}

Skidelsky's account of the rivalry between Britain and the United States has not been well-received by all. Sylvia Nasar (2002) suggests that 'Skidelsky's otherwise nuanced analysis veers into implausibility' on the topic. Bradford DeLong, however, has been by far the most vociferous of the critics. Describing Skidelsky's portrayal of British-US relations in parts of Volume III as 'ugly', he alleges:

Skidelsky appears to have fallen under the influence of a strange and sinister sect of British imperial conservatives who believe that somehow 
the U.S. during World War II provided aid to Britain on niggardly terms, terms guaranteed to destroy Britain as a great power. ${ }^{2}$

(Delong 2000)

DeLong declares that such an analysis of British-U.S. economic relations during the war is 'total nonsense'-nonsense, moreover, that '[a]ny economist would know'. Yet, 'Skidelsky seems to believe it'. How to account for this? For DeLong, it is quite simple'the source of the problem lies in the fact that Robert Skidelsky is not an economist'. This was not, according to DeLong, a problem for the first two volumes. Volume I, he says, was mostly about Keynes 'as a developing intellectual', while Volume II was mostly concerned with Keynes 'as politician, trying to influence events by analyses based on the standard monetarist (sic) toolkit of a Cambridge economist between the wars'. Since the largest portion of Volume II is devoted to the theoretical issues surrounding the genesis, construction and aftermath of the revolutionary General Theory, the latter claim is surprising to say the least.

In the Preface to the American Edition of Volume III, Skidelsky defends his theme against DeLong's attack. Injecting a degree of international relations 'realism' into the debate, Skidelsky reminds us that 'national interests do not disappear just because the cause is noble' (2001:xiii). It was, 'as natural for the United States to use her wartime financial leverage to weaken Britain as a financial and commercial rival as it was for the British to try to minimise or evade the strings attached to American help' (2001:xiii).

So what is to be made of this contretemps? First, if Skidelsky is not an economist, then neither is DeLong an insightful historian of the period. A most revealing example of this is DeLong's citation of one of Churchill's speeches as evidence that Britain's war aims did not encompass (pace Skidelsky) the maintenance of the financial and commercial strength of the British Empire after the war. The speech cited-a famously stirring speech delivered in May 1940 - is worth quoting in part to illustrate how wrong DeLong is on this issue:

You ask, what is our policy? I say it is to wage war by land, sea and air... You ask, what is our aim? ...It is victory. Victory at all costs. Victory in spite of all terrors. Victory, however long and hard the road may be, for without victory there is no survival... No survival for the British Empire, no survival for all that the British Empire has stood for... ${ }^{3}$

DeLong's conclusion from this, that 'Britain fought to defeat a tyranny, not to preserve an empire', would no doubt surprise a Prime Minister who also famously cautioned that he had not become 'the King's First Minister in order to preside over the liquidation of the British Empire'. Compounding it all is a further observation on the question of imperial preservation, in which DeLong states that 'any economist would know that greatness does not lie in numbers of battleships or large foreign exchange reserves'. But this is precisely the point - it was not economists who were in charge of US-Anglo relations during the Second World War. As Woods observes (1990:8), the AngloAmerican dialogue during the Second World War was 'a complex mixture of bureaucratic conflict, conventional politics, transatlantic alliances, national 
characteristics, mutual images, and circumstances'. Through this glass darkly, however, perceptions of national interest shone through. With respect to US-Anglo relations in the Second World War, this meant that

Britain received enough aid to enable it to survive and to play a role in the war against the Axis, but not enough to preserve its overseas investments and markets, to maintain its military outposts, or to participate in a system of multilateral commerce.

(Woods 1990:7)

DeLong is also a poor reader of his personal subject, for he seems to assume that the issue of conflict in Anglo-American relations is Skidelsky's invention (or that of this 'strange and sinister sect'), and was not something that exercised Keynes. He could hardly be more wrong. Keynes greatly cared about the maintenance of British power, especially the power to act independently of the United States. It is why he found the loan negotiations so fraught since his primary objective in them was 'the retention of enough assets to leave us capable of independent action' (Skidelsky 2000a: $x x$ ). In this same context Keynes even minuted on one occasion that 'America must not be allowed to pick out the eyes of the British Empire' (Skidelsky 2000a:98). Skidelsky also reveals (2000a:92) that earlier in the war 'Keynes was enraged by the anti-imperialist diatribes of his New Republic editor, Bruce Bliven, and stopped writing for the journal'.

Skidelsky expected a strong reaction to his story of less than complete harmony between the principal allies of the Second World War for two reasons. First, the story 'shatters the myth of the united front against evil' (2001:xiii-xiv). Secondly, and generalising very broadly, 'because Americans tend to believe that their nation is uniquely idealistic, and therefore exempt from calculation of self-interest' (2001:xiv). Both issues are tendentious - the first because such a myth was surely vanquished many decades ago, in popular discourse as much as in academic revisionism - the second because, while provocative, it is a theory that is not really capable of objective analysis. The differences between Skidelsky and DeLong on these issues are reflective, rather, of a clash of national narratives over the Second World War - a clash that is, if anything, intensifying with the passing of years. Sometimes lost in the rhetoric, however, are the substantive issues behind these narratives.

\section{IV}

In the context of Skidelsky's biography and Keynes's efforts during the Second World War, the greatest substantive issue in US-Anglo relations concerned the 'consideration' the United States expected from Britain for 'Lend-Lease'. This ended in the famous Anglo-American loan that was the subject of Keynes's 'last battle' which, as is movingly described in Volume III, finally killed him. Keynes was Britain's 'envoy extraordinary' over Lend-Lease, and it meant he made four hazardous voyages to the United States during the war, and two after it. In a reminder to readers that communications during the war years were not as they are now, Skidelsky takes the opportunity to point out how this also greatly increased the power and autonomy of envoys such as Keynes: 
Keynes's position as plenipotentiary at large was powerfully reinforced by the slowness and erratic nature of communications between Washington and London. ...With cipher facilities at the Embassy [in Washington] heavily overburdened, even telegrams of instructions took days to reach Keynes... All this gave Keynes considerable latitude in framing his own proposals... London had little choice but to trust him and hope that the thunderbolts he was forging would not turn into boomerangs.

(2000a:119)

The negotiations over the Anglo-American loan are the climax of Volume III. Skidelsky points out that for Keynes it was a matter of justice that Britain's spending in the United States for war materials be written off via a grant, rather than being cause for a loan. These expenditures were a 'moral debt' owed to Britain, whose financial sacrifices in a common cause Keynes asserted were 'incomparably greater than those of any other of the United Nations' (2000a: 322). Skidelsky's three volumes enable us to see, however, that Keynes's fight for what he perceived as justice on such matters was not confined to the case of Britain in the Second World War. As Skidelsky notes in Volume II in relation to outstanding debts from the First World War: 'Keynes had consistently advocated cancellation of inter-Allied debts. He did not consider them moral obligations since they were incurred in a common cause' (1992:124, emphasis added).

Skidelsky is not shy in any of the volumes to detail Keynes's faults, but nowhere are these made more apparent than during the loan negotiations. According to Skidelsky, 'Keynes could never understand that American and British interests were not identical, attributing differences to deficiencies in the American political system, and thus overrelying on logic and eloquence to overcome them' (2000a:117). Other short-comings had been in place from the time of Keynes's first visit to the United States (also on Treasury business) in 1917 during which, according to a contemporary, he had made a 'terrible impression for his rudeness'. Twenty-five years and innumerable negotiations later, Skidelsky tells us that Keynes; was 'not patient'; was 'prone to exasperated outbursts'; 'his great intelligence led him to overcomplicate an argument'; his 'tendency to score points off opponents hampered him as a negotiator'; 'he suffered from an incurable tendency to tell Americans how they ought to be running the country' (2000a:110). Exhausted and ill by the time of the climax of negotiations in 1946, Keynes was probably not the right person to convince a still ever-insecure United States that the old empire was not about to 'pull a fast one on them' (2000a:110).

\section{$\mathbf{V}$}

Apart from the negotiations over Lend-Lease, Keynes's Second World War career was dominated by his efforts to recreate, and reform, the international monetary system. These efforts reached their purest intellectual form in his famous proposal for an 'International Clearing Union' (ICU). Through this device, Keynes believed it would be safe for Britain and other debtor countries to accept multilateral payments, and to begin the process of dismantling the trade and other barriers erected between the wars. Skidelsky argues that the original ICU paper (together with an accompanying one on 
buffer stocks) 'were the most important he ever wrote in terms of their direct influence on events' (2000a:205).

Skidelsky is surely correct in his assessment of the importance of the ICU in Keynes's policy work. ${ }^{6}$ On this subject Skidelsky's biography outshines all of the others, and many specialty works besides. Above all, Skidelsky uniquely manages to capture the boldness and excitement of the ICU. Of course, we already had Harrod's (1951:525-85) famously rapt, if somewhat self-centred recollection. Skidelsky recounts Harrod, but generously casts the net more broadly around Keynes's contemporaries. He cites James Meade, for whom the ICU was 'the only real hope of a generous and spacious economic collaboration after the war'; Lionel Robbins, who thought it 'a real release of fresh air in this surcharged and stale atmosphere'; and, most evocatively, Dennis Robertson, who wrote to Keynes that he not only read his proposal with 'great excitement' but 'with a growing hope that the spirit of Burke and Adam Smith is on earth again' (2000a:219).

Alas, this spirit was not to be made manifest, for the ICU was not the only proposal for reforming the international monetary system on the table. Opposing it was the superficially similar 'Stabilisation Fund' (SF) proposal of the US State Department. Devised by Harry Dexter White, an enormously controversial figure both then and now, the SF was a much more orthodox animal than the ICU. ${ }^{7}$ The SF reflected US interests as the world's largest creditor country, just as the ICU was motivated by Britain's debtor status. Skidelsky does a masterful job in contrasting the ICU and SF As with his coverage of Anglo-American relations generally during the war, however, Skidelsky's approach has not pleased all. The principal protagonist again has been Bradford DeLong.

DeLong maintains $(2000 ; 2002)$ that Skidelsky overstates the differences between the ICU and the SF.Further, Skidelsky's presentation (2000a:239) of the battle between Keynes and White, as 'one of the grand political duels of the Second World War, though it was largely buried in financial minutiae' is, according to DeLong, 'a gross misrepresentation'. From the viewpoint of an economist he tells us, one is struck not by the differences between the ICU and the SF, 'but by their extraordinary similarities' (DeLong 2002:159).

DeLong, however, is wrong. As Skidelsky makes clear throughout the 150 or so pages in Volume III concerned with the monetary plans (and what is also abundantly clear from the source documents), the ICU and the SF were different devices that reflected their different purposes. These were not merely technical, but fundamental differences - a cleavage that is clear from the broadest survey of the issues. The ICU, for example, was based on what Keynes labelled the 'banking principle'-liquidity was created via overdrafts available to each country that depended not on their reserve holdings, but the volume of their trade. The SF too made loans, but only out of subscribed capital. The ICU also placed the onus of adjustment for balance of payments difficulties on creditor as well as debtor countries, which was an objective long sought by Keynes. The SF placed no sanction on creditors. Under the ICU, the foreign exchange market would be replaced by transactions channelled through its accounts (conducted in its own currency, finally named by Keynes 'bancor') via country's central banks. The SF, by contrast, encouraged the emergence of foreign exchange markets. In an effort to eliminate gold as the primary reserve asset the ICU allowed only one-way convertibility - of gold into bancor, but not bancor into gold. Finally though fixed in each, exchange rates were much more rigid in the SF (where a change required approval from the SF governing body) 
than in the ICU. There are countless other differences, but the above are sufficient to denote profoundly different principles, ideas and institutions. Keynes summed it up best when he observed that, in its fundamentals, the SF was 'not much more than a version of the gold standard' (Keynes 1971-89: $C W$ XXV, 160).

\section{VI}

Keynes's first task in the Second World War was to devise ways of securing domestic finance for the war effort-specifically, a means by which resources could be diverted from consumption and into the production of armaments. His ideas to this end, outlined in a series of newspaper articles collected as How To Pay for the War, were, in Skidelsky's view, some of the most important he ever wrote.

According to Skidelsky, How To Pay for the War is an immensely significant work in the Keynes opus which has hitherto been underestimated. ${ }^{8}$ Three issues, he argues, especially stand out from it. The first of these is that it demonstrates, through the application of the principles of The General Theory to policy, that Keynes was very much the 'impresario' of his own revolution. Since, however, it argued for policies of restriction, it left many of Keynes's followers behind and to Keynes himself being labelled, Skidelsky tells us, as 'anti-Keynesian' (2000a:xix). While this interpretation must be seen in the light of other attempts throughout the biography to 'liberate' Keynes from 'Keynesians', Skidelsky nevertheless demonstrates that How to Pay for the War did lead to a rapprochement between Keynes and pillars of orthodoxy such as the Treasury and the Bank of England. It also led to a warming of relations between Keynes and Hayek - the latter writing to Keynes following the publication of How to Pay for the War that '[i]t is reassuring to note that we agree so completely on the economics of scarcity, even if we differ on when it applies' (2000a:xix).

The second critical issue to emerge from How To Pay for the War relates, according to Skidelsky, to Keynes's attitude to inflation, and the flexibility of his new theoretical apparatus in dealing with it. Aiming to dispel the (once) widely held notion that Keynes was a dove on inflation, Skidelsky traces the evolution of How To Pay for the War in Keynes's writings in the two years leading into the Second World War-writings in which he voiced concerns for what we would now call an 'overheating' British economy. How to Pay for the War adapted the economics of a less than fully-employed economy into one that was not only able to deal with a situation of excess demand, but also to channel it in socially desirable ways.

The third issue that Skidelsky chooses to highlight from How To Pay for the War relates to the element of liberalism that underlay Keynes's approach to wartime policy. According to Skidelsky, How to Pay for the War presented an alternative to 'totalitarian' methods - rationing, price controls, physical planning - in favour of an approach that essentially rationed income, but otherwise left the price mechanism in place (2000a, $x x$ ). Whilst only certain aspects of How to Pay for the War were adopted by the British Government (forced saving notably), Skidelsky writes that the episode is important for understanding Keynes's view that prices were 'the essential element of freedom in the economic system, however restricted their scope might have to be' (2000a:67). 


\section{VII}

In his splendid review of the first two volumes, Pollard (1994:138) observed that

economists are not, on the whole, actors upon the historical stage. Even Keynes, who came closer to being one than most, particularly towards the end of his life, was an adviser, not a decision maker. The interest he excites most is intellectual, not heroic.

The great achievement of Skidelsky's monumental biography, now concluded, is that the historical actor, and even the decision maker at critical moments, is plain to see. Perhaps we now have an undisputed subtitle for the promised single-volume abridgement of this great work-'John Maynard Keynes: The Economist as Hero'.

\section{Notes}

* We thank but in no way implicate, Stephanie Blankenburg, Wylie Bradford, Tony Brewer, John Coates, William Coleman, Robert Dixon, Meghnad Desai, Gordon Fletcher, Peter Kriesler, Ray Petridis, Claudio Sardoni, Robert Skidelsky, John Smithin and two anonymous referees for their comments on a draft of this chapter.

1 There is, in any case, something of a truce in this 'war', with Skidelsky himself as one of the peacemakers. For more on such matters, see Darity (1994). Moreover, we agree with David Vines's superb case, that 'Keynes needed to create the discipline of international macroeconomics, and he did so...' (Vines 2003:339, emphasis in original). We also agree with Vines that while Skidelsky showed vividly why Keynes needed to do this, he does not explicitly show what the creation is.

2 This quotation is taken from DeLong's (still active) website review, first written in December 2000. In the shorter review published in the Journal of Economic Literature, "strange and sinister sect' has been replaced by the more muted 'set of British imperial conservatives' (DeLong 2002:161).

3 Emphasis added. This speech cited by DeLong is as famous as that which promised 'blood, toil, tears and sweat'. It is reproduced in full in Cannadine (1989).

4 In a speech by Churchill on 10 November 1942, cited in Gilbert (1991:734).

5 Sir Basil Blackett, the Treasury's representative in the United States during the First World War. Cited by Skidelsky (1983:342).

6 Just as Vines (2003) is surely correct concerning its importance for Keynes's theoretical contributions.

7 In an appendix labelled 'Harry Dexter White; Guilty and Naïve' (2000a:256-63), Skidelsky finds for the prosecution regarding the accusation that White was a Soviet spy. Skidelsky speculates that White's belief that power in the post-war world was best shared between the US and the Soviet Union, allowed him to rationalise passing documents to the Soviets as loyalty to his country. It is a rationalisation that Skidelsky rejects. Skidelsky's verdict is disputed in Boughton and Sandilands (forthcoming).

8 Moggridge (1992:629) writes that How to Pay for the War was 'the most sophisticated and successful of Keynes's many campaigns as a publicist'. Relative to Skidelsky, however, he places less importance on it in defining the canon of Keynes's work. For a criticism of what is seen as undue stress placed by Skidelsky on How to Pay for the War, particularly as an application of The General Theory, see Laidler (2002). 


\title{
16 \\ HOPE in the Antipodes
}

\author{
John Lodewijks ${ }^{*}$
}

The last two decades have been an extraordinarily productive research period for historians of economics in Australia and New Zealand. To a large extent the growth in research output reflects the increased number of specialist journals in the field and the book publishing opportunities opened by Routledge, Edward Elgar, and other publishing houses. The formation of the History of Economic Thought Society of Australia (HETSA) in 1981 and the Newsletter, and its successors the Bulletin and the History of Economics Review (established in 1991), also played a significant role. Nonetheless the Australasian contribution, in per capita terms, is quite remarkable.

Undoubtedly the major resident figure in Australian history of economic thought has been Peter Groenewegen, who has described the major stage posts in his career in Groenewegen (1997). Groenewegen established the Centre for the Study of the History of Economic Thought at the University of Sydney in 1989. An encyclopedic command of the history of the discipline has made him an essential source for ideas and suggestions for almost every scholar in this region. One could not attend a HETSA conference without appreciating his commanding knowledge of the literature and the respect in which he is held. Over the five years to 2001 he has published five books, including his massive 1995 magnum opus, A Soaring Eagle: Alfred Marshall 1842-1924 (preparatory work for which had began in 1983), 17 book chapters and eight journal articles. His research output since then has continued to be prolific as his bibliography demonstrates. Groenewegen's links with European historians of economics and journals has been quite important for Australian researchers. He is on the advisory boards of all the major journals in the field. Moreover, his support of Marx's view of the origins of classical political economy and advocacy of the rehabilitation of classical political economy as an essential pre-requisite for the reconstruction of modern political economy, has influenced the character of Australian history of economic thought (HET). In this context, Groenewegen has moved in tandem with another strong influence on Australian history of economics, Geoffrey Harcourt. While based at the University of Cambridge, Harcourt's influence through $\mathrm{PhD}$ supervision, and hospitality to visiting Australasian historians of thought during sabbaticals at Cambridge, cannot be underestimated. It is not surprising then that both Groenewegen and Harcourt were included in Arnold Heertje's four volumes of The Makers of Modern Economics.

John Creedy is another example of a prolific publisher in the history of economics. While he was educated at Bristol and Oxford, he was appointed to the Truby Williams Chair of Economics at the University of Melbourne in December 1987. His research output over the last decade has been impressive. He has written four books, edited three others, completed five book chapters and published 16 journal articles in the history of economic thought. A number of features of his work stand out. Six of the seven books 
were either originally published or reprinted by Elgar. Six of the journal articles were later reprinted in Elgar collections and two in Routledge collections. While many of the journal articles appear in HET journals (History of Political Economy (HOPE), Journal of the History of Economic Thought (J.HET) and the History of Economics Review (HER)), a considerable number appear in general journals such as the Scottish Journal of Political Economy, Scandinavian Journal of Economics, Manchester School and Oxford Economic Papers. Moreover, and this is characteristic of most leading historians of thought from this region, this research is only a part of Creedy's broader research agenda. $\mathrm{He}$ also has a considerable reputation in public economics, labour economics and income distribution. Indeed, over the last decade he published in total 17 books, edited 11 more, wrote 34 book chapters and 107 journal articles.

Creedy's research deals with aspects of the technical development of neo-classical analysis. He believes that we need to bring historical perspective to bear on modern economic analysis and stresses the importance of a thorough knowledge of modern economic theory when examining the history of economic analysis. Creedy is a loner in terms of the local HET community. His work is highly specialised, focusing on mathematical contributions to marginalist economics. In contrast, many other Australian contributors find the study of non-marginalist and non-mathematical contributions more interesting.

John King is an interesting contrast. Like Creedy, he was educated at Oxford. King then taught for twenty years at the University of Lancaster but took visiting positions at La Trobe University in 1975-76 and 1979-80, before permanently moving there in 1988 . His interest in the history of economics stems from the influence of a colleague, Michael Schneider, at La Trobe in the 1970s. Schneider convinced King that Marx was not the only ancient economist worth taking seriously. During the last decade King has written or edited seven books on Marx and Post Keynesian economics, primarily published by Edward Elgar and Macmillan. Twenty-eight book chapters and 26 journal articles deal with the contributions of Marx, Hobson, Kaldor, Kalecki, Minsky, Joan Robinson, Meek and Steindl. In addition to the standard HET journals, these articles are published in places like the Cambridge Journal of Economics, Science and Society, Review of Political Economy and Journal of Post Keynesian Economics. Again, like Creedy, King's research output in the history of economics listed above is only part of his publication record over the last decade. He is also active in labour economics.

Allen Oakley is another clear example of aggressively seizing the opportunities provided by academic publishers keen on expanding their history of economics titles. His main research activity has been writing books on Marx, Schumpeter, Austrian economics and classical economics. Of the nine books he has written, five were published by Edward Elgar and three by Routledge. Indeed a case can be made that an Australian really started off this particular sort of publishing activity in the history of economics in a major way. Since 1982 John Cunningham Wood has edited 92 volumes on various great economists. This publishing venture involved selecting and reading the secondary literature on a great economist, negotiating with journals and publishers and arranging copyright for reprinted articles, and writing a brief general commentary. Despite the small print runs, there is clearly a market for this sort of work, even if it sometimes arouses the hostility of academic reviewers. 


\section{The Teaching of History of Economic Thought in Australian universities}

Next we focus on the teaching of the history of economics in a subset of Australian universities and find that in modern times the teaching situation stands in deep contrast to the prolific research performance. In the early postwar period there were a small number of degree-granting universities. In 1950 there were just six fully accredited universities; by 1960 there were nine. We pay particular attention to the fourth (honours) year of study. This is an extremely intensive, highly demanding course where students are expected to work at the frontiers of knowledge. A First Class grade of Honours leads to scholarships, $\mathrm{PhD}$ programs and high-level public service opportunities.

Groenewegen (1982b; 2003d) has outlined the strong HET tradition at the University of Sydney. Teaching of HET had been a striking feature of its syllabus there for well over seventy years. In 1931 the final year of the pass and honours course in economicsEconomics IV - was totally devoted to the study of economic classics under the guidance of R.C. Mills. By the end of the 1930s, HET was established as a compulsory final year course in the faculty in conjunction with Economics IV, and this continued until the early 1960s. In the postwar period up to 1960, teaching was conducted by John La Nauze, Cyril Renwick and Syd Butlin, as well as by Kurt Singer, Ted Wheelwright, Jim Wilson and Bruce McFarlane.

The importance of HET at the University of Sydney was demonstrated through the Randolph G.Rouse Prize. Postgraduate studies in HET were assisted by the superb collection of economic classics in the Fisher library, especially its jointly held microfiche holdings of the Kress Collection at Harvard and the Goldsmiths' Library at London. There is also a series of reprints in HET including The Bullion Report (1810), papers by Malthus and McCulloch, extracts from Mrs Marcet's Conversations and Lloyd's Lecture of Value (1834). This series of reprints of economic classics was started in 1950 under the general editorship of Syd Butlin, with assistance from Cyril Renwick, and discontinued after 1955. The series was revived by Groenewegen in 1982, starting with reprints of Pulteney, Quesnay and Turgot, and the tenth and final reprint appeared on Boisguilbert. Nine of the ten were edited and supplied with an introduction by Groenewegen, and five are translated into English, from French or Italian (Coleman 2000).

The imposition of compulsory HET for all Faculty fourth year honours courses, irrespective of the discipline majored in, created resentment and the requirement was removed from disciplines other than economics. By the early 1980s HET was an option in third year that attracted 30 to 40 students annually, while during the previous decade the majority of Honours students undertook a study of the classics (Smith, Ricardo, Marx, Marshall or Wicksell). The situation since then has shown a steady decline in both the quality and quantity of students studying the classics. Whereas in the late 1950s essential reading for economics students at University of Sydney included Marshall, Edgeworth, Pigou, Bowley, Robertson, Hawtrey and Jevons, these readings have been steadily replaced by modern American texts. The decline of HET, was also paralleled by the decline in economic policy analysis, and reflects the dominating concern for formalism in the profession.

The University of Melbourne was the University of Sydney's major rival in terms of the training of economists. University of Melbourne economics graduates largely staffed 
both the University of Adelaide and Monash University. At Melbourne the history of economic thought was compulsory for Honours students, except for those who followed a mathematical stream. The history of thought was taught in the late forties and fifties by Herbert Burton, later with Graham Tucker and John La Nauze. Dr F.Schnierer (an acquaintance of F. Machlup) contributed lectures on Austrian economics. In the first year, students were exposed to Alexander Gray's Development of Economic Doctrine (1933), and Eric Roll's A History of Economic Thought (1938) was the HET text. Ken Rivett informs us that in second year, Marshall's Principles was used as late as 1946 as a text and Keynes' General Theory as late as 1953. (These two books lasted as texts at the University of Sydney until the late 1950s). The Cambridge Economics Handbook Series, containing books by Maurice Dobb, Roy Harrod, Austin Robinson and Dennis Robertson, was also widely used at Melbourne.

John Pullen (1990), an authority on the works of Malthus and author of the variorum edition of Malthus' Principles of Political Economy, recounts the experiences of a smaller regional university, that originally was a branch of the University of Sydney. At the University of New England, history of thought was initially taught by James Belshaw (1908-1984). Belshaw was one of the original five academics when the institution was established, and had an immense interest in HET, especially in his later years, and an exhaustive knowledge of the subject. He was responsible for establishing a remarkable collection of HET books in the University library. During this time (prior to 1975) HET was taught at Honours level as a quasi-compulsory unit. It was a regular, non-optional part of the course-work component of the Honours programme. All students wishing to do Honours were therefore expected to study HET. In 1975 Belshaw retired and John Pullen was appointed to lecture in HET Despite Pullen's best efforts, HET was gradually weeded out of the Honours program. First the HET course was reduced from two terms to one semester and then students were permitted to substitute other options for HET. Frantic attempts were made to resurrect HET via timetabling, change of name and focus, to encourage the application of history to current issues. As a result, the fortunes of HET revived somewhat in the 1990s with the introduction of a postgraduate course in addition to the undergraduate one. But with recent financial cutbacks, and falling enrolments in economics courses, HET reverted to just one course and is in danger of disappearing from the curriculum altogether. One development is a joint course offered with the Politics Department, entitled 'Political Economy', with an institutionalist, antineoclassical and Post Keynesian approach. Perhaps the future of the history of economics lies outside economics. In economics at UNE few dissertations are written in the subject and none of the Honours students study HET now. This is quite a transformation from the Belshaw days.

In Australian departments of economics, where power and control typically resided with one or a small number of Professors, HET could prosper with a sympathetic Head. The foundation Professor of Economics at Monash University (Donald Cochrane) appointed Michael Schneider to teach HET at both third and fourth year levels in time for the first batch of third year students in 1963, and it has been taught there ever since, for over a decade now, by Mike White. Equally sympathetic were the foundation Professors of Economics at La Trobe University (Donald Whitehead and Frank Davidson), where Schneider has taught the subject since the first batch of third year students in 1969 . Ominously, however, 'insufficient' enrolments have prevented the third year subject 
being taught since 1999, and the fourth year subject was taught in 2001, only after a lapse of three years (due to no enrolments).

In other places, a charismatic lecturer could have a significant influence. At the University of Queensland, history of economic thought was linked by Richard Staveley to political philosophy. Staveley completed his undergraduate economics degree at the University of Sydney in 1951 and went to Chicago to study political philosophy. He then taught in several departments at Queensland including history, government and economics. Staveley raised questions that went outside the normal confines of economics and promoted an awareness of the relevance of political philosophy to economics. For example, the notion that Keynes reconciled economics with the older tradition of moral and political philosophy, and that the General Theory was not a scientific text but a return to pre-classical traditions, which understood economics as an art, based on common sense, subject to the principles of reason. His influence can be seen on a number of contemporary Australian historians of thought in the Post Keynesian tradition. Athol Fitzgibbons' books, Keynes's Vision (1988), Adam Smith's System of Liberty, Wealth and Power: The Moral and Political Foundations of the Wealth of Nations (1995) and The Nature of Macroeconomics (2000) are a case in point.

But we are running ahead of the story. Two further important characteristics of the early study of the history of economic thought at Australian universities stand out. First, there was really no community of scholars that actively interacted in Australia until the early 1980s. There were a small number of influential figures who sometimes moved among the major institutions, and left strong imprints on their students, but often their main interest was economic history rather than the history of economics (Syd Butlin, Herbert Burton, John La Nauze). La Nauze taught history of thought but later moved into chairs of economic history and then history at Melbourne University. History of thought articles were presented at the Economic Society of Australia and New Zealand (founded in 1925) meetings and the annual meetings of the Economics Section of the Australian and New Zealand Association for the Advancement of Sciences (ANZAAS). The Conference of Economists replaced the latter as a more popular venue to present specialist papers in economics after 1970. Yet, given the tyranny of distance and the available communication methods, there was no fraternity of historians of thought.

Peter Groenewegen recollects that there was really very little contact between historians of thought in Sydney, for example, and those relatively nearby at Newcastle (Barry Gordon), or at Armidale (John Pullen). Take the case of Barry Gordon (19341994). Gordon completed his initial studies in economics at the University of Sydney. He was influenced particularly by Kurt Singer, 'the mystical economist from Hamburg', as Keynes called him. Singer was more often to be seen in departments of German, Greek and philosophy, than in economics. He shared the one-year course in the history of economic thought with John La Nauze and was responsible for the period up to Adam Smith. When La Nauze took over, he discovered that Singer had got only as far as Aristotle (Arndt 2000:74). The link to Gordon is obvious to those familiar with his work on the Ancients, particularly Economic Analysis Before Adam Smith: Hesiod to Lessius (Macmillan 1975). Work in this area led to three more books: The Economic Problem in Biblical and Patristic Thought (Brill 1989), Economic Analysis in Talmudic Literature (with R.A.Ohrenstein) (Brill 1992), and in the book he edited with S.Todd Lowry, which was published after his death, Ancient and Medieval Economic Ideas and Concepts of 
Social Justice (Brill 1998). It was Singer that got Gordon interested in the Greeks. After Sydney, Barry Gordon went to the University of Newcastle as one of its foundation lecturers in economics and taught three courses annually on 'Economic Doctrines and Methods'. His first published article was in the Quarterly Journal of Economics (QJE) in 1961 and during the sixties he acquired an international reputation with further papers in Economica, Oxford Economic Papers and the QJE. His standing was secured with five books between 1975 and 1992, including Political Economy in Parliament, 1819-1823 (Macmillan 1976) and Economic Doctrine and Tory Liberalism, 1824-1830 (Macmillan 1979). He had visiting appointments at Oxford, MIT, Cambridge and London. Gordon was clearly Australia's leading authority in the history of thought, surpassed only by Peter Groenewegen later. Yet, and this is the point of this interlude, Groenewegen met Gordon for the first time at the Inaugural HETSA Conference in 1981. Scholarly interaction in the sub-discipline was more active internationally than domestically.

Another important characteristic of the early education of Australian historians of thought (and economists generally) is that they went overseas to pursue their $\mathrm{PhD}$ studies. Only in the 1960s did Australian production of economics PhDs begin seriously. Take Graham S.L.Tucker (1924-1980), for instance. Tucker went to Cambridge in 1951 to be supervised by Sraffa, and later Lionel Robbins was one examiner of his doctorate. This was published by Cambridge University Press in 1960 as Progress and Profits in British Economic Thought, 1650-1850 and led to two influential articles: 'On the Origin of Ricardo's Theory of Profits' (Economica 1954) and 'Ricardo and Marx' (Economica 1961). Tucker taught at the University of Melbourne and then the Australian National University, where he subsequently supervised Neil De Marchi's PhD on John Stuart Mill, which was awarded in 1970. Anthony M.C.Waterman also completed his $\mathrm{PhD}$ at the Australian National University. Waterman was there from July 1964 to July 1967 but his thesis was on macroeconomics. His interest in the history of economics only began in 1979.

The other leading Melbourne historians of thought (Burton and La Nauze) had studied at Oxford. Geoffrey Harcourt started his undergraduate studies at the University of Melbourne in 1950, in a Faculty that was very Keynes and Cambridge based: 'it was Cambridge-oriented economics that he studied there, which he has loved ever since' (Arestis, Palma and Sawyer 1997:xxiii). Marjorie Harper (née Ronaldson) inspired Harcourt as an undergraduate to take an interest in HET. King (1997:301) notes that 'between the wars Cambridge was the natural destination for a talented young Australian economist'. Except for agricultural economists, American PhDs were very uncommon before the 1970s. Almost all students interested in a PhD or staff on study leave went overseas, and there was enormous respect for Cambridge. Some Australians returned with accent and manner permanently affected by their British experience. Many returned as Keynesians. As late as 1982 it could be triumphantly reported in the HETSA Newsletter (No. 3, Summer) that Geoffrey Harcourt had left the University of Adelaide to move 'to his new post in that fount of all economic truth-English Cambridge'. (Harcourt had initially been a research student at King's in 1955 and in September 1982 left Adelaide to take up a post in the Faculty at Cambridge and a Fellowship at Jesus). Cambridge economics has had a profound effect on Australian history of economic thought, primarily in recent years through the presence of Harcourt (similar to the influence of Sraffa on Italian HET). Indeed, Murray Kemp has suggested that Cambridge 
UK has had a 'deadening effect' on Australian economics, while for others it represents a flickering light in an ever darkening discipline that screens out heterodoxy.

\section{Recent Australian history of thought}

The emergence of a HET community in Australia coincides with the formation of HETSA.John C.Wood, in the final stages of completing his $\mathrm{PhD}$ under the supervision of A.W.Coats, arrived at the University of New England and, with the unbridled enthusiasm he is well known for, proposed the formation of a Society. John Pullen, Peter Groenewegen and Ray Petridis (a student of Craufurd Goodwin) were all supportive, and the first conference was held in 1981. There were 21 participants and papers were presented by Schneider, White, Groenewegen, Gordon, Boot and Harcourt. The conference provided a public airing of Michael White's first major paper on W.S.Jevons, the start of more than twenty Jevons publications, and a number of others on Henry Thornton, Nassau Senior, William Whewell, W.E.Hearn and Richard Jennings. Tony Endres (then at Wollongong) attended, as did the other Duke connection-Joe Remenyi, and also Toshihiro Tanaka. Tanaka bought 200 copies of reprints from the University of Sydney HET series, for distribution to members of the Japanese HET Society, thereby providing the funding for the series to continue. The Japanese presence has been fairly continuous at HETSA meetings. Perhaps more symbolically important, Harcourt gave the after-dinner speech, flanked by photographs of Joan Robinson and Piero Sraffa.

There has been a strong connection between work in Post Keynesian economics and the study of the history of economics in Australia (King 1997). Not surprisingly, Keynes features most prominently in articles published by the History of Economics Review. Groenewegen (1979b) in his survey of radical economics in Australia provides an overview of this work in the Post Keynesian and Neo-Ricardian traditions. This research is not only a critique of orthodox economics but also an attempt to reconstruct a new political economy either on classical, Marxist or Kalecki-Keynes lines. As Groenewegen (1979b:176) noted, the Post Keynesian group 'bases itself on the Marshallian Cambridge tradition, as revitalised by Keynes and Kalecki, and enriched by Sraffa's rehabilitation of classical political economy (that is, from the Physiocrats up to and including Marx)'. The risk is that such a concentration will put off others with an interest in the craft who are less committed to perceptions often fiercely advocated by advocates of this approach.

Groenewegen credits the efforts of G.C.Harcourt for spreading Post Keynesianism in Australia. Harcourt's influence is difficult to overstate and since the 1970s he has written many essays in intellectual biography, and HET subjects, ancient and modern, figure prominently in his publication list. His helpful and generous nature has endeared him to countless students (see Hatch and Petridis 1997). Doctoral supervision gives some insight into the chains of influence at work. Harcourt has been an exceedingly popular $\mathrm{PhD}$ supervisor, and even when he was not the formal supervisor, his support and encouragement was often crucial. He played a role in the research of Rod O'Donnell, Peter Kriesler and Roy Green at Cambridge. Some of his other Australian postgraduate students who wrote on HET include Mike White, Kieran Sharpe, Terry O'Shaughnessey, Wylie Bradford and Beth Webster. Prue Kerr is an interesting case. Harcourt taught her as an undergraduate and supervised her Masters and $\mathrm{PhD}$ degrees. They have authored 
HET papers together and are the editors of the five volume Routledge publication of critical essays on Joan Robinson. Harcourt also supervised Claudio Sardoni's 1983 PhD on 'Ricardo, Marx and Keynes' while at the University of Adelaide. Another Adelaide $\mathrm{PhD}$ he supervised was Allen Oakley's 'The intellectual origins and evolution of Karl Marx's theory of surplus value' (1980). In turn, Oakley supervised Phil O'Hara on 'Marxist and Institutionalist political economy' in 1992 and Jerry Courvisanos on 'Kaleckian investment cycles' in 1995.

Peter Groenewegen also has a long list of students who went on to achieve considerable reputations in the history of economics: Tony Aspromourgos and Murray Milgate come to mind immediately. Aspromourgos had earlier completed an undergraduate Honours thesis at the University of Queensland (with Staveley) comparing Pigou and Keynes, a Masters at Melbourne on John Locke, another Masters in Politics from the University of Chicago, before he specialised on Sir William Petty. He takes the view that Petty was the founder of classical political economy and that he deserves high praise for clearly formulating a concept of surplus. Milgate taught at the University of Sydney in the mid-1980s. He rejects the neoclassical approach to value, distribution, output and employment and urges a return to the classical economists and Marx, rehabilitated by Piero Sraffa, with separable explanations of the forces which determine relative prices and distribution on the one hand, and outputs and employment on the other. Milgate was coeditor of the New Palgrave Dictionary of Economics (London: Macmillan 1987).

The interest in Cambridge economics and what Terence Hutchison has termed 'The Cambridge version of the history of economics' can be partly explained by historical circumstances and the influence of key figures. Its longevity in Australian history of thought also reflects the sub-discipline's receptivity to intellectual traditions outside the mainstream. Whereas someone like Joseph Halevi has difficulty in finding an audience for his ideas outside of Europe, there is always an opening at HETSA meetings. While Post Keynesians were influential, Australian HET was always more heterogenous, and the interest in Post Keynesianism must be set in the context of the 1970s when there appeared to be a promising research program emerging to challenge mainstream thinking, and critiques of orthodoxy were common. This research program may have failed to achieve the initial high expectations. Groenewegen (1995a:137) notes that: 'Post Keynesian economics survives as a minority interest in a number of economics departments while its intellectual elite is an ageing set of professors whose writings are falling on deaf ears in an increasingly homogenised profession built on the North American model'.

Perhaps the best-known New Zealand historian of thought is Tony Endres. Yet his research program does not fit the Post Keynesian mould. Endres completed his $\mathrm{PhD}$ at the University of Wollongong in Australia in 1982 on 'Economic thought and numerical observations' and has had a lot to do with Sam Hollander over the years. Endres' Wollongong thesis was motivated by an earlier influence at the University of Waikato, in New Zealand, where he was taught HET and supervised by W.Reindler, an Austrian refugee who did his PhD in Vienna under Hans Meyer and Othmar Spann. Endres has published extensively on Austrian economics, Adam Smith and the history of New Zealand economics, and supervised, among others, Simon Chapple and Grant Fleming. 


\section{What Might the Future Hold?}

Despite the impressive research output, the job market for historians of thought in Australasia today is poor. Why? Let us take the case of John Pullen. Pullen completed his undergraduate degree at the University of Sydney. The course left him uninspired, except for the one year course in the history of economics taught by Cyril Renwick. He then left for Paris to pursue philosophy for three years. He read Hume, Smith and Locke and saw the connections with the history of economics he had earlier studied. At the University of Liverpool a Masters thesis, on land and rent in English political economy and after, followed. This was as much economic history as it was HET. Returning to Australia, Pullen completed a $\mathrm{PhD}$ on Malthus at the University of Newcastle in 1974 under the supervision of Barry Gordon. Pullen has spent much of his professional life poring over the editions of Malthus' Principles. (To be fair a little over half of Pullen's 50 publications are on non-Malthus themes-Senior, Hearn, Major Douglas, Henry George, Richard Jones). Would a department of economics today hire a 'young' Pullen? No. It is doubtful that such a specialisation would be encouraged or that a person with such a background would even be considered suitable for an appointment in the first place.

Increasing formalism in economics has meant that there is less room in the curriculum for more literary and historical studies like HET. The teaching situation is quite desperate. In 1995 there were only three (out of six) States in Australia where history of thought was being taught, with twenty courses in total being offered. Since then there has been further attrition, The situation in New Zealand is equally tenuous. While they have no formal HET organisational structure, New Zealanders have always played a role in HETSA and attended its conferences, but there is not enough interest in HET to warrant a session at the annual New Zealand Economics Association Conference. New Zealanders present their HET work elsewhere. Perhaps HET is offered at about half the New Zealand universities. James Alvey and Alfred Oehlers used to jointly teach HET at Massey but the subject has been under threat for four years, and now it is not even taught internally but only in correspondence mode. The picture is brighter at Auckland. Horace Belshaw (brother of James) returned from Cambridge with a recommendation from Keynes in 1926 and took the first Chair in Economics at Auckland. From this date HET has been taught at that institution. Tony Endres teaches the subject there now and his Honours/Masters HET class is well attended, Endres devotes more than half the course to post 1950 developments and includes surveys of evolutionary economics, psychological economics, new institutional economics, feminist economics, new Austrian economics and other heterodox doctrines. He suggests that modernising HET may be the way forward and his own research is taking a post 1950 focus. His book with Grant Fleming on International Organizations and the Analysis of Economic Policy, 1919-1950 was published by Cambridge University Press in 2002.

From our discussion it is clear that the impressive research output in Australasia on the history of economics stands out in sharp contrast to the general teaching situation and the academic employment opportunities. How long these publication options will continue is hard to say. The high prices and low production volumes (around 300) were initially designed for the unique circumstances of the Japanese market. Whether this demand will continue is doubtful. The proliferation of journals is another positive development, 
although the inroads made by commercial publishers raise a number of concerns about price and quality standards.

In the context of a teaching situation which is in decline, except for a few places like Curtin and the University of Western Sydney, the uncertainties relating to commercial research publications, and developments in the broader discipline, the retirement (actual or imminent) of the leading Australian historians of thought (Groenewegen, Ray Petridis, Pullen, Oakley, O'Donnell and Harcourt) do not auger well for the future of the history of economics.

\section{Note}

* This chapter is a companion piece to Lodewijks (2002). It deals with aspects of Australian history of economic thought not covered in that publication. I would like to thank the following for providing information and valuable comments: Jim Alvey, Tony Aspromourgos, Tony Endres, Moira Gordon, Peter Groenewegen, Geoff Harcourt, Warren Hogan, Murray Kemp, John King, Peter Kriesler, Chris Nyland, Allen Oakley, Phil O’Hara, John Pullen, Ken Rivett, Michael Schneider and Anthony Waterman. I am particularly grateful for the detailed comments provided by Mike White, who along with Roy Weintraub, were my not so anonymous referees. The comments of participants at the 2001 HOPE, HES and HETSA Conferences were also helpful. 


\section{Bibliography of Peter Diderik Groenewegen}

1962 'First International Conference on Economic History: a review article', Business Archives and History, 2 (2):137-50 (with B.McFarlane).

'Some Thoughts on Regional Planning', Economic Monograph No. 247, Sydney: Economic Society of Australia and New Zealand (NSW Branch), October.

1967 'Reflections on Two Centenaries in Political Economy', Economic Monograph No. 284,

Sydney: Economic Society of Australia and New Zealand (NSW Branch), February (repr. in Groenewegen, 2003a).

'Authorship of the Natural and Political Observations upon the Bills of Mortality', Journal of the History of Ideas, 28 (4):601-2.

1968 'Some Comments on De Lissa's Multiplier', Economic Monograph No. 295, Sydney:

Economic Society of Australia and New Zealand (NSW Branch), June.

'A New Catalogue of Adam Smith's Library', Economic Record, 44 (December): 498-506

(repr. in Groenewegen, 2002a).

1969 'Labour and the Classical Economists', Labour History, 16 (May): 20-29 (repr. in

Groenewegen, 2002a).

'Turgot and Adam Smith', Scottish Journal of Political Economy, 16 (3):271-87 (repr. in

Groenewegen, 2002a).

1970‘A Reappraisal of Turgot's Theory of Value, Exchange and Price Determination', History of

Political Economy, 2(1):177-96 (repr. in Groenewegen, 2002a).

'Employment and Machinery: two classical debates on the effects of automation', Journal of Industrial Relations, 12 (3):348-59 (repr. in Groenewegen, 2002a).

'The Public Finance of Australia's Conscription to the Vietnam War', Australian Quarterly, 42 (4):63-73.

1971 'A Re-interpretation of Turgot's Theory of Capital and Interest', Economic Journal, 81

(2):327-40 (repr. in Groenewegen, 2002a).

'Rationalising the Australian Taxation System', Economic Record, 47 (December): 531-52.

1972 'Consumer Capitalism', in J.Playford and D.Kirsner (eds.) Australian Capitalism: towards a socialist critique, Ringwood, Vic.: Pelican: 84-107.

'Three Notes on Ricardo's Theory of Value and Distribution', Australian Economic Papers,

11 (June): 53-64 (repr. in Groenewegen, 2003a).

1973 'A Note on the Origin of the Phrase, Supply and Demand', Economic Journal, 83 (2):505-9

(repr. in Groenewegen, 2003a).

'The Australian Budget Process', Public Administration, 32 (3):251-67.

1974 'Taxation, the Wage Level and Inflation', Journal of Industrial Relations, 16 (1): 78-84.

'The Feasibility of a Federal Net Worth Tax', Economic Papers, 43 (January): 28-39.

1976 'The Taxable Capacity of Local Government in New South Wales', Centre for Research on

Federal Financial Relations Research Monograph No. 13, Canberra: Australian National

University Press.

1977 (ed. \& trans.) The Economics of A.R.J.Turgot, The Hague: Martinus Nijhoff.

'A Proposal for an Australian Tax Council', in R.L.Mathews (ed.) State and Local Taxation,

Canberra: Australian National University Press: 363-80. 
'Adam Smith and the Division of Labour: a bicentenary estimate', Australian Economic Papers, 16 (December): 161-74 (repr. in Groenewegen, 2002a).

'Taxation Policy for Recovery: a comment', Economic Papers, 53 (January): 28-31.

1979 Public Finance in Australia: theory and practice, Sydney: Prentice Hall $\left(2^{\text {nd }}\right.$ ed. $1984,3^{\text {rd }}$ ed. 1990).

'Federalism', in A.Patience and B.Head (eds) From Whitlam to Fraser, Melbourne: Oxford

University Press: 50-69.

'Progress and Poverty in Historical Perspective' in Papers Presented in Commemoration of the Centenary of Publication of 'Progress and Poverty' by Henry George, Sydney: Australian School of Social Science.

'Radical Economics in Australia: a survey of the 1970s', in F H.Gruen (ed.) Surveys of Australian Economics, vol. 2, Sydney: Allen and Unwin: 171-223.

'Taxation and the Family Unit: some economic aspects', in R.W.Parsons et al., Taxation and the Family Unit, Sydney: Taxation Institute of Australia: 11-28.

'R. L.Meek and the Physiocrats: an appreciation', History of Economic Thought Newsletter,

23 (Autumn): 12-17.

'The Challenge of Taxation Reform: an overview', Economic Papers, 62 (November): 77-83.

'The Demand for Labour, the State, the Level of Employment and the Distribution of Income',

Economic Papers, 61 (October): 1-19.

1980 (ed.) Readings in Australian Tax Policy, Melbourne: Longman Cheshire (2 $2^{\text {nd }}$ ed. 1987).

'Intergovernmental Financial Relations', in H.Mayer and H.Nelson (eds) Australian Politics 5,

Melbourne: Longman Cheshire: 171-81.

'Taxation Trends: characteristics and issues', in Tax Reform and Social Welfare, Sydney,

Taxation Institute of Australia: 43-59.

'Capital Taxation in Australia: possibilities, practice and planning', Proceedings of the

Taxation Convention of the Taxation Institute of Australia, December, Sydney: Taxation

Institute of Australia.

1981 'Apportioning Tax Powers in a Federation', in R.L.Mathews (ed.) State Taxation in Theory

and Practice, Canberra: Centre for Research on Federal Financial Relations, Australian

National University: 1-24, 29-30.

-'Market Rates or Tax-Exempt Rates on Semi-Government Securities', inJ.Jüttner (ed.) Interest

Rates, Melbourne: Longman Cheshire: 27-45.

'Robert Ewing (1871-1957): taxation commissioner', in Australian Dictionary of Biography,

Melbourne: Melbourne University Press, vol. 8:453-4.

1982 (ed.) [Sir William Pultenay] Some Thoughts on the Interest of Money in General (1738),

Reprints of Economic Classics, Series 2, No. 1 (Sydney: Department of Economics, University of Sydney).

-Australian Taxation Policy: policy survey 1965-80, Sydney: Taxation Institute of Australia. 'History and Political Economy: Smith, Marx and Marshall', Australian Economic Papers, 21

(June): 1-17 (repr. inGroenewegen, 2003a). Also repr. inJ.C.Wood (ed.) (1996) Alfred

Marshall: critical assessments, $2^{\text {nd }}$ series, 4 vols., London: Routledge: vol. VI, 85-104.

'Problems and Prospects of Public Sector Growth in Australia', Centre for Research on

Federal Financial Relations Occasional Paper No. 27, Canberra: Australian National

University.

'Reflections on "Razor Gangs", Thatcherism and Reagonomics: a critical evaluation of the

contemporary sport of public sector bashing', Journal of Australian Political Economy, nos. 12-

13 (June): 4-19.

'Thomas de Quincey: faithful disciple of Ricardo?', Contributions to Political Economy,

1:51-8 (repr. in Groenewegen, 2003a).

'Turgot: forerunner of neoclassical economics?', Kenzei Kenku (Hitotsubashi Economic

Review), 33 (2):119-33 (repr. in Groenewegen, 2002a). 
1983 The Wholesale Sales Tax in Historical Perspective, Sydney: Australian Tax Research Foundation.

(ed. \& trans.) François Quesnay, Farmers (1756), and A.R.J.Turgot, Sur la Grande et la Petite Culture (1766), Reprints of Economic Classics, Series 2, No. 2 (Sydney: Department of Economics, University of Sydney) (Introduction partly repr. in Groenewegen, 2002a).

(ed.) Italian Economics Past and Present, Sydney: May Foundation of Italian Studies, University of Sydney (with J.Halevi).

'Australian Taxation Policy', in F.H.Gruen (ed.) Surveys of Australian Economics, vol. 3, Sydney: Allen and Unwin: 188-249.

'The Political Economy of Federalism', in B.Head (ed.) Economy and the State, Melbourne:

Oxford University Press: 169-95.

'Prospects and Problems of Australian Public Sector Growth', in R.Mendelsohn (ed.) Social

Welfare in Australia, Sydney: Allen and Unwin: 58-79.

'Turgot, Beccaria and Smith', in P.D.Groenewegen and J.Halevi (eds.) Italian Economics Past and Present, Sydney: May Foundation of Italian Studies, University of Sydney: 31-78 (repr. in Groenewegen, 2002a).

'The Fiscal Crisis of Australian Federalism', in A.Patience and G.Scott (eds.) Australian

Federalism and Future Tense, Melbourne: Oxford University Press: 123-58.

'Tax Assignment and Revenue Sharing in Australia', in C.McLure Jr. (ed.) Proceedings of the

International Seminar on Public Economics, Canberra: Australian National University Press:

293-318.

'The Australian Wholesale Sales Tax in Perspective', in J.G.Head (ed.) Taxation Issues of the 1980s, Sydney: Australian Tax Research Foundation: 339-64.

'Joan Violet Robinson (1903-1983)', Australian Left Review, no. 86:62-3 (repr. in

Groenewegen, 2003a).

'Joseph Alois Schumpeter (1883-1950): a centenary tribute', History of Economic Thought

Society of Australia Newsletter, no. 4 (Winter): 17-25.

'Turgot's Place in the History of Economic Thought: a bicentenary estimate', History of

Political Economy, 15 (4):585-616 (repr. in Groenewegen, 2002a).

1984 (ed.) Robert Torrens, The Economists Refuted and Other Early Economic Writings (1808),

Reprints of Economic Classics, Series 2, No. 3 (Sydney: Department of Economics, University of Sydney) (repr. New York: Kelley, 1993).

'Distributional and Allocational Effects of Tax Avoidance', in D.J.Collins (ed.) Tax

Avoidance and the Economy, Sydney: Australian Tax Research Foundation: 23-38.

'The Physiocrats: origins of scientific political economy and the single tax' (First Henry

George Memorial Lecture, Macquarie University, Sydney, 30 October 1984), Sydney:

Macquarie University (repr. in Groenewegen, 2002a).

'Rationalising Australian Taxation Revisited', Economic Record, 60 (June): 113-27.

1985 Everyone's Guide to Australian Taxation, Sydney: Allen and Unwin.

'Taxation of Capital and Capital Gains-Reflections on Objectives and Potential Instruments',

in D.J.Collins (ed.) Major Issues in Australian Tax Reform, Sydney: Australian Tax Research

Foundation: 65-80.

'The Economy', in R.L.Mathews (ed.) Australian Federalism 1981, Canberra: Centre for

Research on Federal Financial Relations, Australian National University: 1-28.

'The 1985/86 Budget and the 19 September 1985 Tax Reform Measures: their growth and

fairness aspects', Discussion Paper no. 4, Canberra: Department of the Parliamentary Library

Legislative Research Service, November.

'Options for the Taxation of Wealth', Australian Tax Forum, 2 (3): 305-26.

'Professor Arndt on Political Economy: a comment', Economic Record, 61 (December): 744-

51.

'The National Taxation Summit: success or failure?', Economic Papers, 4 (3): 1-17. 
1986 (ed. \& trans.) Pietro Verri, Reflections on Political Economy (1771), Reprints of Economic Classics, Series 2, No. 4 (Sydney: Department of Economics, University of Sydney) (repr. New York: Kelley, 1993).

'Options for the Taxation of Wealth', in J.G.Head (ed.) Changing the Tax Mix, Sydney: Australian Tax Research Foundation: 375-92.

'In Defence of Post-Keynesian Economics' (Newcastle Lecture in Political Economy), Research Report No. 131, Newcastle: Department of Economics, University of Newcastle. 'Professor Porta on the Significance of Understanding Sraffa's Standard Commodity and the Marxian Theory of Surplus: a comment', History of Political Economy, 18 (3):455-62. Repr. in M.Blaug (ed.) (1992) Piero Sraffa (1898-1983), Aldershot UK: Elgar: 147-54.

'R.C.Mills (1886-1952)', in Australian Dictionary of Biography, Melbourne: University of Melbourne Press: vol. 10, 517-19.

1987 'The International Foundations of Classical Political Economy', in S.Todd Lowry (ed.) PreClassical Economic Thought, Dordrecht: Kluwer: 211-20.

'Foreign Debt, the Current Trade Balance, International Competitiveness and Private Capital Formation: Australia's budget 1987-88', Rivista di Dirito Valutario ed Economia Internazionale 23 (4):843-77.

'Marx's Conception of Classical Political Economy: an evaluation', Political Economy:

Studies in the Surplus Approach, 3(1):19-35 (repr. in Groenewegen, 2003a). Japanese trans. in T.Tanaka (ed.) (1990) The Formation and Development of Classical Political Economy: studies in classical political economy II, Tokyo: Nippon Keizai Hyoronsha: 239-64.

'Reflections on Pietro Verri's Political Economy', Storia del Pensiero Economico, no. 15:310 (repr. in Groenewegen, 2002a).

Entries in J.Eatwell, M.Milgate \& P.Newman (eds) The New Palgrave: a dictionary of economics, 4 vols., London: Macmillan:

'Nicolas Baudeau': 1, 205-6.

'Cesare Bonesana, Marchese di Beccaria': 1, 218-19.

'Max Beer': 1, 220.

'Jerome Adolphe Blanqui': 1, 253.

'Pierre le Pesant, Sieur de Boisguillebert': 1, 259-60.

'Etienne Bonnot de Condillac': 1, 564-5.

'Bernardo Davanzati': 1, 747-8.

'Charles Davenant': 1, 748-9.

'Denis Diderot': 1, 836-7.

'Division of Labour': 1, 901-7.

'Pierre Samuel Du Pont de Nemours': 1, 942-3.

'Ephemerides': 2, 166.

'Fiscal Federalism': 2, 366.

'François Veron de Forbonnais': 2, 396.

'Isaac Gervaise': 2, 519-20.

'Jean Claude Marie Vincent de Gournay': 2, 554.

'Guillaume François le Trosne': 3, 169-70.

'Piere Paul Mercier de la Riviere': 3, 449-50.

'Victor Riquetti, Marquis de Mirabeau': 3, 478-9.

'Political Economy and Economics': 3, 904-7.

'Pseudo-distribution': 3, 1037.

'Antonia Serra': 4, 313-14.

'Supply and Demand': 4, 553-4.

'Anne Robert Jacques Turgot': 4, 707-12.

'Jacob Vanderlint': 4, 797-8.

'Pietro Verri': 4, 807. 
1988 (ed.) Taxation and Fiscal Federalism: essays in honour of Russell Mathews, Canberra: ANU Press (with H.G.Brennan and B.S.Grewal).

-Rehabitating the Classical Notions of "Productive" and "Unproductive" with Special Reference to their Relevance to Taxation', in G.H.Brennan, B.Grewall and P.D.Groenewegen (eds) Taxation and Fiscal Federalism: essays in honour of Russell Matthews, Canberra: Australian National University Press: 83-102.

'Taxation and Public Finance', in The Australian Encyclopedia, 5th ed., Sydney: Australian Geographic: vol. 8, 1805-11 (repr. in rev. version in the $6^{\text {th }}$ ed., vol. 7, 2872-7, 1996).

'Alfred Marshall and Australian Economics', HETSA Bulletin, no. 9 (Winter): 1-16 (History of Economic Thought Society of Australia) (repr. in Groenewegen, 2003a).

'Alfred Marshall and the Establishment of the Cambridge Economics Tripos', History of Political Economy, 20 (4):627-67. Repr. in J.C.Wood (ed.) (1996) Alfred Marshall: critical assessments, $2^{\text {nd }}$ series, 4 vols., London: Routledge: vol. VII, 72-113.

'Pickering's Collected Malthus: a review article', Journal of Political Economy, 96 (2):429-

46 (repr. in Groenewegen, 2003a).

'Tax Reform in Australia and New Zealand', Government and Policy, 6(1):93-144.

1989 'Federalism', in B.W.Head and A.Patience (eds) From Fraser to Hawke, Melbourne:

Longman Cheshire: 240-72.

'Innovation Possibilities in State Business Taxation', in New South Wales Tax Task Force,

Commissioned Studies, vol. 2, Sydney: Government Printer: 270-346.

'New Light on the Origins of Modern Economics: a survey', Economic Record, 65 (June):

136-49 (repr. in Groenewegen, 2002a).

'Teaching Economics at Cambridge at the Turn of the Century: Alfred Marshall as lecturer in political economy', Scottish Journal of Political Economy, 37 (1):40-60.

'The Australian Indirect Taxation Regime: targeting the defects', Australian Tax Forum, 6 (3):183-302.

'The Development of Economics in Australia: a tale of two centuries', Economic Papers, 8(1):97-108.

1990 A History of Australian Economic Thought, London: Routledge (with B.McFarlane).

- (ed.) Alfred Marshall, On History and Method of Economics (circa 1870), Reprints of

Economic Classics, Series 2, No. 5 (Sydney: Centre for the Study of the History of Economic Thought, University of Sydney).

'Local Government Finance', in Evatt Research Centre, Breach of Contract: Privatisation and the Management of Australian Local Government, Sydney: Pluto Press (for the Evatt Research Foundation): $15-33$.

'Marshall on Taxation', in R.McWilliams (ed.) Alfred Marshall in Retrospect, Aldershot UK:

Elgar: 91-112 (repr. in Groenewegen, 2003a).

_Neo-Classical Value and Distribution Theory: the English speaking pioneers', inK.

W.Hennings and W.J.Samuels (eds.) Neo-Classical Economic Theory 1870 to 1930, Dordrecht:

Kluwer: 13-51 (repr. in Groenewegen, 2003a).

'Progressive Personal Income Tax-An Historical Perspective', in J.G.Head and R.Krever (eds) Flattening the Tax Scale: alternative scenarios and methodologies, Melbourne: Longman Cheshire: 3-31.

'Über Turgots Reflexions', in Kommentar zur Faksimile Ausgabe der 1769-1790 erschienenen erstausgabe von Anne Robert Jacques Turgot, Reflexions sur la formation et la distribution des richesses, Dusseldorf: Verlag Wirtschaft und Finanzen: 67-88.

'Taxation and Decentralisation: a reconsideration of the costs and benefits of a decentralised tax system', in R.J.Bennett (ed.) Decentralization, Local Governments and Markets: towards a post-welfare agenda, Oxford: Clarendon: 87-115.

'Marshall and Hegel', Economie Appliquée, 43 (1):63-84 (repr. in Groenewegen, 2003a). Also repr. in J.C.Wood (ed.) (1996) Alfred Marshall: critical assessments, $2^{\text {nd }}$ series, 4 vols., London: Routledge: vol. VII, 160-78. 
'Taxation: its role in economic growth', Australian Journal of Public Administration, 49

(3):321-31.

'The National Farmers Federation Tax Reform Proposals: an evaluation', Australian Tax

Research Foundation Occasional Paper No. 5

1991 'Deregulation: some general reflections', in B.Head and E.McCoy (eds) Deregulation or Better Regulation, Melbourne: Macmillan: 9-19.

'Laissez-faire: reflections on the French foundations', in P.D.Groenewegen (ed.) Laissez Faire in Historical Perspective, Sydney: Centre for Research on the History of Economic Thought, University of Sydney, Occasional Paper No. 1:18-33 (repr. in Groenewegen, 2002a).

'Alfred Marshall and the History of Economic Thought', Quaderni di storia dell' economia politica, 9 (2-3): 59-88 (repr. in Groenewegen, 2003a).

'The Centenary Year as Seen in the East and South', Marshall Studies Bulletin, no. 1: 25-30.

Repr. in J.C.Wood (ed.) (1996) Alfred Marshall: critical assessments, $2^{\text {nd }}$ series, 4 vols.,

London: Routledge: vol. VIII, 74-9.

1992 (ed.) A.R.J.Turgot, Extracts of Economic Correspondence with Eminent Persons (1765-78),

Reprints of Economic Classics, Series 2, No. 6 (Sydney: Centre for the Study of the History of

Economic Thought, University of Sydney).

'Debouchés, Théorie des', in J.Eatwell, M.Milgate and P.Newman (eds) The New Palgrave

Dictionary of Money and Finance, London: Macmillan: vol. 1, 377-9.

'Über Wilhelm Roscher's Geschichte der National-Oekonomik in Deutschland', Vademecum

zur einem klassiker der Deutschen Dogmengeschichte, Dusseldorf: Verlag Wirtschaft und

Finanzen: 133-57.

'Alfred Marshall's Principles of Economics: a centenary perspective from the antipodes',

Australian Economic Papers, 31 (December): 219-33. Repr. in J.C.Wood (ed.) (1996) Alfred

Marshall: critical assessments, $2^{\text {nd }}$ series, 4 vols., London: Routledge: vol VIII, 276-93.

'Editing the Classics in the Antipodes with Special Reference to the Problem of Identifying

Anonymous Authors', Revue européennes des sciences sociales, 30 (92): 9-24 (repr. in

Groenewegen, 2002a).

'Professor Vaggi and the Physiocrats', Research in the History of Economic Thought and

Methodology, 9:200-19.

'The Corrigenda and Addenda for Marshall's Third and Fourth Editions of the Principles of

Economics', Marshall Studies Bulletin, no. 2:3-13. Repr. in J.C.Wood (ed.) (1996) Alfred

Marshall: critical assessments, $2^{\text {nd }}$ series, 4 vols., London: Routledge: vol. VIII, 172-81.

'What is Political Economy', Methodus, 4(1):16-18.

1993 'Marshall on Ricardo', in M.Baranzini and G.C.Harcourt (eds) The Dynamics of the Wealth of

Nations: Growth, Distribution and Structural Change. Essays in honour of Luigi Pasinetti,

Macmillan: London: 45-70 (repr. in Groenewegen, 2003a).

'Rationalising Australian Taxation Revisited', in M.A.B.Siddique (ed.) A Decade of Shann

Memorial Lectures 1981-90 and the Australian Economy, Singapore: Academic Press

International: 101-27.

'Taxation Issues', in I.Marsh (ed.) Governing in the 1990s: an agenda for the decade,

Melbourne: Longman Cheshire (for CEDA): 171-98.

'Taxation Policy Under Labor 1983-89: frenetic activity but is there an unfinished agenda?',

in G.Mahony (ed.) The Australian Economy Under Labor, Sydney: Allen and Unwin: 52-65.

'A Weird and Wonderful Partnership: Mary Paley and Alfred Marshall, 1877-1924', History

of Economic Ideas, 1 (1): 71-101.

'Marshall and Keynes: observations on the treatment in two recent biographies', Marshall

Studies Bulletin, no. 3:21-35.

1994 (ed.) Feminism and Political Economy in Victorian England, Aldershot UK: Elgar.

- (ed.) Socialist Thought in the Post Cold War Era, Manila: Journal of Contemporary Asia Press

(with B.McFarlane). 
'A Neglected Daughter of Adam Smith: Clara Elizabeth Collett (1860-1948)', in P

D.Groenewegen (ed.) Feminism and Political Economy in Victorian England, Aldershot UK:

Elgar: 147-73 (repr. in Groenewegen, 2003a). Repr. also in German trans. in A. Gronert (ed.)

(2001) Frauen in der Ökonomie. Die Anfänge in Grosbritannien, Marburg: Metropolis Verlag: 221-60.

'Alfred Marshall —Women and Economic Development: labour, family and race', in

P.D.Groenewegen (ed.) Feminism and Political Economy in Victorian England, Aldershot UK:

Elgar: 79-109 (repr. in Groenewegen, 2003a).

'Comments on the Papers by Dorigny, Cardoso and Lemesle', in M.Albertone and A.Masoero (eds.) Political Economy and National Realities, Turin: Einaudi Foundation: 233-8.

'Decentralising Tax Revenues: recent initiatives', in R.J.Bennett (ed.) Local Government and Market Decentralisation: experiences in industrialised, developing and former eastern bloc countries, Tokyo: United Nations University Press: 267-86.

'Introduction: women in political economy and women as political economists in Victorian

England', in P.D.Groenewegen (ed.) Feminism and Political Economy in Victorian England,

Aldershot UK: Elgar: 1-24.

'Pietro Verri's Mature Political Economy of the Meditazioni: a case study in the highly developed international transmission mechanism of ideas in pre-revolutionary Europe', in M.Albertone and A.Masoero (eds) Political Economy and National Realities, Turin: Einaudi Foundation: 107-25.

'The Political Economy of Federalism since 1970', in S.Bell and B.Head (eds) State, Economy and Public Policy, Melbourne: Oxford University Press: 69-93.

'Alfred Marshall and the Labour Commission', European Journal of the History of Economic Thought, 1 (2):272-95.

'Defending Economic Rationalism..., and Boosting the Image of "Free Market

Economists"?', Economic and Labour Relations Review, 5 (1):154-67.

'Jacob Viner and the History of Economic Thought', Contributions to Political Economy,

13:69-86 (repr. in Groenewegen, 2003a).

'La "French Connection": influences françaises sur l'économie politique britannique', Dix-

Huitième Sièclé, no. 26:15-36 (repr. in English in Groenewegen, 2002a).

'The Making of Good Economists: reviewing some consequences of Colin Clarke's life and

practice', Australian Quarterly, 66 (1):7-24 (repr. in Groenewegen, 2003a).

1995 A Soaring Eagle: Alfred Marshall 1842-1924, Aldershot UK: Elgar.

- (ed. \& trans.) Pierre Samuel Dupont de Nemours, On the Origins and Progress of a New

Science (1768), Reprints of Economic Classics, Series 2, No. 7 (Sydney: Centre for the Study of the History of Economic Thought, University of Sydney) (Introduction repr. in Groenewegen, 2002a).

'Vertical Fiscal Imbalance in Australia: some reflections', in The State of Australian

Government 1994-95, Sydney: Evatt Foundation: 321-25.

'Hans von Mangoldts Beitrag zur "Marshallischen" Wirtschaftstheorie-Die graphische

Darstellung von Angebot und Nachfrage', in Vademecum zu einem frühen Klassiker der

Preistheorie, Dusseldorf: Verlag Wirtschaft und Finanzen: 83-105.

'Keynes and Marshall: methodology, society and politics', in A.F.Cottrill and M. S.Lawler

(eds) New Perspectives on Keynes (Annual Supplement to History of Political Economy, vol.

27), Durham NC: Duke University Press: 129-55 (repr. in Groenewegen, 2003a).

'Land Policy, Taxation, Growth and the Multiplier: learning from Physiocracy in Australia',

Economies et Sociétés, 22-3 (1-2):441-59; and in B.Delmas, T.Demals and P.Steiner (eds) La

Diffusion Internationale de la Physiocratie, Grenoble: Presses Universitaires de Grenoble: 44159.

1996 (ed.) Official Papers of Alfred Marshall: a supplement, Cambridge: Cambridge University Press.

(ed.) Economics and Ethics?, London: Routledge. 
'Boisguilbert und die Ökonomik des 18. Jahrhunderts', in Vademecum zu dem Kolumbus der

Nationalökonomie, Dusseldorf: Verlag Wissenschaft und Finanzen: 111-48 (repr. in English in Groenewegen, 2002a).

'Introduction', in P.D.Groenewegen (ed.) Economics and Ethics?, London: Routledge: 1-14.

'The Australian Experience', in A.W.Coats (ed.) The Post-1945 Internationalisation of

Economics (Annual Supplement to History of Political Economy, vol. 28), Durham NC: Duke

University Press: 61-79.

'Unemployment and Price Stability: aspects of the Marshallian legacy on the monetary economy', in A.Cencini and M.Baranzini (eds) Unemployment and Price Stability, London:

Routledge: 151-77 (repr. in Groenewegen, 2003a).

'Marshall and Keynes: a survey of some recent literature', History of Economics Review, no. 25:11-18.

1997 (ed.) Alfred Marshall: collected essays, vols. 1-2 of Collected Works of Alfred Marshall, 8 volumes, London: Overstone Press.

'Economics Does Have a Useful Past and Yes, History is Important', in A.Heertje (ed.) The

Makers of Modern Economics, Aldershot UK: Elgar: vol. 3, 1-31.

'Fixed Capital as a Problem in Joint Production: some historical considerations', in P.Arestis,

G.Palma and M.Sawyer (eds) Capital Controversies, Post-Keynesian Economics and History of

Economics: essays in honour of Geoff Harcourt, London, Routledge: 70-81.

'Marshall and Keynes', in T.Cate (ed.) An Encyclopedia of Keynesian Economics, Aldershot

UK: Elgar: 400-14.

'Public Expenditure: leviathan or force for civilisation', in P Kriesler (ed.) The Australian

Economy, Sydney: Allen and Unwin: 133-52.

'The Correspondence of Alfred Marshall: economist', Journal of Political Economy, 105

(October): 1114-20 (repr. in Groenewegen, 2003a, as 'Marshall's Correspondence 1868-1924: a review').

1998 (ed.) John Asgill, On Land Banks (1696) and Charity Schools (1731), Reprints of

Economic Classics, Series 2, No. 9 (Sydney: Centre for the Study of the History of Economic

Thought, University of Sydney).

(ed.) Alfred Marshall: critical responses, 2 vols., London: Routledge.

'Der Fortschrittsgedanke und Henri de Saint-Simons "Du Systeme industriel", in Vademecum zur einem Klassiker des Utopischen Sozialismus: Henri de Saint-Simon, "Du Systeme industrielle”, Dusseldorf: Verlag Wissenschaft und Finanzen: 83-103.

_Division of Labour', in H.D.Kurz and N.Salvadori (eds) Elgar Companion to Classical Economics, Aldershot UK: Elgar: vol. 1, 217-22.

'Maffeo Pantaleoni', in F.Meacci (ed.) Italian Economists of the 20th Century, Aldershot UK:

Elgar: 44-68 (repr. in Groenewegen, 2003a).

_Mercantilism', in H.D.Kurz and N.Salvadori (eds) Elgar Companion to Classical Economics,

Aldershot UK: Elgar: vol. 2, 120-4.

'Sir James Steuart et Richard Cantillon', Economies et Sociétés (“Oeconomia”), nos. 11-12

(December): 47-61 (repr. in English in Groenewegen, 2002a). Also repr. in English in

R.Tortajada (ed.) (1999) The Economics of Sir James Steuart, London: Routledge: 27-40.

'Voices from the Journals: women contributors to four Australian economic periodicals,

1925-1996', Economic Papers, 17 (March): 13-31 (with S.King).

1999 'Adam Smith and Alfred Marshall: some reflections', in S.Daniel, P.Arestis and J.Grahl (eds)

The History and Practice of Economics: essays in honour of Bernard Corry and Maurice

Peston, Cheltenham UK: Elgar: vol. 2, 81-95 (repr. in Groenewegen, 2003a).

'Alfred Marshall and Herbert Somerton Foxwell: a tale of two libraries', in M.Fase,

W.Kanning and D.A.Walker (eds) Economics, Welfare Policy and the History of Economic

Thought: essays in honour of Arnold Heertje, Cheltenham UK: Elgar: vol. 2, 364-77 (repr. in

Groenewegen, 2003a). 
'Perfect Competition, Equilibrium and Economic Progress: that wretched division of labour and increasing returns', in S.Dow and P.Earl (eds) Economic Organisation and Economic Knowledge: essays in honour of Brian J.Loasby, Aldershot UK: Elgar: vol. 1, 225-38 (repr. in Groenewegen, 2003 a).

'Public Expenditure: taming leviathan for the next millennium?', in P.Kriesler (ed.) The Australian Economy, $3^{\text {rd }}$ ed., Sydney: Allen and Unwin: 129-45.

'Productivity of Labour, Thrift and Economic Progress: Adam Smith's optimistic view of economic development', in G.F.Davanzati and V.Gioia (eds) Reflections on Economic Development from the Enlightenment to the Classical School, Lecce: Edizioni Milella: 17-26 (repr. in Groenewegen, 2002a).

'From Optimism in Progress to Pessimism: some major implications of Malthus's first Essay on Population (1798) for attitudes to growth and welfare in the nineteenth century', in G.F.Davanzati and V.Gioia (eds) Reflections on Economic Development from the Enlightenment to the Classical School, Lecce: Edizioni Milella: 27-37 (repr. in Groenewegen, 2002a).

'The Notion of the Subsistence Wage in Pre-Smithian Classical Political Economy: some reflections inspired by the surplus approach', in G.Mongiovi and F.Petri (eds) Value, Distribution and Capital: essays in honour of Pierangelo Garegnani, London: Routledge: 181203 (with T.Aspromourgos) (repr. in Groenewegen, 2002a).

'The Significance of Verri's Meditazioni in the History of Economic Thought: the wider European influences', in C.Capra (ed.) Pietro Verri e il suo tempo, vol. II, Milan: Cisalpino: 693-708.

'Reflections on the Centenary of John Bates Clark-The Distribution of Wealth', History of Economics Review, no. 30 (Summer): 82-8.

2000 (ed. \& trans.) Pierre le Pesant, Sieur de Boisguilbert, A Treatise on the Nature of Wealth, Money and Taxation in which the mistaken views which are fashionable in the world with regard to these three subjects are laid bare (1704), Reprints of Economic Classics, Series 2, No. 10 (Sydney: Centre for the Study of the History of Economic Thought, University of Sydney).

'Amy Howes', in R.W.Dimand, M.A.Dimand and E.L.Forget (eds) A Biographical Dictionary of Women Economists, Cheltenham UK: Elgar: 209-11.

'Clara Elizabeth Collet', in R.W.Dimand, M.A.Dimand and E.L.Forget (eds) A Biographical Dictionary of Women Economists, Cheltenham UK: Elgar: 109-15.

'Exemplary Economists of the Twentieth Century: a review article of 36 economists' autobiographies', History of Economics Review, no. 32 (Summer): 67-82 (repr. in Groenewegen, 2003 a).

'Helen Dendy Bosanquet', in R.W.Dimand, M.A.Dimand and E.L.Forget (eds) $A$ Biographical Dictionary of Women Economists, Cheltenham UK: Elgar: 60-5.

2001 (ed.) Physicians and Political Economy: six studies of the work of doctor-economists,

London: Routledge.

'Epilogue: two centuries of physician-economists, 1650-1848', in P.D.Groenewegen, op. cit.: 130-144.

'From Prominent Physician to Major Economist: some reflections on Quesnay's switch to economics in the 1750s', in P.D.Groenewegen, op. cit.: 93-115.

-'Introductory Remarks', in P.D.Groenewegen, op. cit.: 1-9.

'Joseph Clément Juglar (1819-1905): from physician to analyst of business cycles', in

P.D.Groenewegen, op. cit.: 116-29.

'Alfred Marshall 1842-1924', in C.Jessua, C.Labrousse and D.Vitry (eds) Dictionnaire des sciences économiques, Paris: Presses Universitaires de France: 551-5.

'German Political Economy, History, and the Law of Value: Marx and Engels contra Achille Loria', in H.D. Kurz and V. Gioia (eds) Science, Institutions and Economic Development, Milan: Giuffrè: 623-46 (repr. in Groenewegen, 2002a). 
'The Evolutionary Economics of Alfred Marshall: an overview', in J. Laurent and J. Nightingale (eds) Darwinism and Evolutionary Economics, Cheltenham UK: Elgar: 49-62 (repr. in Groenewegen, 2003a).

'Boisguilbert's Theory of Money, Circular Flow, Effective Demand and Distribution of Wealth', History of Economics Review, no. 33 (Winter): 33-43.

'The Place of Galiani's Della Moneta in the History of Economic Thought: a $250^{\text {th }}$ th anniversary assessment', History of Economic Ideas, 9 (3): 217-43.

'Thomas Carlyle, "the Dismal Science", and the Contemporary Political Economy of Slavery', History of Economics Review, no. 34 (Summer): 74-94.

2002 A Concise History of Economic Thought: from Mercantilism to Monetarism, London:

Palgrave; and in Italian as II Pensiero Economico - dai Fisiocrati ai Monetaristi, Roma: Carocci Editore (with G. Vaggi).

Eighteenth-Century Economics: Turgot, Beccaria and Smith and their contemporaries, London: Routledge.

'Die Bedeuting der "Philosophie Rurale" als ein Physiokratischer Text', in Vademecum zu einem Klassiker der Physiokratie, Dusseldorf: Verlag Wirtschaft und Finanzen: 21-47.

'R. C. Mills and Fiscal Federalism with Special Reference to the Methodology of the Grants Commission', History of Economics Review, no. 36 (Summer): 66-77.

2003 Classics and Moderns in Economics: essays on nineteenth and twentieth century economic thought, 2 vols., London: Routledge.

'Alfred Marshall on Homo Economicus: evolution versus utilitarianism', in J. Laurent (ed.) Evolutionary Economics and Human Nature, Cheltenham UK: Elgar: 114-33.

'Competition and Evolution: the Marshallian conciliation enterprise', in R.Arena and M.Quéré (eds) The Economics of Alfred Marshall, London: Palgrave: 113-33.

'Concorcet and Equality of the Sexes: one of the many fronts for a great fighter for liberty of the eighteenth century', in R.Dimand and C.Nyland (eds) The Status of Women in Classical Economic Thought, Cheltenham UK: Elgar: 127-41.

'Teaching the History of Economic Thought at the University of Sydney: some reflections', History of Economics Review, no. 37 (Winter): 109-25. 


\section{References}

Abbagnano, N. and Fornero, G. (1998) Dizionario di Filosofia, Torino: UTET.

Ahmad, S. (1990) 'Adam Smith's four invisible hands', History of Political Economy, 22: 137-44.

Ambirajan, S. (1977) 'Economics and economists in the formation of a monetary policy for India,

1873-1893', History of Political Economy, 9:122-43.

(1978) Classical Political Economy and British Policy in India, Cambridge: Cambridge University Press.

Andrews, P.W.S. (1951) 'Industrial analysis in economics: with special reference to Marshallian doctrine', in T.Wilson and P.W.S.Andrews (eds) (1954) Oxford Studies in the Price Mechanism, Oxford: Clarendon.

Arbuthnot, G. (1857) Sir Robert Peel's Act of 1844, Regulating the Issue of Bank Notes, Vindicated, London: Longman, Brown, Green, Longmans and Roberts.

Arena, R. and Quéré, M. (2003) The Economics of Alfred Marshall, Basingstoke: Palgrave.

Arestis, P., Palma, G. and Sawyer, M. (eds) (1997) Capital Controversy, Post-Keynesian Economics and the History of Economic Thought: essays in honour of Geoff Harcourt, vol I, London: Routledge.

Argyll, the Duchess Dowager (ed.) (1906) George Douglas, Eighth Duke of Argyll, Autobiography and Memoirs, London: J.Murray and Co..

Aristotle [1952] Nicomachean Ethics, in The Works of Aristotle (W.D.Ross trans.), vol. II, Chicago: Encyclopaedia Britannica (repr. 1994).

[1952] Politics, in The Works of Aristotle (B.Jowett trans.), vol II, Chicago: Encyclopaedia Britannica (repr. 1994).

Arndt, H.W. (1985) A Course Through Life: memoirs of an Australian economist, Canberra: Australian National University.

(2000) Essays in Biography: Australian economists, History of Economics Review (Supplement), no. 32.

Arrow, K.J. (1995) 'Viewpoint: the future', Science, 267:1617.

Ashley, W.J. (1895) 'Aristotle's doctrine of barter', Quarterly Journal of Economics, 9; as reprinted in Blaug, M. (ed.) (1991) Aristotle (384-322 BC) (Pioneers in Economics Series), Aldershot UK: Elgar.

Aspromourgos, T. (2003) 'Peter Groenewegen: a life (unfinished!) of scholarship', History of Economics Review, no. 37:1-18.

Bagehot, W. (1873) Lombard Street: a description of the money market, 14th ed., London: John Murray (1915).

Bain, A. (1882) John Stuart Mill, a Criticism: with personal recollections, London: John Murray. Barber, W.J. (1975) British Economic Thought on India 1600-1858, Oxford:

Clarendon.

Barens, I. and Caspari, V. (1997) 'Own-rates of interest and their relevance for the existence of underemployment equilibrium conditions', in G.C.Harcourt and P.A. Riach (eds) A 'Second Edition' of The General Theory, vol. 1, London: Routledge.

Bateman, B.W. (1991) 'Das Maynard Keynes problem', Cambridge Journal of Economics, 15:101-11.

(1996) Keynes's Uncertain Revolution, Ann Arbor: University of Michigan Press.

Baumol, W.J. (1977) 'Say's (At Least) Eight Laws, or What Say and James Mill May Really Have Meant', Economica, 44:145-62. 
(1999) 'Retrospectives: Say's Law', Journal of Economic Perspectives, 13:194-204; repr. in S.Kates (ed.) (2003) Two Hundred Years of Say's Law, Cheltenham UK: Elgar.

(2003) 'Say's Law and More Recent Macro Literature: Some Afterthoughts'; repr. in S.Kates (ed.) (2003) Two Hundred Years of Say's Law, Cheltenham UK: Elgar.

Bayle, P. (1704) Continuation des Pensées Diverses, etc., in P.Bayle (1737) Euvres Diverses, vol. 3; facsimile repr. Hildesheim: Verlag G.Olms (1964-68).

Becattini, G. (1981) 'Marx, Marshall e l'economia applicata. Ricordo di Antonio Pesenti', in VV.AA, La figura e l'opera di Antonio Pesenti, Bologna: Patron; reprinted in G.Becattini (2003) I nipoti di Cattaneo. Colloquie schermaglie fra economisti italiani, Roma: Donzelli.

(1991a) 'Market and communism in the thought of Alfred Marshall', Quaderni di Storia dell' Economia Politica, 9:161-88.

(1991b) 'Four meetings about Marshall: reports, impressions and reflections', Marshall Studies Bulletin, 1:5-20.

(2000) 'Anomalie Marshalliane', Rivista Italiana degli Economisti, 1:3-56; English trans. 'Marshallian anomalies', Marshall Studies Bulletin, 7, available online: http://www.cce.unifi.it/dse/marshall/welcome.htm.

(2001) 'Carlo Cattaneo in the history of Italian economic thought', II Pensiero Economico Italiano, 9:5-32.

Becker, G.S. and Baumol, W.J. (1952) The classical monetary theory: the outcome of the discussion', Economica; repr. in J.J.Spengler (ed.) (1960) Essays in Economic Thought: Aristotle to Marshall, Chicago: Rand McNally.

Bellofiore, R. (2001) 'Monetary analyses in Sraffa's writings: a comment on Panico', in T. Cozzi and R.Marchionatti (eds) Piero Sraffa's Political Economy: a centenary estimate, London: Routledge.

Bharadwaj, K. (1972) 'Marshall on Pigou's Wealth and Welfare', Economica, 39:32-46.

(1989) 'Ricardian theory and Ricardianism', in K.Bharadwaj, Themes in Value and Distribution: classical theory reappraised, London: Unwin Hyman.

Black, R.D.C. (1972) 'Jevons, Bentham and De Morgan', Economica, 39:119-34.

(ed.) (1973-81) Papers and Correspondence of William Stanley Jevons, 7 vols., London: Macmillan.

Blanqui, J.A. (1845) Histoire de l'Économie politique en Europe depuis les anciens jusqu'à nos jours, II, Paris: Guillaumin.

Blaug, M. (1958) Ricardian Economics, New Haven CT: Yale University Pre0ss.

(1964) Economic Theory in Retrospect, London: Heinemann.

(ed.) (1991) Aristotle (384-322 BC) (Pioneers in Economics Series), Aldershot UK: Elgar.

-(1996) [1st ed. 1962] Economic Theory in Retrospect, 5th ed., Cambridge: Cambridge University Press.

Blinder, A.S. (1998) Central Banking in Theory and Practice, Cambridge: MIT Press.

Booth, A. (1989) British Economic Policy, 1931-49. Was there a Keynesian revolution?, New York: Harvester Wheatsheaf.

Z Z (2001) 'Britain in the 1950s: a "Keynesian” managed economy?', History of Political Economy, 33:283-313.

Borio, C.E.V. (1997) 'The implementation of monetary policy in industrial countries: a survey', BIS Economic Papers, no. 47 (July).

Bortkiewicz, L.von (1890) [Review of Leon Walras, Elements d'Economie Politique Pure, ou Theorie de la Richesse Sociale, $2^{\text {nd }}$ edition], Revue d'Economie Politique, 4:80-86.

Boughton, J. and Sandilands, R.J. (forthcoming), 'Politics and the attack on FDR's economists: from the Grand Alliance to the Cold War', Intelligence and National Security.

Boulding, K. (1982) 'A second look at Progress and Poverty', in R.W.Lindholm and A. D.Lynn Jr (eds) (1982) Land Value Taxation. The 'Progress and Poverty' Centenary, Wisconsin: University of Wisconsin Press. 
Brewer, T. (1997) [Review of Groenewegen (1995)], Journal of the History of Economic Thought and Methodology, 15:265-75.

Bridel, P. (1987) Cambridge Monetary Thought: the development of saving-investment analysis from Marshall to Keynes, London: Macmillan.

- and Huck, E. (2002) 'Another look at Leon Walras's theory of tatonnement', European Journal of the History of Economic Thought, 9:513-41.

Brown, M. (1992) Adam Smith's Economics-Its Place in the Development of Economic Thought, London, Routledge.

Brusco, S. (1989) Piccole imprese e distretti industriali, Torino: Rosenberg \& Sellier.

Bryce, J.C. (ed.) (1983) Adam Smith. Lectures on Rhetoric and Belles Lettres, Oxford: Oxford University Press.

Burkett, P. (1986) 'Dillard on Keynes and Marx: comment', Journal of Post Keynesian Economics, 8:623-31.

Cairnes, J.E. (1874) Some Leading Principles of Political Economy, Newly Expounded, London: Macmillan.

Caldari, K. (2000) 'Marshall's bound collection of essays', Marshall Studies Bulletin, 7, available online: http://www.cce.unifi.it/dse/marshall/welcome.htm.

Caminati, M. (1981) 'The theory of interest in the classical economists', Metroeconomica, 33:79104.

Cannadine, D. (ed.) (1989) Blood, Toil, Tears and Sweat: the speeches of Winston Churchill, Boston: Houghton Mifflin.

Carabelli, A. (1988) On Keynes's Method, London: Macmillan.

Carlisle, J. (1991) John Stuart Mill and the Writing of Character, Athens GA: University of Georgia Press.

Cerroni, U. (1976) Introduzione alla Scienza Sociale, Roma: Editori Riuniti.

Cesaratto, S., Serrano, F. and Stirati, A. (2003) Technical change, effective demand and employment', Review of Political Economy, 15:33-52.

Chick, V. (1992) 'Inflation from a longer-run perspective', in V.Chick, On Money, Method and Keynes: selected essays, London: Macmillan (repr. from 1977).

Ciccone, R. (1986) 'Accumulation and capacity utilization: some critical considerations on Joan Robinson's theory of distribution', Political Economy: Studies in the Surplus Approach, 2:1736.

Clapham, J. (1930) An Economic History of Modern Britain: the early railway age, 1820-1850, Cambridge: Cambridge University Press.

Z (1932) An Economic History of Modern Britain: free trade and steel, 1850-1886,

Cambridge: Cambridge University Press.

Clarke, M.L. (1962) George Grote: a bibliography, London: Macmillan.

Clarke, P. (1994) 'Keynes in history', History of Political Economy, 26:117-135.

Clay, W.M. (1844) Remarks on the Expediency of Restricting the Issue of Promissory Notes to a Single Issuing Body, London: James Ridgway.

Coase, R.H. (1961) 'The British Post Office and the messenger companies', Journal of Law and Economics, 4:12-65.

Colander, D. (2000) 'The death of neoclassical economics', Journal of the History of Economic Thought, 22:127-43.

Coleman, W. (2000) 'A Treatise on the Nature of Wealth, Money and Taxation', History of Economics Review, no. 32:106-7.

Collini, S., Winch, P. and Burrow, J. (1983) That Noble Science of Politics: a study in nineteenthcentury intellectual history, Cambridge: Cambridge University Press.

Collison Black, R.D. (1976) 'Smith's contribution in historical perspective', in T. Wilson and A.Skinner (eds) The Market and the State, Oxford: Oxford University Press.

Coquelin, C. (1854) Dictionaire de l'économie politique, Brussels: Meline, Cans and Compagnie. 
Cortney, P. (1960) 'The philosophy of Lord Keynes', in H.Hazlitt (ed.) The Critics of Keynesian Economics, Princeton NJ: Van Nostrand; reprinted from the Commercial and Financial Chronicle, New York, 8 and 15 February 1945.

Creedy, J. (1986) Edgeworth and the Development of Neoclassical Economics, Oxford: Blackwell. - (1992) Demand and Exchange in Economic Analysis: history from Cournot to Marshall, Aldershot UK: Elgar. Dardi, M. (1984) II Giovane Marshall: accumulazione e mercato, Bologna: II Mulino.

(2003) 'Partial equilibrium analysis: dynamics in disguise', in R.Arena and M. Quéré, The Economics of Alfred Marshall, Basingstoke UK: Palgrave.

Gallegati, M. and Pesciarelli, E. (eds) (1991-1992) Alfred Marshall's Principles of Economics 1890-1990, 2 vols., special issue of Quaderni di storia dell'economia politica, vols. 9-10.

Darity, W.D. (1994) 'Who owns John Maynard Keynes?', History of Political Economy, 26:15564.

Davis, R. (1990) 'Adam Smith on the providential reconciliation of individual and social interests: is man led by an invisible band or misled by a sleight of band?', History of Political Economy, 22:341-52.

De Cecco, M. (1979) Moneta e impero. II sistema finanziario internazionale dal 1890 al 1914, Torino: Einaudi.

De Morgan, A. (1842a) 'Elementary illustrations of the differential and integral calculus', in A.De Morgan, The Differential and Integral Calculus containing... Elementary Illustrations of the Differential and Integral Calculus, London: Baldwin and Cradock. (1842b) 'The differential and integral calculus', in A.De Morgan, The Differential and Integral Calculus containing... Elementary Illustrations of the Differential and Integral Calculus, London: Baldwin and Cradock.

De Vivo, G. (1984) Ricardo and His Critics: a study of classical theories of value and distribution, Studi e ricerche dell'Instituto Economico, no. 23, Universita Studi di Modena.

Deane, P. (2001) The Life and Times of J.Neville Keynes: a beacon in the tempest, Cheltenham UK: Elgar.

DeLong, J.B. (2000) 'Review of Robert Skidelsky, John Maynard Keynes: fighting for Britain, 1937-1946', available online: http://www.j-bradforddelong.net/Econ_Articles/Reviews/skidelsky3.html.

(2002) 'Review of Skidelsky's John Maynard Keynes: fighting for Britain', Journal of Economic Literature, 40:155-62.

Dillard, D. (1942a) 'Keynes and Proudhon', Journal of Economic History, 2:63-76.

(1942b) 'Silvio Gesell's monetary theory of social reform', American Economic Review, 32:348-52.

(1948) The Economics of John Maynard Keynes: the theory of a monetary economy, London: Crosby Lockwood \& Son.

(1984) 'Keynes and Marx: a centennial appraisal', Journal of Post Keynesian Economics, 6:421-32.

Dobb, M. (1973) Theories of Value and Distribution since Adam Smith: ideology and economic theory, Cambridge: Cambridge University Press.

Dollery, B. (2002) 'A conversation with Peter Groenewegen', History of Economics Review, no. $36: 126-59$.

Dome, T. (1994) History of Economic Theory: a critical introduction, Aldershot UK: Elgar.

Donoghue, M. (1998) 'John Elliot Cairnes and the "rehabilitation" of the classical wage fund doctrine', The Manchester School, 66:396-417.

(1999) 'William Thomas Thornton on trade union efficacy: a fraction too much friction', Review of Political Economy, 11:205-19.

- (2000) 'Some unpublished correspondence of William Thomas Thornton, 1866-1872', European Journal of the History of Economic Thought, 7:321-49. 
(2002) 'The economic writings of William Thomas Thornton: a review article', Review of Political Economy, 14:259-67.

Dow, S. and Dow, A. (1985) 'Animal spirits and rationality', in T. Lawson and H. Pesaran (eds) Keynes' Economics, London: Croom Helm.

Dubois de l'Estang, E. (1892) 'Jean-Baptiste Say', in Nouveau dictionaire d'économie politique, Paris: Guillaumin.

Dühring, I. (1966) Aristoteles (Italian trans.), Milano: Mursia (repr. 1976).

Earl, P.E. (1995) Microeconomics for Business and Marketing, Cheltenham UK: Elgar.

Eatwell, J. (1994) 'Citizen Keynes', The American Prospect, 5 (December). Milgate, M. and Newman, P. (eds) (1987) The New Palgrave: a dictionary of economics, 4 vols., London: Macmillan.

Edgeworth, F.Y. (1889) 'The mathematical theory of political economy', Nature, 40: 434-6.

(1891) 'La theorie mathematique de l'offre et de la demande et le cout de production', Revue d'Economie Politique, 5:10-28.

Ekelund, R.B. and Thommesen, S. (1989) 'Disequilibrium theory and Thornton's assault on the laws of supply and demand', History of Political Economy, 21:567-92.

Elliot, H.S.R. (1910) The Letters of John Stuart Mill, 2vols., London: Longmans Green and Co.

Elliott, J. E. (1990) 'Alfred Marshall on socialism', Review of Social Economy, 47:450-76.

Ellis, H.S. (1934) German Monetary Theory, 1905-1933, Cambridge MA: Harvard University Press.

Eshag, E. (1963) From Marshall to Keynes: an essay on the monetary theory of the Cambridge school, Oxford: Blackwell.

Evensky, J. (1989) 'The evolution of Adam Smith's views on political economy', History of Political Economy, 21:123-45.

Everett, E.M. (1939) The Party of Humanity: The Fortnightly Review and its contributors, 18651874, Chapel Hill NC: University of North Carolina Press.

Fawcett, H. (1883) Manual of Political Economy, London: Macmillan.

Fay, C.R. (1960) 'Reminiscences of a deputy librarian', as reprinted in J.C. Wood (ed.) Alfred Marshall: critical assessments, vol. 1, London: Croom Helm (1982).

Fellner, W. (1960) Emergence and Content of Modern Economic Analysis, New York: McGrawHill.

Fetter, F.W. (1965a) Development of British Monetary Orthodoxy 1797-1875, New Jersey: Kelley (1978).

(1965b) 'The relation of the history of economic thought to economic history', American Economic Review, 55:136-43.

(1969) 'The rise and decline of Ricardian Economics', History of Political Economy, 1:67-85.

Field, D.D. and George, H. [1885] (1936) Land and Taxation. A Conversation between David Dudley Field and Henry George, London: United Committee for Taxation of Land Values (first published North American Review, July 1885); repr. in M.Hassed (ed.) (2000) The Prosperity Paradox: the economic wisdom of Henry George-rediscovered, Canterbury (Australia): Chatsworth.

Finley, M.I. (1970) 'Aristotle and economic analysis', Past and Present, 47:3-25.

Fiori, S. (1992) 'Persuasione e mercato. Note su un problema lasciato aperto a Adam Smith', Trimestre, 5:41-53.

Fishburn, G. (1996) 'Natura non facit saltum', Paper presented to the 9th History of Economic Thought Society of Australia Conference, University of New South Wales, Sydney.

Fisher, F.M. (1987) 'Adjustment processes and stability', in J.Eatwell, M.Milgate and P. Newman (eds), The New Palgrave: a dictionary of economics, vol. 1, London: Macmillan.

Fitzgibbons, A. (1988) Keynes's Vision: a new political economy, Oxford: Clarendon Press.

-(1995) Adam Smith's System of Liberty, Wealth and Power: the moral and political foundations of the wealth of nations, Oxford: Clarendon Press.

(2000) The Nature of Macroeconomics, Cheltenham: Elgar. 
Fletcher, G.A. (1987) The Keynesian Revolution and Its Critics: issues of theory and policy for the monetary production economy, London: Macmillan.

Forget, E.L. (1999) The Social Economics of Jean-Baptiste Say, London: Routledge.

(2003) 'Jean-Baptiste Say and the law of markets: entrepreneurial decision-making in the real world', in S.Kates (ed.) Two Hundred Years of Say's Law, Cheltenham UK: Elgar.

Foster, J. and Metcalfe, J.S. (eds) (2001) Frontiers of Evolutionary Economics, Cheltenham UK: Elgar.

Friedman, M. (1949) 'The Marshallian demand curve', Journal of Political Economy, 57: 463-95.

(1970) 'The new monetarism: comment', Lloyds Bank Review, 10:52-3.

Fry, G.K. (1976) 'The Marshallian School and the role of the state', (Yorkshire) Bulletin of Economic Research, 28:23-35.

Fullarton, J. (1845) On the Regulation of Currencies; being an examination of the principles on which it is proposed to restrict, within certain fixed limits, the future issue on credit of the Bank of England, and of the other banking establishments throughout the country, 2nd ed., New York: Kelley (1969).

Fusfeld, D. (1990) 'The single price theorem', Research in the History of Economic Thought and Methodology, 7:37-62.

Galbraith, J.K. (1987) A History of Economics, London: Hamish Hamilton.

Garegnani, P. (1977-78) 'Notes on consumption, investment and effective demand', Cambridge Journal of Economics, 2:335-53 and 3:63-82; as repr. in J. Eatwell and M. Milgate (eds) (1983) Keynes's Economics and the Theory of Value and Distribution, London: Duckworth. (1990) 'Quantity of capital', in J.Eatwell, M.Milgate and P.Newman (eds) The New Palgrave: capital theory, London: Macmillan.

George, H. [1879] (1956) Progress and Poverty, New York: Robert Schalkenbach Foundation.

- [1881] (1953a) The Land Question, New York: Robert Schalkenbach Foundation (original title, The Irish Land Question).

[1884] (1932) Social Problems, London: Henry George Foundation of Great Britain. [1885] (1938) The Crime of Poverty, London: Henry George Foundation; repr. in M. Hassed (ed.) (2000) The Prosperity Paradox: the economic wisdom of Henry George-rediscovered, Canterbury (Australia): Chatsworth.

[1889] (1936) Thy Kingdom Come (address delivered in Glasgow, 28 April 1889), London: United Committee for Taxation of Land Values; repr. in M.Hassed (ed.) (2000) The Prosperity Paradox: the economic wisdom of Henry George - rediscovered, Canterbury (Australia): Chatsworth. [1890] (1947) Justice the Object-Taxation the Means (address delivered in San Francisco, 4 February 1890), Melbourne; repr. in M.Hassed, (ed.) (2000) The Prosperity Paradox: the economic wisdom of Henry George-rediscovered, Canterbury (Australia): Chatsworth.

[1891] (1953b) The Condition of Labor. An Open Letter to Pope Leo XIII, New York: Robert Schalkenbach Foundation.

- [1892] (1937) A Perplexed Philosopher, London: Henry George Foundation of Great Britain.

Georgescu-Roegen, N. (1968) 'Utility', in International Encyclopedia of Social Sciences, London: Macmillan.

Gerrard, B. (1995) 'Probability, uncertainty and behaviour: a Keynesian perspective', in S.Dow and J.Hillard (eds) Keynes, Knowledge and Uncertainty, Aldershot UK: Elgar. (1997) 'Method and methodology in Keynes's General Theory', in G.C.Harcourt and P.A.Riach (eds) A 'Second Edition' of The General Theory, vol. 2, London: Routledge.

Gerschlager, C. (2003) 'Beyond economic man: Adam Smith's concept of the agent and the role of deception', paper presented to the European Society for the History of Economic Thought Conference, Paris.

Gilbart, J.W. (1841) Currency and Banking: a review of some of the principles and plans that have recently engaged public attention, with reference to the administration of the currency, London: Hooper. 
(1849) A Practical Treatise on Banking 5th ed., 2 vols., London: Longmans, Brown, Green and Longman.

Gilbert, J.C. (1982) Keynes's Impact on Monetary Economics, London: Butterworth.

Gilbert, M. (1991) Churchill: a life, London: Heinemann.

Girton, L. and Roper, D. (1978) 'J.Laurence Laughlin and the quantity theory of money', Journal of Political Economy, 86:599-625.

Goodhart, C.A.E. (1989a) 'Conduct of monetary policy', Economic Journal, 99: 293-346. (1989b) 'Monetary base', in J.Eatwell, M.Milgate and P.Newman (eds) The New Palgrave: money, London: Macmillan.

Goodwin, R.M. (1970) Elementary Economics from the Higher Standpoint, Cambridge: Cambridge University Press.

Gordon, B.J. (1964) 'Aristotle and the development of value theory', Quarterly Journal of Economics, 78:115-28.

(1965) 'Say's Law, effective demand and the contemporary British periodicals, 1820-1850', Economica, 32:438-46.

Gorz, A. (1982) Farewell to the Working Class: an essay on post-industrial socialism; trans. M.Sonenscher (from Adieux au Proletariat, 1980, Paris: Editions Galilée), Boston: Pluto.

Gotti, M. (1994) “The General Theory” as an open-ended work', in A.Marzola and F. Silva (eds) John Maynard Keynes: language and method, Aldershot UK: Elgar.

Gramm, W.S. (1980) 'The selective interpretation of Adam Smith', Journal of Economic Issues, 4:119-42.

Gramsci, A. (1975) Quaderni del Carcere, 4 vols., ed. V.Gerratana, Torino: Einaudi.

Grattan-Guinness, I. (1990a) Convolutions in French Mathematics 1800-1840, vol. 2, Berlin: Birkhauser Verlag.

_ (1990b) 'The varieties of mechanics by 1800', Historia Mathematica, 17:313-38. (2002) 'In some parts rather rough: a recently discovered manuscript version of William Stanley Jevons's "General Mathematical Theory of Political Economy", History of Political Economy, 34:685-726.

Graves, R. and Hodge, A. (1947) The Reader over Your Shoulder: a handbook for writers of English prose, London: Jonathan Cape.

Groenewegen, P D. (1971) 'A re-interpretation of Turgot's theory of capital and interest', Economic Journal, 81:327-41; reprinted in P.Groenewegen (2002a) Eighteenth-Century Economics: Turgot, Beccaria and Smith and their contemporaries, London: Routledge. (1977a) 'Adam Smith and the division of labour: a bicentenary estimate', Australian Economic Papers, 16:161-74.

(ed. \& trans.) (1977b) The Economics of A.R.J.Turgot, Den Haag: Nijhoff.

(1979a) Public Finance in Australia: theory and practice, Sydney: Prentice Hall (2nd ed. 1984, 3rd ed. 1990).

(1979b) 'Radical economics in Australia: a survey of the 1970s', in F.H.Gruen (ed.) Surveys of Australian Economics, vol. 2, Sydney, Allan \& Unwin.

(1979c) 'Progress and Poverty in Historical Perspective', in Papers Presented in

Commemoration of the Centenary of Publication of 'Progress and Poverty' by Henry George, Redfern (NSW): Australian School of Social Science.

(1982a) 'History and Political Economy: Smith, Marx and Marshall', Australian Economic Papers, 21:1-17; reprinted in P.Groenewegen (2003a) Classics and Moderns in Economics: essays on nineteenth and twentieth century economic thought, 2 vols., London: Routledge. (1982b) 'History of economic thought in the Faculty of Economics at Sydney University', HETSA Newsletter, no. 3:2-11.

(1983) 'Joan Violet Robinson (1903-1983)', Australian Left Review, no. 86:62-3; reprinted in P.Groenewegen (2003a) Classics and Moderns in Economics: essays on nineteenth and twentieth century economic thought, 2 vols., London: Routledge. 
(1984) 'The Physiocrats: the origins of scientific political economy and the single tax' (First Henry George Memorial Lecture), Sydney: Macquarie University; reprinted in P.Groenewegen (2002a) Eighteenth-Century Economics: Turgot, Beccaria and Smith and their contemporaries, London: Routledge.

(1986) 'In defence of Post Keynesian economics', 1986 Newcastle Lecture in Political Economy, University of Newcastle Occasional Papers, No. 131, October.

(1988) 'Alfred Marshall and Australian economics', HETSA Bulletin, 9:1-15.

(ed.) (1990) Alfred Marshall, On History and Method of Economics (circa 1870), Reprints of Economic Classics, Series 2, No. 5 (Sydney: Centre for the Study of the History of Economic Thought, University of Sydney).

(1991) 'Alfred Marshall and the History of Economic Thought', Quaderni di Storia dell' Economia Politica, 9:59-88; reprinted in P.Groenewegen (2003a) Classics and Moderns in Economics: essays on nineteenth and twentieth century economic thought, 2 vols., London: Routledge.

(1993a) 'A weird and wonderful partnership: Mary Paley and Alfred Marshall, 1877-1924', History of Economic Ideas, 1:71-101.

(1993b) 'Marshall on Ricardo', in M.Baranzini and G.C.Harcourt (eds) The Dynamics of the Wealth of Nations: growth, distribution and structural change, Essays in Honour of Luigi Pasinetti, London: Macmillan; reprinted in P.Groenewegen (2003a) Classics and Moderns in Economics: essays on nineteenth and twentieth century economic thought, 2 vols., London: Routledge.

(1994) 'Jacob Viner and the history of economic thought', Contributions to Political Economy, 13:69-86; reprinted in P.Groenewegen (2003a) Classics and Moderns in Economics: essays on nineteenth and twentieth century economic thought, 2 vols., London: Routledge. (1995) A Soaring Eagle: Alfred Marshall 1842-1924, Aldershot UK: Elgar.

(1995a) 'Post Keynesian economics: a memorial?', History of Economics Review, no. 24:1379.

(ed.) (1996) Official Papers of Alfred Marshall. A Supplement, Cambridge: Cambridge University Press.

(1997) 'Economics does have a useful past and yes, history is important', in A. Heertje (ed.) The Makers of Modern Economics, vol. III, Cheltenham UK, Elgar.

(2001) 'The evolutionary economics of Alfred Marshall: an overview', in J.Laurent and J.Nightingale (eds) Darwinism and Evolutionary Economics, Cheltenham UK: Elgar.

(2002a) Eighteenth-Century Economics: Turgot, Beccaria and Smith and their contemporaries, London: Routledge.

(2002b) 'Prelude', in P.D.Groenewegen, Eighteenth-Century Economics: Turgot, Beccaria and Smith and their contemporaries, London: Routledge.

- (2003a) Classics and Moderns in Economics: essays on nineteenth and twentieth century economic thought, 2 vols., London: Routledge.

- (2003b) 'Introduction', in P.D.Groenewegen, Classics and Moderns in Economics: essays on nineteenth and twentieth century economic thought, vol. 1, London: Routledge. (2003c) 'Introduction', in P.D.Groenewegen, Classics and Moderns in Economics: essays on nineteenth and twentieth century economic thought, vol. 2, London: Routledge. (2003d) 'Teaching the history of economic thought at the University of Sydney: some reflections', History of Economics Review, no. 37:109-25. -and McFarlane, B. (1990) A History of Australian Economic Thought, London: Routledge.

Guillebaud, C.W. (1942) 'The Evolution of Marshall's Principles of Economics', Economic Journal, 52:330-49.

(ed.) (1961) Marshall's Principles of Economics, variorum edition, vol. II, London: Macmillan. 
Guthrie, W.K.C. (1981) A History of Greek Philosophy, vol. VI (Aristotle. An Encounter), Cambridge: Cambridge University Press (repr. 1990).

Hammond, P.J. (1991) Consequentialist Decision Theory and Utilitarian Ethics, mimeo, Siena, July.

Hahn, F.H. (1991) 'The Next Hundred Years', Economic Journal, 98:47-50.

Harcourt, G.C. (1972) Some Cambridge Controversies in the Theory of Capital, Cambridge: Cambridge University Press.

(1991) 'Marshall's Principles at Cambridge as seen through the eyes of Gerald Shove, Dennis Robertson and Joan Robinson', Quaderni di Storia dell'Economia Politica, 9:335-72.

Harrod, R.F. (1951) The Life of John Maynard Keynes, London: Macmillan.

Harsanyi, J.C. (1987) 'Value judgements' in J.Eatwell, M.Milgate and P.Newman (eds) The New Palgrave: a dictionary of economics, vol. 4, London: Macmillan.

Hart, N. (1995) 'Marshall's theory of value: the role of external economies', Cambridge Journal of Economics, 20:353-69.

(2003) 'From the representative to the equilibrium firm: why Marshall was not a Marshallian', in R.Arena and M.Quéré (eds) The Economics of Alfred Marshall: revisiting Marshall's legacy, London: Palgrave.

Hatch, J. and Petridis, R. (1997) 'A Cambridge economist BUT an Australian patriot', in P.Arestis, G.Palma and M.Sawyer (eds) (1997) Capital Controversy, Post-Keynesian Economics and the History of Economic Thought: essays in honour of Geoff Harcourt, vol. I, London: Routledge.

Hayek, F.A.von (1931) 'Reflections on the pure theory of money of Mr. J.M.Keynes', Economica, 11:270-95.

Hearn, W.E. (1864) Plutology, Melbourne: George Robertson.

Heertje, A. (1971) 'De Wet van Say', in Schaarste en Welvaart. Opstellen aangeboden aan Prof. dr. P.Hennipman, Leiden: H.E.Stenfert Kroese.

Heilbroner, R.L. (1982) 'The socialization of the individual in Adam Smith', History of Political Economy, 14:427-39.

Henderson, W. (2002) 'Review essay [on Groenewegen (2002a)]', Journal of the History of Economic Thought, 24:491-6.

Hicks, J.R. (1937) 'Mr Keynes and the "Classics”; a suggested interpretation', Econometrica, 5:147-59.

(1989) A Market Theory of Money, Oxford: Clarendon.

Hilton, B. (1977) Corn, Cash, Commerce: the economic policies of the Tory government, 1815-30, Oxford: Oxford University Press.

Hodgson, G.M. (1999) Evolution and Institutions: on evolutionary economics and the evolution of economics, Cheltenham UK: Elgar.

(2001) How Economics Forgot History, London: Routledge.

Hogan, W. et al., (1994) 'In memoriam: Barry Lewis John Gordon', History of Economics Review, no. 21:1-9.

Hollander, S. (1973) The Economics of Adam Smith, London: Heinemann.

Hoover, K.D. (1997) 'Is there a place for rational expectations in Keynes's General Theory?', in G.C.Harcourt and P.A.Riach (eds) A 'Second Edition' of The General Theory, vol. 1, London: Routledge.

Howson, S. (1988a) 'Cheap money and debt management in Britain, 1932-51', in P.L. Cottrell and D.E.Moggridge (eds) Money and Power: essays in honour of L.S.Pressnell, London: Macmillan. (1988b) 'Monetary policy and the Labour government in the 1940s', in O.F. Hamouda and J.N.Smithin (eds) Keynes and Public Policy After Fifty Years, vol. 1, Aldershot, UK: Elgar. (1993) British Monetary Policy 1945-51, Oxford: Clarendon. -and Moggridge, D.E. (eds) (1990) The Collected Papers of James Meade, vol. 4 (The Cabinet Office Diary 1944-46), London: Unwin Hyman. 
Hutchinson, D.S. (1995) 'Ethics', in J.Barnes (ed.) The Cambridge Companion to Aristotle, Cambridge: Cambridge University Press (repr. 1999).

Jaffé, W. (ed.) (1965) Correspondence of Léon Walras and Related Papers, 4 vols, Amsterdam: North Holland.

Jenkin, H.C.F. (1870) 'The graphic representation of the laws of supply and demand, and their application to labour', Recess Studies, Edinburgh: Edmonton and Douglas.

Jevons, W.S. (1863) 'Balance', in H.Watts (ed.) A Dictionary of Chemistry and the Allied Branches of Other Sciences, vol. I, London: Longman, Green, Longman, Roberts \& Green.

(1865) 'The variations of prices and the value of the currency since 1782', Journal of the Royal Statistical Society, 28:294-320; as repr. in H.S.Foxwell (ed.) (1884) Investigations in Currency and Finance, London: Macmillan.

(1866) [1862] 'Brief account of a general mathematical theory of political economy', Journal of the Statistical Society, 29:282-7.

(1871) The Theory of Political Economy, London: Macmillan.

(1878) Political Economy, London: Macmillan.

(1905) The Principles of Economics: fragment of a treatise on the industrial mechanism of society and other papers, ed. H.Higgs, London: Macmillan.

(1911) The Theory of Political Economy, 4th ed., ed. H.S.Jevons, London: Macmillan.

(1970) The Theory of Political Economy, ed. R.D.C.Black, Harmondsworth UK: Pelican.

Jha, N. (1973) The Age of Marshall: aspects of British economic thought 1890-1915, London: Cass.

Johnson, A. (1856) Currency Principles versus Banking Principles; being strictures on Mr. Tooke's pamphlet on the Bank Charter Act of 1844, London: Richardson Brothers.

Johnson, E. (1977) 'Keynes as a literary craftsman', in D.Patinkin and J.C.Leith (eds) Keynes,

Cambridge and the General Theory, London: Macmillan.

Jones, E. and Stilwell, F. (1986) 'Political economy at the University of Sydney', in B. Martin, C.M.Ann Baker, C.Manwell and C.Pugh (eds) Intellectual Suppression, London: Angus \& Robertson.

Joplin, T. (1823) Outlines of a System of Political Economy, London: Baldwin, Craddock and Joy.

Kadish, A. (1983) The Oxford Economists in the Late Nineteenth Century, Oxford: Oxford University Press.

Kahn, R.F. (1985) The Making of Keynes' General Theory, Cambridge: Cambridge University Press.

Kaldor, N. (1970) 'The new monetarism', Lloyds Bank Review, 10:1-18.

(1972) 'The irrelevance of equilibrium economics', Economic Journal, 82:237-55.

(1982a) 'Keynes as an economic adviser', in A.P.Thirlwall (ed.) Keynes as a Policy Adviser,

London: Macmillan.

(1982b) The Scourge of Monetarism, London: Oxford University Press.

(1985) Economics Without Equilibrium, New York: Sharpe.

Kant, I. (1787) Kritik der Praktischen Vernunft (Italian trans.), Brescia: La Scuola (repr. 1962).

Kates, S. (1998) Say's Law and the Keynesian Revolution, Cheltenham UK: Elgar.

(ed.) (2003) Two Hundred Years of Say's Law, Cheltenham UK: Elgar.

Kern, W.S. (2001) 'Classical economic man: was he interested in keeping up with the Joneses?', Journal of the History of Economic Thought, 23:353-68.

Keynes, J.M. (1924) 'Alfred Marshall: 1842-1924', in A.C.Pigou (ed.) (1925) Memorials of Alfred Marshall, London: Macmillan.

(ed.) (1926) Official Papers by Alfred Marshall, London: Macmillan. (1930) A Treatise of Money, 2 vols., London: Macmillan.

(1936) The General Theory of Employment, Interest and Money, London: Macmillan; repr. in

Keynes (1971-89), vol. VII.

(1937) 'Alternative theories of the rate of interest', Economic Journal, 47:241-52.

(1944) 'Mary Paley Marshall (1850-1944)', Economic Journal, 54:268-84. 
(1971-89) The Collected Writings of John Maynard Keynes, 30 vols., London: Macmillan.

Khrishnaswami, A. (1942) 'Marshall's contributions to Indian economics', Indian Journal of Economics, 22:875-97.

King, J.E. (1988) 'Henry George (1839-1897)', in J.E.King, Economic Exiles, London: Macmillan.

-(1997) 'Notes on the history of Post-Keynesian economics in Australia', in P. Arestis, G.Palma and M.Sawyer (eds) Capital Controversy, Post-Keynesian Economics and the History of Economic Thought: essays in honour of Geoff Harcourt, vol. I, London: Routledge.

King, W.T.C. (1936) History of the Discount Market, with an Introduction by T.E. Gregory, London: George Routledge and Sons.

Kinzer, B.L. (2001) England's Disgrace? J.S.Mill and the Irish Question, Toronto: University of Toronto Press.

Knight, F. (1921) Risk, Uncertainty and Profit, as repr. New York: Harper \& Row (1965).

Konekamp, R. (1982) 'The work of Harriet Ann Jevons (1838-1910) after her husband's death', Manchester School, 50:379-411.

Kuenne, R.E. (1963) The Theory of General Equilibrium, New Jersey: Prentice Hall.

Kurz, H.D. (1985) 'Effective demand in a "classical" model of value and distribution: the multiplier in a Sraffian framework', Manchester School, 53:121-37.

(2000) 'The Hayek-Keynes-Sraffa controversy reconsidered', in H.D.Kurz (ed.) Critical Essays on Piero Sraffa's Legacy in Economics, Cambridge: Cambridge University Press. -and Salvadori, N. (1995) Theory of Production: a long-period analysis, Cambridge: Cambridge University Press.

Laidler, D. (1991) The Golden Age of the Quantity Theory, Princeton NJ: Princeton University Press.

(2002) 'Skidelsky’s Keynes: a review essay', European Journal of the History of Economic Thought, 9:97-110.

Lambert, P. (1963a) L'oeuvre de John Maynard Keynes, Den Haag: Nijhoff.

(1963b) 'The social philosophy of John Maynard Keynes', Annals of Collective Economy, 34:483-515.

Langholm, O. (1979) Price and Value in the Aristotelian Tradition: a study in scholastic economic sources, Bergen-Oslo-Tromiso: Universitetsforlaget.

Laughlin, J.L. (1903) The Principles of Money, London: John Murray.

Laurent, J. (2001) 'Darwin, economics and contemporary economists', in J.Laurent and J.Nightingale (eds) Darwinism and Evolutionary Economics, Cheltenham UK: Elgar.

Lawrence, J.S. (1960) 'Lord Keynes and the financial community', in H.Hazlitt (ed.) The Critics of Keynesian Economics, Princeton NJ: Van Nostrand.

Lee, F.S. and Earl, P.E. (eds) (1993) Selected Essays of P.W.S.Andrews, Aldershot UK: Elgar.

Letiche, J.M. (1971) 'Soviet views on Keynes: a review article surveying the literature [with an appendix by P.Erdös]', Journal of Economic Literature, 9:442-58.

Levy, D.M. (1995) 'The partial spectator in the Wealth of Nations: a robust utilitarianism', European Journal of the History of Economic Thought, 2:299-326.

Lewis, T.J. (1978) 'Acquisition and anxiety: Aristotle's case against the market', Canadian Journal of Economics, 11:69-90.

Lindholm, R.W. and Lynn Jr, A.D. (1982) Land Value Taxation: the 'Progress and Poverty' Centenary, Wisconsin: University of Wisconsin Press.

Lipkes, J. (1999) Politics, Religion and Classical Political Economy in Britain: John Stuart Mill and his followers, London: Macmillan.

Loasby, B.J. (1989) The Mind and Method of the Economist: a critical appraisal of major economists in the 20th century, Aldershot UK: Elgar. (1990) 'Firms, markets, and the principle of continuity', in J. Whitaker (ed.) Centenary Essays on Alfred Marshall, Cambridge: Cambridge University Press.

(1991) Equilibrium and Evolution, Manchester: Manchester University Press.

(1996) 'The division of labour', History of Economic Ideas, 4:299-323. 
(1999) Knowledge, Institutions and Evolution in Economics, London: Routledge.

Lodewijks, J. (2002) 'The history of economic thought in Australia and New Zealand', in E.R.Weintraub (ed.) The Future of the History of Economics, Durham NC: Duke University Press.

Lowry, S.T. (1969) 'Aristotle's mathematical analysis of exchange', History of Political Economy, 1:44-66; as repr. in Blaug, M. (ed.) (1991) Aristotle (384-322 BC) (Pioneers in Economics Series), Aldershot UK: Elgar.

(1987) The Archaeology of Economic Ideas: the classical Greek tradition, Durham NC: Duke University Press.

Maas, H. (2001) 'Mechanical Reasoning: William Stanley Jevons and the making of modern economics', $\mathrm{PhD}$ thesis, University of Amsterdam.

McCulloch, J. R. (1825) The Principles of Political Economy, Edinburgh: Williams and Charles Tait.

(1845) The Literature of Political Economy, London: Longman, Brown, Green and Longmans. Macfie, A.L. (1967) The Individual in Society: papers on Adam Smith, London: Allen and Unwin. McWilliams-Tullberg, R. (1975) 'Marshall's “tendency to socialism'”, History of Political Economy, 7:75-111.

_-(ed.) (1990) Alfred Marshall in Retrospect, Aldershot UK: Elgar.

Magnus, P. (1875) Lessons in Elementary Mechanics, London: Longmans.

Maine H.S. (1880) The Early History of Institutions, 3rd ed., London: John Murray. (1881) Village Communities in the East and West, 4th ed., London: John Murray. (1905) Ancient Law, 10th ed., London: John Murray.

Maitland, F.W. (1906) The Life and Letters of Leslie Stephen, London: Duckworth.

Maloney, J. (1985) Marshall, Orthodoxy and Professionalisation of Economics, Cambridge: Cambridge University Press.

Malthus, T.R. (1820) Principles of Political Economy, London: John Murray.

- (1823) 'Tooke - on high and low prices', The Quarterly Review, 29 (April \& July): 214-39; as repr. in C.Renwick (ed.) (1953) Five Papers on Political Economy (Series of Reprints of Works on Economics and Economic History, no. 3), Sydney: Faculty of Economics, University of Sydney.

Mandeville, B. (1705) The Grumbling Hive (or The Fable of the Bees: or, Private Vices Publick Benefits); in F.B.Kaye (ed.) The Fable of the Bees, Oxford: Clarendon (repr. 1924).

Marchionatti, R. (2001) 'Sraffa and the criticism of Marshall', in T.Cozzi and R. Marchionatti (eds) Piero Sraffa's Legacy in Economics: a centenary estimate, London: Routledge.

Marshall, A. (1879) The Pure Theory of Domestic Values, repr. in J.K.Whitaker (ed.) (1975) The Early Writings of Alfred Marshall, vol. 2, London: Macmillan.

(1885a) 'How far do remediable causes influence prejudicially (a) the continuity of employment (b) the rate of wages?', in C.Dilke (ed.) Industrial Remuneration Conference: the report of the Proceedings and Papers, London: Cassell; repr. with an Introduction by J.Saville (1968), New York: Kelley.

(1885b) 'The present position of economics', repr. in A.C.Pigou (ed.) (1925), Memorials of Alfred Marshall, London: Macmillan.

(1898a) 'Distribution and exchange', Economic Journal, 8:37-59.

(1898b) 'Mechanical and biological analogies in economics', in A.C.Pigou (ed.) (1925)

Memorials of Alfred Marshall, London: Macmillan.

(1919) Industry and Trade, 2nd ed., London: Macmillan.

(1920a) Industry and Trade, 3rd ed., London: Macmillan.

(1920b) Principles of Economics: an introductory volume, 8th ed., London: Macmillan.

(1923) Money, Credit and Commerce, London: Macmillan; repr. New Jersey: Kelley (1991).

(1926) Official Papers, ed. J.M.Keynes, London: Macmillan.

(1961) Principles of Economics, 2 vols., 9th (variorum) ed., ed. C.W.Guillebaud, London:

Macmillan. 
(1996) Official Papers of Alfred Marshall: a supplement, ed. P.D.Groenewegen, Cambridge:

Cambridge University Press.

and Marshall, M.P. (1879) The Economics of Industry, 2nd ed., London: Macmillan (1881).

— and Marshall, M.P. (1879) The Economics of Industry; as repr. in P.D.Groenewegen (ed.)

(1997) Collected Works of Alfred Marshall, 8 vols., Bristol: Overstone.

Marshall, M.P. (1947) What I Remember, Cambridge: Cambridge University Press.

Marshall Library of Economics (1927) Catalogue, Cambridge: Faculty of Economics, University of Cambridge.

Marx, K.H. (1858) Letter to F.Engels, 5 March 1858, in K.Marx and F.Engels (1983) Collected Works, vol. 40, London: Lawrence and Wishart.

_(1859) Zur Kritik der Politischen Oekonomie (Italian trans.), Roma: Editori Riuniti (1971).

(1859) A Contribution to the Critique of Political Economy, as repr. with an Introduction by

M.Dobb, Moscow: Progress Publishers (1977).

(1861-63) Theories of Surplus Value, 3 vols., Moscow: Progress Publishers (1975-78).

(1867) [1952] Capital, vol. 1, Chicago: Encyclopaedia Brittanica.

(1867) [1986] Capital: a critique of political economy, vol. I, 1st English ed. 1887, trans. and ed. F.Engels, Moscow: Progress Publishers.

(1875) Kritik des Gothaer Programms (Italian trans.), Roma: Editori Riuniti (1976).

(1894) Capital: a critique of political economy, vol. III, ed. F.Engels, Moscow: Progress Publishers (1978).

Marzola, A. and Silva, F. (eds) (1994) John Maynard Keynes: language and method, Aldershot UK: Elgar.

Meade, J. (1993) 'Fifteen propositions concerning the building of an equitable, full-employment, non-inflationary, free-enterprise economy', Economic Notes (Monte dei Paschi di Siena), 22:402-19.

Meek, R.L. (1967) Economics and Ideology and Other Essays, London: Chapman and Hall.

-(1976) Social Science and the Ignoble Savage, Cambridge: Cambridge University Press. -Raphael, D.D. and P.G.Stein (eds) (1978) Adam Smith. Lectures on Jurisprudence, Oxford: Oxford University Press.

Meikle, S. (1979) 'Aristotle and exchange value', in F.D.Miller Jr. \& D.Keyt (eds) A Companion to Aristotle's Politics; as reprinted in Blaug, M. (ed.) (1991) Aristotle (384-322 BC) (Pioneers in Economics Series), Aldershot UK: Elgar.

(1995) Aristotle's Economic Thought, Oxford: Clarendon.

Meltzer, A.H. (1988) Keynes's Monetary Theory: a different interpretation, Cambridge: Cambridge University Press.

(1997-98) 'Keynes on the interest rate and redistribution: reply', Journal of Post Keynesian Economics, 20:315-19.

Mill, J. (1808) Commerce Defended, London; repr. in D.Winch (ed.) (1966) James Mill: selected economic writings, Edinburgh: Oliver and Boyd.

(1821) Elements of Political Economy, London: Baldwin, Cradock and Joy.

(1824) Elements of Political Economy (2nd ed.), London: Baldwin, Cradock and Joy.

(1826) Elements of Political Economy (3rd ed.), London: Baldwin, Cradock and Joy.

Mill J.S. (1826) 'Paper Currency - Commercial Distress', Parliamentary Review, Session of 1826; as repr. in J.M.Robson (ed.) (1963) Collected Works of John Stuart Mill, vol. 4, University of Toronto Press: Toronto. (1829-30) 'On Profits and Interest', in J.S.Mill, Essays on Some Unsettled Questions of Political Economy, 2nd ed., 1874 [1844], New Jersey: Kelley (1974).

(1844a) Essays on Some Unsettled Questions of Political Economy, London: Longmans, Green, Reader and Dyer.

(1844b) Review of 'An Inquiry into the Currency Principle, the Connexion of the Currency with Prices, and the Expediency of a Separation of Issue from Banking', by Thomas Tooke, and 'An Inquiry into the Practical Working of the Proposed Arrangements for the Renewal of the 
Charter of the Bank of England, and the Regulation of the Currency. With a Refutation of the

Fallacies advanced by Mr. Tooke', by R. Torrens, Westminster Review, 59:579-98.

(1848) Principles of Political Economy with Some of Their Applications to Social Philosophy,

London: John W.Parker.

([1848, 1849, 1871] 1965) Principles of Political Economy with some of their applications to

Social Philosophy, in Collected Works of John Stuart Mill, vols. 2-3, ed. J.M. Robson, Toronto:

University of Toronto Press.

([1869] 1967) 'Thornton on labour and its claims', in Collected Works of John Stuart Mill,

vol. 5, ed. J.M.Robson, Toronto: University of Toronto Press.

(1871 [1848]) Principles of Political Economy; with some of their applications to social

philosophy, 7th ed., ed. with an Introduction by W.Ashley, New Jersey: Kelly (1987).

([1873] 1989) Autobiography, London: Longmans, Green, Reader and Dyer.

(1972) The Later Letters of John Stuart Mill, 1849-1873, in Collected Works of John Stuart

Mill, vols. 14-17, ed. F.E.Mineka and D.N.Lindley, Toronto: University of Toronto Press.

(1990) Writings of India, Collected Works of John Stuart Mill, vol. 30, Toronto: University of

Toronto Press.

(1991) Additional Letters of John Stuart Mill, Collected Works of John Stuart Mill, vol. 32,

Toronto: University of Toronto Press.

Mirowski, P. and Tradewell, S. (1999) 'Introduction', Collected Economic Writings of William

Thornton, vol. I, London: Pickering and Chatto.

Moggridge, D.E. (1976) John Maynard Keynes, Harmondsworth, Middlesex: Penguin.

(1992) Maynard Keynes: an economist's biography, London: Routledge.

and Howson, S. (1974) 'Keynes on monetary policy, 1910-1946', Oxford Economic Papers,

26:226-47.

Moir, M. (1990) “'Introduction” to Writings on India', Collected Works of John Stuart Mill, vol.

30, Toronto: University of Toronto Press.

(1993) 'Kaghazi Raj: notes on the documentary basis of company rule: 1773-1858', Indo-

British Review: a Journal of History, 21:185-93.

Mongiovi, G. (1990) 'Keynes, Sraffa and Hayek: on the origins of chapter 17 of The General

Theory', Economie Appliquée, 43:131-56.

Moore, B. (1988) Horizontalists and Verticalists: the macroeconomics of credit money, Cambridge: Cambridge University Press.

Morgan, E.V. (1965) The Theory and Practice of Central Banking, 1797-1913, London: Frank Cass.

Murad, A. (1962) What Keynes Means: a critical clarification of the economic theory of John Maynard Keynes, New York: Bookman Associates.

Naldi, N. (2001) 'Keynes on the nature of capital: a note on the origin of The General Theory's chapter 16', European Journal of the History of Economic Thought, 8:391-401.

Nasar, S. (2002) 'John Maynard Keynes: A man of action as well as ideas', New York Times, 20 January.

Negishi, T. (1982) 'A note on Jevons's law of indifference and competitive equilibrium', Manchester School, 50:220-30.

(1994) The History of Economics: the collected essays of Takashi Negishi, vol. II, Aldershot UK: Elgar.

Newmarch, W. (1857) Evidence to the Commons Select Committee on the Bank Acts, British

Parliamentary Papers 1857 (220), vol. X, Part I (Qs 1554-2009), repr. in Irish University Press

Series, 'Monetary Policy: General 7', Shannon, Ireland: Irish University Press, 1969.

O’Brien, D.P. (1990) 'Marshall's industrial analysis', Scottish Journal of Political Economy, 37:61-84.

(1997) 'Marshall and his correspondence', Economic Journal, 107:1859-85.

O’Donnell, R.M. (1989) Keynes: Philosophy, Economics and Politics, London: Macmillan. 
(1991) 'Keynes on probability, expectations and uncertainty', in R.M.O'Donnell (ed.) Keynes as Philosopher-Economist, London: Macmillan.

(2004) 'Keynes's theory of writing and its impact on clarity', Macquarie Economics Research Papers, Sydney: Macquarie University.

Opie, R. (1974) 'The political consequences of Lord Keynes', in D.E.Moggridge (ed.) Keynes: aspects of the man and his work, London: Macmillan.

Overstone, Lord [Loyd, S.-J.] (1837) Reflections suggested by a perusal of Mr. J.Horsley Palmer's Pamphlet on the Causes and Consequences of the Pressure on the Money Market; as repr. in Overstone (1857) Tracts and Other Publications on Metallic and Paper Currency, compiled by J.R.McCulloch, New York: Kelley (1972).

(1840) Remarks on the Management of the Circulation and on the condition and conduct of the Bank of England and the Country Issuers, during the year 1839; as repr. in Lord Overstone (1857) Tracts and Other Publications on Metallic and Paper Currency, compiled by J.R.McCulloch, New York: Kelley (1972).

Panico, C. (1988) Interest and Profit in the Theories of Value and Distribution, London: Macmillan.

(1993) 'Two alternative approaches to financial model building', Metroeconomica, 44:93133.

(2001) 'Monetary analysis in Sraffa's writings', in T.Cozzi and R.Marchionatti (eds) Piero Sraffa's Political Economy: a centenary estimate, London: Routledge.

Patinkin, D. (1949) 'Involuntary unemployment and the Keynesian supply function', Economic Journal, 59:360-83.

(1956) Money, Interest and Prices: an integration of monetary and value theory, New York:

Row Peterson.

(1981) Essays On and In the Chicago Tradition, Durham NC: Duke University Press.

(1989) Money, Interest and Prices: an integration of monetary and value theory (2nd abridged ed.), Cambridge MA: MIT Press.

Peart, S. (1998) 'Jevons and Menger re-homogenized?: Jaffé after 20 years', American Journal of Economics and Sociology, 57:306-25.

Perrotta, C. (2003) 'The legacy of the past: ancient economic thought on wealth and development', European Journal of the History of Economic Thought, 10:177-229.

Picchio, A. (2003) 'Needs and passions of human subsistence in the moral economy of the early 18th century: Defoe and Mandeville', paper presented to the European Society for the History of Economic Thought Conference, Paris.

Pigou, A.C. (1912) Wealth and Welfare, London: Macmillan.

(1913) 'The inter-dependence of different sources of demand and supply in a market',

Economic Journal, 23:19-24.

(1920) The Economics of Welfare, London: Macmillan.

(ed.) (1925) Memorials of Alfred Marshall, London: Macmillan.

(1927) 'The laws of diminishing and increasing cost', Economic Journal, 37:188-197.

(1928) 'An analysis of supply', Economic Journal, 38:238-57.

Pivetti, M. (1990) 'Wicksell's theory of capital', in J.Eatwell, M.Milgate and P.Newman (eds) The New Palgrave: capital theory, London: Macmillan.

(1991) An Essay on Money and Distribution, New York: St. Martins.

(1998) 'Thomas Tooke and the influence of the rate of interest on prices: implications for distribution theory', Contributions to Political Economy, 17:39-52.

-(2001) 'Money endogeneity and monetary non-neutrality: a Sraffian perspective', in L.-

P.Rochon and M.Vernengo (eds) Credit, Interest Rates and the Open Economy: essays on horizontalism, Cheltenham UK: Elgar.

Poisson, S.D. (1842 [1833]) A Treatise on Mechanics, trans. H.H.Harte, 2 vols, London: Longman \& Co.; Dublin: Milliken, Hodges and Smith.

Pollard, S. (1994) 'New light on an old master', Economic Journal, 104:138-53. 
Pollin, R. (1997) "'Socialization of investment" and "euthanasia of the rentier": the relevance of Keynesian policy ideas for the contemporary US economy', in P. Arestis and M. Sawyer (eds) The Relevance of Keynesian Economic Policies Today, London: Macmillan.

Prendergast, R. (1992) 'Increasing returns and competitive equilibrium - the content and development of Marshall's theory', Cambridge Journal of Economics, 16:447-62.

(1993) 'Marshallian external economies', Economic Journal, 103:454-8.

Presley, J.R. (1984) Review of John Maynard Keynes, Volume I, Hopes Betrayed, Economic Journal, 94:411-12.

Pullen, J. (1990) 'The teaching of the history of economic thought at the University of New England', HETSA Bulletin, Winter, 13:30-40.

- (2001) 'Henry George's land reform: the distinction between private ownership and private possession', American Journal of Economics and Sociology, 60:547-56.

Purdy, D. (1988) Social Power and the Labour Market: a radical approach to labour economics, Basingstoke: Macmillan.

Raffaelli, T. (ed.) (1994) 'The early philosophical writings of Alfred Marshall', Research in the History of Economic Thought and Methodology, Archival Supplement, edited by W. J.Samuels, 4:51-158.

(2001) 'On Marshall's representative firm: a comment on Marchionatti', in T. Cozzi and R.Marchionatti (eds) Piero Sraffa's Legacy in Economics: a centenary estimate, London: Routledge. (2003) Marshall's Evolutionary Economics, London: Routledge.

Biagini, E.F. and MacWilliams-Tullberg, R. (eds) (1995) Alfred Marshall's Lectures to Women, Aldershot UK: Elgar.

Ramsey, F.P. (1978) 'Truth and probability', in D.H.Mellor (ed.) Foundations: essays in philosophy, logic, mathematics and economics, London: Routledge and Kegan Paul (first published 1931).

Ranchetti, F. (2001) 'On the relationship between Sraffa and Keynes', in T.Cozzi and R. Marchionatti (eds) Piero Sraffa's Political Economy: a centenary estimate, London: Routledge.

Raphael, D.D. and Macfie, A.L. (1976) 'Introduction', A.Smith (1759) The Theory of Moral Sentiments, ed. D.D.Raphael and A.L.Macfie, Oxford: Oxford University Press.

Reckitt, M.R. and Bechofer, C.E. (1918) The Meaning of National Guilds, New York: Macmillan.

Reid, G.C. (1996) [Review of Groenewegen (1995)], Economic Journal, 106:1073-4.

Ricardo, D. (1817) On the Principles of Political Economy and Taxation, London: John Murray. (1821) On the Principles of Political Economy and Taxation, 3rd ed., in P.Sraffa (ed.) (with the collaboration of M.H.Dobb), The Works and Correspondence of David Ricardo, vol. I, Cambridge: Cambridge University Press (1951).

Rist, C. (1940) History of Monetary and Credit Theory from John Law to the Present Day, London: Allen and Unwin.

Robbins, L. (1958) Robert Torrens and the Evolution of Classical Economics, London: Macmillan. (1970) The Evolution of Modern Economic Thought, London: Macmillan.

Robertson, D.H. (1924) 'Those empty boxes', Economic Journal, 34:16-21.

Robinson, E.A.G. (1948) Review of What I Remember by Mary Paley Marshall, Economic Journal, 58:123-4.

Robinson, J. (1933) The Economics of Imperfect Competition, London: Macmillan.

- (1953a) “'Imperfect Competition" revisited', in J.Robinson (1978) Contributions to Modern Economics, Oxford: Blackwell.

(1953b) 'On re-reading Marx', in J.Robinson (1973) Collected Economic Papers, vol. 4, Oxford: Blackwell.

(1974) 'History versus equilibrium', in J.Robinson (1978) Contributions to Modern Economics, Oxford: Blackwell.

(1975) 'What has become of the Keynesian revolution?', in M.Keynes (ed.) Essays on John Maynard Keynes, Cambridge: Cambridge University Press. 
(1978a) 'A lecture delivered at Oxford by a Cambridge economist', in J.Robinson, Contributions to Modern Economics, Oxford: Blackwell.

_ (1978b) 'Keynes and Ricardo', Journal of Post Keynesian Economics, 1:12-18.

Robson, J.M. (1989) 'Introduction', in J.M.Robson (ed.) John Stuart Mill Autobiography, London; Penguin.

Rochon, L. (1999) Credit, Money and Production: an alternative Post-Keynesian approach, Cheltenham UK: Elgar.

Roll, E. (1938) A History of Economic Thought (Italian trans.), Torino: Boringhieri (1967).

Rosenberg, N. (1990) 'Adam Smith and the stock of moral capital', History of Political Economy, 22:1-17.

Ross, W.D. (1923) Aristotle (Italian trans.), Bari: Laterza (1946).

Runde, J. (1997) 'Keynesian methodology', in G.C.Harcourt and P.A.Riach (eds) A 'Second Edition of The General Theory, vol. 2, London: Routledge.

Rymes, T.K. (ed.) (1987) Keynes's Lectures, 1932-35: notes of students, Carleton Economic Papers, Ottawa: Carleton University.

-(1989) Keynes's Lectures, 1932-35. Notes of a Representative Student: a synthesis of lecture notes taken by students at Keynes's lectures in the 1930s leading up to the publication of The General Theory, London: Macmillan.

Samuels, W.J. (1966) The Classical Theory of Economic Policy, Cleveland: World Publications.

Samuelson, P. (1967) 'The monopolistic competition revolution', in R.E.Kuenne (ed.) Monopolistic Competition Theory: studies in impact, New York: John Wiley.

_(1977) 'A modern theorist's vindication of Adam Smith', American Economic Review, 67:4250.

Sargant Florence, P. (1924) Economics of Fatigue and Unrest and the Efficiency of Labour in English and American Industry, London: Allen \& Unwin.

Say, J.B. (1803) Traité d'économie politique, ou simple exposition de la manière dont se forment, ea distribuent et se consomment les richesses (2nd ed. 1814, 3rd ed. 1817, 4th ed. 1819, 5th ed. 1826), Paris: Deterville.

(1820) Lettres à M.Malthus, Paris: Bossagne.

(1824) 'Sur la balance des consummations avec les productions', Revue Encyclopédique, vol. 23, July.

(1828-1829) Cours Complet d'Économique politique partique, Paris: Rapilly.

Schabas, M. (1990) A World Ruled by Number: William Stanley Jevons and the rise of mathematical economics, Princeton: Princeton University Press.

Schefold, B. (1999) 'Use value and the "commercial knowledge of commodities": reflections on Aristotle, Savary and the classics'; in G.Mongiovi and F.Petri (eds) Value, Distribution and Capital: essays in honour of Pierangelo Garegnani, London: Routledge.

Schumpeter, J.A. (1954) History of Economic Analysis, London: George Allen and Unwin (repr. Routledge, 1997).

Sciolla L. (1998) 'Valori'; in Enciclopedia delle Scienze sociali, vol. 8, Roma: Istituto della Enciclopedia Italiana.

Sewall, H.R. (1901) The Theory of Value before Adam Smith, New York: Kelley (repr. 1971).

Shackle, G.L.S. (1965) A Scheme of Economic Theory, Cambridge: Cambridge University Press. (1967) The Years of High Theory, Cambridge: Cambridge University Press.

Shove, G.F. (1933) 'The imperfection of the market', Economic Journal, 43:113-25.

(1942) 'The place of Marshall's Principles in the development of economic theory', Economic Journal, 52:294-329.

Simcox, G.A. (1873) 'Review of Old-Fashioned Ethics and Common-Sense Metaphysics', The Academy, 4:192-3.

Skaggs, N.T. (1995) 'The methodological roots of J.Laurence Laughlin's anti-quantity theory of money and prices', Journal of the History of Economic Thought, 17:1-20.

Skidelsky, R. (1983) John Maynard Keynes: hopes betrayed, 1883-1920, London: Macmillan. 
(1988) 'Keynes's political legacy', in O.F.Hamouda and J.N.Smithin (eds) Keynes and Public

Policy After Fifty Years, vol. 1, Aldershot UK: Elgar.

(1992) John Maynard Keynes: the economist as saviour 1920-1937, London: Macmillan.

(1997) 'Keynes's "Concluding Notes"', in G.C.Harcourt and P.A.Riach (eds) A 'Second

Edition' of The General Theory, vol. 1, London: Routledge.

(2000a) John Maynard Keynes: fighting for Britain 1937-1946, London: Macmillan.

(2000b) 'Ideas and the world', The Economist, 23 November.

(2001) John Maynard Keynes, Volume Three: fighting for freedom 1937-1946 (US ed. of

Skidelsky 2000a) New York: Viking Penguin.

Skinner, A.S. (1967) 'Say's Law: origins and content', Economica, 34:153-66.

(1969) 'Of Malthus, Lauderdale and Say's Law', Scottish Journal of Political Economy,

16:177-95.

(1993) 'Adam Smith: the origins of the exchange economy', European Journal of the History of Economic Thought, 1:21-46.

Smith, A. (1759) The Theory of Moral Sentiments, ed. D.D.Raphael and A.L.Macfie, Oxford:

Oxford University Press (1976).

(1776) An Inquiry into the Nature and Causes of the Wealth of Nations, 2 vols., ed. R.

H.Campbell, A.S.Skinner and W.B.Todd, Oxford: Oxford University Press (1976).

(1795) Essays on Philosophical Subjects, ed. W.P.D.Wightman, J.C.Bryce and I.S. Ross,

Oxford: Oxford University Press (1980).

Smith, C. and Wise, M.N. (1989) Energy and Empire: a biographical study of Lord Kelvin,

Cambridge: Cambridge University Press.

Smith, M. (1996a) "A monetary explanation of distribution in a "gold money economy",

Contributions to Political Economy, 15:33-61.

(1996b) 'Introduction', in Variorum of the First and Second Editions of Thomas Tooke's

Considerations on the State of the Currency (1826), ed. M.Smith (in collaboration with

P.D.Groenewegen), Reprints of Economic Classics (Series 2), No. 8 (Centre for the Study of the

History of Economic Thought, University of Sydney).

(2001) 'Endogenous money, interest and prices: Tooke's monetary thought revisited',

Contributions to Political Economy, 20:31-55.

(2002) 'Tooke's approach to explaining prices', European Journal of the History of Economic

Thought, 9:331-56.

(2003) 'On central banking "rules": Tooke's critique of the Bank Charter Act of 1844',

Journal of the History of Economic Thought, 25:39-61.

Soudek, J. (1952) 'Aristotle's theory of exchange: an inquiry into the origin of economic analysis',

Proceedings of the American Philosophical Society, 96; as repr. in M.Blaug (ed.) (1991)

Aristotle (384-322 BC) (Pioneers in Economics Series), Aldershot UK: Elgar.

Sowell, T. (1972) Say's Law: an historical analysis, Princeton: Princeton University Press.

- (1974) Classical Economics Reconsidered, Princeton: Princeton University Press.

Spengler, J.J. (1945) 'The Physiocrats and Say's law of markets', Journal of Political Economy,

53:193-211, 317-47; repr. in J.J.Spengler and W.R.Allen (eds) (1960), Essays in Economic

Thought: Aristotle to Marshall, Chicago: Rand McNally.

(1955) 'Aristotle on economic imputation and related matters', Southern Economic Journal,

21; as repr. in M.Blaug (ed.) (1991) Aristotle (384-322 BC) (Pioneers in Economics Series),

Aldershot UK: Elgar.

Sraffa, P (1926) 'The laws of returns under competitive conditions', Economic Journal, 36:535-50.

_ (1951) 'Introduction', in The Works and Correspondence of David Ricardo, vol. I, ed. P.Sraffa

(with the collaboration of M.H.Dobb), Cambridge: Cambridge University Press.

(ed.) (1951-73) The Works and Correspondence of David Ricardo, 11 vols., with the

collaboration of M.H.Dobb, Cambridge: Cambridge University Press.

(1960) Production of Commodities by Means of Commodities: prelude to a critique of

economic theory, Cambridge: Cambridge University Press. 
Stephen, L. (1886) Life of Henry Fawcett, London: Smith, Elder \& Co. (1893) An Agnostic's Apology and Other Essays, London: Smith, Elder \& Co.

Stigler, G. (1941) Production and Distribution Theories, New York: Macmillan.

(1965) Essays in the History of Economics, Chicago: University of Chicago Press.

(1990) 'The place of Marshall's Principles in the development of economics', in J.

K.Whitaker (ed.) Centenary Essays on Alfred Marshall, Cambridge: Cambridge University Press.

Swan, T.W. (1956) 'Economic Growth and Capital Accumulation', Economic Record, 31:334-61. Sweezey, P.M. (1985) 'Listen Keynesians!', in H.L.Wattel (ed.) The Policy Consequences of John Maynard Keynes, New York: Sharpe; reprinted from Monthly Review, January 1983.

Thornton, W.T. (1846) Over-Population and its Remedy: or, an enquiry into the extent and causes of the distress prevailing among the labouring classes of the British Islands, London: Longman, Brown, Green and Longmans.

(1848) A Plea for Peasant Proprietorship, London; J.Murray and Co.

(1854) Zohrab; or, A Midsummer Day's Dream: and other poems, London: Longman, Brown, Green and Longmans.

(1869) On Labour: Its Wrongful Claims and Rightful Duties. Its Actual Present and Possible Future, London: Macmillan.

(1870a) On Labour: Its Wrongful Claims and Rightful Dues. Its Actual Present and Possible

Future, London: Macmillan.

(1870b) ‘Anti-Utilitarianism', Fortnightly Review, 8 (n.s.): 314-37.

(1871) 'Natural rights and abstract justice', Fartnightly Review, 10 (n.s.): 359-76.

(1872) 'Huxleyism: a fragment', Contemporary Review, 20:666-91.

(1873) 'His [Mill's] career in the India House', in John Stuart Mill: his life and works. Boston:

James R.Osgood and Co.

(1874) A Plea for Peasant Proprietorship, London: Macmillan.

(1879) 'The wages fund', Nineteenth Century, 6:293-307.

Thweatt, W.O. (1979) 'Early formulators of Say's Law', Quarterly Review of Economics and Business, 19:79-96.

(1980) 'Baumol and James Mill on "Say's" Law of Markets', Economica, 47:467-69.

Tobin, J. (1985) 'Keynes's policies in theory and practice', in H.L.Wattel (ed.) The Policy

Consequences of John Maynard Keynes, New York: Sharpe.

Tooke, T. (1826) Considerations on the State of the Currency, 2nd ed., London: John Murray.

- (1838) A History of Prices and of the State of the Circulation from 1793 to 1837; preceded by a brief sketch of the corn trade in the past two centuries, 2 vols., London: P.S. King and Son (1928 reprint).

(1844) An Inquiry into the Currency Principle: the connexion of the currency with prices and the expediency of a separation of issue from banking, 2nd ed., in Series of Reprints of Scarce Works on Political Economy, no. 15, London School of Economics and Political Science (1959 reprint).

(1848a) A History of Prices, and of the State of the Circulation, from 1839 to 1847 inclusive: with a general review of the currency question, and remarks on the operation of the Act, $7 \& 8$ Vict. c32., vol IV, London: P.S.King and Son (1928 reprint).

(1848b) Evidence to the Commons Secret Committee on Commercial Distress, British

Parliamentary Papers 1847-48 (395), vol VIII, Part I (Qs 5301-5493), repr. in Irish University Press Series, 'Monetary Policy: Commercial Distress 3', Shannon, Ireland: Irish University Press, 1969.

-and Newmarch, W. (1857) A History of Prices and of the State of the Circulation, during the Nine Years 1848-1856, vols. V-VI, London: P.S.King and Son (1928 reprint).

Torrens, R. (1829) An Essay on the External Corn Trade; with an Appendix. on the Means of Improving the Condition of the Labouring Classes, 5th ed., New York: Kelley (1972). 
(1840) A Letter to Thomas Tooke, esq., in Reply to his Objections against the separation of the business of the Bank into a Department of Issue and Department of Deposit and Discount: With a Plan of Bank Reform, London: Longman, Hurst, Orme and Brown.

(1844) An Inquiry into the practical working of the proposed arrangements for the Renewal of the Charter of the Bank of England and the Regulation of the Currency: with a refutation of the fallacies advanced by Mr. Tooke; to which is added A Reply to the objections of the Westminster Review to the Government Plan for the Regulation of the Currency, 2nd ed., London: Smith, Elder, and Company.

(1848) The Principles and practical operations of Sir Robert Peel's bill of 1844 explained and defended against the objections of Tooke, Fullarton and Wilson, London: Longman, Brown, Green and Longmans.

(1858) The Principles and Practical Operation of Sir Robert Peel's Act of 1844, Explained and Defended. Third Edition, Revised and Enlarged: Comparing critical Examinations of the Report of the Lords' Committee of 1848, upon National Distress; of the Novel Principles of Currency Propounded by Tooke and Mr. Wilson; and of the Chapter on Regulation of Currency in Mr. J.S.Mill's Principles of Political Economy, London: Long-mans and Ridgway.

Toye, J. (2000) Keynes on Population, Oxford: Oxford University Press.

Tozzi, G. (1961) Economisti greci e romani, Milano: Feltrinelli.

Trever, A.A. (1916) A History of Greek Economic Thought, Chicago: University of Chicago Press.

Trezzini, A. (1995) 'Capacity utilisation in the long run and the autonomous components of aggregate demand', Contributions to Political Economy, 14:33-66.

Tucker, G.S.L (1960) Progress and Profits in British Economic Thought 1650-1850, Cambridge: Cambridge University Press.

Turner, C.B. (1969) An Analysis of Soviet Views on John Maynard Keynes, Durham NC: Duke University Press.

Vaggi, G. (1996) 'Adam Smith and the economic policy of laissez faire', History of Economic Ideas, 4:107-47.

Veblen, T. (1898) 'Why is economics not an evolutionary science?', Quarterly Journal of Economics, 12:373-97.

Vines, D. (2003) 'John Maynard Keynes 1937-1946: the creation of international macroeconomics', Economic Journal, 113:338-61.

Vinogradoff, P.G. (1968) Villainage in England. Essays in English Medieval History, Oxford: Clarendon Press.

Vivenza, G. (1997) 'L'Aristotele greco e l'Aristotele latino alle origini della teoria del valore', Studi storici Luigi Simeoni, 47:9-34.

Wagner, A. (1857) Beiträge zur Lehre von den Banken, Vaduz: Topos (1977 reprint).

Walsh, V. and Gram, H. (1980) Classical and Neoclassical Theories of General Equilibrium, Oxford: Oxford University Press.

Weintraub, E.R. (1996) 'What defines a legitimate contribution to the subdiscipline "the history of economics”?', History of Economics Society HES List (Guest Editorial, Long Version), available online: http://www.eh.net/HE/hes_list, posted 9 September 1996.

Wenzer, K. (1997a) An Anthology of Henry George's Thought (vol. I of the Henry George Centennial Trilogy), Rochester: University of Rochester Press.

(1997b) An Anthology of Single Land Tax Thought (vol. III of the Henry George Centennial Trilogy), Rochester: University of Rochester Press.

Whitaker, J.K. (ed.) (1975) The Early Writings of Alfred Marshall, 1867-1890, 2 vols., London: Macmillan.

(ed.) (1990a) Centenary Essays on Alfred Marshall, Cambridge: Cambridge University Press. (1990b) 'What happened to the second volume of the Principles? The thorny path to Marshall's last books', in J.K.Whitaker (ed.) Centenary Essays on Alfred Marshall, Cambridge: Cambridge University Press. 
(ed.) (1996) The Correspondence of Alfred Marshall, Economist, 3 vols., Cambridge: Cambridge University Press.

(1999) 'Alfred Marshall and scientific management', in S.C.Dow and P.E.Earl (eds) Economic Organization and Economic Knowledge: essays in honour of Brian Loasby, vol. I, Cheltenham UK: Elgar.

(2002) 'Alfred Marshall's Principles and Industry and Trade two books or one? Marshall and the joint stock company', in R.Arena and M.Quéré (eds) The Economics of Alfred Marshall: revisiting Marshall's legacy, Basingstoke: PalgraveMacmillan.

White, M.V. (1987) 'Robinson Crusoe', in J.Eatwell, M.Milgate and P.Newman (eds) The New Palgrave: a dictionary of economics, vol. 4, London: Macmillan.

(1989) 'Why are there no supply and demand curves in Jevons?', History of Political Economy, 21:425-56.

(1994a) 'That God-forgotten Thornton: exorcising higgling after On Labour', in N. de Marchi and M.Morgan (eds) Higgling: Transactors and their Markets in the History of Economic Thought, Durham NC: Duke University Press.

(1994b) 'The moment of Richard Jennings: the production of the marginalist economic agent', in P.Mirowski (ed.) Natural Images in Economics: markets read in tooth and claw, New York: Cambridge University Press.

(2001) 'Indeterminacy in exchange: disinterring Jevons' trading bodies', Manchester School, 69:208-26.

(2003) 'Ghosts in the machine: value and distribution in W.S.Jevons' Theory of Political Economy', mimeo.

(2004) 'In the lobby of the energy hotel: W.S.Jevons' formulation of the post-classical economic problem', History of Political Economy, 36:227-71.

Wicksell, K. (1954 [1893]) Value, Capital and Rent, trans. S.H.Frowein, London: George Allen and Unwin.

(1898) Interest and Prices: a study of the causes regulating the value of money, trans. R.

F.Kahn 1936, New Jersey: Kelley (1965 reprint).

1906) Lectures on Political Economy, Volume II (Money), trans. E. lassen and ed. with an Introduction by L.Robbins 1935, New Jersey: Kelley (1978 reprint).

Wilson, J. (1847) Capital, Currency and Banking; being a collection of a series of articles published in the Economist..., London: The Economist.

Wilson, T. (1976) 'Sympathy and self-interest', in T.Wilson and A.Skinner (eds) The Market and the State, Oxford: Oxford University Press.

Winch, D. (ed.) (1966) James Mill: selected economic writings, Edinburgh: Oliver and Boyd.

(1969) Economics and Policy: a historical study, London: Hodder and Stoughton.

Wise, M.N. (1989) 'Work and waste: political economy and natural philosophy in nineteenth century Britain (I)', History of Science, 27:263-301.

Wood, D. (2002) Medieval Economic Thought, Cambridge: Cambridge University Press.

Woods, R.B. (1990) A Changing of the Guard: Anglo-American relations, 1941-1946, Chapel Hill NC: University of North Carolina Press.

Wray, L.R. (1990) Money and Credit in Capitalist Economies: the endogenous money approach, Aldershot UK: Elgar.

Wright, D.M. (1962) The Keynesian System, New York: Fordham University Press.

Young, A.A. (1913) 'Pigou's Wealth and Welfare', Quarterly Journal of Economics, 27: 672-86. (1928) 'Increasing returns and economic progress', Economic Journal, 38:527-40.

Zanini, A. (1993) 'The individual and society: on the concept of "middle conformation" in Adam Smith's Theory of Moral Sentiments', History of Economic Ideas, 2:1-19. 


\section{Index}

Abbagnano, N. 16

Academy of Social Sciences in Australia 2

Adelaide University 248, 251, 253

agricultural economics 251

Alembert, J.L. d' 110-11

altruism (benevolence) 28, 31-2, 35, 39-40

Alvey, James 254

ancient economics 13, 16-29, 159, 250

Andrews, P.W.S. 152

Anglo-Saxon temperament 170, 174

Antisthenes 17

ANZAAS 250

Arab economics 20

Arena, R. 143, 148

Arestis, P. 251

Argyll, Duke of 84

Aristotle 13, 16-29, 250

Arndt, H.W. 250

Arrow, Kenneth 194

Ashley, W.J. 17

Aspromourgos, Tony:

career xi, 253;

essay by $14,217-35$;

introduction $\mathrm{xv}, 1-15$;

preface xvii

Association Charles Gide pour l'Etude de la Pensée Economique 2

attainment of equilibrium 105-6, 108, 111-16

Auckland University 254

auction (Jevons) 99-100

Australian and New Zealand Association for the Advancement of Science (ANZAAS) 250

Australian economic scholarship xv-xvi, 1-14, 109, 121, 182, 245-55

Australian National University 251

Australian public finance $1-3,7,12$

Australian Research Council 2, 4

Australian tax 1-3

Austrian economics 67, 191, 247-8, 254-5

Baconian scholarship 153

Bagehot, W. 68

Bain, Alexander 86, 93

balance metaphor (Jevons) 109-12

Bank Charter Act (1844) 58, 61-2, 65 
Bank of England 62, 64, 242

banking:

Keynes 225, 232, 242;

Marshall 158;

Tooke 57-8, 61-7, 69, 71

Banking School 13, 57-9, 61-3, 65-9

Barens, I. 220

bargaining:

Aristotle 22;

Adam Smith 41

Barker, T. 106-7

barter:

Aristotle 18, 22;

Say's law 52-3;

Adam Smith 40

Bateman, B.W. 202, 211

Baumol, W.J. 44, 54-6

Bayle, P. 28

Becattini, Giacomo:

career xi;

essay by $13-14,142-55$;

as referee $\mathrm{xvii,} 7$

Becker, G.S. 44, 54

Bellofiore, R. 227

Belshaw, Horace 254

Belshaw, James 248-9, 254

benevolence (altruism) 28, 31-2, 35, 39-40

Bentham, Jeremy 78, 92, 173

Biagini, E.F. 144

biological analogy 179, 187-91, 193-4

Black, R.D.C. 103-4, 106, 110, 113

Blackheath Park circle 76, 83, 85

Blanc, J.J.L. 170

Blanqui, J.A. 44

Blaug, Mark 44, 49, 52, 54, 179

Bliven, Bruce 239

Boisguilbert, Pierre de 248

Bonar, James 158

Boot, H.M. 252

Booth, Charles 169

Bortkiewicz, Ladislaus von 115

Boulding, Kenneth 130

Bowley, A.L. 248

Bradford, Wylie 253

Braithwaite, R.B. 202, 204

Brewer, T. 6

Bridel, P. 68, 115

Bristol University 246

British economic policy:

Keynes and 14, 218, 221-6, 231-3, 236-44;

Marshall and social reform 170-1, 174-5;

J.S.Mill and W.T.Thornton 94; 
relations with United States 237-41;

Tooke's influence 57, 60, 62, 64-5.

see also British Empire

British economists:

Groenewegen on 13;

on India 156, 165;

Say's law 46-54;

Tooke's influence 59.

see also classical political economy;

Marshallian economics;

neo-classical economics

British Empire 156, 161, 164, 237-9, 241

brokers (Jevons) 99, 116

Brown, M. 37-8

Burke, Edmund 241

Burton, Herbert 248, 250-1

business cycles (Marshall) 157-8, 176

business organization (Marshall) 148-9, 182, 184, 186, 189

Butlin, Syd 247-8, 250

Byzantine economics 20

Cairnes, John Elliott 87-9, 91-2, 100, 104

calculus (Jevons) 110

Cambridge Economics Handbook Series 248

Cambridge Journal of Economics 246

Cambridge School 67-8, 149

Cambridge University:

Australian links 10, 245, 250-4;

Indian and Japanese students 164;

Keynes and 238;

Marshall and 7, 66, 139-41, 144-5, 159, 164, 180-2, 189;

Marshallian studies 142-3, 149, 189

Cambridge University Press 251, 255

capital:

accumulation (Say's law) 46-7, 51;

classical theory 10 ;

interest rate and 9;

marginal theory 66 ;

Marshall 173-5;

Marx 65;

Tooke 59-61, 63-4, 66, 68

capital market (J.S.Mill) 61

capitalism:

classical political economy 6;

George 120, 132;

Marshall 14, 151-2;

Marxists 142;

Ricardo 150;

without property income (Keynes) 217-33

Carabelli, A. 211

Carlyle, Thomas 88 
Carnac, Sir James 77

Cartwright, John 77

cash balance:

Marshall 67

Caspari, V. 220

Cerroni, U. 25

Cesaratto, S. 229

Chancellor of the Exchequer (UK) 221, 237

change (Marshall) 161-3, 181, 183

Channel Islands 86

Chapman, Henry 83

Chapple, Simon 254

character (Marshall) 145-9, 152, 176, 181

Charity Organisation Societies 169

Chicago University 249, 253

China 162

Christian tradition 164

Churchill, Winston 237-8

civic consciousness (Marshall) 151

clarity. see English language

Clark, J.B. 163

Clarke, M.L. 51

class:

Marshall 145, 148, 151, 169, 173-4, 176, 181;

Marx 151

classical political economy:

Australian research and teaching 247-8, 252-3;

Groenewegen's scholarship and teaching 3-7, 9-10, 13, 245;

land tax 132;

Marshall and 145, 147, 150, 152, 157, 171, 180-1, 183;

monetary theory 57-9, 62, 65-7, 69-71

(see also quantity theory of money);

Say's law 48-50, 52, 54-5;

Sraffa and 226-7;

W.T.Thornton and 76, 89, 94

Coase, Ronald H. 7, 142

Coats, A.W. (Bob) xv-xvi, 7

Cochrane, Donald 249

cognitive economy 148

Colander, D. 30

Cole, G.D.H. 172

Coleman, W. xvii, 248

collective property $118-19,133,172$

collectivism (Marshall) 168-9, 172, 177

colonies 156, 161, 164, 237-9, 241

commodities:

fetishistic nature (Marx) 26-7;

Jevons 98, 100, 107;

Marshall 149, 152, 163;

Say's law 47, 53;

value 27

common property rights (George) 118-27, 130-1, 133 
common public ownership (George) 118, 123, 125-6, 129, 131, 134-5

Commons, J.R.. 12

communism:

George 134;

Marshall 171;

Marx 148

community services. see social services

competition:

custom and 14, 156, 159-64;

Jevons 98-9, 104;

Keynes 217-18, 220, 224;

Marshall 162-4, 172, 174-5, 184;

Sraffa 70

competitive equilibrium 189-92

Comte, Auguste 153

Conference of Economists 250

confidence (Keynes) 207-12

consequences, unintended 33

conservatism:

Keynes 238;

Marshall 167

consumption:

Jevons 100-2;

Marshall 147;

Say's law 44-5, 47-8, 51-2;

Tooke 63

context:

in Groenewegen's scholarship 5-6, 9-10;

Jevons 112-14;

Marshall 144, 169

continuity (Marshall) 182, 184, 186, 188

contracts (Adam Smith) 40-1

cooperative movement (Marshall) 167, 171, 176

Coquelin, C. 44

Corry, Bernard 9

cost controversies (1920s) 190, 192

Cournot A.A. 187

Courtney, Leonard 85

Courvisanos, Jerry 253

credit:

Marx 65;

Tooke 61-3, 67

Creedy, John xvii, 115, 246

Critical Drinking xv

Crusoe metaphor 30-1, 34, 40-2

cultural values (Marshall) 164-5

Cunningham, William 159, 162

currency:

India 156-8, 165;

Tooke 58-9, 61-3, 66-7;

Tooke and J.S. Mill 61

Currency School 58, 61, 63 
Curtin University 255

custom, competition and 14, 156, 159-64

cycles (Marshall) 68, 157-8, 176

Dalton, Hugh 221-2

Danvers, Evelyn 93

Dardi, Marco 143, 148

Darwin, Charles 146, 153, 163, 182-4, 193. see also evolutionary approach

Darwin, George 106

Davidson, Frank 249

De Marchi, Neil 251

De Morgan, Augustus 110-11

De Quincey Thomas 6

debt management (Keynes) 221-3

deduction and induction:

Marshall 181;

Adam Smith 37

Defoe, Daniel 30

DeLong, Bradford 237-9, 241-2

demand:

Aristotle 24-5;

Jevons 113;

Keynes 219, 231;

Marshall 140, 147;

Say's law 44-5, 47-54, 56;

Tooke 62-3, 66-9.

see also supply and demand

deposit banking (J.S.Mill) 61

depreciation (Marshall) 157

depressive situations (Say's law) 47

development economics (Marshall) 143

diagonal conjunction 22

discount rate:

Marshall 68;

Wicksell 67

disequilibrium. see equilibrium

disposable capital (Tooke) 60-1, 63-4, 66, 68

distribution:

classical approach 5, 71, 226-7;

Groenewegen 5, 9-10, 13;

Keynes 217, 219, 222;

Marshallian approach 5, 7, 191;

Sraffa 70, 226-8;

W.T.Thornton 87;

Turgot 10, 13;

Wicksell 66.

see also production;

surplus approach to value and distribution division of labour:

Marshall 150-1, 164, 184, 187; 
Say's law 55;

Adam Smith 31, 34, 37, 39-42

Dobb, Maurice 9, 248

Dollery, B. 3-4, 6, 9-12

Dome, T. 115

Donoghue, Mark:

career xi;

essay by 13, 76-96;

on Groenewegen 4, 6;

as referee xvii

Douglas, Major 254

Dow, S. and Dow, A. 211

dual-circulation framework (Tooke) 61-3

Dubois de l'Estang 44

Dühring, I. 17

Duke University 252

Duval, Charles Raoul 51

Duval, Octave (Mrs) 51

dynamics:

Jevons 106-8, 111, 115;

Marshall 184-6, 191

Earl, P.E. 152

East India College, Haileybury 156

East India Company 76-83, 87, 93, 156

Eatwell, J. 2, 236

economic agents:

Jevons 100-1, 103;

Marshall 144, 181;

Say's law 54;

Adam Smith's socioeconomic man 13, 30-43

economic biology 179, 187-91, 193-4

economic change (Marshall) 161-3, 181, 183

economic crises:

financial crisis (1825-26) 59;

Tooke 68

economic efficiency (Marshall) 148, 171-2, 184, 187

economic growth:

classical political economy 6 ;

Marshall 171, 173-4, 176;

Say's law 55

economic history (Australian research and teaching) 250, 254

Economic Journal 8, 159-60, 183

economic man. see economic agents

Economic Papers 2

economic policy:

Australian research and teaching 248.

see also British economic policy

economic progress:

India 156;

Marshall 156, 172, 174, 188 
economic rationalism 5

Economic Society of Australia 2

Economic Society of Australia and New Zealand 250

economic value. see value

Economica 250-1

Economist 58, 236

Edgeworth, Francis Y. 115, 161, 248

Edgeworth-Bowley box 115

Edinburgh Review 88-9, 91

education:

Australian historians of thought 251;

India 156, 158, 165;

Marshall 150-1, 158, 165, 168-9, 173, 176-7;

of J.S.Mill 78-9;

Adam Smith 39;

women's 140-1, 144

Edward Elgar (publisher) 245-7, 250

Edwardian Britain 146-7

efficiency (Marshall) 148, 171-2, 184, 187

Ekelund, R.B. 116

Elgar, Edward (publisher) 245-7, 250

Ellis, H.S. 67

employment:

Keynes 243;

Marshall 149.

see also full employment;

unemployment

endogenous money 62, 66, 69, 71

Endres, Tony xvii, 252-4

Engels, F. 59, 150

English economics. see British economic policy;

British economists

English language:

Jevons' rhetoric 111, 114-16;

Keynes' use 14, 197-216

English law 160

Enlightenment 28;

Scottish 33

enterprise. see private enterprise

equal ownership (George) 118-23, 126-35

equal private ownership (George) 118-19, 126-7, 129, 131, 133-5

equality (Aristotle) 20-3

equilibration of measurable motives:

Marshall 159

equilibrium theory:

attainment 105-6, 108, 111-16;

classical political economy 5 ;

competitive 189-92;

Jevons 97-117;

Keynes 207, 229;

Marshall 14, 153, 179-80, 184-9, 193-4;

Marshallian 189-94; 
neo-classical approach 5, 13;

Say's law 46-56;

Sraffa 227;

Thornton 111-14.

see also long-period equilibrium

error, law of 100-1

ethics:

Aristotelian 27-8;

Keynes 224;

Marshall 149, 168;

Adam Smith 31-9;

W.T.Thornton and J.S.Mill 91-2

Euclid 78

eugenics (Keynes) 221

European economics 13, 46, 57, 86, 157, 159, 164, 182;

Say's law 13, 44-56

European scholarship xv, 3, 160, 245, 253

European travel (W.T.Thornton and J.S.Mill) 81, 86-8

euthanasia of the rentier (Keynes) 14, 217-35;

in 1940s 221-6;

full employment 217, 219-21, 224-5, 227, 232;

in General Theory 219-21;

Sraffa and conventionality of interest 226-8

Evensky, J. 33

Everett, E.M. 92

evolutionary approach:

Australian research and teaching 255;

Marshall on India 159, 163;

Marshallian studies 146, 153;

Marshall's methodology 14, 182-3, 186-7, 193-4;

Marshall's social reform 167-8, 171-3, 176;

Adam Smith 37, 42

exchange:

classical theory 10 ;

Jevons 102-9, 111-15;

Marx 27;

Say's law 46-7;

Adam Smith 40-2

exchange ratio (Jevons) 97-9, 102-3, 105-7, 109

exchange value:

Aristotle 16-25, 27;

Marx 27;

Turgot 9

expenditure:

Say's law 49, 51-5;

Tooke 60, 63, 66-7

experience (Adam Smith) 36-7, 39-40

external-internal economies (Marshall) 143, 151-2, 187, 189-90

Fabianism 169-70

family law 160 
Fawcett, Henry 94, 156

Fay, C.R. 66

Fellner, W. 55

feminist economics 255

Fetter, F.W. 54

Field, D.D. 121, 125, 128-9

finance, public:

Australia 1-3, 7, 12;

India 156-8, 165.

see also war-related finance

financial crisis (1825-26) 59

financial markets:

Jevons 100;

Tooke $60-1,63-5,69$

financial socialism 172-4

Finley, M.I. 20-2, 25

Finzi, Roberto 10

Fiori, S. 36

Fisher, F.M. 97, 114

Fitzgibbons, Athol 249

Fleming, Grant 254-5

Fordism 148

Forget, E.L. 56

formalism 13, 248, 254

Fornero, G. 16

Fortnightly Review 87-9, 91

Fourier, Charles 172

France, J.S.Mill and W.T.Thornton in 84-6

free enterprise. see private enterprise

freedom (Marshall) 149

freedom of trade 5,164

French scholarship 2, 110, 254

French Wars (1793-1815) 60

Friedman, Milton:

career xi;

negative income tax 130 ;

review by xvi, xvii, $8,13,139-41$

frugal man 33

full employment:

euthanasia of the rentier 217, 219-21, 224-5, 227, 232;

Say's law 54, 56

Fullarton, John 57-9

Fuller, J.F.C. 213

functionalism (Marshall) 164

functionless investor. see euthanasia of the rentier (Keynes)

Fusfeld, D. 99

Galbraith, J.K. 197

Gallegati, M. 143

George, Henry 13, 118-38, 173, 254

Georgescu-Roegen, N. 142, 147 
German scholarship 12, 147, 170, 174, 182

Gerrard, B. 211

Gibson Paradox 67-8

Gilbart, J.W. 58

globalized world economy, Keynes and 232-3

glut (Say's law) 47

Gold and Silver Commission (1877) 157

gold standard:

Keynes 242;

Marshall 157-8

Goldsmiths' Library (London) 247

goods, types of (Aristotle) 18

goods and services tax (GST, Australia) 3

Goodwin, Craufurd 252

Goodwin, R.M. 55

Gordon, Barry J. 25, 47, 250-2, 254

Gorz, André 131

Gotti, M. 198

government. see state

gradualism (Keynes) 221, 227

Grattan-Guinness, I. 110

Graves, Robert 199-201, 212-13

Gray, Alexander 248

Greek language 24, 78. see also Aristotle

Green, Roy 252

Groenewegen, Peter D.: appreciations 4-8; career $1-2,7,9,11,245,247-8,250,253$;

foreword xv-xvi, xvi;

history of economic thought teaching and research in Australia 245, 247-8, 250-3, 255;

inaugural lecture 10-12, 179-80, 191, 193-4;

intergenerational relationships 8-11;

on Keynes 5, 198, 236;

Marshall biography 1, 3, 7, 245;

Marshall biography, opinions of xvi, 139-41, 143, 236;

Marshall scholarship 3-4, 6-8, 68, 119, 144, 159, 161-2, 164, 177, 189;

Marshall's importance (Groenewegen's inaugural lecture) 11-12, 179-80, 193;

post-retirement 11-13;

preface xvii;

on Robinson 10-11, 191;

Say's law 44, 55;

scholarship 1-4

Grote, George 80

Grote-Lewin, H. (Mrs) 51

growth. see economic growth

GST (goods and services tax, Australia) 3

Guillebaud, C.W. 159-61, 183

Guthrie, W.K.C. 20

habit (Adam Smith) 37-8 
Hahn, Frank 194

Halevi, Joseph 253

Harcourt, G.C.: career xi, 245, 251-3, 255;

essay by $14,236-44$

Harper, Marjorie (née Ronaldson) 251

Harrod, Roy 197, 241, 248

Harsanyi, J.C. 16

Hart, Neil:

career xii;

essay by 13-14, 179-96;

as referee $\mathrm{xvii}$

Hatch, J. 252

Hawtrey, R.G. 68, 212, 248

Hayek, Friedrich von 142, 220, 242

Hearn, William Edward 182, 252, 254

Heertje, Arnold xii, 246;

essay by $13,44-56$

Hegel, G.W.F. 162, 182, 184

Heilbroner, R.L. 4

HETSA. see History of Economic Thought Society of Australia

Hicks, J.R. 213, 226

Hickson, William 87

historical context. see context

historical institutions. see institutionalism

historical materialism (Marx) 148

Historical School 180, 182

history of economic thought:

Australian and New Zealand teaching and research, xv-xvi, 1-13, 245-55;

economic theory and (Marshall) 14, 146, 162, 179-96;

essays 13-14;

Groenewegen's contribution 1-13;

political economy and (J.S.Mill and Grote) 80

History of Economic Thought Society of Australia (HETSA) 2, 4, 245, 251-4;

Bulletin 245;

Newsletter 245, 251

History of Economics Review (HER) 245-6, 252

History of Political Economy (HOPE) 5, 246

hoarding:

Say's law 53, 55;

Tooke 58

Hobson J.A. 246

Hodge, Alan 199-201, 212-13

Hollander, Samuel 5-6, 179, 254

HOPE (History of Political Economy) 5, 246

Hopkins, Richard 222

House of Commons 84-5

Howson, S. 221-2, 226

Huck, E. 115

human conduct:

Marshall 147, 164-5;

Adam Smith 13 
human nature:

Marshall 160-2, 167-9, 172;

Adam Smith 31-7, 40-1

Hume, David 27, 30-1, 254

Hutcheson, Francis 32

Hutchinson, D.S. 20

Hutchison, Terence 5, 253

Huxleyism 92

impartial spectator (Adam Smith) 36-9

income, unearned. see euthanasia of the rentier

income distribution:

Creedy 246;

Keynes 217, 222;

Marshall 147, 157

India:

currency and finance $156-8,161,165$;

East India Company 76-83, 87, 93, 156;

economic progress 156 ;

education 156, 158, 165;

industrial economics 156, 158;

land tenure 156, 159;

Marshall on 14, 156-66;

J.S.Mill and 80, 83-4;

religion 164 ;

social progress and policy $156,160-1,163-5$;

trade 158, 162, 164;

transport 156;

women's conditions 156

India House (East India Company) 76-83, 87, 93, 156

India Office 83-4, 158

Indian Central Bank 157-8

Indian Civil Service 158, 164

Indian Currency Committee of 1899 156-8, 161

indifference, law of (Jevons) 99-102, 105, 115

individual. see economic agents

individualism 36, 169

induction and deduction:

Marshall 181;

Adam Smith 37

industrial capitalists (Marx) 64-5

industrial districts (Marshall) 150-2

industrial economics:

India 156, 158;

Marshall 143, 146-52, 158, 170-5, 181-4, 186-7;

organizational forms 148-9, 182, 184, 186, 189

industrial relations:

labour economics 246;

W.T.Thornton and J.S.Mill 77, 89-91

Industrial Remuneration Conference (1885) 168

inflation: 
Keynes 221-3, 231-2, 243;

Marshall 157

innovation (Marshall) 163-5, 175

institutionalism:

Australian research and teaching 249;

George 133;

Groenewegen 12;

Marshall 146, 159, 163-4, 167-8, 181, 193-4;

J.S.Mill 60-1, 64;

neo-institutionalists 163 ;

Adam Smith 37, 41-2;

Tooke and Marx 64-5, 71.

see also neoclassical economics

instrumental rationality $30,39-40$

integral of utility (Jevons) 106, 108, 111-12

interest:

conventionality (Sraffa) 226-8;

Marx on 59, 63-4

interest rates:

Marshall 157;

Tooke 58-61, 63-71;

Turgot 9-10;

zero (Keynes' euthanasia of the rentier) 217-23

internal-external economies (Marshall) 143, 151-2, 187, 189-90

International Clearing Union (ICU) 241-2

international monetary policy $241-2$

internationalization of economic discourse 5

investment:

Ricardo 150;

Say's law 45, 52

investor, functionless. see euthanasia of the rentier (Keynes)

invisible hand 31,33

Ireland 86-7, 94

Italian scholarship 2, 142, 153, 251

Jaffé, William xvi

Japanese scholarship 163, 252, 255

Jenkin, H.C.Fleeming 113-14

Jennings, Richard 110, 252

Jevons, Harriet 107

Jevons, W.S. 13, 97-117, 156, 248, 252

Jewish social reform 170

Johnson, E. 197, 199

joint rights (George) 122-3

joint stock companies (Marshall) 171, 175

Jones, E. 11

Jones, Richard 156, 159, 254

Journal of Post Keynesian Economics 246

Journal of the History of Economic Thought (J.HET) 246

justice:

exchange as act of (Aristotle) 18-23, 25, 27; 
George 124-5, 129;

Adam Smith 35, 37-9

Kahn, R.F. 149

Kahneman, Daniel 30

Kaldor, N. 213, 236, 246

Kalecki, Michal 236, 246, 252-3

Kant, Immanuel 16, 182

Kates, S. 56

Kautz, G. 161

Kemp, Murray 251

Kerr, Prue 253

Keynes, John Maynard:

Australian teaching and research 248-54;

essays on 14 ;

euthanasia of the rentier 14, 217-35;

Groenewegen on 5, 198, 236;

limited logical insight 201-7;

long-term expectations and confidence 207-11;

Marshall and 68, 140, 144, 148, 156-8, 161, 164, 180;

policy and

World War II 14, 236-44;

Say's law 44, 54;

as a writer 14, 197-216

Keynes, John Neville 140

Keynesian economics 71, 192, 242, 251

Keynes's Principle 227

Khrishnaswami, A. 157

Kidd, Benjamin 176-7

King, John xvii, 246, 251

Kinzer, B.L. 86

Knies, Karl 182

Knight, Frank 191

knowledge:

Keynes 204-6;

Marshall 182, 184, 187

Konekamp, R. 107

Koninglijke Nederlandse Akademie der Wetenschappen 2

Kress Collection (Harvard) 247

Kriesler, Peter xvii, 7, 252

Kuenne, R.E. 44

Kurz, H.D. 220

La Nauze, John 247-8, 250-1

La Trobe University 246, 249

labour:

Aristotle 25;

Australian research and teaching 246;

Marshall 145, 148, 151, 173-5;

measures of value $7,22,24-5,27$;

property rights $118,123-4,126-7,132$; 
Say's law 46;

skilled 22;

W.T.Thornton and J.S.Mill 88-91, 94;

working class 148, 169, 173-4, 176, 181

Labour Party (UK) 170, 222

Lagrange, J.L. 110

Laidler, D. 67, 236

Lambert, P. 50

Lancaster University 246

land:

peasant proprietorship 77, 81, 86-8, 94;

political economy 254;

property rights (George) 118-38

land tenure (India) 156, 159

land value property rights (George) 118-38

land-value tax (George) 13, 118-19, 122-3, 125-7, 132-4, 173;

disposing of revenue 122-3, 128-33, 135

Langholm, O. 24

language. see English language;

Greek language

Lassalle, Ferdinand 170

Latin economics 20

Latin literature 78

Lavington, F. 68

law of unintended consequences 33

Lee, F.S. 152

Leftism 10

legal fiction (Marshall) 160

Lend-Lease 240-1

Leo XIII, Pope 123

lever analogy (Jevons) 98, 106, 108-12

Levy, D.M. 33

Lewis, Thomas 22-3

Liberal Party (UK) 167

liberalism 167, 217, 243

Lipkes J. 76, 85, 92-3

liquidity preference (Tooke) 60

List, Friedrich 182

Littleboy, B. xvii

Liverpool University 254

loan capital (Tooke) 60-1, 63-4, 66, 68

Loasby, B.J. 37, 142, 189

local society (Marshall) 151

Locke, John 118, 253-4

Lodewijks, John:

career xii;

essay by 14, 245-55;

introduction xv, 1-15;

preface xvii

logic (Keynes) 201-7

London:

social reform 169; 
Victorian political economy 76-7, 87

London School of Economics and Political Science 1-2, 9

London University 250

long-period equilibrium:Keynes 207-12, 229;

Marshall 179-80, 186-91;

Say's law 55

Lowry, S.Todd 22-3, 250

McCulloch, J.R. 50, 156, 247

McFarlane, Bruce 1, 247

Macfie, Alec L. 31, 38

Machlup, F. 248

Mackintosh, Sir James 92

McLeod, H.D. 156

Macmillan (publisher) 250, 253

macroeconomics:

Marshall 8;

Robinson 192;

Say's law 45-6, 52, 55-6;

Adam Smith 30-43;

Waterman 251

McWilliams-Tullberg, Rita 7, 143-4

Magnus, Philip 109-10

Maine, Henry Sumner 159-62

Maitland, F.W. 163

Malthus, Thomas R.:

Australian research on 4, 247-8, 254;

East India College 156;

Marshall on 184;

Pickering edition of works 5 ;

Say's law 45, 47, 50-1, 54

man. see economic agents

management (Marshall) 175-6

Manchester School 246

Mandeville, B. 28

Marcet, Mrs 247

marginalist economics:

Creedy 246;

equilibrium 97-8, 100-1, 103-4, 109-11;

Groenewegen and 5, 7-8, 10;

Keynes and 226;

Marshall and 7-8, 145-6;

monetary thought 57-8, 65-9;

tools 30 ;

Turgot and 10.

see also Jevons, W.S.;

Marshall, Alfred;

neoclassical economics;

Wicksell, Knut

market equilibrium. see equilibrium theory

market exchange (Jevons) 102-9, 111-15 
market period trading (Jevons) 97-101, 107-8, 111, 115

market price (Jevons) 97-105, 113-14

markets:

Aristotle 23, 25;

competitive 30;

Keynes 207;

law of (Say's law) 13, 44-56;

Marshall 149, 153, 162, 164, 189;

Ricardo 142;

Adam Smith 33, 35-6, 41

Marshall, Alfred:

Australian study of 248;

current and future research 142-55;

essays on 13-14;

George and 119;

Groenewegen's biography 1, 3, 7, 236, 245;

Groenewegen's biography, opinions of xvi, 139-41, 143, 236;

Groenewegen's inaugural lecture 11-12, 179-80, 193;

Groenewegen's scholarship 3-4, 6-8, 68, 119, 144, 159, 161-2, 164, 177, 189;

history and theory in 179-96;

inaugural lecture 144-5, 159, 162, 179-83, 193;

on India 156-66;

J.M.Keynes and 68, 140, 144, 148, 156-8, 161,164, 180;

social reform 167-78;

studies of 142-55;

Tooke and 13, 57-8, 65-9

Marshall, Mary Paley:

biography xvi, 139-41, 156, 164;

as co-author $68,150,162,182$

Marshallian economics:

in Australia 252;

new orientations $142-55$;

rejection of history 189-92, 194;

value and distribution 5-6

Marx, Karl:

Aristotle and 25-7;

Australian research and teaching 245-8, 251-3;

Groenewegen on 11-12, 179, 245, 253;

Marshall and 142, 148, 150-1;

Tooke and 13, 57-9, 62-5, 68

Marxist economics xv, 142

Marxist political economy 252

Marxist social reform 169-70

Marzola, A. 199

Massachusetts Institute of Technology 250

Massey University 254

mathematics:

Australian research and teaching 246, 248;

Jevons 106-8;

Marshall 146-7, 180-2, 187, 191, 193-4;

Marx 179;

methods 30; 
J.S.Mill's education 78

Meade, James 131, 221, 223, 241

mechanics:

Jevons 98, 106-14;

Marshall 181, 183-6, 188-9.

see also dynamics;

statics

Meek, Ronald L. 9-10, 54, 246

Meikle, S. 22-5, 27

Melbourne University 246, 248, 250-1, 253

mercantile relations (Marx) 26-7

Mercantilism 30

Merivale, Herman 156

metaphysics (W.T.Thornton and J.S.Mill) 91-2

methodology:

history of economics 6 ;

individualism 30, 40;

Marshall 147, 165, 181-4, 189, 191;

W.T.Thornton 87

Meyer, Hans 254

microeconomics:

Jevons 102;

Marshall 7-8;

Robinson 192;

Say's law 44-52, 56;

Adam Smith 30-43

Middle Ages 20, 24, 27, 159, 161, 163-4

middle class (Adam Smith) 33

middle way (Marshall) 175-7

Milgate, Murray 253

Mill, George Grote 81-2

Mill, James:

East India Company 77-9, 82, 156;

J.S.Mill and 78-9, 92;

Say's law 45-51, 55-6

Mill, John Stuart:

De Marchi on 251;

East India Company 76-83, 87, 93, 156;

Jevons and 100, 104-5, 108, 111;

Marshall and 146, 149, 152-3, 182;

Say's law 46, 51-5;

Thornton and 13, 76-96;

Tooke and 13, 57-62, 64-5, 67-9

Mills, R.C. 247

Minsky, Hyman P. 246

Mirowski, P. 76, 81, 93

Mitchell, W.C. 12

moderation (Adam Smith) 39

modern economics 13, 246

Moggridge, D.E. xvii, 158, 221, 225-6

Moir, M. 79, 81

Monash University 248-9 
monetary economics:

Aristotle 24;

classical tradition 57-9, 62, 65-7, 69-71

(see also quantity theory of money);

endogenous money $62,66,69,71$;

marginalist tradition 57-8, 65-9;

Marshall 145, 147, 153, 156-8, 161, 165;

Marx and Tooke 59, 62-5;

J.S.Mill 59-62;

Say's law 44, 46, 49, 52, 55;

Tooke's legacy 57-75

monetary policy:

India 156-8, 161, 165;

international 241-2;

Keynes 221-6, 232, 238, 241-2;

Sraffa 227-8;

Tooke's influence 57, 67, 69, 71

money capitalists (Marx) 60-5

Mongiovi, G. 220

monopolisation (Marshall) 187, 190

Moore, B. 69

moral sciences. see social sciences

moral value. see value

morality. see ethics

Naldi, N. 220

Nasar, Sylvia 237

national consciousness (Marshall) 151-2, 164-5

National Debt Enquiry (UK, 1945) 221-2

National Guild movement 170, 172

national income (Say's law) 48, 51-4

national product:

Marshall 176;

Say's law 48, 51

nationalization:

George 125, 131, 134;

Marshall 170

natural laws: George 123;

rule of nature (Marshall) 161-2;

Adam Smith 32-3

natural philosophy. see physical science

natural rights:

George 13, 118-19, 121, 124, 126-7;

Marshall 168

needs:

Aristotle 25;

Marshall 147

Negishi, T. 115

neo-classical economics:

Australian research and teaching 1, 5, 7, 9-10, 246, 253;

human conduct 13; 
institutionalism 12;

market equilibrium 13, 97, 99, 114

(see also equilibrium theory);

Marshall and 1, 7, 142, 147-50, 192;

scepticism 27;

Adam Smith and 5;

Turgot and 9-10.

see also marginalist economics;

Marshall, Alfred

neo-institutionalists 163

neo-Ricardian tradition 252

Netherlands 1-2

New England University 248-50, 252

New Palgrave Dictionary of Economics 2-3, 253

New Republic 239

New Zealand Economics Association Conference 254

New Zealand scholarship 14, 245, 253-5

Newcastle University $250-1,254$

Newmarch, W. 57

Nice Conference 143

Nobel Prize 130, 153

non-Euclidean geometry 146

North American economics 253

Northcote, Sir Stafford 83-4

Oakley, Allen 247, 253, 255

O'Brien, Denis P. 6-8

O'Donnell, Rod:

career xii, 252, 255;

essay by $14,197-216$;

as referee $\mathrm{xvii}$

OECD 3

Oehlers, Alfred 254

O'Hara, Phil 253

organic growth $179,187-91,193-4$

organizational forms (Marshall) 148-9, 182, 184, 186, 189

O'Shaughnessey, Terry 253

output, theory of (Keynes) 71

over-trading (J.S.Mill) 59

Overstone, Lord 68

Owen, Robert 149, 170

Owens College 103-4, 106

ownership.see property rights

Oxford Economic Papers 246, 250

Oxford University 159, 199, 246, 250

Oxford University Press 249-50

Panico, C. xvii, 63, 227, 229

Pareto, Vilfredo 191

Patinkin, Don 5, 44, 48, 53-5

Peart, S. 116 
peasant proprietorship 77, 81, 86-8, 94

pensions (George) 128, 130

Perrotta, Cosimo:

career xii;

essay by 13, 16-29;

as referee $\mathrm{xvii}$

personality.see character

persuasion (Adam Smith) 40-1

Pesciarelli, E. 143

Petridis, Ray 252, 255

Petty, Sir William 253

philosophy:

Australian research and teaching 249, 254;

Australian teaching and research 12;

Keynes 197, 199, 201;

Marshall 12, 144-6, 182;

of science 6;

W.T.Thornton and J.S.Mill 78, 86, 91-2

physical science (natural philosophy):

Jevons 98, 106;

Marshall and successors 145, 186, 191, 193-4

Physiocrats 5, 55, 252

Pigou, A.C.:

Australian teaching and research 248, 253;

Keynes and 213;

Marshall and 68, 189-90, 192;

Memorials of Alfred Marshall (1925) 144, 148, 156-7, 159, 163-4, 167, 171-5

Pivetti, M. 64, 70-1, 226-8, 232

Plato $17-18$

Poisson, S.D. 110-11

policy. see economic policy

political acceptability (George's land- value taxation) 13, 125-6, 130, 134

political context. see context

political economy:

Aristotle (crematistics) 17-19, 21, 26-7;

Jevons 97;

land and rent 254;

Marshall and 180-1, 189;

J.S.Mill 78, 80-1, 86-9, 94;

modern xv, 245, 249, 252;

Ricardo 150;

Say's law 49, 51-2;

W.T.Thornton 76-7, 80-1, 86-9, 94.

see also history of economic thought

Political Economy Club 87

political opinions and career:

Groenewegen 10, 236;

Keynes 197;

Marshall 167-71;

W.T.Thornton and J.S.Mill 84-5, 93-4

Pollard, S. 236, 243

population (W.T.Thornton) 80,89 
positivism (Marshall) 153, 164

post-Central Planning phase 148

post-classical economics. see neoclassical economics

post-Fordism 148

Post-Keynesian economics:

Australian teaching and research 249, 252-3;

Groenewegen on xv, 7, 10-11;

Say's law 55;

Tooke and 69

poverty (Marshall) 169, 171, 173-6, 181

Presley, J.R. 236

prices:

Aristotle 22, 24-5, 27;

Jevons 97-105, 113-14;

Keynes 218, 243;

Marshall 139, 157-8, 161, 163, 187, 191;

natural 5;

Say's law 46, 49-55;

signals 31 ;

Sraffa 226-7;

Tooke $61-2,65-8,70-1$

private enterprise:

George 119-20;

Marshall 171-2, 174-5, 177, 183

private ownership (George) 118-19, 122-9, 133-5

privatisation 129

probability, subjective theory of (Keynes) 201-7

production:

Aristotle 22, 24-5;

classical political economy 5 ;

Groenewegen 5,

9-10, 13;

Keynes 229;

Marshall 148-50, 152, 187;

Robinson 191;

Say's law 44-55;

Tooke 63-4, 70;

Turgot 10, 13;

Wicksell 67.

see also surplus produce

productivity (Marshall) 151, 175, 177

profit:

Aristotle 18;

George 132;

Marshall 149, 181;

W.T.Thornton and J.S.Mill 90-1

profit, rate of:

Keynes 229;

Sraffa 226, 228;

Tooke 58-61, 63-5, 69-71

progress:

economic 156, 172, 174, 188; 
technical $150-1$.

see also social progress and policy

progressive taxation $172-2,177$

property income, capitalism without (Keynes) 217-33

property rights:

definitions 119-20;

Keynes 220;

land and land value (George) 118-38;

Marshall 168, 170-1.

see also common property rights;

common public ownership;

equal ownership;

equal private ownership;

private ownership;

public ownership

prose style. see English language

protective duties (Marshall) 164

prudent man 33-7, 39

psychological and experimental economics:

Australian research and teaching 255;

Keynes 222-4;

Nobel Prize winners 30, 153

public debt management (Keynes) 221-3

public economics (Creedy) 246

public finance:

Australia 1-3, 7, 12;

India 156-8, 165 .

see also war-related finance

public interest (Adam Smith) 32

public ownership 118-19, 133, 172

public works (George) 128, 130-2, 134-5

Pullen, John:

career xii, 248-50, 252, 254-5;

essay by $13,118-38$;

on Malthus 4;

as referee $\mathrm{xvii}$

Pulteney, William 248

purchasing power:

Marshall 157;

Say's law 45-6;

Tooke and J.S.Mill 61-2

Purdy, David 131

Pusey, Michael 5

Pythagoreans 19-20

quantity theory of money:

Marshall 13, 57-8, 65-9, 157;

J.S.Mill 61-2;

Tooke's critique $13,57-8,61-2,65-9,71$;

Wicksell 13, 57-8, 65-9

Quarterly Journal of Economics (QJE) 250 
Queensland University 249, 253

Quéré, M. 143, 148

Quesnay, François 9, 248

race (Marshall) 147, 164-5, 177

radical economics $\mathrm{xv}, 252$

Raffaelli, Tiziano:

career xii;

essay by 13-14, 156-66;

on Marshall 143-4, 146-7;

as referee $\mathrm{xvii}$

Ramsey, Frank 201-4, 206

Ranchetti, F. 227-8

Raphael, D.D. 31

ratio of exchange (Jevons) 97-9, 102-3, 105-7, 109

reason:

psychological economics 30;

Adam Smith 34, 37-40, 42

recessions (Say's law) 56

reciprocity:

Aristotle 19-23, 26;

Adam Smith 16, 28

redistribution (Keynes) 219, 222

reductionism (Adam Smith) 40

Reeve, Henry 89-91

reflux, law of 58, 62

reform, social (Marshall) 14, 167-78

Reid, Gavin 8

Reindler, W. 254

relativism 6

Remenyi, Joe 252

rent $125,132,254$

Renwick, Cyril 247-8, 254

representative form (Marshall) 187, 190

Reprints of Economic Classics (University of Sydney) 1, 247-8, 252

revenues (Marshall) 149

Review of Political Economy 246

revolutionary consciousness:

Keynes 221;

Marx 151

Ricardo, David:

Australian teaching and research 248, 251, 253;

George and 132;

Marshall and 7, 142, 145, 150, 181;

J.S.Mill and 78;

neo-Ricardian tradition 252;

Say's law 45-7, 49-51, 54-5;

Tooke and 57, 59, 66;

value 27

rights. see joint rights;

natural rights; 
property rights

riskless security (Keynes) 217-19, 232

Rivett, Ken 248

Robbins, Lionel 52, 221, 223, 241, 251

Robertson, D.H. 68, 189, 241, 248

Robinson, Austin 139-42, 248

Robinson, Joan:

Australian teaching and research 246, 252-3;

on equilibrium

97;

Groenewegen on 10-11, 191;

Keynes and 222;

Marshall and 7, 149, 190-2

Robinson Crusoe metaphor 30-1, 34, 40-2

Robson, J.M. 76, 78, 81

Roll, Eric 24, 248

Roman law 160

Ronaldson, Marjorie 251

Roscher, Wilhelm 182

Rosenberg, N. 32, 35

Ross, W.D. 19, 24

routines (Marshall) 147

Routledge (publisher) xvii, 2, 245-7, 253

Royal Commission on the Depression of Trade and Industry (1886) 68

Royal Commission on the Value of Gold and Silver (1887-88) 68

rule of nature (Marshall) 161-2

Saint Simon, C.H. 170, 172

Sallust 78

Samuels, W.J. 37, 41-2

Samuelson, P. 142, 179

Sardoni, Claudio 253

Say, J.B. 13, 44-51, 54-6

Say's Law 13, 44-56

Scandinavian Journal of Economics 246

scepticism 27

Schabas, M. 116

Schefold, B. 17

Schmoller, Gustav 182

Schneider, Michael xvii, 246, 249, 252

Schnierer, F. 248

Schoolmen 28

Schumpeter, Joseph:

on Aristotle 22, 25;

Australian research on 247;

Marshallians and 191;

on Say's law 44, 55;

on scholarship 139

science, philosophy and history of 6

Science and Society 246

Sciolla, L. 16 
Scottish Journal of Political Economy 246

Select Committee on Indian Currency and Finance 158

self-command (Adam Smith) 38-41

self-interest:

Aristotelian thought 17, 25-8;

Jevons 98;

Adam Smith 16, 31-5, 39-40, 42.

see also utility

self-sufficiency (Aristotle) 26

Senior, Nassau 100, 252, 254

Serrano, F. 229

Sewall, H.R. 21

Shackle, G.L.S. 44, 142, 186

Sharpe, Kieran 252

Sidgwick, Henry 139

Silva, F. 199

Singer, Kurt 247, 250

single tax 129, 131-2, 135

Sismondi, J.C. 51

Skidelsky, Robert 14, 197, 221, 224, 236-43

skilled labour 22

Skinner, A.S. 44,54

small businesses (Marshall) 150-2

Smith, Adam:

Aristotle and 22, 27-8;

Australian teaching and research 248-50, 254;

Groenewegen on 5, 11-12, 179;

Jevons and 100;

Keynes and 241;

Marshall and 161, 164, 171, 184;

Say's law 55-6;

socioeconomic man 13, 30-43;

Tooke and 59;

value 16

Smith, Matthew:

career xiii;

cited 71 ;

essay by $13,57-75$;

as referee $\mathrm{xvii}$

Smith, Vernon 30

social analysis (Aristotle) 18

social change. see social reform

social context. see context

social economy (Adam Smith) 13

social exchange (Aristotle) 20

social institutions. see institutionalism

social needs (Aristotle) 25

social organisms. see economic biology

social philosophy (W.T. Thornton and J.S. Mill) 86

social policy. see social progress and policy

social production (Marshall) 148-9

social progress and policy: 
Cambridge tradition 10;

India 156, 160-1, 163-5;

Marshall 14, 148-9, 156, 160-1, 163-5, 168-71

social reform (Marshall) 14, 167-78

social sciences:

Groenewegen 12;

Marshall 8, 145, 153, 181-2, 184;

Adam Smith 31

social services:

George 128-33, 135;

Marshall 169, 172-3, 176

social system (Marshall) 147-50

socialisation (Adam Smith) 31, 34-9, 41

socialism:

administrative 170-2;

financial 172-4;

George 120, 131, 134;

Keynes 222;

Marshall 14, 145, 151, 167-77

Società Italiana degli Economisti 2

socioeconomic institutions. see institutionalism

socioeconomic man. see economic agents

sociology 5

Socrates 8, 17, 78

solidarity:

Marx 27;

reciprocal autonomy 28

Sophists 17

Soudek, J. 18-19, 22-4

Sowell, T. 55

Spann, Othmar 254

specialisation. see division of labour

speculation (Tooke) 61-2

speech (Adam Smith) 40

Spencer, Herbert 153, 182, 184

Spengler, J J. 22-3, 55

Sraffa, Piero:

Australian links 251-3;

Keynes and 226-8;

Marshall and 7, 142, 190;

on Say's law 45-7, 49, 54;

on Tooke 57, 69-70

Sraffian economics xv, 5-6, 148

Stabilisation Fund (SF) 241-2

state:

George 119-20, 122-3, 128-33, 135;

Jevons 100;

Keynes 225, 231;

Marshall 168, 170-3, 175-7;

Adam Smith 32;

Tooke 60

state ownership 118-19, 133, 172 
State Socialism 170

statics:

Jevons 106-8, 110-11, 115;

Marshall and successors 184-6, 188, 190-1, 193

statistics:

Marshall 180-1;

Marx 179

Staveley, Richard 249, 253

Steedman, I. xvii

Steindl, Josef 246

Stephen, Leslie 93

Stigler, George xvi, 6, 45

Stilwell, F.11

Stirati, A. 229

subjective theory of probability (Keynes) 201-7

supply and demand:

Jevons 97, 99, 101-5, 108, 113-15;

Marshall 5, 7-8, 67, 69, 145, 181, 185-7, 190;

Marx 64;

Say's law 44-5, 48, 53-4;

Sraffa 226;

W.T.Thornton and J.S.Mill 90;

Tooke 60;

Turgot 9;

Wicksell 66, 69.

see also demand

surplus approach to value and distribution:

Groenewegen on 5, 7, 10;

Marx 63

surplus produce:

Petty 253;

Say's law 44-9;

Adam Smith 41-2;

Sraffa 70

Swedish School 67

Sydney Mint 109

Sydney University. see University of Sydney

sympathetic man 31-5, 39

syndicalism (Marshall) 170, 172

Tanaka, Toshihiro 252

taxation:

Australia 1-3;

progressive 172-2, 177;

single tax 129, 131-2, 135.

see also land-value tax

Taylor, Harriet 76-7, 82-5, 93

Taylor, Helen 83-5, 87, 92-3

Taylorism 148, 175

technical progress:

Marshall 151; 


\section{Ricardo 150}

Thommesen, S. 116

Thornton, Edward Zohrab 93

Thornton, Evelyn 93

Thornton, Henry 57, 252

Thornton, William Thomas:

East India Company 76-83, 87, 93, 156;

Jevons and 104-5, 111-14;

J.S.Mill and 13, 76-96

Thweatt, W. 56

time-period analysis:

Marshall 186.

see also long-period equilibrium

Tooke, Thomas 13, 57-75

Torrens, R. 58, 156

town planning (Marshall) 176-7

Toye, J. 221

Toynbee Hall 169

trade:

freedom of 5, 164;

illegitimacy of gain from (Aristotle) 17-18, 27;

India 158, 162, 164;

Keynes 237, 241-2;

Marshall 145, 147-8, 162, 164

trade cycles (Marshall) 68

trade unions:

Marshall 169, 171, 176;

W.T.Thornton and J.S.Mill 90-1

Tradewell, S. 76, 81, 93

transmission mechanism:

Marshall 68;

Tooke and J.S.Mill 69;

Wicksell 66

transport (India) 156

Treasury (UK) 221-2, 240, 242

Trever, A.A. 17, 25

Tucker, Graham S.L. 248, 251

Turgot, A.R.J. 1, 3, 9-10, 12, 55, 248

Turnell, Sean:

career xiii;

essay by $14,236-44$

uncertainty (Keynes) 207

unearned income. see euthanasia of the rentier unemployment:

long-term 131, 207;

Say's law 53, 55-6

unintended consequences, law of 33

unions. see trade unions

United Kingdom. see British economic policy

United Nations 240 
United States:

Commission on Intergovernmental Relations 3;

Declaration of Independence 121;

economic policy 57,171 ;

George in 121 ;

relations with Britain 237-41;

scholarship xv, 248, 251, 253;

State Department 241

University College, London 110

University of Adelaide 248, 251, 253

University of Cambridge. see Cambridge University

University of Chicago 249, 253

University of Lancaster 246

University of Liverpool 254

University of Melbourne 246, 248, 250-1, 253

University of New England 248-50, 252

University of Newcastle 250-1, 254

University of Queensland 249, 253

University of Sydney:

Groenewegen's career 1-2, 7, 9, 11, 245, 247-8, 250, 253;

history of economic thought teaching and research xv, 245, 247-50, 252-4;

political economy dispute $\mathrm{xv}, 11$;

support for festschrift xvii

University of Waikato 254

University of Western Sydney 255

University of Wollongong 252-4

use values 17, 22

utilitarianism:

Bentham 78;

economic agents 30 ;

economic value $17,25-8$;

George 119, 124;

J.S.Mill 78, 81;

Adam Smith 33-4;

W.T.Thornton's anti-utilitarianism $81,91-2$

utilities (Marshall) 170-1, 173

utility:

Aristotelian thought 16-17, 24, 26;

integral of $106,108,111-12$;

Jevons 98, 106, 108-14;

Marshall 147;

maximisation tools 30,98 ;

Say's law 51-2;

Adam Smith 32, 40.

see also self- interest

utopianism 168, 170-2

Vaggi, Gianni:

career xiii;

essay by $13,30-43$

value: 
classical theory 7, 9-10, 13;

definitions 16-17;

economic and moral (Aristotle) 13, 16-29;

Jevons 102, 104;

labour measures 7 ;

Marshallian approach 5, 153, 162-3;

subjective approaches 5;

Thornton 87;

Tooke 71 ;

use 17, 22;

utilitarian relationship (Aristotle) 25-6;

utilitarian relationship (later thought) 26-8.

see also exchange value;

surplus approach to value and distribution

value added tax (goods and services tax, Australia 3

Veblen, T. 12, 193

Victorian England:

Marshall 146, 148-9, 153;

W.T.Thornton and J.S.Mill 76-96

Viner, Jacob 9-10

Vinogradoff, P.Gavrilovitch 159, 162-3

virtual velocities (Jevons) 98, 108-11, 115-16

virtue. see ethics

virtuous man $32-3,41$

Vivenza, G. xvii, 20, 24

wage-fund doctrine:

Marshall 150;

W.T.Thornton and J.S.Mill 89, 91

wages:

George 132;

Marshall 149-50, 163, 181;

W.T.Thornton and J.S.Mill 89-91;

Tooke and Sraffa 70-1

Waikato University 254

Walker, Donald xvi

Walker, F.A. 174

Walras, Leon 53, 115, 191

war-related finance:

Keynes 200-1, 237, 242-3;

Tooke and J.S.Mill 60

Waterman, Anthony M.C. 251

wealth, social:

J.S.Mill 52;

Adam Smith 33-5, 40-1

wealth-getting (Aristotle) 17-19, 23, 26, 28

Webb, Sidney and Beatrice 140

Webster, Beth 253

Weintraub, E.R. 6

welfare services. see social services

Western law 160 
Western societies 161, 164

Westminster Review 58, 87-8

Wheelwright, Ted 247

Whewell, William 252

Whig history 4

Whitaker, John K.:

career xiii;

essay by 13-14, 167-78;

on Marshall 7-8, 143-4, 161, 163-5, 182

White, Harry Dexter 241

White, Michael V:

career xiii, 249, 252;

essay by $13,97-117$;

as referee and commentator xvii, 7, 9

Whitehead, Donald 249

Wicksell, Knut:

Australian study of 248;

Jevons and 114-15;

Tooke and 13, 57-8, 62, 65-9

Wilson, James 57-8, 247

Wilson, T. 31

Winch, Donald 46, 167

Wollongong University 252-4

women's rights (Marshall) 140-1, 144, 156

Wood, D. 27

Wood, John Cunningham 247, 252

Woods, R.B. 239

working class (Marshall) 148, 169, 173-4, 176, 181

World War I 176, 240

World War II 200-1, 236-44

Wray, L.R. 69

writing styles. see English language

Xenophon 17, 78

Young, Allyn 189

Zanini, A. 36 